\title{
AIDS prevention among Dutch drug users : an intervention mapping approach
}

Citation for published version (APA):

van Empelen, P. (2001). AIDS prevention among Dutch drug users : an intervention mapping approach. [Doctoral Thesis, Maastricht University]. Universiteit Maastricht. https://doi.org/10.26481/dis.20011130pe

Document status and date:

Published: 01/01/2001

DOI:

10.26481/dis.20011130pe

Document Version:

Publisher's PDF, also known as Version of record

\section{Please check the document version of this publication:}

- A submitted manuscript is the version of the article upon submission and before peer-review. There can be important differences between the submitted version and the official published version of record.

People interested in the research are advised to contact the author for the final version of the publication, or visit the DOI to the publisher's website.

- The final author version and the galley proof are versions of the publication after peer review.

- The final published version features the final layout of the paper including the volume, issue and page numbers.

Link to publication

\footnotetext{
General rights rights.

- You may freely distribute the URL identifying the publication in the public portal. please follow below link for the End User Agreement:

www.umlib.nl/taverne-license

Take down policy

If you believe that this document breaches copyright please contact us at:

repository@maastrichtuniversity.nl

providing details and we will investigate your claim.
}

Copyright and moral rights for the publications made accessible in the public portal are retained by the authors and/or other copyright owners and it is a condition of accessing publications that users recognise and abide by the legal requirements associated with these

- Users may download and print one copy of any publication from the public portal for the purpose of private study or research.

- You may not further distribute the material or use it for any profit-making activity or commercial gain

If the publication is distributed under the terms of Article $25 \mathrm{fa}$ of the Dutch Copyright Act, indicated by the "Taverne" license above, 
AIDS PREVENTION AMONG DUTCH DRUG USERS

AN INTERVENTION MAPPING APPROACH 



\section{AIDS PREVENTION AMONG DUTCH DRUG USERS}

\section{AN INTERVENTION MAPPING APPROACH}

\section{PROEFSCHRIFT}

ter verkrijging van de graad van doctor aan de Universiteit Maastricht,

op gezag van de Rector Magnificus, Prof. Dr. A.C. Nieuwenhuijzen Kruseman, volgens het besluit van het College van Decanen, in het openbaar te verdedigen op vrijdag 30 november 2001 om 14.00 uur

door

Pepijn van Empelen 


\section{Promotores}

Prof.dr. G. Kok

Prof.dr. G. S. Parcel

\section{Co-promotor}

Dr. L. K. Bartholomew (University of Texas, Houston, USA)

\section{Beoordelingscommissie}

Prof.dr. N. K. de Vries (voorzitter)

Prof.dr.ir. J. Brug

Prof.dr. N. H. Gottlieb (University of Texas, Austin, USA)

Prof.dr. R. Knibbe

Prof.dr. Th. G. W. M Paulussen (TNO Preventie en Gezondheid, Leiden)

\section{Colofon}

Vormgeving: NORA OOSTING [grafische vormgeving], Maastricht Leo Zander, Maastricht

Printing: Unigraphic, Maastricht

ISBN 90-5681-120-7

The studies presented in this dissertation were conducted under the auspices of the Maastricht Research Institute for Prevention and Care (Health) at Maastricht University, The Netherlands. Health is part of the Netherlands School of Primary Care Research (CaRe), which has been acknowledged since 1995 by the Royal Dutch Academy of Art and Sciences (KNAW). The studies presented in this dissertation were financially supported by a grant from Stichting AIDS Fonds (grant no. 2166). 


\section{ACKNOWLEDGEMENT}

I would like to thank the following people, for their participation within the project or because of being important in a different way during the length of the project: Hugo van Aalderen, Kay Bartholomew, Arjan Bos, John Deckers, Corien Gijsbers, Christian Hoebe, Desi Hollman, Anke Hollnagel, Harm Hospers, Maria Jansen, Karin Kloostra, Gerjo Kok, Marieke Kools, Rene Lennaerts, Nora Oosting, Guy Parcel, Peter Pontiac, Rob Ruiter, Marga Smit, Nicoline van der Spek, Ben Viergever, Trijntje Völlink, Maureen Wollaert, other collaborators of Mainline, colleagues of the department of health education (1997-1999) and experimental psychology (1999present). A special thank you to Herman Schaalma for his many constructive contributions.

Finally, I would like to express my gratitude to Jeroen, Anne-Marie and Nicole for their support and trust during the project, and I am very glad they can witness its finalization by means of the present thesis.

Pepijn 



\section{CONTENTS}

CHAPTER 1 INTRODUCTION AND OUTLINE OF THE THESIS 9

$\begin{array}{lll}\text { CHAPTER } 2 & \text { HIV RISK AND SAFE SEXUAL BEHAVIOR AMONG DUTCH } & 21\end{array}$

DRUG USERS: AN INTERVENTION MAPPING APPROACH TO

PLANNING

CHAPTER 3 DETERMINANTS OF UNSAFE AND SAFE SEXUAL BEHAVIOR:

QUANTITATIVE AND QUALITATIVE INSIGHTS

Overview

Section 3.1 Predicting condom use with casual and

Section 3.2 The additional value of anticipated regret and psychopathology in explaining intended condom use among drug users

Section 3.3 A qualitative focus on transitional factors of the motivation-action relationship in condom use among drug users

CHAPTER 4 INTERVENTION MAPPING: METHODS, STRATEGIES AND

PROGRAM, STEP 2 AND 3

Overview

Section 4.1 Effectiveness of psychosocial HIV prevention programs: A review

Section 4.2 Matching methods and strategies to matrices

Section 4.3 The development of sexual risk reduction materials among Dutch drug users: Translating methods and strategies to program

ChAPTER 5 USING INTERVENTION MAPPING: PROMISES AND PITFALLS 



\section{CHAPTER 1}

INTRODUCTION AND OUTLINE OF THE THESIS 


\section{INTRODUCTION}

\section{HIV/AIDS and prevention}

HIV is still an incurable disease. Although the use of highly active anti-retroviral therapy (HAART) has substantially reduced the number of AIDS cases and prolonged the lives of a lot of HIV-infected people, there is still no cure for HIV/AIDS. A great many efforts have been made to develop an HIV vaccine, but several phases have to be overcome before the first vaccine will be actually developed and implemented - not even mentioning the need for subtype vaccines (Esparza \& Bhamarapravati, 2000). It is clear, therefore, that attention must be focused on the prevention of HIV infections.

HIV transmission can be reduced by treatment of other sexually transmitted infections (STIs). A person with an untreated STI is more likely both to contract and to pass on HIV during unprotected intercourse. Evidence suggests that prompt diagnosis and treatment of curable STI (e.g., syphilis) can sever this link and reduce the number of HIV infections (UNAIDS, 2000). Yet STI treatment alone does not guarantee that someone is risk-free - the only way to really prevent transmission is to change one's behavior, in other words, not to engage in unprotected sexual intercourse (UNAIDS, 2000)

Another possibility to prevent the risk of HIV infections is by means of post-exposure prophylaxis (PEP), which is the use of anti-retrovirals following accidental exposure, for instance due to needle-stick or condom-leakage accidents. The use of antiretrovirals, however, is not a $100 \%$ effective alternative either. PEP may increase the resistance of HIV to existing anti-retrovirals. Moreover, it may lead to feelings of invulnerability, which would be counterproductive in promoting protective behavior, for example to avoid other STIs. For this reason, the medical profession is reluctant to treat HIV-positive people in some communities, such as the drug-abusing community, with HAART. Although the results are as yet inconclusive, several studies suggest that there is a trend towards more risk-taking behavior in the era of HAART among a number of populations.

The best and probably cheapest way to prevent HIV transmission therefore seems to be to reduce HIV risk-taking behavior, which implies the promotion of safe sex and drug use behavior. To do so means that one has to change the behavior of individuals, and provide an environment that facilitates such behavior. Hence, AIDS prevention programs should focus on the facilitation of HIV risk reduction behavior.

AIDS prevention programs, like any health promotion program, are most likely to be effective when they are systematically planned, including theory and empirical findings (Bartholomew, Parcel, Kok, \& Gottlieb, 2001; Green \& Kreuter, 1999).

Theory and empirical evidence are applied both in conducting a needs assessment and in the evaluation of a program. But theory and evidence are also applied in program development. With regard to the needs assessment and program evaluation, frameworks have been developed providing information of how to use theory and evidence. However, explicit frameworks for applying theory and empirical evi- 
dence in program development have been lacking. Intervention Mapping should provide such a system, including several steps and procedures for the integration of theory, empirical evidence from the literature, and information collected from the target population.

The purpose of this thesis is to apply Intervention Mapping to creating an AIDS prevention intervention for drug users. In the course of this application we addressed the following research questions:

- What are the predictors of unsafe and safe sexual behaviors among drug users?

- What role does anticipated regret and psychopathology play in explaining intended condom use among drug users?

- Which factors play a role in the transition of intended condom use into actual use?

- What are the pros and cons of using Intervention Mapping?

Before discussing the project, we will explain the Intervention Mapping protocol as a tool for developing theory- and evidence-based interventions. Having explained Intervention Mapping we will discuss related health promotion tools that are used during the process of Intervention Mapping. First, we will discuss the PRECEDE/ PROCEED model. Second, we discuss the use of theory in predicting and changing behaviors. Finally, we will explain into more detail our Intervention Mapping approach to planning an AIDS prevention program.

\section{INTERVENTION MAPPING}

We have stressed the need to apply theories in the analysis of the problem and in program development and implementation in order to create an effective program that will be used by its intended audience. In practice, however, there is a lack of theory-guided intervention, which is largely due to the difficulty of applying and integrating theories and empirical evidence.

Intervention Mapping is a systematic process that explicates a series of five steps for the development of health education programs based on theory, empirical evidence and additional qualitative and quantitative research (see figure 1) (Bartholomew, Parcel, \& Kok, 1998; Bartholomew, et al., 2001). The steps are followed in an iterative way, which means that program planners are moving back and forth throughout the process. Each step comprises several tasks resulting in a clear end product, each of which provides the foundation for the next step. Providing guidance for the planning, development, implementation and evaluation of a program, Intervention Mapping should enable health educators to create feasible and effective programs, because of its thoughtful, iterative and interactive process. 


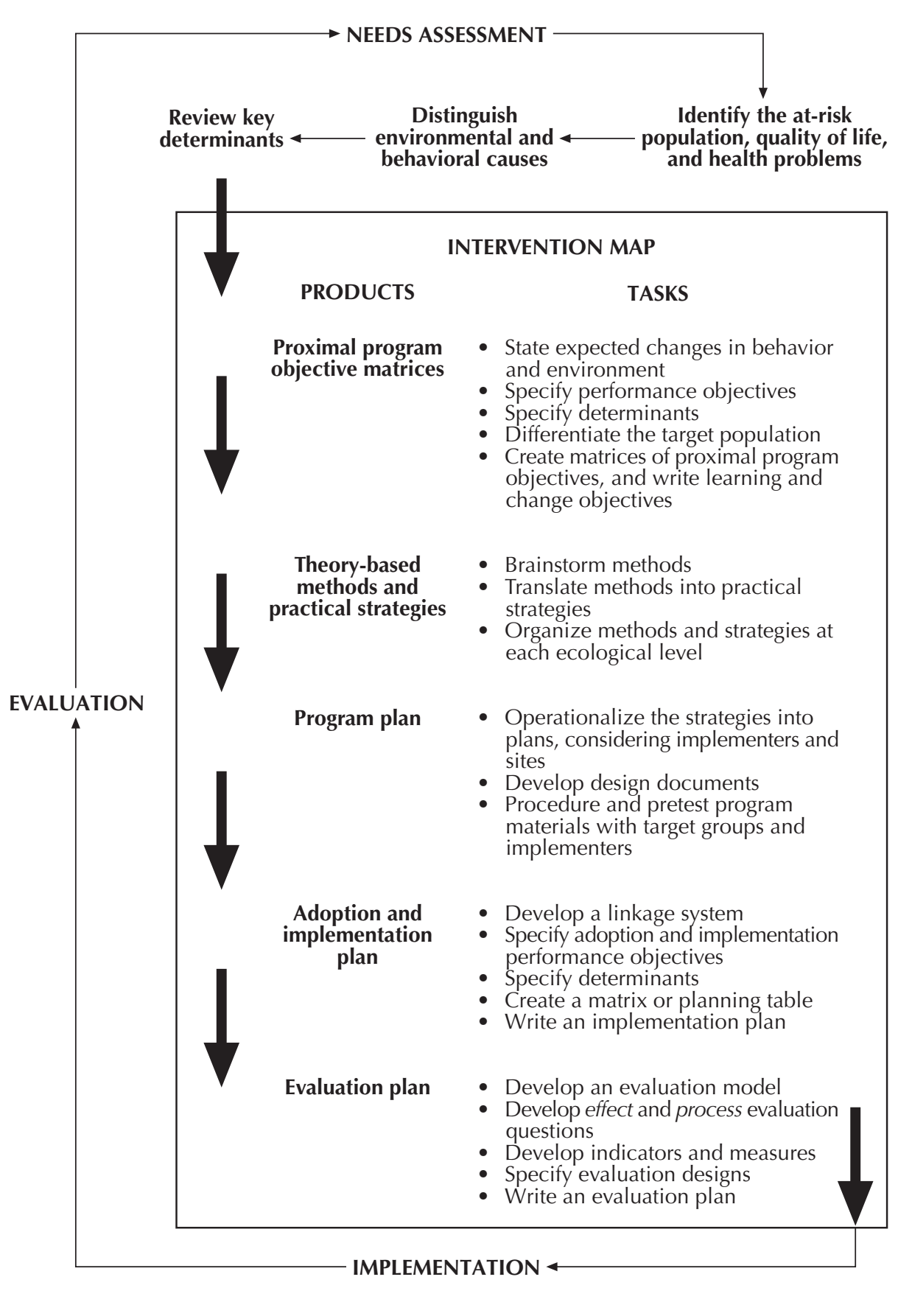

Figure 1 Intervention Mapping (Bartholomew, Parcel, Kok, \& Gottlieb, 2001) 
Before starting Intervention Mapping it is essential to perform a needs assessment which can be based on the PRECEDE model. A more thorough explanation of the PRECEDE model is given in the next section. Once the need for a program and its objectives are identified, one can start with Intervention Mapping. After looking at risk or problem behavior, Step 1 focuses on desired behaviors that will reduce the health problem. In the first step, the program developer creates matrices of proximal program objectives, which combine the expected behavior of the target group with the proposed determinants of that behavior. The creation of the matrices of proximal program objectives is based on three tasks.

First, performance objectives must be specified. In other words, for each desired change in behavior and environment, several specific behaviors must be listed that the target group or key figures in the environment have to adopt as a result of the program. For the promotion of clean needle use among intravenous drug users, for example, this would mean: deciding to use clean needles and syringes only; obtaining clean syringes; have clean syringes available at all times; using clean syringes and continuing to use only clean syringes.

Second, one must specify the personal and external determinants that are important predictors of whether one will carry out the desired behavior. Personal determinants include motivational factors within an individual, for example, attitudes or perceived social norms. External determinants include factors in the environment such as social support or pressure, and barriers.

The last task of Step 1 is to merge the performance objectives with the determinants, creating learning objectives for when a behavior is crossed with a personal determinant and change objectives when a behavior is crossed with an external determinant. An example of a proximal program objective to promote clean syringe use only is the following: 'Intravenous drug users [target population] express confidence [determinant self-efficacy] to have clean syringes available at all times [performance objective].

The product of Step 2 of Intervention Mapping is to link the proximal program objectives to theoretical methods and practical strategies. This step focuses on the following tasks: brainstorming about theoretical methods [task 1]; specifying the most potentially useful methods and justifying the selections with the literature and theories - from which the methods have been derived. Furthermore, the program developer identifies conditions under which such methods have shown to be effective [task 2]. The translation of the methods into practical applications - strategies should match with the proximal program objectives specified in Step 1 [task 3]. One method can lead to several strategies, but also several methods may be translated into one strategy. For example, a method of modeling can be translated into several strategies, such as role-playing, role models or demonstrations.

The product of Step 3 is a health education program. This step, too, involves three tasks: first, strategies must be operationalized into a program plan, taking into account the context in which the program will be used [task 1]. Second, one must design the program materials [task 2]. Third, concept materials must be pretested with target groups and implementers before the final materials can be produced [task 3]. 
The product of Step 4 is to write an adoption and implementation plan. Although implementation is discussed in Step 4, in practice it should be anticipated during the needs assessment or Step 1 of the Intervention Mapping. The first task of Step 4 is to develop a linkage system to connect the developers with the users of the intervention. The linkage system should enable collaboratively developed user-relevant interventions and stimulate the diffusion process of adoption and implementation. In fact, tasks 2 and 3 of this step are identical to the process specified in Steps 1-3 of Intervention Mapping, except for the target population, which consists of decisionmakers and program users. In task 2, matrices are created specifying proximal program objectives for adoption and implementation, once again the product of merging determinants with performance objectives. In task 3, an implementation plan is written.

Finally, in Step 5 of Intervention Mapping, an evaluation plan is created to evaluate the program. It is vitally important to evaluate all educational programs. One needs to understand why a program was a success or a failure. The first task is to develop an evaluation model. The content of the model is based upon the previous steps (needs assessment and Intervention Mapping steps). On the basis of the needs assessment and Intervention Mapping Step 1, effect evaluation questions can be created. Process evaluation questions can be developed using the results of Step 4. Questions that need to be answered within the process of evaluation are (cf. Rossi, Freeman, \& Lipsey, 1999): 1) Questions about the need for program services; 2) Questions about program conceptualization or design; 3) Questions about program operations and delivery; 4) Questions about program outcomes; and 5) Questions about program cost and efficiency.

\section{Related Health Promotion TOOls}

Next, we describe health promotion tools that are used within the context of Intervention Mapping. For the needs assessment preceding Intervention Mapping we rely on the commonly used PRECEDE model of Green and Kreuter (1999). Second, we give an overview of theories that can be used to explain behavior and theories that can be applied to change behavior.

\section{PRECEDE}

As has been discussed, every health promotion activity starts with the analysis of the problem, i.e., a needs assessment. A commonly used planning model is the PRECEDE/PROCEED model of Green and Kreuter (Green \& Kreuter, 1999), of which the 


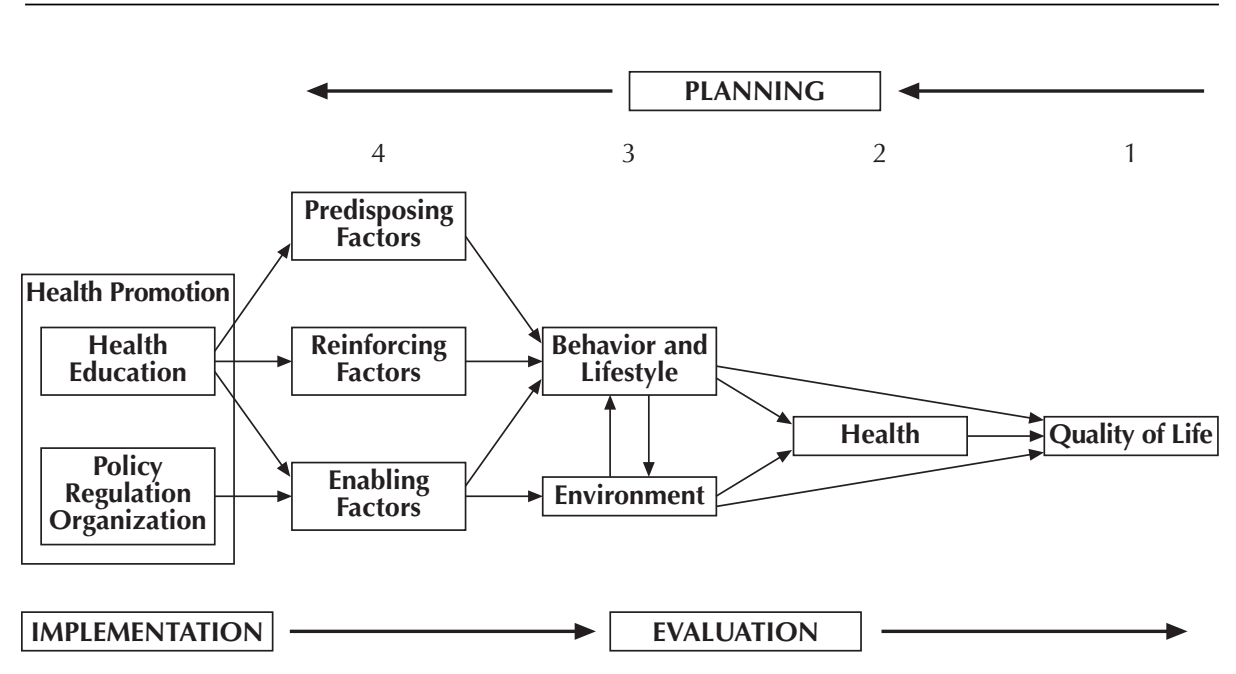

Figure 2 PRECEDE/PROCEED model

PRECEDE part describes several phases in analyzing the health problem (see figure 2). The two first phases are concerned with the analysis of the health problem and the quality of life. The goal of any health promotion program is to create a change by which the latter two improve. The analysis describes the epidemiology of the health problem as well as its subjective and objective consequences. The next phase is concerned with the analysis of behavioral and environmental factors causing the health problem. The behavioral part of this phase focuses on an analysis of what causes the at-risk population to increase chances of contracting the health problem. In the environment analysis, an assessment is made of social or physical factors that may be related to the risk behaviors, or that are a direct cause of the health problem. This analysis includes the identification of key figures that are responsible for these environmental conditions.

The fourth phase identifies the antecedents of the behavioral and environmental factors. Green and Kreuter divide these antecedents into three categories: predisposing factors, reinforcing factors and enabling factors. Predisposing factors are motivational factors, generally cognitive or affective predictors of behavior, such as knowledge, perceptions, attitudes, fear etc. Reinforcing factors are negative or positive factors that can be materialistic (e.g., incentives) or social in nature (e.g., praise or punishing remarks from others) that increase or decrease the prevalence of a behavior. Enabling factors such as individual skills and the availability or accessibility of facilities make the behavior more or less difficult.

The PROCEED phases focus on intervention development and implementation. An evaluation of the planning process indicates whether each goal of every phase is 
reached. Although the PRECEDE/PROCEED is a very helpful tool for conducting a needs assessment, it provides little guidance for program design and development.

\section{Theories of social and behavioral sciences}

In general, educational programs that have shown to be effective are based on theories originating from behavioral and social sciences (Glanz, Lewis, \& Rimer, 1997; Mullen \& Persinger, 1985). The use of theory is both an essential tool in the analysis of the health problem and in intervention development. Theories that are used to analyze the problem can be used in analyzing the antecedents of risk or health behaviors of the target population, but also in explaining behaviors of key figures in the environment. But theories can also be specifically used to describe how behavior can be changed. There are a number of theories that can be applied in both areas.

\section{Searching for theories}

There are three approaches, issue, concept and general theories, to search the literature for applicable theories (Buunk \& Veen, 1995). The issue-related approach is much like a topical review. It focuses on the problem at hand, which guides the search for theory dealing with the issue. For example, in the field of AIDS prevention, one looks for topics such as 'HIV prevention' or 'sexual-risk behavior'. Using this approach one may encounter the use of a specific theory, such as persuasion theories applied to HIV prevention. The second approach is the concept-related approach. This approach actually begins with concepts that are based on provisional answers that have been derived from brainstorming the causes and solutions of the specific problem. This approach leads to theoretical constructs and to evidence of the relation of those constructs to the behavior of interest. A provisional answer for example might, be 'seeing advances of the behavior' which may lead, for example, to theoretical concepts such as 'attitude', 'susceptibility', 'persuasion', which in turn may lead to theories, such as the Health Belief Model (Janz \& Becker, 1984). The last approach focuses on the use of familiar theoretical models, which are applied to the specific problem.

\section{Theories of the problem}

A number of theoretical frameworks have been specifically developed to explain sexual risk-taking behavior, for example the information-motivation-behavior model (IMB) of Fisher \& Fisher (1992) and the AIDS Risk Reduction Model (ARRM of Catania, Kegeles, \& Coates, 1990). Other models focused on explaining health behavior, for example the Health Belief Model (HBM, Janz \& Becker, 1984) or behavior in general, such as Social Cognitive Theory (SCT, Bandura, 1997) or the Theory of Reasoned Action (Fishbein \& Ajzen, 1975) and its successor, the Theory of Planned Behavior (Ajzen, 1991). 


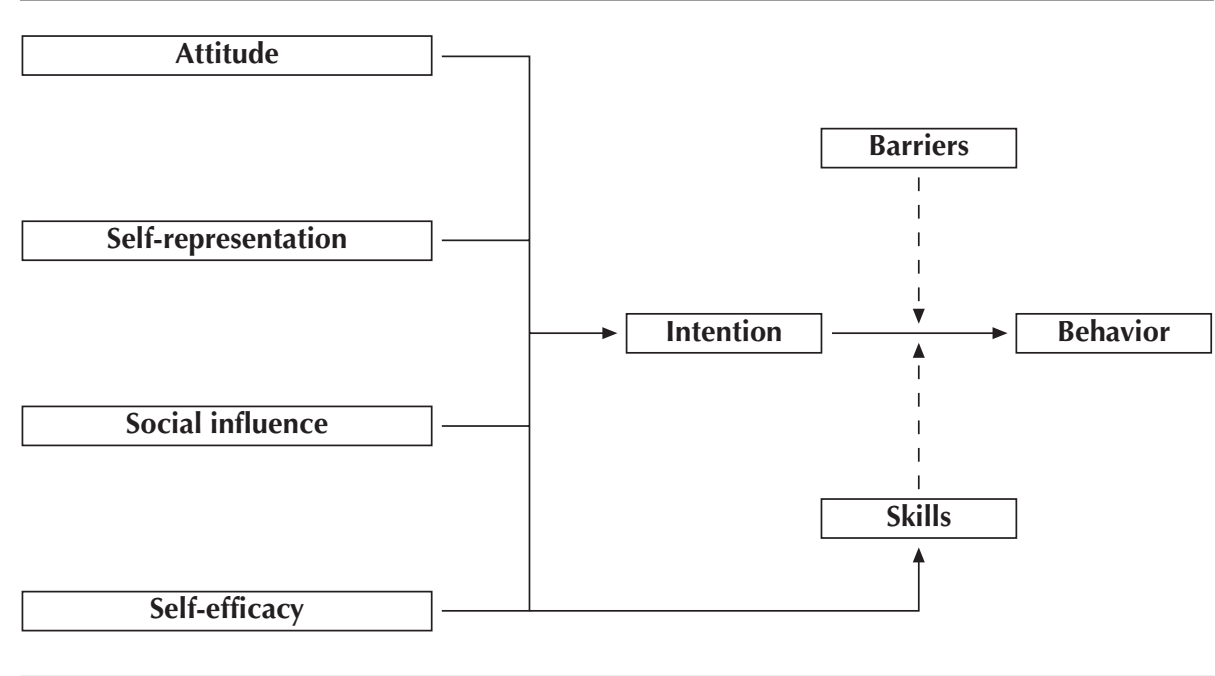

Figure 3 Core model of predictors of behavior

Abraham, Sheeran and Johnston (1998) reviewed the theoretical concepts of a range of social cognitive models to identify antecedents of individual motivation and behavior (see figure 3). They identified four main concepts of individual motivation (or intention) and behavior: attitudes, perceived norms, self-efficacy and self-representation. In their review of antecedents of health-related behavior, Godin and Kok (1996) suggest similar concepts. Attitudes are based on the beliefs (or outcome expectancies, Bandura, 1986) a person has about the advantages and disadvantages of certain behavior (Fishbein \& Ajzen, 1975). These are conceptually related to personal vulnerability (Janz \& Becker, 1984) and anticipated affect of negative outcomes (Richard, Van der Pligt, \& De Vries, 1995; Richard, Van der Pligt, \& De Vries, 1996), beliefs about the efficacy of the prevention response (Rogers, 1983) and beliefs about the consequences of actions (Fishbein \& Ajzen, 1975). Perceived norms are composed of subjective norms - beliefs about people's approval of one's behavior (Fishbein \& Ajzen, 1975) - and descriptive norms, referring to the observation of what others do (Cialdini, Reno, \& Kallgren, 1990; De Vries, Backbier, Kok, \& Dijkstra, 1995). Self-efficacy (or perceived behavioral control, Ajzen, 1991) is dependent on the expectations of a person regarding his or her ability to perform certain behavior in a number of (difficult) situations (Bandura, 1997). Finally, selfrepresentations are concerned with the principles of a person about certain behavior. Such principles may be based on moral values, including personal feelings of responsibility, or they may be closely related to an individual's self-identity, focusing on societal rather than personal values. It has been shown that moral values are in general more important predictors than self-identity, although it may be dependent of the domain (Conner \& Armitage, 1998). 
The assumption is that the four concepts predict one's intention to perform certain behavior. Although intention has shown to be a major predictor of actual behavior, it is acknowledged that intention does not translate into action automatically. For example, Abraham et al. (1998) stress the importance of preparatory behaviors for the achievement of one behavioral goal. De Vries, Dijkstra and Kuhlman (1988) and Fishbein (2000) argue that the translation of intention into action depends on existing skills and potential barriers. However, if the environment facilitates behavior, and a person is able to perform certain behavior, his or her commitment to the behavior will ultimately determine whether (s)he will carry out that specific behavior.

\section{Theories of change}

Theories of change can be used to find methods for behavioral change, but also for implementing the program developed. They are concerned with changing individual behavior or changing the behaviors of collectives. The theories suggest methods for change and the conditions under which such a method has shown to be effective (referred to as parameters). For the successful translation of methods into strategies, the parameters are essential. For example, SCT suggests that people can be instructed, persuaded and trained by the method of modeling. Modeling can be effective only if the role model is a) similar to the target population, b) a coping rather than a mastery model, and c) reinforced for the modeled behavior. The modeled behavior can be effective only if it fits in with the a) available skills of the target population, and b) is rewarding (positive reinforcement). Examples of theories about attitude change include the Elaboration Likelihood Model (ELM, Petty \& Cacioppo, 1986) and the Heuristic Systematic Model (HSM, Eagly \& Chaiken, 1993). These models view argumentation as a method to achieve attitude change. However, argumentation is most likely to be effective if a person is motivated and able to elaborate on the message, or in other words, if the message is relevant, challenging and understandable and if the arguments used within the message are strong. Other change theories are the goal-setting theory of Latham and Locke (1991) and the relapse-prevention theory of Marlatt and Gordon (1985). Other examples of behavior change theories can be found in Chapter 4.2 (for an overview see also Bartholomew, Parcel, Kok, \& Gottlieb, 2001; Glanz et al., 1997). Finally, the Diffusion of Innovations model of Rogers (1995) and Social Cognitive Theory (Bandura, 1997) are useful when implementing a new program.

\section{The PROJECT}

We undertook this project to use Intervention Mapping in developing a program in the field of AIDS prevention. The collaborating local public health center (GGD Maastricht) was responsible for identifying the target population. The center under- 
lined the need to focus on drug users, partly based on the relatively high HIV, Hepatitis B (HBV) and Hepatitis C (HCV) rates among its target population. The needs assessment had shown that IV drug users had reduced needle sharing to a great extent, even though one in five continues to share needles. Needle sharing in the Netherlands is low in comparison to other countries. This is probably partly due to the harm reduction approach in the Netherlands, which has increased the availability of clean syringes, and due to the Dutch drug law, which authorizes the carrying of syringes. Nevertheless, the unremitting increase in HIV prevalence, the high rates of HBV among drug users in steady relationships, and the lack of HIV prevention aimed at high sexual risk-taking behavior among drug users, were decisive factors in the decision to focus on the sexual behavior of drug users. Following the process of Intervention Mapping: 1) We reviewed the literature on HIV/AIDS prevention and determinants of sexual risk behavior, in particular condom use; 2) We carried out additional research to assess the problem in the local community, and to examine predictors of condom use; 3) We reviewed the HIV/AIDS prevention literature and theories concerning methods and strategies of behavior change; 4) We created a linkage approach, starting with researchers from Universiteit Maastricht and the infectious diseases coordinator from GGD Maastricht. This group was expanded to include outreach workers, coordinators from other public health centers, as well as a number of associates from Mainline, an NGO aimed at health prevention for drug users. For the implementation step we also involved several other drug and health prevention institutes; 5) We developed and pilot-tested an AIDS prevention program, and 6) We developed an evaluation plan.

\section{OUTLINE}

The thesis moves back and forth between the steps of Intervention Mapping, and this is a fairly accurate representation of the process of Intervention Mapping. However, the chapters should be seen and read as freestanding chapters. Chapter 2 presents an assessment of the problem of HIV/AIDS, the related behavioral and environmental factors, and antecedents of the behavioral and environmental factors among drug users. Furthermore, a description is given of Intervention Mapping Step 1: discussing the performance objectives of the behavior desired - condom use; specifying the most important and changeable determinants; and finally, creating matrices of proximal program objectives by merging the performance objectives of condom use with the determinants specified. Chapter 3 describes the qualitative and quantitative research we conducted to answer the questions about the need for a program, and Intervention Mapping Step 1. It gives an overview of risk-taking behavior among drug users in general and of determinants of condom use in particular. 
Chapter 4 focuses on Steps 2 and 3 of the Intervention Mapping process. Following Step 2 of Intervention Mapping, methods are selected focusing on issuerelated, concept-related and general theory approaches. The issue-related approach is based on the review of the HIV/AIDS prevention literature discussed in section 4.1 and other reviews. Section 4.1 reviews the literature on psychosocial interventions aimed at the reduction of sexual risk-taking behavior for drug users, people of developing countries, ethnic minorities, and HIV-positive people. The search for suitable theoretical methods is described in section 4.2. Furthermore, methods are translated in practical strategies. Section 4.3 discusses the use of Intervention Mapping in developing a program to reduce sexual-risk behavior with casual sex partners among drug users. It focuses on program design, pretesting and development, following Step 3 of Intervention Mapping, and discusses the linkage approach applied. In Chapter 5 we evaluate the Intervention Mapping process followed throughout the project and address the promises and pitfalls of such an approach. Moreover, we anticipate upon the evaluation of the AIDS prevention programs. 


\section{CHAPTER 2}

HIV RISK AND SAFE SEXUAL BEHAVIOR AMONG DUTCH DRUG USERS: AN INTERVENTION MAPPING APPROACH TO PLANNING 


\section{INTRODUCTION}

\section{Purpose}

AIDS risk has been associated with people who inject drugs (CDC, 1998; CESES, 2001), but also with non-injecting drug users (Booth, Kwiatkowski, \& Chitwood, 2000). Where IV drug users (IDUs) are mainly at risk for HIV via needle-sharing, both injecting and non-injecting drug users risk acquiring and transmitting HIV through sexual intercourse. Drug users who do not inject, such as crack cocaine smokers, are likely to be at risk for HIV, because they have sexual encounters with IV drug users or exchange sex for money or drugs. Moreover they report having sex with more individuals than do IV drug users (Booth et al., 2000). Finally, it has been shown that (IV) drug users are the main source of heterosexual HIV transmission in Europe and the United States (CDC, 1998; CESES, 2001; Des Jarlais, 1992; Fennema, 1997). Lukashov, Op de Coul, Coutinho and Goudsmit (1998) found a common origin for HIV strains in Dutch IV drug users and heterosexuals in the Netherlands, suggesting that most infections originated from Dutch IV drug users.

Harm reduction programs have been successful in reducing drug risk behavior, diminishing needle sharing by means of needle exchange programs, and drug injection frequency by methadone maintenance programs. Although this has reduced drug risk behavior to a great extent, one in five IV drug users continues to share needles (Berns, Van de Laar, Houweling, \& Wiessing, 2000). These programs have, however, disregarded sexual risk-taking behavior, and it has even been suggested that they may have a negative impact on safe sexual behavior (Rhodes \& Quirk, 1995). Additionally, harm reduction programs have paid no attention to non-injecting drug users. The sexual risk behavior of drug users has been addressed mainly through media campaigns, such as the general safe sex television commercials, or by the provision of information about HIV/AIDS and transmission risk via leaflets and similar written materials. The main focus of these programs was on raising AIDS awareness, and as such they have contributed little or nothing to changing unsafe sexual behavior among drug users. Although being quite knowledgeable about HIV and HIV risk, drug users have continued unsafe sexual practices both with casual and with steady sex partners (e.g., Van den Hoek, Van Haastrecht, \& Coutinho, 1992; Beuker et al., 2000). Targeting their sexual risk behavior therefore seems a very important prevention strategy to prevent HIV infections within and from the drugusing community.

In this chapter we focus on Intervention Mapping (IM) in the process of planning (Bartholomew, Parcel, Kok, \& Gottlieb, 2001). Within this chapter we focus on the current health risk of HIV/AIDS among Dutch drug users. The end product of this chapter is a specification of program objectives for AIDS preventive programs targeting drug users.

Intervention Mapping is a systematic process explicating a series of five steps for the development of health education programs based on theory, empirical evidence 
and additional qualitative and quantitative research (see chapter 1, figure 1). The steps are followed in an iterative way, meaning that program planners are moving back and forth throughout the process. Each step comprises several tasks, which result in a clear end product, providing the foundation for the next step. Intervention Mapping should enable health educators to make decisions on the basis of data and theory. This in turn would lead to theory- and data-based interventions, which have shown to be most effective (e.g., Mullen, Green, \& Persinger, 1985). Intervention Mapping is aimed at guiding the planning, development, implementation and evaluation of a program.

Prior to starting Intervention Mapping, it is essential to conduct a problem analysis, based on the PRECEDE model (Green \& Kreuter, 1999). When it is clear that there is a need for a program, and what the program is supposed to address, Intervention Mapping can be started. Step 1 does look at desired behaviors that will reduce the health problem. The product of Step 1 concerns the creation of matrices of proximal program objectives. These objectives provide the foundation for who and what will change as a result of the intervention. Three tasks have to be realized to create the matrices of proximal program objectives. The first is to specify performance objectives, in other words, identifying, for each desired change in behavior and environment, several specific behaviors that the target group or key figures in the environment have to achieve as a result of the program. For the promotion of clean needle use among intravenous drug users, this would mean: deciding to use clean needles and syringes only; obtaining clean syringes; having clean syringes available at all times; (continuing to) use clean syringes only. The next task is to specify personal or external determinants that are important to carry out the desired behavior. Examples of personal determinants are attitudes or perceived social norms. External determinants include social support or pressure, barriers or availability. The last task of Step 1 is the creation of the matrices by merging the performance objectives with the determinants, creating learning objectives for the target population and change objectives for key figures at community or organizational levels.

The product of Intervention Mapping Step 2 is to link the proximal program objectives to theoretical methods and practical strategies that seem useful to accomplish the objectives. The tasks that have to be completed are: brainstorming of theoretical methods [task 2.1]; specifying important methods with reference to sources literature and theories - from which the methods have been derived, to identify the conditions under which such methods have shown to be effective [task 2.2]. The translation of the methods into practical applications - strategies - should match the proximal program objectives specified in Step 1 [task 2.3]. One method can lead to several strategies, but several methods may also be translated into one strategy. A method of modeling can be translated into several strategies, such as role-playing, role models or demonstrations. The product of Step 3 is a health education program. In order to achieve the end project, once again three tasks have to be undertaken: operationalize strategies in a program plan, taking into account the context in which the program will be used [task 3.1]; design the program materials [task 3.2]; pretest preliminary materials with target groups and implementers, and produce the final 
materials [task 3.3]. The product of Step 4 is to write an adoption and implementation plan. Although implementation is not addressed until Step 4, the sooner it is anticipated during the needs assessment or Intervention Mapping Step 1, the better. The first task of Step 4 is to establish a linkage system, i.e., a board to connect those who are developing the intervention with those who will be using the program (Orlandi, Landers, Weston, \& Haley, 1990). The linkage system should enable collaboratively developed user-relevant interventions and stimulate the diffusion process of adoption and implementation. In fact, tasks 4.2 and 4.3 are similar to the process specified in Intervention Mapping Steps 1-3, except for the target population, which consists of decision-makers and program users. In task 2 matrices are created that specify proximal program objectives for adoption and implementation. Again, this is the product of merging determinants with performance objectives. In task 3 an implementation plan is written. Finally, in Step 5 of Intervention Mapping, an evaluation plan is created to evaluate the program. The first task is to develop an evaluation model, of which the content is based on the previous steps (needs assessment and Intervention Mapping steps). On the basis of the needs assessment and Intervention Mapping Step 1, effect evaluation questions can be identified. The results of Step 4 serve to develop process evaluation questions.

Following the sequence of tasks in IM Step 1 we specify performance objectives of the desired health behavior and influencing environmental conditions. Second, we propose the most important and changeable personal or external determinants that are essential in carrying out the desired behavior, and we merge the products of task 1, performance objectives, and task 2, personal and external determinants, in task 3 , creating matrices of proximal program objectives. These matrices provide the foundation for intervention development.

Before starting with Step 1 of Intervention Mapping, we describe the needs assessment that was carried out to address the need for possible programs, based upon a modified version of the PRECEDE model of Green and Kreuter (1999). The phases of the needs assessment were identification and analysis of: 1) The health problem and description of the target population; 2) Possible consequences of the health problem for quality of life; 3) The behavioral and environmental causes of the health problem, and finally; 4) The antecedents of the behavioral and environmental causes.

\section{NEEDS ASSESSMENT}

AIDS still is an incurable disease and can eventually lead to death. Moreover, HIV infection increases the chance of becoming infected with other STDs (UNAIDS, 2000). Among HIV-positive IV drug users, those being treated have low rates of compliance with therapy (Van Ameijden, 1998). Therefore, out of concern for creating a 
drug-resistant viral strain, a lot of HIV-positive drug users are still not being treated with the expensive anti-retrovirol treatment therapies (HAART). Drug users represent an isolated and stigmatized group in society, and HIV-positive drug users are doubly stigmatized and become further isolated, even within the IV drug-using community (Bos, Dijker, \& Jansen, 2000).

In the Netherlands, HIV infection data is mostly unavailable, as a result of which national HIV prevalence and incidence are primarily based upon AIDS diagnoses. However, due to the new treatment programs (HAART) and the high mortality of HIV-positive IV drug users for reasons other than AIDS, these diagnoses may represent an underestimation of current HIV prevalence and incidence rates. The majority of AIDS cases in the Netherlands (1982-1998) can be attributed to infection through homosexual intercourse (69.3\%), followed by heterosexual intercourse $(14.5 \%)$ and intravenous drug use (10.8\%) (Aidsfonds, 1999). Relatively speaking, the number of AIDS cases among IV drug users (13.2\%) and heterosexuals (35.1\%) has increased in recent years (1998).

Recent local studies have shown that HIV prevalence among IV drug users is stable but high, with the highest HIV prevalence found in Amsterdam (25.9\%) and South-Limburg (14\%) (Beuker, Berns, Van Ameijden, Houweling, \& Van de Laar, 2000). Hepatitis B (HBV) is another marker of HIV transmission modes (use of needles or unsafe sex) and HBV is highly prevalent among IV drug users (Carsauw et al., 1997; Donoghoe \& Wodak, 1998). Non-injecting drug users have also been shown to be at high risk for HIV/HBV transmission (e.g., Longshore \& Anglin, 1995). HIV risk among drug users is associated with young and homeless people living in AIDSendemic areas. HIV transmission among the non-drug-using populations appears to be largely dependent on sexual intercourse with HIV-positive drug users. In the United States it has been estimated that drug users are the HIV source in 70 to 80 percent of all heterosexually transmitted AIDS cases (e.g., Des Jarlais, Friedman, Choopanya, Vanichseni, \& Ward, 1992). Lukashov et al. (1998) also found evidence that most Dutch heterosexual HIV infections originated from Dutch drug users.

\section{Behavior and environmental risk factors of HIV infection}

\section{Behavioral risk factors}

The major behavioral risk factors of HIV infection among drug users are 1) needle sharing (including back- and frontloading, i.e., sharing drugs that are mixed within one syringe) and sharing injection materials and 2) unprotected sexual intercourse (both vaginal and anal). The most important HIV risk behavior for IV drug users continues to be the sharing of needles or injecting materials (Gibson, McCusker, \& Chesney, 1998). Such drug risk behavior has significantly decreased in recent years, although a stable proportion of IV drug users continue to share used needles or used injection materials (e.g., Carsauw et al., 1997; Van Empelen, Schaalma, Kok, \& Jansen, 2001). Also non-injecting drug users have been shown to be at greater risk for contracting HIV or infecting others, because they are part of the same networks 
as the IV drug users, in which unprotected sex is a common practice (Des Jarlais et al., 1992; Rhodes, Stimson, \& Quirk, 1996). Within AIDS-endemic areas, needle sharing normally stabilizes, and unprotected sexual intercourse becomes a more important HIV transmission route within the drug-using community (Blower, Hartel, Dowlatabadi, Andersan, \& May, 1991). Moreover, Friedman et al. (1997) showed that large sociometric networks of HIV-negative drug users demonstrated less drugrisk behavior, but were more likely to engage in unprotected sex than 2-core group members. In other words, once a high-centrality member of a large network becomes infected, unprotected sex may be an important source of HIV spread. Sexual HIV transmission occurs within both steady and casual sexual relationships and through prostitution. The CDC (1998) reported that of the total number of IDUassociated AIDS cases in 1998, 13\% were homosexual IV drug users and $12 \%$ concerned the heterosexual partner of an IV drug user. Several studies have reported that most IV drug users (60\%-90\%) are sexually active (Donoghoe, Stimson, \& Dolan, 1989; Klee, Faugier, Hayes, Boulton, \& Morris, 1990; Van Empelen, Schaalma et al., 2001). IV drug users report that a large proportion of their sex partners either does not inject drugs or does not use drugs at all. Furthermore, most IV drug users report having unprotected sexual intercourse, especially with steady sex partners (Beuker et al., 2000; Carsauw et al., 1997; Van Empelen, Kok, Jansen, \& Hoebe, 2001; Van Empelen, Schaalma et al., 2001). As stated before, non-injecting drug users are also at significant risk, because they have sexual encounters with IV drug users or exchange sex for money or drugs and are a potential source of sexual HIV transmission. Finally, studies have shown a link between drug risk behavior and unsafe sexual behavior, which further increases the chance of catching and spreading HIV (e.g., Carsauw et al., 1997).

\section{Environmental risk factors}

Drug users report that condoms and clean syringes are available at the CADs (Centers for Alcohol and Drug Abuse), drugstores, vending machines and public health centers, and they can be purchased at low or no cost (Van Empelen, Schaalma et al., 2001). Steady sex partners do not seem to use condoms, because their partner does not support condom use or because they hold a negative attitude towards condom use themselves (Krauss, Wolitski, Tross, Corby, \& Fishbein, 1999; Van Empelen, Kok, Hoebe, \& Jansen, 2001). Partners therefore seem to be an important environmental factor related to unprotected sex. In conclusion, it seems that condom and syringe availability is not a forceful environmental risk factor. Partners may be important, but because partners are often part of the drug-using community a focus on the target population would also influence the partners of drug users.

\section{Determinants of unsafe sex}

We analyzed potential determinants of unsafe sexual behavior among drug users by performing a literature review, interviews with outreach workers of CAD sites and a 
public health center, a qualitative study among drug users (Van Empelen, Kok et al., 2001) and two surveys among drug users in South-Limburg, the Netherlands (Van Empelen, Kok et al., 2001; Van Empelen, Schaalma et al., 2001).

The determinant analysis showed that drug users in Western Europe are generally knowledgeable about HIV/AIDS and possible HIV transmission routes (Helal, Momas, Prétet, Marsal, \& Poinsard, 1995; Thornton \& Catalan, 1993; Van Empelen, Kok et al., 2001; WHO, 1993). However, even drug users who understand the risks of HIV transmission misperceive their personal risk in the sense that they do not consider themselves to be at risk sexually, especially those in steady sexual relationships (Liebman, Mulia, \& Mcllvaine, 1992; Van Empelen, Kok et al., 2001; Van Empelen, Schaalma et al., 2001). Helal and colleagues (1995) found that IV drug users who were knowledgeable about HIV risk shared needles less often, but had the same sexual patterns as those who were not aware of the risks (WHO, 1993). There are two reasons for this perceived HIV invulnerability among drug users. First, they have a false belief that they have a monogamous relationship, which could be described as 'serial monogamy' in most cases. Second, IV drug users that have sex with non-IV drug users feel less vulnerable to HIV infection. For this reason, a lot of IV drug users prefer to have sex with non-IV drug users.

Drug users mostly have positive attitudes with regard to unprotected sex, especially with steady sex partners, because they think unprotected sex is more pleasurable. The majority does not enjoy sex when using a condom, because it feels unnatural and the condom reduces sexual feelings (Hartgers, Van den Hoek, Coutinho, \& Van der Pligt, 1992; Jones \& Vlahov, 1989; Magura, Shapiro, Siddiqi, \& Lipton, 1990; Paulussen, Kok, Knibbe, \& Cramer, 1990; Weiss, Weston, \& Quirinale, 1993). Moreover, they think condoms are unreliable because these might slip or break. In general, steady sex partners do not tend to use condoms for the purposes of preventing pregnancy because of the availability of other birth control methods. Additionally, the use of condoms in itself is viewed as a sign of deception or distrust in the relationship. Furthermore, carrying condoms might be seen as inappropriate. (e.g., Van Empelen, Kok et al., 2001; Weiss et al., 1993).

Sexual risk taking may further be increased by the use of alcohol or drugs (especially cocaine), because in accordance with the notion of myopia, intoxication decreases cognitive capacity and therefore people are more likely to focus on salient cues of behavior (which is short-term benefits over long-term costs) (cf. MacDonald, Zanna, \& Fong, 1996).

Drug users within steady sexual relationships do not relate unsafe sexual behavior to any of the possible negative consequences of having unprotected sex, such as feelings of worry or regret. In such relationships, drug users do not relate unprotected sex with negative feelings (Van Empelen, Kok et al., 2001). Drug users who feel less responsible for the protection of others are less inclined to use condoms, especially with steady sex partners (Van Empelen, Kok et al., 2001).

Research among intravenous drug users has demonstrated the normative importance in drug users' social and material relationships of 'sharing' (McKegany \& Barnard, 1992). Research has also indicated the role of peer support in influencing 
behavioral norms and behavioral change (Friedman et al., 1992). A lack of safe-sex norms might therefore be related to ongoing risk-taking behavior. Condom use is not a cultural norm among drug users, especially in steady sexual relationships (e.g., Van Empelen, Kok et al., 2001; Van Empelen, Schaalma et al., 2001). Pressure from others to have unsafe sex also leads to a lack of support for safe sex and increases risk-taking behavior. For example, in one study, drug-abusing women stated that they are discouraged from using condoms by men (Weiss et al., 1993).

A lack of skills or perceived self-capabilities with regard to sexual risk reduction is also related to increased HIV risk-taking behavior. Difficult situations might decrease one's perceived self-efficacy, for example suffering from withdrawal symptoms or not having a condom available (Hartgers et al., 1992; McKegany \& Barnard, 1992; Paulussen et al., 1990; Weiss et al., 1993). The use of drugs and alcohol may further decrease one's capabilities and therefore increase risk-taking behavior. A lack of practical skills (how to put on a condom), negotiation and problem-solving skills, or self-management skills (being able to anticipate certain risk situations and respond to them, for instance by having condoms on hand) with respect to condom use are related to increased sexual risk-taking behavior (Kelly, 1995). Van Empelen and colleagues (Van Empelen, Kok et al., 2001; Van Empelen, Schaalma et al., 2001) found that unprotected sex among drug users is related to a perceived inability to use condoms and to a lower perceived self-efficacy with respect to having condoms available, to using condoms when feeling sexually aroused, or (to continuing) to use condoms when suffering from withdrawal symptoms.

Psychopathology (such as depression, anti-social personality and hostility), found among the majority of drug users, has been shown to be related to HIV risk-taking behavior (e.g., Hartgers et al., 1992; Van Empelen, Kok et al., 2001). A study of Van Empelen and colleagues (Van Empelen, Kok et al., 2001) showed that drug users who felt hostile towards others (a subscale of the SCL-90 psychopathology list) were less likely to use condoms.

\section{Needs assessment summary}

Based on a fairly high and stable HIV prevalence among the drug-using population in the larger Dutch cities (Amsterdam, Rotterdam), and specifically in our region of interest, South-Limburg, we decided to aim our AIDS prevention intervention at this group. We focused on drug users in general because both IV drug users and noninjecting drug users are at great HIV risk through unprotected sexual intercourse and are potential sources of HIV transmission to other drug users as well as the nondrug-using community. The latter is underlined by the large proportion of AIDS cases associated with drug users and the, relatively speaking, increasing AIDS prevalence found among heterosexuals. Several HIV prevention programs have successfully targeted needle sharing, but current HIV prevention programs have disregarded sexual HIV transmission and therefore it needs to be addressed. The current project will therefore focus on safe sex practices (particularly condom use) among drug users. 
Finally, several determinants are related to practicing unsafe sex and should be targeted within an HIV prevention program:

1 Drug users underestimate the actual risk of unsafe sex both for themselves and for others;

2 The attitude of drug users concerning safe sexual behavior, particularly condom use, is quite negative;

3 Drug users appear to lack responsibility for others;

4 A safe sex norm is not established among drug users;

5 Drug users appear to lack the practical, communication, and self-management skills needed to use condoms, and;

6 The use of alcohol and drugs may further increase the risk of contracting HIV in the drug-using population as well as others, possibly because of the focus on short-term salient benefits of unprotected sex.

\section{INTERVENTION MAPPING STEP 1 MATRIX OF PROXIMAL PROGRAM OBJECTIVES}

\section{Behavior change and differentiation of the group at risk}

As we have previously indicated in the needs assessment, the major shortcoming in AIDS prevention for IV drug users has been the lack of trying to change unsafe sexual behavior. The drug-using population is as sexually active as the non-drugusing heterosexual population, and they show similar norms concerning the acceptability of unprotected sex, especially in long-term relationships (cf. Kane, 1991; Rhodes \& Quirk, 1995). We concluded that more consistent condom use among drug users is essential to reduce the sexual transmission of HIV.

The Intervention Mapping process suggests that when behavior or motivation within populations greatly differ, it may be necessary to divide the population into sub-populations. We found significant differences in safe sex practices between steady and casual sex partners. According to the Stages-of-Change model of Prochaska and colleagues (1997) people can be differentiated in five stages, that is precontemplation - people do not recognize a problem or a need to change; contemplation - people are seriously thinking about the problem and the possibility to change; preparation - people are making a commitment to change; action - successful modification of the behavior, and; maintenance - which is long term continuation of change. In terms of the Stages-of-Change model it could be argued that most drug users seem to be in the precontemplation stage with regard to condom use within steady relationships (Bowen \& Trotter, 1995; Corby, Jamner, \& Wolitski, 1996; Van Empelen, Schaalma et al., 2001). The majority of drug users seem to be in 
stages of contemplation or preparation with regard to condom use with casual sex partners (Montoya, 1997; Van Empelen, Schaalma et al., 2001). Hence, it seems most relevant to reinforce existing attitudinal and normative beliefs and to enhance the self-efficacy of drug users with regard to condom use and anticipation of possible risk situations.

Thus, it is clear that in order to promote condom use one should differentiate between two types of behavior in the drug-using population, because of differences in importance of determinants for those with primary "monogamous" partners and those with casual partners. The two main goals are the promotion of correct and consistent condom use by drug users when having sex with casual partners, and the promotion of correct and consistent condom use by drug users when having sex with primary partners.

\section{Performance objectives}

The performance objectives for drug users having sexual intercourse with steady and casual sex partners are the following (Abraham, Sheeran, \& Johnston, 1998; Kelly, 1995):

1 The person will make the decision to use condoms when having sexual intercourse;

2 The person will purchase condoms;

3 The person will carry condoms or have condoms available;

4 The person will successfully negotiate condom use;

5 The person will use condoms correctly;

6 The person will maintain the use of condoms on each occasion of intercourse.

\section{Determinants}

\section{Personal determinants}

In order to identify important and changeable determinants, we used our own studies among drug users in South-Limburg (Van Empelen, Kok et al., 2001; Van Empelen, Schaalma et al., 2001) as well as other available literature. Although the most important determinants of the risk behavior (unsafe sex) have been discussed within the needs assessment, now we have shifted our focus to intervention planning for risk reduction, the importance of determinants may differ in relation to the stated performance objectives.

Knowledge has not shown to be a highly important determinant. Knowledge, however, is a necessary step in promoting any change. Therefore, drug users should at least have some basic understanding of HIV/AIDS and HIV transmission routes, and special attention should be given in the programs to misperceptions. Perceived vulnerability is another prerequisite for any attitude change and seems to be particularly important in view of the performance objectives specified for steady sexual 
relationships, especially in making the decision to use condoms.

Furthermore, it is important to change existing negative attitudes or reinforce existing positive attitudes regarding condom use with casual sex partners, and, more importantly, to change the current negative attitudes regarding condom use within steady sexual relationships in order to reach the performance objectives described. Several studies have shown that positive attitudes are related to intended condom use among drug users (Corby, Jamner, \& Wolitski, 1996; Magura et al., 1990; Van Empelen, Kok et al., 2001). Moreover experienced negative affect of having unprotected sex may motivate drug users to use condoms. In accordance, we found that drug users who experienced more anticipated negative regret in steady sexual relationships were more inclined to use condoms with steady sex partners (Van Empelen, Kok et al., 2001). Apart from attitudes, personal norms have also been found to be important predictors of condom use with both casual and steady sex partners (Van Empelen, Kok et al., 2001; Van Empelen, Schaalma et al., 2001). Personal norms might be of importance when deciding to use condoms and to have condoms available at all times. Perceived social norms are important with regard to condom use both with casual and steady sex partners, making it easier to communicate about condom use and actually use condoms. This is particularly important in steady relationships (Corby, Jamner, \& Wolitski, 1996; Magura et al., 1990; Van Empelen, Kok et al., 2001; Van Empelen, Schaalma et al., 2001).

Finally, perceived self-efficacy has proved to be one of the most important predictors of condom use with both steady and casual sex partners (Baker, Heather, Wodak, Dixon, \& Holt, 1993; Bowen, 1996; Bowen \& Trotter, 1995; Kowaleski, Longshore, \& Anglin, 1994; Paulussen et al., 1990). The studies provided specific information about the performance objectives specified. The self-efficacy expectations of drug users concerning their capability to use condoms, to negotiate condom use, and to have condoms available at all times proved to be most important. Both the skills and the perceived self-efficacy regarding skills appear to be important. Selfefficacy enhancement is more important in the context of casual sex partners, because drug users seem inclined to use condoms, but experience certain barriers.

Alcohol and drug use in itself may increase risk behavior. Yet habitual patterns are difficult to change. As an additional complication, most drug users do not believe they will have problems using condoms even after the intake of drugs or alcohol (Van Empelen, Kok, Hoebe \& Jansen, 2001). Drug users however reported lower self-efficacy expectations in the context of withdrawal symptoms (Van Empelen, Schaalma, et al., 2001). Moreover drug users report who report lower selfefficacy when being sexually aroused also report lower condom use intentions, and this may be partly explained by their use of alcohol or drugs, as has been shown in studies of MacDonald and colleagues (a.o. MacDonald, MacDonald, Zanna, \& Fong, 2000), who showed that intoxication may influence decisions by people, because it restricts atttentional capacity so that people are highly influenced by the most salient cues in their environment. They showed that sexual arousal may be a very powerful internal cue that in combination with intoxication might increase sexual risk-taking. 


\section{External determinants}

Steady sex partners of drug users play an important role in the promotion of condom use. First of all, being in a relationship with a high-risk partner, they represent a population at risk and should therefore protect themselves. Second, condom use and the communication about condom use is dependent on the social support to use condoms in steady relationships, which in turn depends on their own attitude towards condoms within steady relationships. To achieve the performance objectives specified, steady sexual partners should thus support condom use in steady relationships. Therefore, targeting steady sex partners of drug users is equally relevant. In any case, the principal program will reach most partners, because they are part of the same drug-using network. It might be more difficult to reach the non-drug-using sex partners. In an initial attempt to include this population in a study addressing the issue of unprotected sex in sexual relationships, we found that this population is very hard to reach (Van Empelen, Kok, Hoebe, \& Jansen, 2000). However, if possible these non-drug-using partners will be reached (and possibly included in the program) via drug users (Table 1a).

Addiction and health care centers do mostly do not actively support condom use by means of active distribution, although making condoms available at low or no costs. It is also essential that existing channels of the public health centers promote condom use more actively in order to ensure that drug users have condoms available when needed. Existing channels, such as outreach workers, should therefore reinforce drug users to carry condoms on them at all times.

\section{Summary of personal and external determinants}

In conclusion, the promotion of consistent condom use with primary partners should focus on the following determinants (Table 1a):

a Knowledge (basic knowledge about HIV/AIDS and the possible risks of HIV and STD transmission);

b Perception of personal risk of contracting HIV/STD or infecting others with STD/HIV;

c Attitude (i.e., positive beliefs should be promoted, negative beliefs should be decreased, and new beliefs should be created);

d Partner norms within steady relationships;

e Self-efficacy to negotiate condom use with steady sex partners;

f Partner support within steady sexual relationships; and

g Reinforcement (e.g., of condom use by the public health centers)

The promotion of condom use with casual partners should focus on the following determinants (Table 1b):

a Knowledge about HIV/AIDS and the possible risks of HIV and STD transmission;

b Attitude (promotion of positive beliefs and new beliefs about condom use with casual partners);

c Self-efficacy (to negotiate the use of condoms and to use condoms within casual relationships); and

d Reinforcement (of condom use by the public health centers). 
Table 1a Determinant delineation - Individual behavior, concerning condom use with steady partners

\begin{tabular}{|c|c|c|c|}
\hline Individual & Importance & Changeable & Evidence \\
\hline Knowledge & + & +++ & $\begin{array}{l}\text { Basic knowledge about HIV/AIDS pre- } \\
\text { vention is a precondition for a posi- } \\
\text { tive attitude toward safe sex behavior }\end{array}$ \\
\hline Perceived susceptibility & ++ & + & $\begin{array}{l}\text { Drug users should feel that HIV preven- } \\
\text { tion is necessary even when having } \\
\text { sex with relatively well-known partners }\end{array}$ \\
\hline Attitude & +++ & + & $\begin{array}{l}\text { Positive attitudes have been shown to } \\
\text { be important for commitment to safer } \\
\text { sex and are a condition for establishing } \\
\text { and maintaining a behavior change }\end{array}$ \\
\hline Personal norm & +++ & + & $\begin{array}{l}\text { Altruistic feelings towards the partner } \\
\text { seem an important commitment to } \\
\text { safe sex }\end{array}$ \\
\hline Social influence & +++ & 0 & $\begin{array}{l}\text { The perception of the norms of the part- } \\
\text { ner and of the behavior of others seem } \\
\text { essential to actually using condoms }\end{array}$ \\
\hline Self-efficacy & +++ & 0 & $\begin{array}{l}\text { Self-efficacy regarding having con- } \\
\text { doms present, using condoms and dis- } \\
\text { cussing condoms seems vital for con- } \\
\text { dom use intention }\end{array}$ \\
\hline Drug and alcohol use & +++ & -- & $\begin{array}{l}\text { Although drug seems highly important } \\
\text { in the relation to unsafe sex, it seems } \\
\text { difficult to address these habitual } \\
\text { behaviors of the target group }\end{array}$ \\
\hline
\end{tabular}

\section{External}

Partner support

$+++$

Reinforcement by outreach workers

$+++$

0

Social support of the partner seems important to promote condom use within steady relationships, but partners seem difficult to reach

Active reinforcement of condom carrying seems very important to increase condom availability among drug users 
Table 1b Determinant delineation - Individual behavior, concerning condom use with casual sex partners

\begin{tabular}{|c|c|c|c|}
\hline Individual & Importance & Changeable & Evidence \\
\hline Knowledge & + & +++ & $\begin{array}{l}\text { Basic knowledge about HIV/AIDS pre- } \\
\text { vention is a precondition for a posi- } \\
\text { tive attitude toward safe sex behavior }\end{array}$ \\
\hline Perceived susceptibility & + & + & $\begin{array}{l}\text { Drug users should feel that HIV pre- } \\
\text { vention is necessary even when hav- } \\
\text { ing sex with casual partners }\end{array}$ \\
\hline Attitude & ++ & + & $\begin{array}{l}\text { Positive attitudes have been shown to } \\
\text { be important for commitment to safer } \\
\text { sex and are a condition for establish- } \\
\text { ing and maintaining a behavior } \\
\text { change }\end{array}$ \\
\hline Personal norm & + & + & $\begin{array}{l}\text { One's own responsibility for safe sex } \\
\text { seems related to safe sexual intentions }\end{array}$ \\
\hline Social influence & ++ & + & $\begin{array}{l}\text { The perception of the norms of valu- } \\
\text { able others (partner, family, friends) } \\
\text { and of the behavior of others seems } \\
\text { essential to actually use condoms }\end{array}$ \\
\hline Self-efficacy & +++ & 0 & $\begin{array}{l}\text { Self-efficacy regarding having con- } \\
\text { doms present, using condoms and dis- } \\
\text { cussing condoms seems vital for con- } \\
\text { dom use intention }\end{array}$ \\
\hline Drug and alcohol use & +++ & -- & $\begin{array}{l}\text { Although drug seems highly important } \\
\text { in the relation to unsafe sex, it seems } \\
\text { difficult to address these habitual } \\
\text { behaviors of the target group }\end{array}$ \\
\hline \multicolumn{4}{|l|}{ External } \\
\hline Availability & 0 & + & $\begin{array}{l}\text { The availability of condoms is impor- } \\
\text { tant, but is already arranged well }\end{array}$ \\
\hline Accessibility & 0 & 0 & $\begin{array}{l}\text { The accessibility of condoms is impor- } \\
\text { tant, but seems to be in order at present }\end{array}$ \\
\hline $\begin{array}{l}\text { Reinforcement by } \\
\text { outreach workers }\end{array}$ & ++ & ++ & $\begin{array}{l}\text { Active reinforcement of condom car- } \\
\text { rying seems very important to } \\
\text { increase condom availability among } \\
\text { drug users }\end{array}$ \\
\hline
\end{tabular}




\section{Matrix of proximal program objectives for the groups at risk}

On the basis of the performance objectives and determinants, matrices of proximal program objectives were created. The matrices specify learning objectives and change objectives that are the result of intersections between the performance objectives for the use of condoms, and the important, changeable determinants of condom use. Learning objectives and change objectives should be stated as measurable. This means they should be defined as a specific action. For learning objectives this means that they should state what the participant in the program needs to learn (related to the determinant) to achieve the performance objective. The change objectives define what changes are required in the determinants that are external to the individual and needed to accomplish the performance objective. Based on the target population differentiation, we separated the matrices on the basis of relationship status (Tables $2 \mathrm{a}$ and $2 \mathrm{~b}$ ). Tables $3 \mathrm{a}$ and $3 \mathrm{~b}$ describe the learning and change objectives for respectively steady and casual sex partners. The matrices provide the foundation for intervention development and evaluation and are useful both to find theoretical methods and to create strategies.

\section{CONCLUSION}

The needs assessment provided evidence of the HIV risk taking behavior of Dutch drug users. The needs assessment showed that drug users are at great HIV-risk by means of unprotected sexual intercourse and have the potential of transmitting HIV towards other (non-) drug using individuals. Factors related to unsafe sexual practices by drug users were: 1) an underestimation of the actual risk both for themselves and for others in having unsafe sex; 2 ) their attitude concerning safe sexual behavior, particularly condom use, are quite negative; 3 ) they appear to lack a feeling of responsibility for others; 4) a safe sex norm is not established; 5) it appears that drug users lack the practical, communication, and self-management skills needed to use condoms, and 6) the use of alcohol and drugs may further increase the risk in this population, as it does in others.

Intervention Mapping Step 1, showed the need to differentiate between casual and steady sexual practices. Finally, the performance objectives of condom use, and the important and changeable determinants related to the performance objectives provided the matrices of proximal program objectives. The proximal program objectives provide a foundation for the following Intervention Mapping steps. 
Table 2a Proximal program objectives matrix - Condom use with steady sex partners

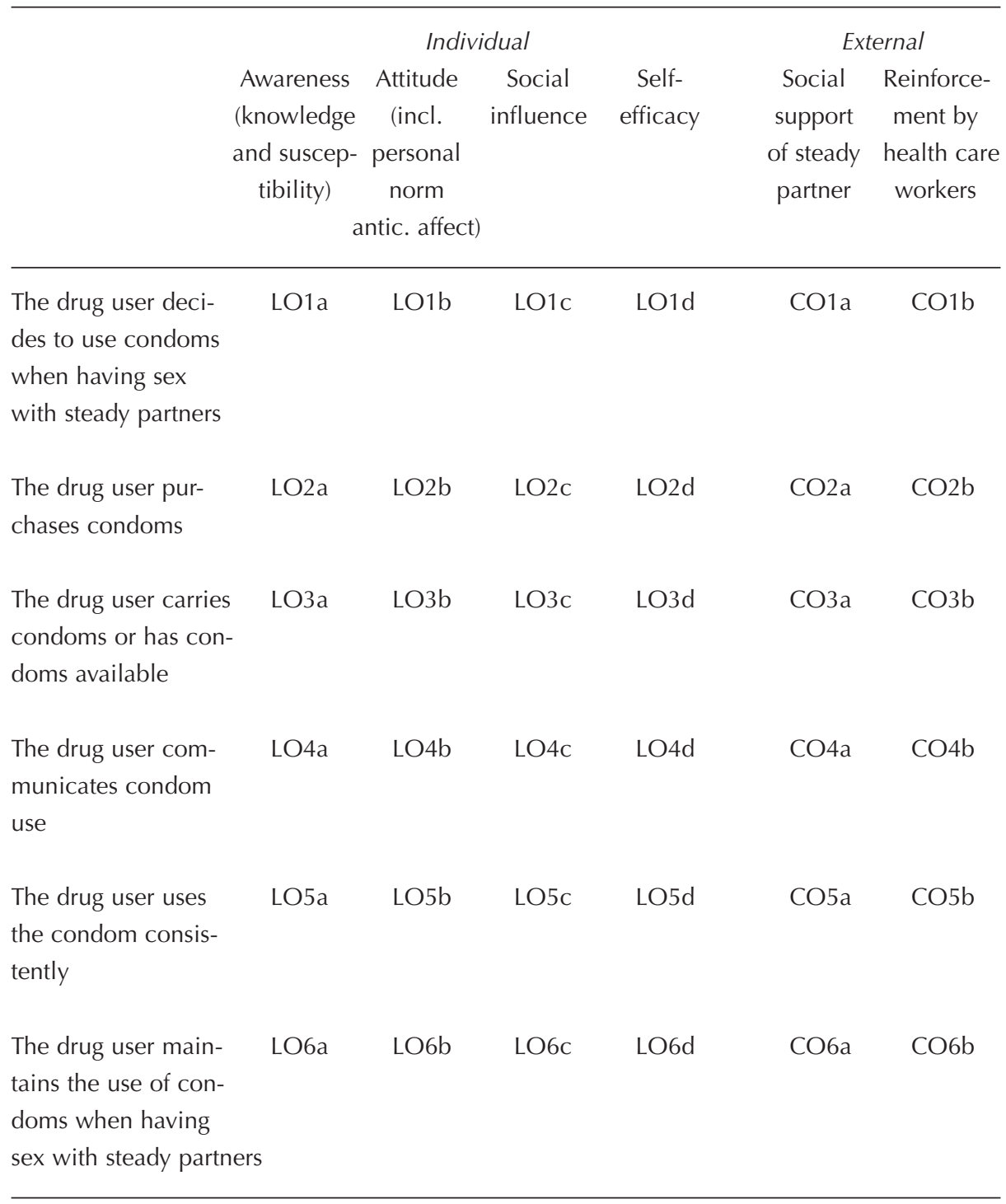


Table 2b Proximal program objectives matrix - Condom use with casual sex partners

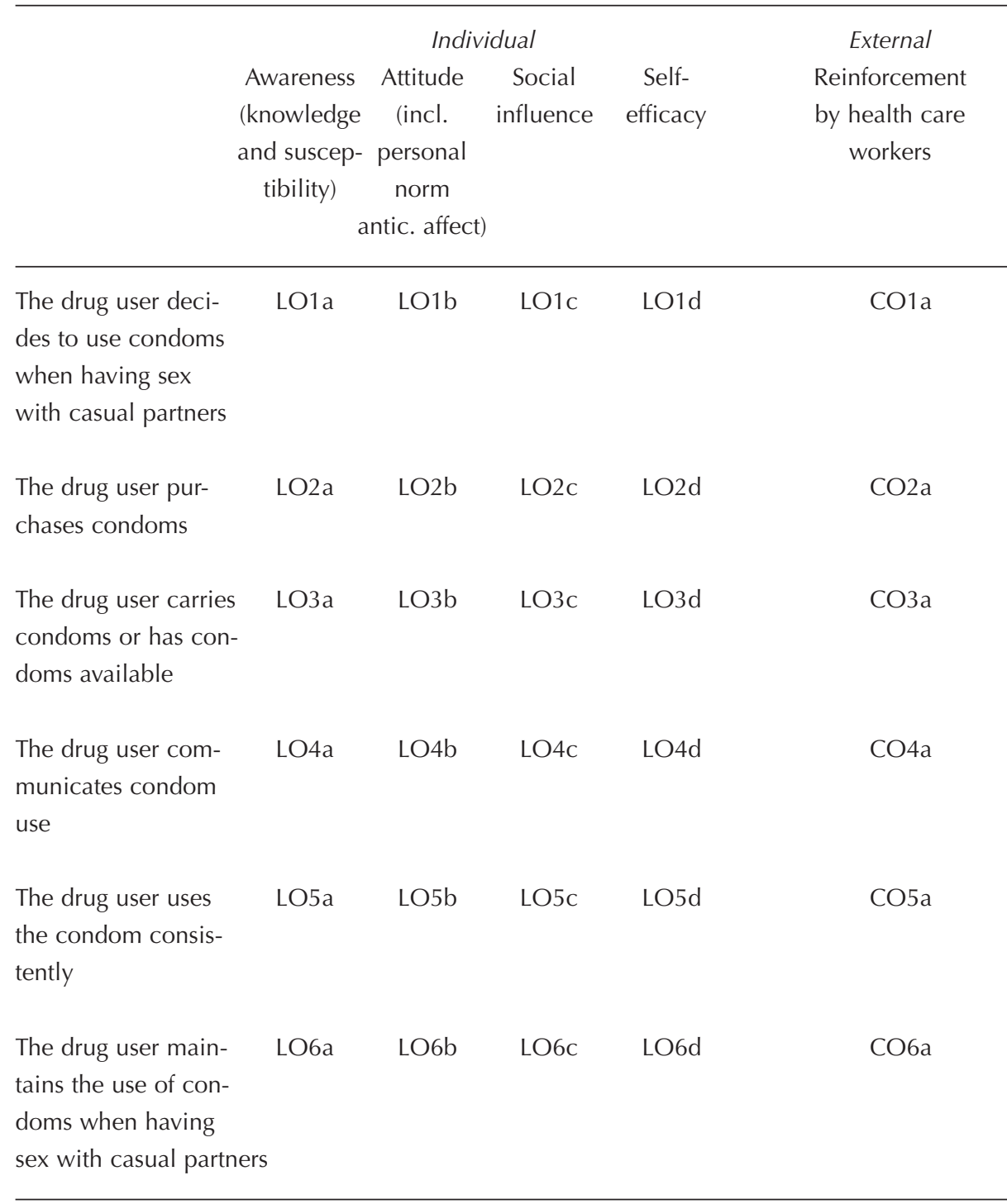


Table 3a Learning and change objectives per determinant - Steady sex partners

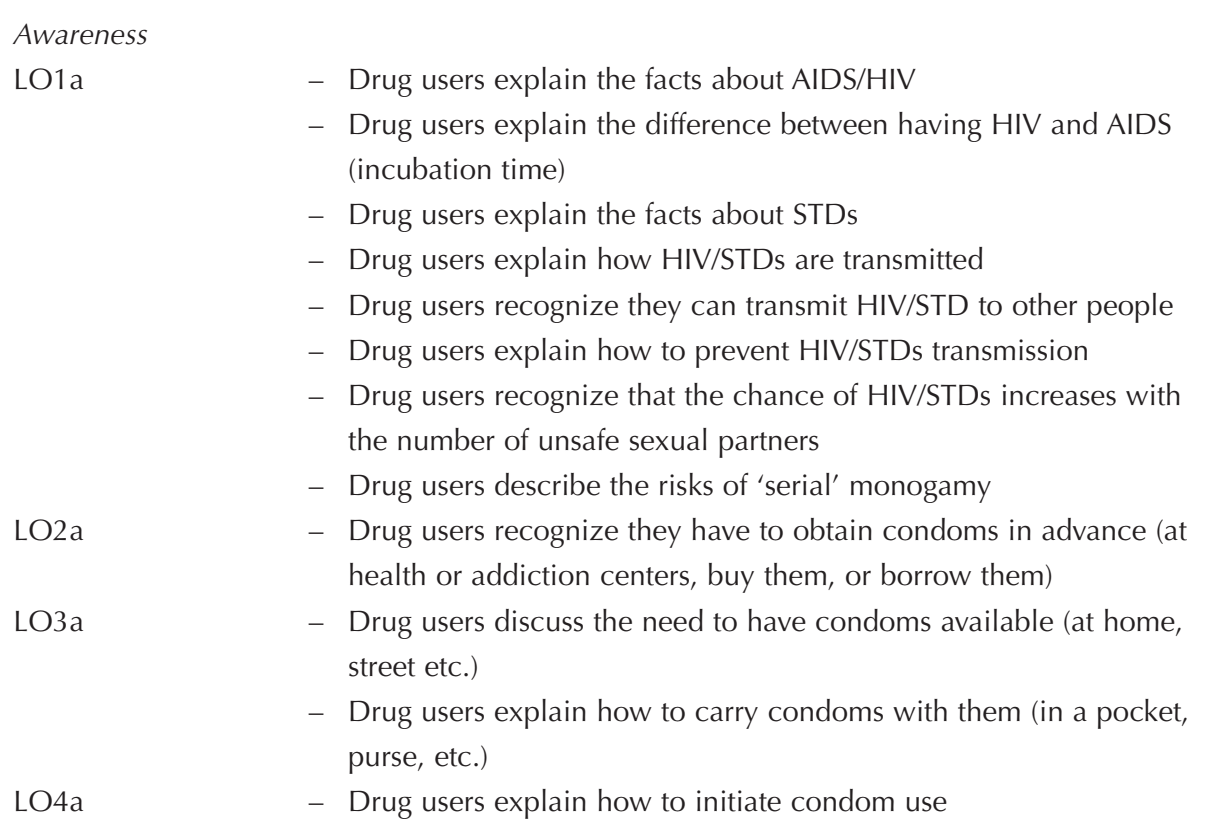

Attitude

LO1b

$\mathrm{LO} 4 \mathrm{~b}$

LO1b, LO5b

LO1b, LO5b, LO6b
- Drug users recognize the advantages of condom use as protection for HIV/STDs

- Drug users recognize the advantages of condom use as protection for unwanted pregnancies

- Drug users recognize the advantages of condom use to avoid unwanted feelings of regret, worries, etc.

- Drug users recognize the advantage of discussing safe sex with the partner

- Drug users anticipate on the negative consequences of using condoms with steady partners (annoying, awkward, difficulties with erections, etc)

- Drug users recognize that the advantages of condom use with steady partners outweigh the disadvantages

- Drug users recognize the advantages of not having sex or protected sex with other partners than the steady partner 
Table 3a Continued

\begin{tabular}{|c|c|}
\hline \multicolumn{2}{|l|}{ Social influence } \\
\hline LO1c, LO5c, LO6c & $\begin{array}{l}\text { - Drug users have an adequate perception of the partner norm } \\
\text { regarding safe sex } \\
\text { - Drug users establish mutual commitment towards safe sex } \\
\text { - } \text { Drug users feel responsible to protect others for HIV/STDs }\end{array}$ \\
\hline LO4c & - Drug users adduce counter arguments towards unsafe sex \\
\hline LO1c, LO6c & - Drug users know important others who use condoms \\
\hline \multicolumn{2}{|l|}{ Self-efficacy } \\
\hline LO1d, LO5d, LO6d & $\begin{array}{l}\text { - Drug users express confidence/demonstrate how to use condoms } \\
\text { adequately and consistently } \\
\text { - Drug users express confidence to avoid situations in which they } \\
\text { feel less capable to use condoms adequately (e.g., withdrawal } \\
\text { symptoms, intoxication) }\end{array}$ \\
\hline LO2d, LO3d & $\begin{array}{l}\text { - Drug users describe where they fetch condoms } \\
\text { - Drug users express confidence to have condoms available at all times }\end{array}$ \\
\hline LO4d & $\begin{array}{l}\text { - Drug users demonstrate how to discuss condom use with steady } \\
\text { sex partners }\end{array}$ \\
\hline LO4d, LO5d & $\begin{array}{l}\text { - Drug users express confidence to resist unsafe sex with steady partners } \\
\text { - Drug users express confidence to resist a proposal of unsafe sex by } \\
\text { steady partners }\end{array}$ \\
\hline
\end{tabular}

Social Support

CO1a, 4a, 5a, 6a $\quad$ - Partner expresses being favorable to use condoms

Reinforcement

CO1b _ - The health care worker encourages the use of condoms

$\mathrm{CO} 2 \mathrm{~b} \quad-$ The health care worker administers condoms

$\mathrm{CO} 3 \mathrm{~b} \quad-$ The health care worker reinforces the availability of condoms

$\mathrm{CO} 4 \mathrm{~b} \quad$ - The health care worker discusses how to communicate condom use

CO5b, CO6b _ - The health care worker reinforces consistent condom use 
Table 3b Learning and change objectives per determinant - Casual sex partners

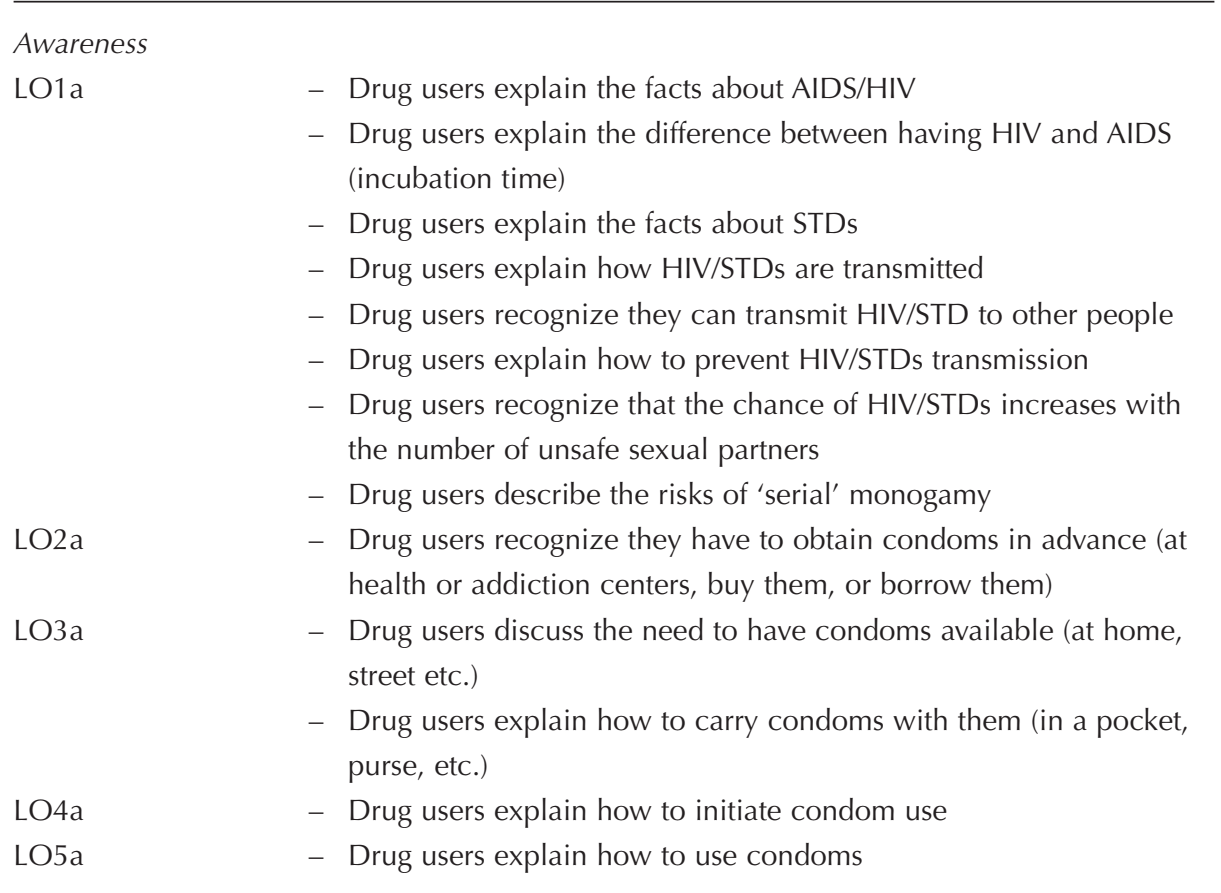

Attitude

LO1b

- Drug users recognize the advantages of condom use as protection for HIV/STDs

- Drug users recognize the advantages of condom use as protection for unwanted pregnancies

- Drug users recognize the advantages of condom use to avoid unwanted feelings of regret, worries, etc.

LO1b, LO5b _ _ Drug users anticipate on the negative consequences of using condoms with casual partners (sign of distrust, annoying, difficulties with erections, etc.)

LO1b, LO5b, LO6b - Drug users recognize that the advantages of condom use with casual partners outweigh the disadvantages

Social influence

LO1c, LO6c

LO4c

LO4C

LO1c, LO6c
- Drug users have an adequate perception of norms regarding safe sex with casual sex partners

- Drug users establish mutual commitment towards safe sex

- Drug users feel responsible to protect others for HIV/STDs

- Drug users adduce counter arguments towards unsafe sex

- Drug users know important others who use condoms 
Table 3b Continued

\begin{tabular}{|c|c|}
\hline \multicolumn{2}{|l|}{ Self-efficacy } \\
\hline LO1d, LO5d, LO6d & $\begin{array}{l}\text { - Drug users express confidence/demonstrate how to use condoms } \\
\text { adequately and consistently } \\
\text { - Drug users express confidence to avoid situations in which they } \\
\text { feel less capable to use condoms adequately (e.g., withdrawal } \\
\text { symptoms, intoxication) }\end{array}$ \\
\hline LO2d, LO3d & $\begin{array}{l}\text { - Drug users describe where they obtain condoms } \\
\text { - Drug users demonstrate they carry condoms with them }\end{array}$ \\
\hline LO4d & $\begin{array}{l}\text { - Drug users demonstrate how to discuss condom use with casual } \\
\text { sex partners } \\
\text { - Drug users express confidence to resist unsafe sex with casual sex } \\
\text { partners } \\
\text { - Drug users express confidence to resist a proposal of unsafe sex by } \\
\text { casual partners }\end{array}$ \\
\hline \multicolumn{2}{|l|}{ Reinforcement } \\
\hline CO1a & - The health care worker encourage the use of condoms \\
\hline $\mathrm{CO} 2 \mathrm{a}$ & - The health care worker administers condoms \\
\hline $\mathrm{CO} 3 \mathrm{a}$ & - The health care worker reinforces the availability of condoms \\
\hline $\mathrm{CO} 4 \mathrm{a}$ & - The health care worker discuss how to communicate condom use \\
\hline CO5a, CO6a & - The health care worker reinforces consistent condom use \\
\hline
\end{tabular}





\section{CHAPTER 3}

\section{DETERMINANTS OF UNSAFE AND SAFE SEXUAL BEHAVIOR:}

QUALITATIVE AND QUANTITATIVE INSIGHTS

\section{Overview}

Section 3.1 Predicting condom use with casual and steady sex partners among drug users

Section 3.2 The additional value of anticipated regret and psychopathology in explaining intended condom use among drug users

Section 3.3 A qualitative focus on transitional factors of the motivation-action relationship in condom use among drug users 

OVERVIEW 
Chapter 3 gives an overview of the additional empirical research we conducted in order to answer questions raised in the needs assessment and Intervention Mapping Step 1. Section 3.1 describes a survey study among 103 Dutch drug users. An analysis of determinants related to condom use with casual and steady sex partners among drug users, based upon the general model of health behavior that has been described in chapter 1, was performed. The participants indicated their intentions, vulnerability, attitude, personal norms, subjective norms, descriptive norms, self-efficacy and response efficacy regarding condom use with steady and casual sex partners. The results showed that some drug users had borrowed used syringes, and that most drug users practice unsafe sex, especially with steady partners. Most drug users were hardly motivated to start using condoms. The study also showed that antecedents of condom use differ with regard to steady sex partners and casual sex partners. Self-efficacy and subjective norms were predictors of intentions to use condoms with steady partners; intention to use condoms with casual partners was only predicted by self-efficacy.

Section 3.2 describes a second survey study examining determinants of intended condom use with casual and steady sex partners among drug users. However, in that study the aim was to find out whether anticipated regret and psychopathology represent additional factors in explaining condom use behavior, on top of the constructs defined in traditional psychosocial models of behavior. The results showed that similar results were found when only including similar constructs as described in the first study. However, when including additional factors, we found that intended condom use with steady sex partners was mainly predicted by self-efficacy, personal norm and anticipated regret, and that the variance explained was significantly higher. Lower feelings of hostility and a more positive personal norm, subjective norm and attitude significantly predicted intended condom use with casual sex partner, and also increased the explanatory value. The results showed that intended condom use with steady sex partners seems related to anticipating possible barriers, whereas condom use with casual sex partners is largely a matter of having safe sex norms.

The study described in section 3.3 was based on semi-structured interviews with drug users. The purpose of this study was to gain insight into factors that may improve the transition from motivation to use condoms to action. The study showed that most drug users in steady sexual relationships were negatively motivated. But also in casual sexual relationships, where most drug users were motivated to use condoms, several enactment factors might inhibit them from actually using condoms. The majority reported that they did not anticipate sexual encounters, and did not communicate or have experience with communicating HIV/AIDS and safe sex with their sex partners. Both the enactment factors discussed and the difference in the type of sexual relationship should be taken into account in efforts to promote safe sex among drug users.

The information gathered with these studies were integrated in the needs assessment and Intervention Mapping Step 1 described in chapter 2. 


\section{SECTION 3.1}

PREDICTING CONDOM USE WITH CASUAL AND STEADY SEX PARTNERS AMONG DRUG USERS

\section{Published as}

Van Empelen, P., Schaalma, H. P., Kok, G., \& Jansen, M. W. J. (2001). Predicting condom use with casual and steady sex partners among drug users. Health Education Research, 16, 293-305. 


\section{INTRODUCTION}

To date, AIDS prevention campaigns have mainly focused on sexual behavior and commitment to safer sex. Examples are interventions targeting the population of homosexual and bisexual men (De Wit, 1996; Kalichman \& Hospers, 1997; Stall et al., 1988) and adolescents (Kim et al., 1997). Interventions aimed at drug users have, however, mainly concentrated on drug-injecting behavior. Although these interventions have proved to be effective in reducing needle sharing (Coyle et al., 1998; Marsch, 1998; Vlahov \& Junge, 1998), so far they have failed to reduce risk-taking sexual behavior (Booth \& Watters, 1994; Gillies \& Carballo, 1990). Drug users continue to practice unsafe sex to a great extent, even if they are aware of the risks of heterosexual HIV transmission (Berns et al., 1998; Carsauw et al., 1997; Magura et al., 1990; WHO, 1993). Recent data has revealed that the non-drug-injecting heterosexuals are put at high risk for contracting HIV (CDC, 1998; Dutch Aids Fund, 1998). Moreover, studies from the United States and Western Europe suggest that drug users account for the majority of heterosexual HIV transmissions (Fennema, 1997; Liebman et al., 1992; Lukashove et al., 1998; McKegany \& Barnard, 1992; Op de Coul et al., 1998; Rhodes et al., 1996). These findings indicate that more forceful attempts are needed to prevent further heterosexual transmission of HIV by drug users to other drug users and larger non-drug-using populations (see also Williams et al., 1997).

AIDS educational campaigns should comprise more than increasing knowledge of HIV/AIDS. More effective interventions have shown to be systematically planned and are based on theory and data (Fisher \& Fisher, 1992; Kim et al., 1997; Schaalma et al., 1996).

Meta-evaluations and planning models (Bartholomew et al., 1998; Green \& Kreuter, 1991; Witte, 1995) have shown that effective interventions require a needs assessment to analyse the problem, the behavior at both individual and environmental levels, as well as the determinants of such behavior. A fair amount of knowledge is available about the problem of HIV/AIDS and the risk behaviors involved. However, only few studies have tried to identify determinants of safe and unsafe sexual behavior among drug users. Studies among drug users revealed that both knowledge of HIV/AIDS (Helal et al., 1995; Thornton \& Catalan, 1993) and perceived vulnerability to HIV risk (Robles et al., 1995) were unrelated to safe sexual behaviors. Studies among (injecting) drug users (Bowen, 1996; Bowen \& Trotter, 1995; Corby et al., 1996; McKegany \& Barnard, 1992; Montoya, 1997; Paulussen et al., 1990) found that attitudes towards the use of condoms were moderately good predictors of condom use intentions. Furthermore, they found that self-confidence regarding the ability to use condoms and negotiate condom use is a strong predictor of condom use with both steady (Bowen, 1996; Corby et al., 1996) and casual sex partners (Bowen \& Trotter, 1995; Corby et al., 1996; Montoya, 1997; Paulussen et al., 1990). In regard to the influence of the social environment of drug users, the support has been rather mixed. Subjective norms were found to have little or no 
impact on condom use behavior (Corby et al., 1996; Paulussen et al., 1990). However, in their studies among IV drug users, Corby et al. (1996) and Magura et al. (1990) found that the norms of partners predicted condom use with steady partners. Other studies revealed that the safe sex behavior of other drug users was related to safer sexual intention (Abdul-Quader et al., 1990; Kowaleski et al., 1994; Magura et al., 1990).

Thus, although a number of studies - mainly oriented to the United States - have examined determinants of condom use among drug users, their focus on possible antecedents of condom use was limited, and the evidence they provided is mixed. Furthermore, with the exception of Corby et al. (1996), these studies have offered little insight into differences in antecedents of condom use between casual and steady sex partners. The present study is an attempt to broaden the insight into other cognitive antecedents of condom use and specify those for steady and casual sex partners. Its focus is based upon a core model of motivation previously identified by Abraham et al. (1998), who reviewed theoretical concepts of multiple social cognitive models, and identified several key cognitive constructs of individual motivation and behavior, i.e., attitudes, self-representations, social influence, self-efficacy and intention (see figure 1). Intention is viewed as a construct that mediates the effect of the other variables on behavior.

In the present study we have conceptualized the construct of attitudes in three ways. First, attitude is conceptualized as a set of beliefs about a certain behavior i.e., condom use - as proposed by the Theory of Reasoned Action (TRA, Fishbein \& Ajzen, 1975). In his Protection Motivation Theory, Rogers (1975) proposes two other attitude-related concepts that are also used in this study: an individual's perceived vulnerability to a threat (e.g., HIV) and an individual's perceived response efficacy, i.e., the belief about the efficacy of the possible preventive action (e.g., condom use). The present study conceptualizes the construct of self-representation by personal normative belief (Triandis, 1977), which covers an individual's personal feelings of responsibility to perform or refuse a certain behavior. Social influence is also likely to affect an individual's intention and is conceptualized by subjective norms as proposed within the TRA (i.e., beliefs about people's approval for one's behavior) and descriptive norms, referring to the observation of what others do (Cialdini et al., 1990; De Vries et al., 1995). The final construct examined is that of self-efficacy. This construct seems important within the context of less volitional behavior, such as condom use, and refers to an individual's perception of his or her ability to perform a specific behavior (Bandura, 1986).

In addition, we will examine environmental barriers that might directly or indirectly increase the chances of contracting HIV (i.e., risky drug use behavior, travelling to AIDS-endemic areas, the costs of condoms, and the availability of condoms and clean needles). 


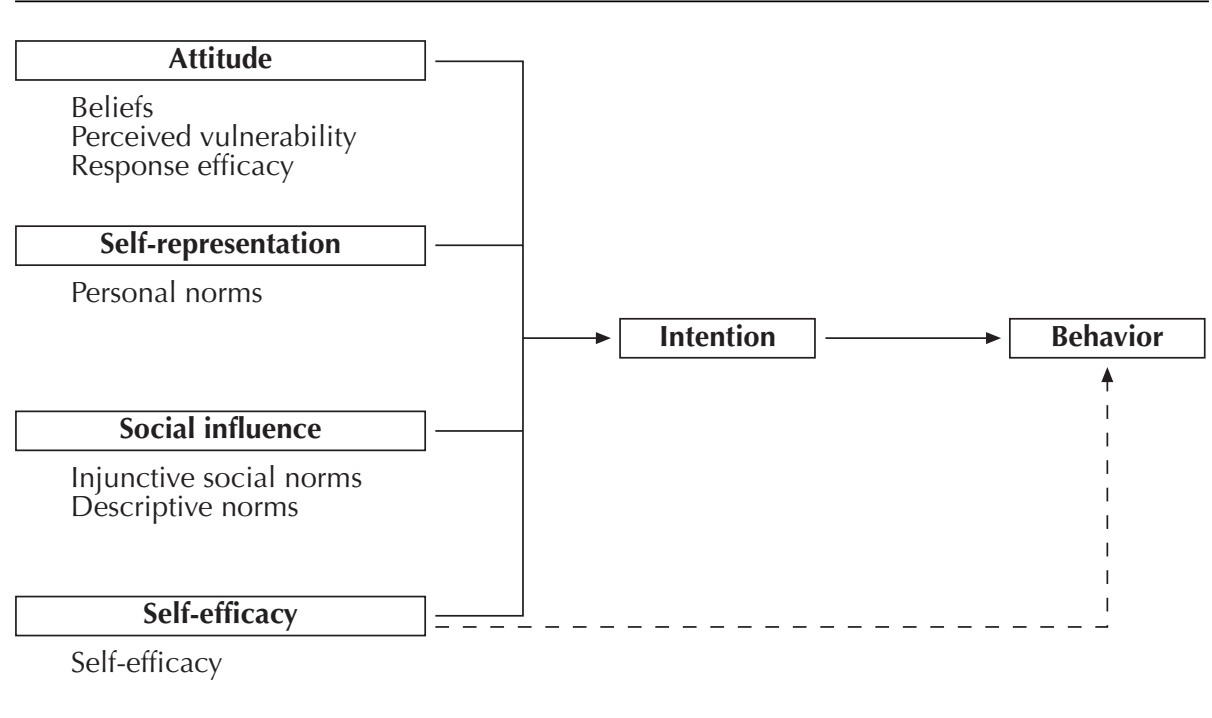

Figure 1 Core model of predictors of behavior (adapted from Abraham et al., 1998)

\section{METHOD}

\section{Participants}

A total of 103 drug users participated in the study. The studied area of Maastricht comprises approximately 400 drug users, of which 200 are assumed to inject drugs. With an estimated number of $25 \%$ of the total population, our sample therefore seems a good reflection of that community. The majority was male $82.5 \%$ and of Dutch nationality $85.5 \%$. For the injecting drug users this was respectively $85.7 \%$ and $87.3 \%$. These numbers are similar to figures reported elsewhere (e.g., Beuker et al., 2001; Carsauw et al., 1997), and therefore the group seems representative for the total population. The average age of sample was 34.

\section{Setting}

The participants were recruited in Maastricht, the Netherlands, via outreach workers and treatment centres of the Centre for Alcohol and Drug Abuse over a five-month period. The main selection criterion was that participants had used drugs during the six months preceding the study, other than alcohol, marihuana or methadone. A small number of people (eight) declined to participate. The questionnaire was handed out to the participants and required about 20 minutes to complete. All participants received a compensation of 15 guilders (approximately US \$6). 


\section{The questionnaire}

The items used in the questionnaire to assess attitudes, perceived vulnerability, response efficacy, social influences, self-efficacy, intentions, and barriers were based on a literature survey and interviews with outreach workers. The questionnaire was pre-tested among a small group of drug users for comprehension and completeness. The scales and items are described below. Most items were measured on 5-point scales (ranging from 'never' to 'always'). Exceptions are indicated where applicable.

\section{Demographics and behavior}

The participants were asked to state their age, gender, sexual preference, history of sexually transmitted diseases (STDs) and hepatitis, drug use history (past drug-injecting behavior), present drug use (during the 6 months preceding the study) and sexual history (past sexual relationships with a steady partner/casual partner/client). Unsafe drug-use behavior was measured by the frequency of used syringes or needles borrowed throughout the past 6 months, and the frequency of dirty cotton, filters, spoons, or rinsing water used throughout the past 3 months. Sexual behavior was measured separately for steady partners, casual partners and clients. In the questionnaire a steady sex partner was defined as a person with whom the participant had had a relationship for at least 3 months, whom the participant was seeing at least once a week, and with whom the participant had frequent sexual intercourse. A casual sex partner was defined as a person with whom the participant had had sexual intercourse at least once, without having been paid or having received drugs or other rewards in return, and with whom the participant did not have a relationship. Finally, a client was defined as a person with whom the participant had had sexual intercourse in return for money, drugs or other rewards.

We measured the number of partners (steady, casual, clients) and estimated the frequency of sexual intercourse throughout the past 6 months as well as the number of incidences of unprotected sex. Also we asked the respondents whether they had ever thought about using condoms with partners (steady, casual, clients). Additionally, participants answered questions about the drug use history of their last sex partner (steady, casual and client) by 'yes', 'no' or 'do not know'.

\section{Perceived vulnerability}

Vulnerability was measured by a self-assessment of respondents of their own chances of contracting HIV when having sex without a condom, and their assessment of the chances of other drug users contracting HIV when having sex without a condom. Measurements were rated separately for sexual intercourse with steady and casual partners. Participants had to provide probability estimations in percentages.

\section{Attitudes}

Separate measurements were conducted for attitude towards condom use with steady partners and attitude towards condom use with casual partners. Both scales were constructed from a set of five items regarding personal consequences related to 
condom use. Both attitude scales includes items such as: 'Using condoms when having sexual intercourse with your steady/casual partner is annoying' ('disagree' to 'agree'), 'Using condoms with your steady/casual sex partners is a sign of distrust', 'Using condoms with your steady/casual sex partner is very pleasant'. The attitude scale for condom use with steady sex partners was reliable at Cronbach's $\alpha=.71$; the scale for casual sex partners was reliable at Cronbach's $\alpha=.59$.

\section{Response efficacy}

Response efficacy was measured by three items: 'Condoms offer good protection against the AIDS virus', 'Condoms offer good protection against STDs', 'Condoms offer good protection against pregnancy' ('never' to 'always'). This scale was reliable at $\alpha=.78$.

\section{Personal norms}

Two items were used to assess personal norms toward condom use with steady partners and casual partners, respectively: 'Do you permit yourself to have sex with your steady partner without using a condom?', and 'Do you permit yourself to have sex with casual partners without using a condom?'('never' to 'always').

\section{Perceived social influence}

Social influence was measured using two concepts: the subjective norm and the descriptive norm. Both concepts were measured by means of a single item (subjective norm: 'Do you think your steady partner expects you to use condoms when having sexual intercourse?' ('never'-'always'), cf. Corby et al., 1996); descriptive norm: 'Do you think your closest friends always use condoms?', cf. Kowaleski et al., 1994).

\section{Self-efficacy}

Self-efficacy towards condom use with steady partners (Cronbach's $\alpha=.66$ ) and selfefficacy toward condom use with casual sex partners (Cronbach's $\alpha=.77$ ) were measured each with five items, such as 'Suppose you want to use condoms when having sex, will you be able to do so when you are sexually aroused? ('never''always')' (cf. Bowen \& Trotter, 1995; Montoya, 1997).

\section{Intention}

Measures of intention to use condoms when having sex with steady and with casual partners were each indexed with a single item: 'I intend to use condoms with steady partners in the next three months' ('absolutely not' to 'absolutely'), and 'I intend to use condoms with casual partners in the next three months'.

\section{Barriers}

Participants answered questions addressing barriers to AIDS-preventive behavior. First, they reported whether they were able to obtain new needles or syringes, and condoms, and if so, where they obtained these. Second, the perceived cost of condoms was indexed on a five-point scale ('expensive' to 'inexpensive') as a possible 
barrier to using condoms. Third, in order to estimate the possibility of transmission between highly and lowly HIV-endemic areas participants were asked to indicate if they had traveled to other HIV epicentres, and whether they had had sexual intercourse and/or drugs injected in those HIV epicentres.

\section{RESULTS}

\section{Descriptive analyses}

The educational level of the participants was generally low; most had only gone to school up to the age of 17 . Most participants were heterosexually inclined (85\%). One quarter of the participants reported a history of STDs (23.3\%) and about half the sample reported a history of hepatitis $(40.8 \%)$. The majority of the participants $(70.9 \%)$ had injected drugs at least once, and started using drugs at an average age of 22. Most had used more than one drug in the 6 months preceding the study. Heroin was the most commonly used drug $(62.1 \%)$. However, in most participants reported using more than one drug. Poly-drug use ${ }^{1}$ in the last 6 months was also reported often among the sample of drug users $(77.2 \%)^{2}$, of which all participants reported also using heroin. Other drugs that were often reported were cocaine $(42.3 \%)$, speedball (a combination of cocaine and heroin, 35.5\%), medicine $(35.1 \%)$, cannabis $(55.2 \%)$ and alcohol $(52.1 \%)$. Most participants were in methadone maintenance treatment (65.0\%).

Half the studied population had injected during the 6 months preceding the study $(48.5 \%)$. The average age of these current drug injectors was 34.5 years. Of the current drug injectors, $20.0 \%$ had borrowed a used needle or syringe in the 6 months preceding the study, and $30.0 \%$ of the participants had used old cotton, filters, spoons, or rinsing water in the last 3 months.

Table 1 shows that 73 drug users (70.9\%) had been sexually active during the 6 months preceding the study. Fifty-two of the sexually active participants had had sexual intercourse with one or more steady sex partners, the majority of them without using condoms $(69.2 \%)$. About half of the drug users with a steady partner reported that their partner never injected drugs, and a quarter reported that their partner never used drugs. A total of 32 participants $(31.1 \%)$ had had one or more casual sex partners. Half of these participants reported that their casual sex partners had either never used condoms $(37.5 \%)$ or had used condoms inconsistently (12.5\%). Participants reported that most casual partners (53.1\%) did not inject any drugs, and that $18.8 \%$ did not use any drugs. Seven participants had had sex in exchange for drugs or money, of whom only three participants reported having always used condoms. 
Table 1 Descriptives of sexual behavior and traveling behavior of the sample of drug users $(\mathbf{N}=103)$

\begin{tabular}{lll}
\hline & $N$ & $\%$ \\
& & \\
& & \\
Sexual risk behaviour & 73 & 70.9 \\
$\quad$ Sexually active in the past 6 months & 52 & 50.5 \\
Sexual intercourse with one or more steady partners & $27(52)$ & 51.9 \\
$\quad$ Non-drug-injecting steady partner & $14(52)$ & 26.9 \\
Non-drug-using steady partner & $36(52)$ & 69.2 \\
Unprotected sex with steady partners & 32 & 31.1 \\
Sexual intercourse with one or more casual partners & $17(32)$ & 53.1 \\
$\quad$ Non-drug-injecting casual partner & $6(32)$ & 18.8 \\
Non-drug-using casual partner & $12(32)$ & 37.5 \\
Unprotected sex with casual partners & 7 & 6.8 \\
Sexual intercourse with clients & & \\
$\quad$ & 68 & 66.0 \\
Traveling patterns & 29 & 28.2 \\
Outside the home area in the past 6 months & 21 & 20.4 \\
Sexual intercourse outside the home area & & \\
Injected outside the home area & & \\
\hline
\end{tabular}

Eleven participants had had sexual intercourse with both steady and casual sex partners. Of the seven participants that had reported sex in exchange for money, drugs or other things, three participants had also had sexual intercourse with casual partners, and four participants had had sexual intercourse with steady partners.

\section{Barriers}

Forty-nine participants $(47.6 \%)$ reported that needles or syringes were available when needed. Most participants $(87.5 \%)$ obtained the needles from the Centre for Alcohol and Drug Abuse. Sixty-seven (65.0\%) participants reported where they obtained condoms if they needed them. Participants usually obtained condoms from the consultation Centre for Alcohol and Drug Abuse (34.4\%), followed by shops and drugstores $(25.4 \%)$, vending machines $(16.4 \%)$, relatives $(4.5 \%)$ and the community health centre $(4.5 \%)$. Hence, both syringes and condoms seem to be readily available from various outlets.

\section{Perceived vulnerability and attitude}

The drug users estimated their chances of being infected as a result of unprotected sex with casual partners as being higher than their chances as a result of unprotected sex with steady partners (see table 2). Furthermore, drug users estimated their own 
Table 2 Paired t-test samples concerning differences in predictors of condom use for steady and casual partners $(N=103)$

\begin{tabular}{lcc}
\hline & Steady partners & Casual partners \\
\hline Past condom thoughts $(0-100)$ & 44.2 & $73.8^{* *}$ \\
Vulnerability (0-100) & 37 & $63^{* *}$ \\
Attitude $(-10 /+10)$ & -2.3 & $-.43^{* *}$ \\
Personal Norm (-2/+2) & -.38 & $1.3^{* *}$ \\
Self-efficacy (-10/+10) & 3.2 & $2.0^{*}$ \\
Intention $(-2 /+2)$ & -.39 & $.61^{* *}$ \\
\hline
\end{tabular}

Note. ${ }^{*} \mathrm{p}<.01,{ }^{* *} \mathrm{p}<.001$

chances of contracting HIV when having unsafe sex with a steady partner $(M=37)$ as being lower in comparison with other drug users $(M=49, t(96)=3.4, p<.005)$. Only a marginal difference was found between their own probability estimates for contracting HIV when having unsafe sex with a casual partner $(M=63)$, and probability estimates of others $(M=69, t(96)=1.9, p<.07)$.

In general, drug users considered condoms to be a good protection against HIV, STDs and pregnancy $(M=3.8)$, and condoms to be relatively inexpensive $(M=3.4)$. However, the attitude towards the use of condoms was negative, especially attitude towards condom use with steady partners (see table 2).

\section{Normative beliefs and self-efficacy}

Both the subjective norm $(M=-.00$, range $-2 /+2)$ and the descriptive norm toward the use of condoms were weakly negative $(M=-.30$, range $-2 /+2)$. Furthermore, drug users reported a more negative personal norm towards sex with a condom with a steady partner than with casual partners (see table 2). Finally, drug users felt reasonably confident about their ability to use condoms, with drug users reporting lower self-efficacy towards the use of condoms with casual partners than towards the use of condoms with steady partners (see table 2).

\section{Condom use intention}

Participants' intentions to use condoms with steady partners were statistically significant lower than their intentions to use condoms with casual partners (see table 2). Both these intentions, however, were rather low. Of the 61 participants that ever had sexual intercourse with a casual partner, $73.8 \%$ had thought about using condoms with casual partners. Of the 86 participants that had had a steady partner at some point, only $44.2 \%$ had thought about using condoms with a steady partner. 


\section{Correlation coefficients between intended condom use and the variables measured}

Table 3 provides correlation matrices of the variables measured. Attitude toward condom use with steady sex partners, self-efficacy, the subjective norm and the descriptive norm showed the highest correlation coefficients with intended condom use with steady sex partners, with values ranging between .29 and $.35(p<.001)$. Self-efficacy was the only variable that was significantly related to intended condom use with casual sex partners $(r=.43, p<.001)$. Furthermore table 3 shows that attitudes toward condom use were unrelated to condom response-efficacy ratings. This is in contrast to suggestions that these would be similar constructs (see Abraham et al., 1998). Moreover, table 3 shows that there is a low correlation between the subjective norm and the descriptive norm. Similar findings have been reported elsewhere (De Vries et al., 1995; Schaalma et al., 1993). Finally, table 3 shows that the constructs of the Theory of Planned Behavior were positively related (Ajzen, 1991).

\section{Regression analysis of the predictors with condom use intention}

A regression on intention to use condoms with steady sex partners was conducted for the antecedents of condom use discussed previously. This regression yielded a multiple correlation of .43 ( $\left.\mathrm{R}^{2}=.18, p<.001\right)$ with self-efficacy $(B=.31, p<.005)$, and subjective norm $(B=.23, p<.05)$ as statistically significant predictors of the intention to use condoms with steady sex partners. The other variables did not contribute to explaining additional variance.

A similar analysis was conducted for intended condom use with casual sex partners. This regression revealed that self-efficacy $(B=.43, p<.001)$ was the only variable explaining a significant proportion of variance in the intention to use condoms with casual sex partners $\left(R=.43, R^{2}=.19, p<.001\right)$. All other variables did not contribute to explaining additional proportions of variance.

\section{Self-efficacy expectations concerning condom use}

To determine which of the self-efficacy beliefs distinguished between individuals that intended to use condoms and those who did not, we divided the participants in three groups on the basis of intention scores. The first group consisted of participants who were unlikely or did not have any intention to use condoms with steady partners ('non-intenders'; $N=52$ ). The second group was composed of participants who scored neutrally on the intention scale $(N=19)$. The third group consisted of participants who were sure or very likely to use condoms with steady partners ('intenders'; $N=28$ ). Table 4 shows the means for each self-efficacy belief broken down by intention with univariate test results. It shows that those with no intention expected to have more difficulties with using condoms when they are sexually aroused, or 
Table 3 Correlation matrix of intended condom use and related variables $(N=103)$

\begin{tabular}{|c|c|c|c|c|c|c|c|c|}
\hline Steady partners & (1) & (2) & (3) & (4) & (5) & (6) & (7) & (8) \\
\hline Intention (1) & 1.00 & & & & & & & \\
\hline Attitude (2) & $.29 * *$ & 1.00 & & & & & & \\
\hline Self-efficacy (3) & $.35^{* *}$ & $.33^{* *}$ & 1.00 & & & & & \\
\hline Response efficacy (4) & .03 & -.09 & $.23 *$ & 1.00 & & & & \\
\hline Descriptive norm (5) & $.30^{* *}$ & $.22^{*}$ & $.24^{* *}$ & $.19 *$ & 1.00 & & & \\
\hline Subjective norm (6) & $.31 * *$ & $.31^{* *}$ & $.26^{* *}$ & .13 & .12 & 1.00 & & \\
\hline Personal norm (7) & -.04 & -.13 & -.10 & .08 & .14 & -.01 & 1.00 & \\
\hline Vulnerability (8) & .01 & .04 & .02 & -.01 & .13 & .16 & .06 & 1.00 \\
\hline Casual partners & (1) & (2) & (3) & (4) & (5) & (6) & (7) & (8) \\
\hline Intention (1) & 1.00 & & & & & & & \\
\hline Attitude (2) & .07 & 1.00 & & & & & & \\
\hline Self-efficacy (3) & $.43^{* *}$ & $.39 * *$ & 1.00 & & & & & \\
\hline Personal norm (4) & .03 & .05 & .06 & 1.00 & & & & \\
\hline Descriptive norm (5) & .05 & .15 & $.20^{*}$ & -.15 & 1.00 & & & \\
\hline Subjective norm (6) & .03 & $.28^{* *}$ & .17 & $.25^{* *}$ & .12 & 1.00 & & \\
\hline Response efficacy (7) & .10 & -.10 & .15 & -.11 & $.19^{*}$ & .13 & 1.00 & \\
\hline Vulnerability (8) & .01 & .03 & -.04 & -.02 & -.03 & .11 & -.02 & 1.00 \\
\hline
\end{tabular}

Note. ${ }^{*} \mathrm{p}<.05,{ }^{* *} \mathrm{p}<.001$

when they suffer from drug withdrawal symptoms. With regard to condom availability, non-intenders were more likely to expect problems with having condoms available than intenders. A gender difference was found with regard to the self-efficacy assessment of being able to use condoms in a state of sexual arousal, with women $(M=-.41)$ being more likely to expect problems to use condoms than men $(M=$ $.81, t[98]=3.4, p<.005)$. Female drug users also expected to have more serious problems with regard to the use of condoms when having withdrawal symptoms $(M=-1.2)$ compared to male drug users $(M=-.15, t[95]=2.5, p<.05)$. To assess the impact of self-efficacy on intention to use condoms with casual partners, we once again divided the participants in three groups based on their intention score: 1) a non-intender group ( $N=26), 2)$ an undecided group ( $N=15)$, and 3$)$ a group of intenders $(N=57)$. Analysis of variance showed that those with low intentions felt less capable of using condoms with casual partners and expected to have more difficulties to discuss condom use prior to having sexual intercourse than high intenders (see table 4). Non-intenders also expected more difficulties when being aroused or having withdrawal problems than intenders. Finally, non-intenders expected to have 
Table 4 Mean scores of self-efficacy assessments regarding consistent condom use with steady and casual sex partners, classified per intention group

\begin{tabular}{|c|c|c|c|}
\hline $\begin{array}{l}\text { Steady partners } \\
N=\end{array}$ & $\begin{array}{l}\text { Non-intenders } \\
\quad(52)\end{array}$ & $\begin{array}{l}\text { Undecided } \\
\text { (19) }\end{array}$ & $\begin{array}{c}\text { Intenders } \\
(28)\end{array}$ \\
\hline Self-efficacy items (all ranging from $-2 /+2$ ) & M & M & M \\
\hline Capable of using condoms & .69 & 1.1 & 1.2 \\
\hline $\begin{array}{l}\text { Delay sexual intercourse until the partner is } \\
\text { convinced of condom use }\end{array}$ & .37 & .50 & .50 \\
\hline Able to use condoms when being sexually aroused & $.31^{\mathrm{a}}$ & $.58^{\mathrm{ab}}$ & $1.1^{b}$ \\
\hline Able to have condoms available & $.16^{\mathrm{a}}$ & $.26^{\mathrm{a}}$ & $1.3^{\mathrm{b}}$ \\
\hline $\begin{array}{l}\text { Able to use condoms when suffering from with- } \\
\text { drawal symptoms }\end{array}$ & $-.77^{\mathrm{a}}$ & $.13^{b}$ & $.19^{b}$ \\
\hline $\begin{array}{l}\text { Casual sex partners } \\
N=\end{array}$ & $\begin{array}{l}\text { Non-intenders } \\
\text { (26) }\end{array}$ & $\begin{array}{l}\text { Undecided } \\
\qquad(15)\end{array}$ & $\begin{array}{c}\text { Intenders } \\
(57)\end{array}$ \\
\hline Self-efficacy items (all ranging from $-2 /+2$ ) & M & $M$ & M \\
\hline Capable of using condoms & $.36^{\mathrm{a}}$ & $.13^{\mathrm{a}}$ & $1.5^{\mathrm{b}}$ \\
\hline $\begin{array}{l}\text { Delay sexual intercourse until the partner is } \\
\text { convinced of condom use }\end{array}$ & $.56^{\mathrm{a}}$ & $.56^{\mathrm{a}}$ & $1.3^{b}$ \\
\hline Able to use condoms when being sexually aroused & $.46^{\mathrm{a}}$ & $.33^{\mathrm{a}}$ & $1.1^{\mathrm{b}}$ \\
\hline Able to have condoms available & $.00^{\mathrm{a}}$ & $.00^{\mathrm{a}}$ & $.94^{\mathrm{b}}$ \\
\hline $\begin{array}{l}\text { Able to use condoms when suffering from with- } \\
\text { drawal symptoms }\end{array}$ & $-.63^{a}$ & $.13^{a b}$ & $.14^{b}$ \\
\hline
\end{tabular}

Note. Means in rows with unequal superscripts differ $(p<.05)$

more difficulties with having condoms available than drug users who intended to use condoms with casual partners. Women $(M=1.8)$ felt more capable of using condoms than men $(M=.84, t[50]=4.6, p<.001)$. Women $(M=1.5)$ also felt more capable of delaying sexual intercourse until the casual partner is convinced of the need to use condoms than men $(M=.77, t[31]=2.9, p<.01)$. 


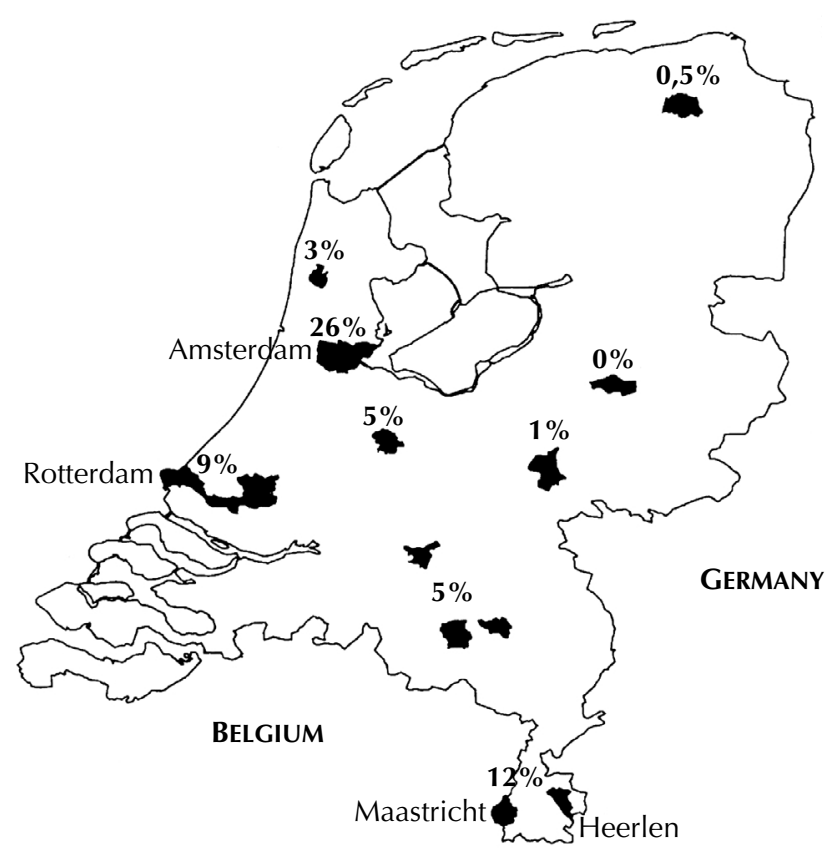

Figure 2 Prevalence of HIV among IDUs in the Netherlands (Berns et al., 2000).

\section{Discussion}

The data presented show that drug users in Maastricht run the risk of contracting HIV and STDs and transmitting HIV/STD to other parts of society. The low rates of condom use with casual and steady partners - of whom a considerable number does not inject or even use drugs - make actual transmission quite likely. Finally, due to the finding that quite a few drug users in the study sample injected drugs (20.4\%) or had sexual intercourse (28.2\%) in other AIDS epicentres in the Netherlands, it is very likely that HIV and STD are transmitted from high-prevalence areas to low-HIV prevalence areas (see figure 2).

The participating drug users acknowledged the risk of contracting the HIV infection and were convinced that the use of condoms is an effective protection against HIV, STDs and unwanted pregnancy.

Perceived self-efficacy seemed to be an important determinant in explaining consistent condom use intention, both in steady sexual relationships and in sexual 
encounters with casual partners. Drug users with a higher perceived self-efficacy were more likely to intend to use condoms with both steady and casual partners. Low perceived efficacy seems to be related to having self-management problems, with drug users not being able to anticipate on risk situations in which sexual encounters may happen, or to anticipate on difficult situations that should be avoided. Especially interesting seems the fact that drug users perceive themselves less capable to use condoms when being sexually aroused. This may partly be explained by the effect of being intoxicated. Intoxicated people will have limited attentional capacity, and this causes them to focus only on the most salient cues in the environment. In this case an internal cue such as sexual arousal may be an powerful internal cue that interacts with intoxication, therefore leading to less preventive behavior (cf. MacDonald, MacDonald, Zanna, \& Fong, 2000).

The gender differences in self-efficacy expectations regarding the use of condoms with casual and steady sex partners seem to indicate that mainly women determine whether or not to aim for safe sex. We found lower self-efficacy expectations for female drug users in comparison with male drug users regarding the use of condoms within steady sexual relationships. This seems to indicate a difficulty to resist pressure to having unprotected sex or a difficulty to insist to a lesser extent upon condom use when experiencing psychological or physical barriers (cf. Cabral et al., 1998).

The results further suggest that norms are an important predictor of condom use within steady relationships. Drug users who perceived their steady partner to feel positive about the use of condoms were more likely to intend using condoms with steady partners. This finding is not entirely surprising as condom use is usually based upon mutual commitment with a partner. Although descriptive norms did not predict condom use in the regression model, we found that the perceived behavior of what others do was clearly related to intention to use condoms with steady sex partners.

In contrast to other studies (Bowen, 1996; Bowen \& Trotter, 1995; Corby et al., 1996; McKegany \& Barnard, 1992; Montoya, 1997; Paulussen et al., 1990), attitudes did not predict condom use intention. However, the results presented show that attitudes towards condom use are negative, particularly within steady relationships. Moreover, drug users hold the personal normative belief that sex without a condom is okay when having sex with steady partners. Furthermore, we found a clear relation between attitude toward using condoms with steady sex partners and intention to use condoms, with respondents with lower intentions towards condom use with steady sex partners finding condoms less necessary than respondents with a higher intention $(M=-.71$ vs. $M=.11, t[93]=2.5, p<.01)$, and for casual sex partners, people with a low intention to use condoms found condoms more unpleasant $(M=$ -.45 vs. $M=.22, t[91]=2.2, p<.05)$ and unnecessary $(M=.86$ vs. $M=1.8, t[52]$ $=4.0, p<.001)$ than people with a high intention. These findings are worrying and should be given serious attention.

The results further showed that most drug users did not use condoms when having sexual intercourse with a steady partner, and that most had never even thought about using condoms with steady partners. A majority of drug users had thought about using condoms with casual sex partners, and most of the participating 
drug users who had had sex with casual partners had actually used condoms. In terms of a stage-of-change approach (Prochaska et al., 1997), it may be argued that drug users are in a different stage of using condoms with casual partners than with their main partners. In accordance with the expectations of the Transtheoretical Model, which assumes that self-efficacy rises along the stages as people become more motivated (DiClemente et al., 1991; Maibach \& Cotton, 1995; Montoya, 1997), we found self-efficacy to be most important for condom use with casual partners. In line with the stages approach we also found that norms and attitudes were most important in the context of steady sexual relationships, where people are not or less motivated to use condoms.

The data presented have important implications for the planning of interventions to promote the use of condoms among drug users. First, it seems important to make a distinction in motivational stages for condom use with steady partners and condom use with casual partners, as also psychosocial determinants may differ in those contexts. The most important step in the promotion of condom use with steady partners seems to be a change in risk perception, attitude and social influence. For the promotion of condom use with casual sex partners it seems to be most important to enhance self-efficacy regarding the communication about and use of condoms.

An initial step in promoting the use of condoms within steady sexual relationships could be risk identification and acknowledgement. However, it has been shown that often this is not enough to convince people to use condoms (Flowers et al., 1997) and that other factors may be more important. Maibach and Cotton (1995) state that besides personalising risk, the positive attributes of alternative behavior should be emphasized, and a re-evaluation of the beliefs that include the new information should be encouraged. The focus should not only be on personal risk identification, but also on the vulnerability of the sex partner and on a certain responsibility to protect that partner.

Furthermore it seems important to make condom use more acceptable in society by changing the current unsafe sexual norm. Community level interventions designed to change community norms might be effective in dealing with unsafe sexual behaviors. For example, Kegeles et al. (1996) proved the effectiveness of a community level intervention targeting gay men, based on a process of informal communication and modeling by peers within interpersonal networks (Kegeles et al., 1996; Kelly et al., 1992). Jamner et al. (1997) also showed that an approach of peer outreach to deliver persuasive mass-media material, by means of role model stories together with condoms, can be effective in changing norms and behaviors.

Finally, self-efficacy to use condoms should be enhanced. People should feel able to talk about and practice the use of condoms. Effective methods to enhance self-efficacy have been derived from Social Cognitive Theory (Bandura, 1997), such as modeling, vicarious learning, by means of role model stories (e.g., Jamner et al., 1997; Maibach \& Cotton, 1995). Other methods that enhance self-efficacy are communication or self-management skills training.

Caution is warranted in interpreting the findings. The low variance of the antecedents of condom use behavior for both casual and steady partners shows that we 
still lack understanding of other cognitive, affective and behavioral factors predicting condom use among drug users. More psychosocial determinant studies have to be conducted among drug users, to decrease gaps in our understanding of the safe and unsafe sexual behavior of drug users with both steady and casual sex partners. Also, insights into the effect of psychopathology in relation to HIV risks and motivational principles might further improve our understanding of how condom use could be promoted. For example, Hartgers et al. (1992) have shown psychopathology to be related to current HIV risk-taking behavior.

Furthermore, one could criticize the reliability of self-reports of drug users. However, several studies have shown that drug users' self-reports of drug use and sexual behavior are reliable (Needle et al., 1995; Dowling et al., 1994; McElrath et al., 1994). Moreover, studies have shown that self-administered questionnaires show a high level of agreement in comparison with face-to-face interviews, but have shown to lead to less underreporting of drug use (McElrath, 1994). Also DesJarlais et al. (1999) report that socially sensitive behaviors are less likely to be underreported when using self-administered questioning - in this case via computer-assisted selfinterviewing - rather than face-to-face interviews.

Also, one could doubt the appropriateness of analyzing the whole sample with not all participants having been sexually active in the last 6 months. Analyses however revealed that there were no differences on any of the determinants measured between the sexually active participants and the ones who had not been sexually active in the last 6 months. Moreover, all participants reported having had sexual experiences in the past. On the basis of these arguments we think it is appropriate have included the entire sample.

Finally, one could argue the use of a single item to measure intention. However, the item was stated as explicit as possible, with a precise operationalization of the target, namely condom use with steady sex partners, or condom use with casual sex partners. The confidence within this measurement is further enhanced by the reasonable correlations between the intention measurement and the actual behavior (respectively $r=.58, p<.001$ for steady sex partners, and $r=.42, p<.05$ for casual sex partners). Moreover, similar kinds of operationalizations have been reported elsewhere (e.g., Kowalewski et al., 1994; Paulussen et al., 1990).

\section{Endnote}

1 According to the Netherlands Institute of Mental Health and Addiction (Trimbos, 2001) poly-drug use can be defined as using three different drugs at the same time.

2 Based on their research among drug users in and around Heerlen, Coumans, Neve, \& Van de Mheen (2000) also concluded that there are almost no typical heroin users anymore. Instead most drug users in their sample also reported poly-drug use. 


\section{SECTION 3.2}

THE ADDITIONAL VALUE OF ANTICIPATED REGRET AND PSYCHOPATHOLOGY IN EXPLAINING INTENDED CONDOM USE AMONG DRUG USERS

\section{Published as}

Van Empelen, P., Kok, G., Jansen, M. W. J., \& Hoebe, C. J. P. A. (2001). The additional value of anticipated regret and psychopathology in explaining intended condom use among drug users. AIDS Care, 13, 309-318. 


\section{INTRODUCTION}

Evidence suggests that once HIV infection is well-established in the drug user population, the latter act as a bridge toward the wider heterosexual population (Des Jarlais, 1992; Fennema, 1997; Op de Coul et al., 1998; Rhodes et al., 1996). Drug users continue to practice unsafe sex with primary and casual sex partners. It therefore seems imperative to aim AIDS-preventive interventions at unsafe sexual behavior, or more specifically at the promotion of condom use, among drug users. Present evidence concerning key determinants of condom use is lacking or rather mixed.

In a previous study (Van Empelen, Schaalma et al., 2001) we examined the predictive value of several psychosocial determinants in predicting condom use among drug users based upon a core model of health behavior proposed by Abraham et al. (1998, see figure 1). The model addressed a number of key psychosocial antecedents of motivation and behavior that were identified in a review of a range of social cognitive models (see figure 1): attitudes, social influence, self-representation and selfefficacy. Each of these concepts can be operationalized in several ways. In the previous study, attitudes were operationalized via two constructs: the beliefs about condom use (Fishbein \& Ajzen, 1975) and the response-efficacy of condom use (e.g., the perceived effectiveness of condom use in avoiding HIV infection) (Rogers, 1983). Social influence was operationalized by means of the subjective norm of condom use (i.e., the acceptance of condom use by the partner) (Fishbein \& Ajzen, 1975) and the descriptive norm of condoms (i.e., the perception of what others do, in this case whether people use condoms) (Cialdini et al., 1990; De Vries et al., 1995). Self-representation was operationalized by means of personal normative beliefs (i.e., an individual's own (moral) values related to a certain behavior) (Triandis, 1977). Finally, we also measured self-efficacy expectations about condom use (Bandura, 1986).

The previous study enabled us to draw a number of conclusions. First, the study showed the importance of distinguishing between intended condom use with casual and that with steady sex partners. Second, we found that the theoretical constructs allowed to some extent for predicting intended condom use with steady sex partners and casual sex partners, but the predictive value was rather low $\left(R^{2}\right.$ steady $=.18$ and $R^{2}$ casual $=.19$ ). We found that social norms and self-efficacy predict intended condom use with steady sex partners and that only self-efficacy predicted intended condom use with casual sex partners.

In the present study we extended the core model used in the previous study. We examined the additional value of other determinants - anticipated regret (a.o. Richard et al., 1995) and psychopathology (Hartgers et al., 1992) - in explaining intended condom use with primary and casual sex partners among drug users. The assumption underlying the predictive value of anticipated regret is that people anticipating the negative affective consequences of unsafe sexual behavior prior to having actual sexual intercourse, might be influenced by these negative feelings and therefore decide to use condoms. So far, this concept of anticipated regret has not been 
applied in the context of drug users, but has shown to be of additional value in explaining condom use behavior among adolescents (Richard et al., 1995). Anticipated regret is assumed to be a more affective component of attitudes.

Furthermore, it is assumed that psychopathology is related to HIV risk. Hartgers et al. (1992) have shown that psychopathology, measured by the General Health Questionnaire (GHQ-30), is related to HIV risk injecting behavior - that is, more recent injecting, and more frequent injecting of drugs - among HIV-negative IV drug users. Increased HIV risk taking has also been found among adults with severe and persistent psychiatric conditions (Carey, Carey et al., 1997; Kalichman et al., 1996). Therefore, we explored the additional value of psychopathology in relation to intended condom use among drug users, investigating the following multi-dimensions of psychopathology: phobic anxiety, anxiety, depression, somatization, obsessive-compulsive, paranoid ideation and interpersonal sensitivity, hostility, sleeping disorder.

Finally, we slightly changed some of the constructs we originally used: personal normative beliefs were operationalized in accordance with Godin et al. (1997), being more of a moral value of someone to use condoms. In addition to the indirect measurement of attitudes by means of beliefs, we also included a direct measure of attitude toward condom use. Finally, social norm measurement was extended to include not only the perceived partner norm, but also the norm of significant others in the direct environment. Because response-efficacy failed to contribute to the first study - drug users generally agree that condoms are an effective method to prevent HIV, STDs or unwanted pregnancy - it was no longer included.

\section{METHOD}

\section{Sample and setting}

A total of hundred and fifty drug users of two Dutch cities - Heerlen and Maastricht - participated in the present study. These drug users were participating in an ongoing Hepatitis B vaccination campaign, and were asked to complete the questionnaire. The participants were recruited via outreach work and the methadone treatment or needle exchange centers. They received 10 guilders (approximately US\$4) for their participation. The majority of the drug users were male $(78.1 \%)$ and the average age was 36. There was no difference between the Heerlen and Maastricht participants in terms of gender or age. For most drug users heroin was the main drug $(84.2 \%)$, followed by cocaine $(8.6 \%)$ or a combination of these two $(7.2 \%)$. Most drug users however report poly-drug use (see also Coumans, Neve, \& Van de Mheen, 2000; Van Empelen, Schaalma et al., 2001). 


\section{Questionnaire}

A questionnaire was constructed consisting of several determinants explaining condom use behavior: attitude, beliefs, subjective norms, descriptive norm, personal norm, self-efficacy and intention. Separate scales were used for condom use with steady sex partners and casual sex partners for beliefs, personal norm, self-efficacy and intention. Second, the Symptom Check List '90 (SCL-90) was used to measure psychopathology (Derogatis, 1977). We used a validated Dutch version of the SCL90 (Arrindell \& Ettema, 1986).

\section{Attitude}

Attitude towards condom use was measured using four direct affective measures of condom use: very unpleasant/very pleasant, very unimportant/very important, very unwise/very wise, and very bad/very good. Bipolar scales were used ranging from -2 to +2 . The Cronbach's $\alpha$ was .66.

\section{Attitudinal beliefs}

Beliefs were measured separately for condom use with steady sex partners and casual sex partners (e.g., 'using condoms when having sexual intercourse is a sign of distrust', 'using condoms when having sexual intercourse diminishes the feeling', cf. Van Empelen, Schaalma et al., 2001). Each scale consisted of six items, using scales ranging from 1 (totally disagree) to 5 (totally agree). Both the beliefs concerning condom use with steady and casual sex partners had a reliability of Cronbach's $\alpha=.65$.

\section{Personal norm}

Personal norm was measured separately for steady and casual sex partners, each with a single item, such as: 'As a matter of principle, I use condoms each time I have sex with my steady partner/casual partners' and ranged from 1 (certainly not) to 5 (certainly) (cf. Godin et al., 1997).

\section{Anticipated regret}

Participants were asked respectively how worried and how regretful they would be in the following situations: after having had unprotected sex with steady partners $(r=$ .90); after having had unprotected sex with a new partner $(r=.84)$. These four items were scored on a scale ranging from 1 (certainly not) to 5 (certainly).

\section{Subjective norms}

Subjective norm consisted of four items (ranging from 1 (certainly not) to 5 (certainly)), measuring the normative belief of steady partners (cf. Corby et al., 1996), new sex partners, best friends and family toward using condoms. Cronbach's $\alpha$ was .75 .

\section{Descriptive norm}

One item was used to measure the descriptive norm ('Do you think your best friends 
always use condoms?', cf. Kowaleski et al., 1994), with scales ranging from 1 (certainly not) to 5 (certainly)).

\section{Perceived self-efficacy}

Perceived self-efficacy concerning the use of condoms was measured separately for casual and steady sex partners, each with 6 items (e.g., 'Can you discuss condom use with your steady/casual partner?', 'Can you use condoms with your steady/ casual partners when you are sexually aroused?', 'Are you able to postpone sex until you have persuaded your casual/steady partner to use condoms?'). All items were scored on a scale ranging from 1 (certainly not) to 5 (certainly). Self-efficacy concerning steady partners had a reliability of Cronbach's $\alpha=.85$. Self-efficacy toward casual sex partners had a reliability of Cronbach's $\alpha=.87$.

\section{Intention}

All intention items were scored on a scale ranging from 1 (certainly not) to 5 (certainly). Intention toward condom use with steady sex partners was measured using three items ('Do you intend to use condoms when having sexual intercourse with steady partners in the next six months?', 'Suppose you do not have condoms. Do you intend not to have sexual intercourse with your steady partner in the next six months?', 'Suppose your steady partner wants to have sex without a condom. Do you intend to refuse having sex with this partner in the next six months?') and had a reliability of Cronbach's $\alpha=.67$. Intention toward casual sex partners was measured using similar items, and had a reliability of Cronbach's $\alpha=.54$.

\section{Psychopathology}

The SCL-90 is a 90-item (items scored on a scale ranging from 1 (not at all) to 5 (very much)) checklist consisting of nine dimensions: phobic anxiety, anxiety, depression, somatization, obsessive-compulsive, paranoid ideation and interpersonal sensitivity, hostility, sleeping disorder. The combined score on these dimensions and a number of other items of the SCL-90 indicate a psychoneuroticism score. A psychoneuroticism score of 131 or higher could be considered a sign of psychopathology if it is based on the norm scores of a sample of Dutch males, in which a score above 131 was viewed as a high score on psychopathology (Arrindell \& Ettema, 1986). In the study we examined the single contribution of each of the eight dimensions.

\section{Behavior}

In terms of behavior we measured the number of casual and steady sex partners in the last six months, the frequency of sexual intercourse, and the amount of condom use on those occasions. Furthermore, the injecting frequency was measured. 


\section{RESULTS}

\section{Descriptive statistics}

Table 1 presents drug use and sexual behaviors of the sample. It shows that the majority of the drug users reported having injected drugs, 67 of whom reported being current drug users, with an average frequency of 254 times $(S D=270)$ in the last six months, or 1.4 times a day. Most drug users report having been tested for HIV. However, there is considerable variability in terms of time of HIV testing, as a result of which the reported HIV status might not be a reliable measure of the current HIV status. Furthermore, most drug users (55.6\%) who reported having had sex with steady sex partners report that they did not use condoms. Drug users who reported having had two steady partners in the last six months had had significantly less unprotected sex than drug users that had had only one steady partner $(60.3 \%$ vs. $\left.22.2 \% ; \chi^{2}(5,72)=16.97, p<.001\right)$. A large proportion of drug users that had had sex with casual sex partners during last six months also report that they did not use condoms (30.8\%) or used condom inconsistently $(10.3 \%)$.

Psychopathology was found among $75.7 \%$ of the participants in the study $\left(M_{\text {psycho }}=195, S D=77\right)$. A high prevalence of psychopathology among drug users has also been found in other studies (Campbell \& Stark, 1990; Hartgers et al., 1992). Drug users in Maastricht were found to have a higher psychopathology score than drug users in Heerlen ( $M=207$ vs. $M=180, t[127]=2.04, p<.05)$. The participants' mean scores on all of the psychopathology dimensions (phobic anxiety, anxiety, depression, somatization, obsessive-compulsive, paranoid ideation and interpersonal sensitivity, hostility, sleeping disorder) were higher than the mean scores of the comparison sample.

In accordance with Hartgers et al. (1992) we examined for differences in psychopathology in relation to HIV risk injection behavior. We found injection behavior to be related to psychopathology, in other words, having ever injected was related to current psychopathology $\left(\chi^{2}(1,132)=8.52, p<.005\right)$. However, in contrast to Hartgers et al. (1992) we did not find psychopathology to be related to current drug use, injection frequency or injected drug type. Additionally, we examined the relation between psychopathology, sexual intercourse frequency, frequency of unprotected sex, and the number of steady and casual sex partners. Analyses did not show a difference between psychopathology and sexual risk behaviors.

Table 2 shows the means and standard deviations of independent and dependent variables related to condom use with steady sex partners and casual sex partners. Attitude items varied from -2 to +2 . Missing values were recoded as 0 . A missing value analysis was conducted separately for dependent and independent variables relating to condom use intention with both steady sex partners and casual sex partners. Cases with missing values exceeding $5 \%$ ( 3 or more missing items) in a particular group (steady sex partners or casual sex partners) were left out of further data analysis. For the other cases with less than $5 \%$ missing values, the scale score was 


\section{Table 1 Descriptive analyses}

\begin{tabular}{lcc}
\hline & $N$ & $\%$ \\
Total sample & 150 & 100 \\
Ever injected & 114 & 76.5 \\
Ever been tested for HIV & & \\
$\quad$ Yes & 86 & 57.3 \\
$\quad$ No & 56 & 38.7 \\
Reported serostatus of tested persons & $5(86)$ & 5.8 \\
$\quad$ HIV+ & $75(86)$ & 87.2 \\
HIV- & $6(86)$ & 7.0 \\
$\quad$ Unknown & 64 & \\
Sex partners last 6 months & 9 & 42.7 \\
$\quad$ One steady sex partner & 41 & 27.3 \\
$\quad$ Two steady sex partners &
\end{tabular}

Table 2 Means and standard deviations of determinants of condom use with casual and steady sex partners

\begin{tabular}{|c|c|c|c|c|}
\hline & \multicolumn{2}{|c|}{ Steady sex partners $(N=147)$} & \multicolumn{2}{|c|}{ Casual sex partners $(N=141)$} \\
\hline & $M$ & $S D$ & M & $S D$ \\
\hline Attitude $(-2 /+2)$ & .73 & .83 & .75 & .82 \\
\hline Subjective norm (1-5) & 3.6 & .92 & 3.6 & .93 \\
\hline Self-efficacy* (1-5) & 3.4 & 1.1 & 3.9 & .93 \\
\hline Beliefs* (1-5) & 2.9 & .97 & 3.1 & 1.1 \\
\hline Anticipated regret* (1-5) & 2.6 & 1.6 & 3.8 & 1.3 \\
\hline Personal norm* (1-5) & 2.3 & 1.5 & 4.4 & 1.1 \\
\hline Descriptive norm (1-5) & 2.9 & 1.1 & 2.9 & 1.1 \\
\hline Intention* $(1-5)$ & 2.7 & 1.2 & 3.1 & 1.1 \\
\hline
\end{tabular}

Note. ${ }^{*}$ Determinants are measured separately for condom use with steady and casual sex partners 
replaced with the group mean. As a result, analysis of intention to use condoms with casual sex partners was conducted among 141 cases, and that with steady sex partners was conducted among 147 cases.

A paired sample t-test was conducted to examine differences between the determinants that were measured separately concerning steady sex partners and casual sex partners. These analyses revealed that drug users reported lower perceived selfefficacy $(t[132]=5.77, p<.001)$, less positive beliefs $(t[126]=8.01, p<.005)$, a lower personal norm $(t[142]=13.6, p<.001)$ and having less intention to use condoms with steady partners than with casual partners $(t[133]=3.30, p<.005)$.

\section{Regression analyses on intended condom use with steady and casual sex partners}

Table 3 and 4 depict correlation coefficients between the variables and intended condom use. The highest correlation coefficients for intended condom use with steady sex partners were found for anticipated regret, personal norm, self-efficacy and subjective norm. None of the different dimensions correlated significantly with condom use intention with steady partners $(r<.13, n s)$. Therefore, those variables have been excluded from further analyses. For intended condom use with casual sex partners, the highest correlation coefficients were found for social norm, attitude, personal norm, self-efficacy and anticipated regret. Hostility was the only dimension of the SCL-90 that correlated significantly with intention to use condoms with casual sex partners. None of the other SCL-90 dimensions correlated with intended condom use with casual sex partners $(r<.08, n s)$.

Hostility was only related to intention and beliefs. To obtain a better understanding of the relation, we explored the relation between each of the six belief items and hostility. A median-split was used to distinguish low-hostility and high-hostility drug users. Independent t-tests revealed that high-hostility drug users, more than low-hostility drug users, seem to think of condom use as being less pleasurable $(t[130]=$ $2.0, p<.05)$, an annoying interruption $(t[131]=2.2, p<.05)$, decreasing feelings $(t$ $[131]=2.2, p<.05)$, and being expensive $(t[125]=3.0, p<.005)$. However, participants with a high hostility score did not differ with regard to their beliefs about the necessity of condoms, or the mistrust created by condom use.

A regression analysis was conducted analyzing the impact of the determinants attitude, social norm, self-efficacy and beliefs - of the Theory of Planned Behavior (TPB; Ajzen, 1991) on intended condom use with casual and steady sex partners. The regression on intended condom use with steady partners $(N=147)$ of the TPB variables explained a variance of $R^{2}=.28$, with subjective norm $(B=.27, p<.005)$ and self-efficacy $(B=.30, p<.001)$ being significant predictors. To investigate the additional value of other determinants, we also regressed the other variables. Personal norm and anticipated regret entered the equation and were shown to have an additional predictive value on intended condom use with steady partners $\left(\mathrm{R}^{2}=\right.$ $.41, p<.001)$, with self-efficacy $(B=.18, p<.05)$, personal norm $(B=.21, p<.05)$ 
Table 3 Pearson correlation coefficients between determinants and intended condom use with steady partners $(N=147)$

\begin{tabular}{|c|c|c|c|c|c|c|c|}
\hline & (1) & $(2)$ & (3) & $(4)$ & (5) & (6) & (7) \\
\hline Attitude (1) & 1.000 & & & & & & \\
\hline Subjective norm (2) & $.300 * *$ & 1.000 & & & & & \\
\hline Self-efficacy (3) & $.374 * *$ & $.500 * *$ & 1.000 & & & & \\
\hline Anticipated regret (4) & .120 & $.441^{* *}$ & $.472 * *$ & 1.000 & & & \\
\hline Descriptive norm (5) & $.159^{*}$ & $.389^{* *}$ & $.446^{* *}$ & $.348^{* *}$ & 1.000 & & \\
\hline Personal norm (6) & $.176^{*}$ & $.540^{* *}$ & $.478^{* *}$ & $.727^{* *}$ & $.474^{* *}$ & 1.000 & \\
\hline Beliefs (7) & $.280^{*}$ & $.375^{* *}$ & $.448^{* *}$ & $.376^{* *}$ & .120 & $.300 * *$ & 1.000 \\
\hline Intention (8) & $.275^{* *}$ & $.433^{* *}$ & $.482^{* *}$ & $.534^{* *}$ & $.365^{* *}$ & $.542^{* *}$ & $.369 * * 1.000$ \\
\hline
\end{tabular}

Note. ${ }^{* *} \mathrm{p}<.001,{ }^{*} \mathrm{p}<.05$

Table 4 Correlation coefficients among determinants of condom use with casual sex partners $(N=141)$

\begin{tabular}{|c|c|c|c|c|c|c|c|c|c|}
\hline & $(1)$ & $(2)$ & (3) & (4) & (5) & (6) & (7) & (8) & (9) \\
\hline Attitude (1) & 1.000 & & & & & & & & \\
\hline Sociale norm (2) & $.323 * * 1$ & 1.000 & & & & & & & \\
\hline Self-efficacy (3) & $.310^{* *}$ & $.347^{* *}$ & ${ }^{k} 1.000$ & & & & & & \\
\hline Descriptive norm (4) & $.183^{*}$ & $.404 * *$ & $.303^{* *}$ & 1.000 & & & & & \\
\hline Personal norm (5) & $.230^{*}$ & $.277^{* *}$ & $.492^{* *}$ & $.270^{* *}$ & ${ }^{k} 1.000$ & & & & \\
\hline Hostility (6) & -.084 & .093 & -.068 & .071 & -.042 & 1.000 & & & \\
\hline Anticipated regret (7) & $.324^{* *}$ & $.506^{* *}$ & $.449 * *$ & $.282^{* *}$ & *. $.440^{* *}$ & $* .052$ & 1.000 & & \\
\hline Beliefs (8) & $.309 * *$ & $.189 *$ & $.274^{*}$ & .101 & $.236^{*}$ & $-.258^{*}$ & .195 & 1.000 & \\
\hline Intention (9) & $.320^{* *}$ & $.335^{* *}$ & $.314^{* *}$ & $.160^{*}$ & $.329 * *$ & $*-.200^{* *}$ & $* .310^{* *}$ & * .216* & 1.000 \\
\hline
\end{tabular}


and anticipated regret $(B=.24, p<.05)$ explaining the largest proportion of variance. No other variables contributed to explaining extra variance. A regression analysis was performed to study the single contribution of the self-efficacy expectation items to intended condom use with steady sexual partners. Although every item was significantly correlated with intended condom use, the regression analysis in which intention was regressed on the self-efficacy expectations revealed that only one item emerged as being significant in relation to intended condom use with steady partners - the expected ability to have condoms available at all times, when wanting to have sex with steady partners ( $B=.27, p<.05)$.

A regression on intended condom use with casual sex partners $(N=141)$ for the TPB determinants yielded an $R^{2}$ of .20, with attitude $(B=.20, p<.05)$, subjective norm $(B=.20, p<.05)$ and self-efficacy $(B=.19, p<.05)$ all being significant predictors. In the second step we found hostility and personal norm to attribute additional predictive value $\left(\mathrm{R}^{2}=.24, p<.001\right)$ with hostility $(B=-.19, p<.05)$, personal norm ( $B=.18, p<.05)$, subjective norm $(B=.22, p<05)$, and attitude $(B=.17, p<$ .05) explaining the largest proportion of variance. Other determinants did not explain additional variance.

\section{DisCUSSION}

In line with the previous study (Van Empelen, Schaalma et al., 2001) we found once again that the Theory of Planned Behavior can be used to predict intended condom use to a certain extent. Self-efficacy and social norms seem to be the best predictors of condom use intention with steady partners. For intended condom use with casual sex partners we once again found self-efficacy to be an important predictor. In addition, this study showed that social norms and attitude are related to intended condom use with casual sex partners. The explained variance of determinants, as proposed by the Theory of Planned Behavior, is consistent with the previous study.

Furthermore, the results showed that anticipated regret and personal norms predicted a significant proportion of variance on top of the TPB components in explaining the intention to use condoms with steady sex partners. The results also point to a strong relation between anticipated regret and personal norms. This suggests that the more drug users expect to have negative feelings after having had unsafe sexual contact, the stronger their principle about condom use with steady partners will be.

For intended condom use with casual partners we found that hostility predicted additional variance on top of the TPB components. In other words, the more hostility is felt, the less a drug user intends to use condoms with casual partners. This finding is supported by the study of Kennedy et al. (1993), who showed that HIV-positive women that used condoms experienced lower hostility, and by the study of Perkins 
et al. (1993), who found a relation between hostility and inconsistent condom use among HIV-negative homosexual men. Also other studies have revealed a relation between risk taking and hostility, including bad driving (Hemenway \& Solnick, 1993), and driving after drinking (Houston \& Vavak, 1991). Perkins et al. (1993) assume a possible relationship between anger and self-destructive behavior.

The present study shows that an extension of TPB with other factors should be considered. This is in line with results found by Godin and Kok (1996), who reviewed the applications of the TPB in the area of health behavior. They stress the importance of personal norms in explaining health behavior. Abraham et al. (1998) argue that attitude could be divided into an evaluative (e.g., beliefs) and an affective component (e.g., anticipated regret). The current study supports the idea that such an affective component may be a powerful motivator.

In this study, we have not replicated the findings of Hartgers et al. (1992), who found a relation between HIV injecting behaviors and psychopathology. Although we found a relation between past injection behavior and current psychopathology, we did not find a relation between current injection practices and psychopathology, nor did we find a relation between current sexual behavior and psychopathology. However, the finding that lower hostility might be related to stronger intention to use condoms, especially in casual relationships, provides a basis for the idea that reductions in psychopathology, more specifically feelings of hostility towards others, might lead to reductions in sexual risk behavior.

\section{Practical implications}

Anticipation seems to be a keyword when talking about safe sex within steady relationships. Not only does the anticipation of negative affect seem to be related to intended condom use with steady sex partners, but equally so the expected ability to have condoms available at all times. It therefore seems particularly important that people develop self-management skills in order to anticipate situations and make environmental changes when needed. Moreover it seems relevant that drug users are aware that they may make other judgments when intoxicated, than they would do on rational grounds (see McDonald et al., 1996).

How can we address anticipated affect in actual practice? First, condoms must be available. Furthermore, AIDS-preventive campaigns should increase the awareness that unsafe sexual behavior can lead to negative feelings, whereas safe sexual behavior is likely to result in positive feelings (cf. Richard et al., 1996). A possible way to do this would be by using role modeling, or more specifically, role model stories, describing a scenario, for example, which addresses the negative affect after having had sex without condoms. The use of role model stories, combined with the distribution of condoms, has shown to be effective and feasible, also within the context of drug users (CDC, 1999).

A positive community norm about safe sex seems essential to promote condom use with casual sex partners among drug users. Indeed, Abdul-Quader et al. (1990) 
and Magura et al. (1990) found that social support of other drug users or friends had a positive effect on individual risk behavior. Rietmeijer et al. (1996) and Jamner et al. (1997) showed that discussions and reinforcement of peers concerning safe sex with casual partners, when making condoms available, is a good strategy to increase condom use with casual sex partners, and having condoms available in general.

Finally, we need a better understanding of the relation between hostility and HIV risk. Although the relationship is not entirely clear, risk reduction programs aimed at drug users should take into consideration the possible decreasing HIV risk effect of hostility treatment. 


\section{SECTION 3.3}

\section{A QUALITATIVE FOCUS ON TRANSITIONAL FACTORS OF THE MOTIVATION-ACTION RELATIONSHIP IN CONDOM USE AMONG DRUG USERS}

\section{Submitted for publication as}

Van Empelen, P., Kok, G., Hoebe, C. J. P. A. \& Jansen, M. W. J. (2001). A qualitative focus on transitional factors of the motivation-action relationship in condom use among drug users. 


\section{INTRODUCTION}

In the past, HIV prevention aimed at drug users targeted mainly the promotion of safe injecting behavior. The harm reduction strategies applied in the Netherlands have reduced needle sharing and injecting in general (Van Ameijden \& Van den Hoek, 1998). However, with the exception of AIDS prevention programs aimed at drug using prostitutes, these activities have left sexual risk behavior largely unattended, while programs for other groups, such as homosexuals and youth, have been developed to promote condom use (e.g., Van Empelen, Schaalma, Kok, \& Jansen, 2001). Sexual risk behavior among drug users has been addressed mainly by mass media campaigns, such as general Dutch population television commercials, or small media sources, like brochures (Van Haastrecht, 1995). Although both media sources are known to increase awareness, they produce only minor effects with regard to changing actual behavior (McGuire, 1985).

Consistent with this knowledge, research has shown that (non-commercial) sexual risk behavior of drug users has not or only slightly changed. Hard drug users, both injectors and non-injectors like crack-cocaine smokers, run the risk of acquiring and transmitting HIV. Drug injectors are at risk of acquiring and transmitting HIV not only due to needle-sharing but also due to unsafe sexual practices. Non-IV drug users are at risk mainly due to their reported high number of sex partners, unprotected sex and sexual mixing with IV drug users (e.g., Booth, Kwiatkowski, \& Chitwood, 2000).

A few studies in the Netherlands have tried to gain insight into the relationship between behavior patterns (sex and drugs) and motives for that behavior among drug users. For example, De Graaf, VanWesenbeeck, Van Zessen, Straver and Visser (1994) conducted a qualitative study among male prostitutes, trying to obtain insight into the relationship between private and work circumstances in explaining risk and protective behavior. They found that male prostitutes used condoms less consistently with steady, trusted or attractive clients, and when they were in need of drugs.

VanWesenbeeck, De Graaf, Van Zessen, Straver and Visser (1993) conducted a similar study among female prostitutes, and found that inconsistent condom use depended on work location and drug use, but was also part of a client-friendly attitude.

However, there is little evidence about possible factors of sex risk and unprotected sex among Dutch drug users in the context of non-commercial relationships. Based on a general model of health behavior proposed by Abraham, Sheeran and Johnston (1998), Van Empelen and colleagues made a first attempt to explain risk behavior and condom use among Dutch drug user in the context of steady and casual sexual relationships (Van Empelen, Kok, Jansen, \& Hoebe, 2001; Van Empelen, Schaalma, et al., 2001). The core model of Abraham et al. (1998) suggests that there are four general concepts that explain an individual's intention to perform certain (health) behavior, i.e, self-regulation, attitudes, social influence and self-efficacy, which in turn would be good predictors of actual behavior. In their studies, Van Empelen et al. examined predictors of intention to use condoms with casual 
and steady sex partners. They found that the model was capable of explaining intention to use condoms to some extent (up to $41 \%$ for intended condom use with steady sex partners, and $19 \%$ for intended condom use with casual sex partners) (Van Empelen, Kok et al., 2001; Van Empelen, Schaalma, et al., 2001).

Although intention has shown to be a major predictor of condom use, it is acknowledged that it does not translate into action automatically. For example, Abraham et al. (1998) stress the importance of preparatory behaviors for the achievement of one behavioral goal. De Vries, Dijkstra and Kuhlman (1988), and Fishbein (2000) argue that the translation of intention into action depends on existing skills (e.g., negotiation skills) and potential barriers (e.g., the availability of condoms). However, if the environment facilitates behavior, and a person is able to perform certain behavior, his or her commitment to certain behavior will ultimately determine whether (s)he will carry out that specific behavior. The AIDS Risk Reduction Model (Catania, Kegeles, \& Coates, 1990; Catania, Coates, \& Kegeles, 1994) also posits that apart from acknowledging risk and being committed to use condoms, a third stage (enactment) of taking action - that is to say, condom use - depends on whether one actually communicates about condom use, experiences social support, and, lastly, on the type of sexual relationship.

In sum, although a lot of researchers have acknowledged the problem of translating intention into a behavior, little insight has been provided into possible factors that might enable or disable this transition. Qualitative data are expected to provide information about underlying processes of possible factors that hamper or facilitate the transition of intention into behavior, and seem to represent a necessary first step to understand why people act or do not act. Such information is crucial if one aims at achieving any change in behavior.

This paper reports on semi-structured interviews among drug users, and highlights three areas that are particularly important to understand sexual risk-taking behavior:

1 Current HIV risk behavior and HIV/AIDS-related behavior changes;

2 Factors related to an individual's motivation to reduce (sexual) risk-taking behavior;

3 Enactment factors disabling or enabling motivated people to actually translate their intention into condom use behavior.

\section{METHOD}

\section{Sample and recruitment}

Thirty-four drug users (8 women and 26 men) were recruited via shelters or centers of the Institute of Addiction Care in Maastricht and Heerlen. A drug user was defined 
Table 1 Demographic variables

\begin{tabular}{lcc}
\hline & $N$ & $\%$ \\
& 34 & 100 \\
Total & 29 & 85.3 \\
Dutch nationality & 38.8 years & \\
Age & & \\
Self-reported HIV-status & 22 & 64.7 \\
$\quad$ Unknown & 10 & 29.4 \\
$\quad$ Negative & 2 & 6.0 \\
$\quad$ Positive & 19.5 years & \\
Age first drug use & 22 & 64.7 \\
Ever injected drugs & 17.9 years & \\
Age first injected drugs & 12 & 35.3 \\
Currently injecting & & \\
\hline
\end{tabular}

as an individual who uses drugs other than or besides alcohol, hash or marihuana. Drug users in the area of Maastricht and Heerlen commonly use more than one drug. However, of those drugs heroin $(80 \%)$, or a combination of heroine and cocaine is most often used (Van Empelen, Schaalma et al., 2001).

Of the 34 interviewees, 29 had the Dutch nationality, and the average age was 39 (range 24-49 years) (see table 1). The average age at which the drug users had started their hard drug use was 19 years. Of the drug users, 22 reported having injected drugs, of which 13 drug users reported being current drug injectors. The drugs used most often in the sample were heroin $(68 \%)$, followed by a combination of heroin and cocaine $(21 \%)$. Besides one participant, all respondents reported to be heterosexually oriented. The demographic variables are in accordance with reports based on large samples sizes among the drug using population of Heerlen and Maastricht, except that the current sample seems slightly older (e.g., Beuker et al., 2001; Carsauw et al., 1997; Van Empelen, Kok, et al., 2001; Van Empelen, Schaalma et al., 2001). Two male drug users reported being HIV positive. Some drug users spontaneously reported that they had been infected with hepatitis B or C. But as we did not ask drug users about their hepatitis serostatus, it is unclear how prevalent hepatitis B and C were within the sample. Furthermore three women reported having been or currently being a commercial sex worker. Finally, 12 drug users were in a steady relationship at the time of the interview, which means having a regular sexual relationship with someone for at least three months. 


\section{Procedure}

The interviews took an average of 30 minutes. All interviews were recorded on tape, after which transcriptions of these recordings were made. The drug users were paid 25 guilders (approximately US \$10) for the interview. Social nurses from the participating public health centers, Maastricht and Heerlen, conducted the interviews. The interviews were semi-structured, and consisted of oral questions. Subjects covered were the onset of drug use and current drug use, risk and protective behavior; motivational factors, such as AIDS knowledge, experiences with new and steady sex partners covering attitude towards condom use; and finally, enactment factors, covering barriers of condom use and preparatory behaviors of condom use.

The interviews were analyzed using the qualitative analysis package QSR NUDIST 4.0. A QSR NUDIST project is organized in two interlocking sub-systems, linked by search procedures: The document system contains information about every document whether on-line or off-line and optionally, a memo about it. If the document is on-line, it also contains the text of the document and annotations of it. By exploring and coding documents, they can be linked to categories made in the index system. The index system is made up of nodes, which are containers for thoughts about the project. Nodes store the index categories constructed by the user. With the category is stored information such as the title and definition of the category, a memo of ideas about it and references to the parts of documents coded at the node. By exploring nodes, and the coding at them, they are linked to documents. The search procedures allow searches among either document text or coding at nodes to discover and explore patterns and themes, and construct and test theories.

Following the general model for health behavior we made categories fitting with the motivational concepts specified in that model (Abraham et al., 1998). Furthermore we categorized factors related to the enactment stage. On the basis of initial analyses, especially the enactment categories could be broken up in subsets, specifying specific topics.

\section{RESULTS}

\section{Current HIV-risk behavior and HIV/AIDS-related behavior changes}

Most drug users (11 of the 13 current injectors) who reported injecting drugs, reported using their own equipment or when that was not possible, to clean the syringes thoroughly (in their opinion). However, a WHO report (1993), has shown that most drug injectors in fact clean their syringes poorly, although drug users consider it thoroughly done. Drug users who reported never having injected drugs 
reported fear for needles was their main reason for not having done so. Furthermore, most drug users reported being more cautious since having heard of HIV/AIDS: Having stopped sharing needles was the most often reported behavior change. But three drug users also reported having changed from injecting drugs to smoking drugs. Drug users also quit injecting for other reasons than HIV/AIDS, like a lack of good veins, negative side-effects experienced when injecting, or a felt responsibility toward the partner or family.

A second important behavior change concerned the reduction of the number of sex partners and increased use of condoms, although this was specifically related to new sex partners. Unsafe sex was however often reported, especially within steady sexual relationships. Safe sex decreased with an increased perception of the partner being a trustworthy sex partner.

\section{Motivational factors}

\section{Knowledge and misperceptions}

The interviewees seemed generally to have basic knowledge about HIV/AIDS. The majority was able to tell that HIV is not curable and that you can eventually die from it. Moreover they showed to have knowledge about the possibility to transmit HIV by syringes and by unsafe sex, although the latter was less often mentioned spontaneously. Although having some basic knowledge, some misperceptions are persistent. Drug users (7 of 34 ) report they are able to estimate when someone is HIVinfected on the basis of their feelings, or on the basis of the external looks of someone. One men for example stated, 'When it is a proper girl I don't ask if she has AIDS. If only I wash myself and she does too'. Some drug users reported they feel 'safe' having sexual intercourse, because they let themselves test for HIV regularly or because they only had sexual intercourse with what they called 'decent' sex partners. One of the HIV-positive male drug users reported never having used condoms with anybody, also not with his steady sex partner.

\section{Attitudinal and normative responses}

Almost all drug users interviewed thought that condoms are an effective method to avoid HIV infections. Three drug users (two males and one female) stated this is only the case when the condoms fulfill certain quality demands, mainly meaning not being cheap. For instance one male drug user stated: 'Well, safe sex, it depends if the condoms are cheap or expensive. You've got condoms, when you put those on, they are already torn before you have inserted them, or before you unrolled them. For example, those Durex' you'll find in those vending machines in toilets, those are not worth a dime. I rather prefer a good one, with lubricant, that doesn't rub'. Drug users report that they prefer not to use condoms in sexual relationships. No other advantages were seen than avoidance of pregnancies when sex with steady partners was discussed. Several drug users (seven men and two women) in the sample reported reasons for wanting to use condoms to avoid pregnancies: by prior negative 
experiences of children taken away from them; not feeling ready for children because of their addiction problem; having become pregnant even when using contraceptive pills. The importance of condoms might be more important as contraceptive within drug-using communities as compared to non-drug using communities. Drug use (at least heroin) disturbs or ends the menstruation cycle (Trimbos, 2001), thereby decreasing the reliability of the pill as contraceptive, or as one female drug user stated, '...I used [drugs]. Then you have...irregular periods. The second time I got pregnant, I was using the pill.'

The majority of the drug users $(N=25)$ reported that they used condoms or would use condoms with casual sex partners out of fear for HIV and STDs. As one man said, 'Simply, to avoid the infection when they perhaps are infected. Just to avoid the risk', 'I don't feel like ... to bear the consequences of a lifetime for something what - well, I just name something - takes ten minutes'. Nevertheless, some drug users also reported in this case not using condoms when the partner is seen as being 'decent'. Avoidance of pregnancies was often mentioned as an advantage of using condoms with casual sex partners. One woman stated that an extra advantage of condom use with casual sex partners was also to avoid the uncleanness of ejaculation.

Drug users reported in many ways condoms have negative consequences: they reduce sexual sensations, they are discomforting, they are a proof of distrust. Examples of statements made were: 'I think that it is a sign of distrust', 'You trust her for her word', 'Something unnatural, you know. A piece of fabric around your genitals'.

Females reported less often disadvantages of using condoms. The disadvantages mentioned were mainly related to the negative feelings of the partner regarding condom use.

\section{Intended condom use}

Drug users stated whether they were and would continue using condoms in their relationships or - in case of not having a relationship - about their intention with regard to condom use in relationships. Of the 23 drug users that clearly answered this question in the context of steady sexual relationships, 20 respondents reported not to use condoms or to stop using condoms when a basis of trust or 'a lack of necessity' would be established. Of the three respondents that answered positively to whether or not to use condoms in steady relationships, one respondent told to use condoms until both tested for HIV, and two respondents said they thought they would use condoms. Thus, most drug users do not seem motivated to use condoms in steady sexual relationships.

Twenty respondents explained their (lack of) motivation to use condoms with casual sex partners. Three respondents - all men - said they would not use condoms, giving attitudinal statements, for instance finding condom use 'not relaxed', 'establishing a trustworthy situation', or only having sexual intercourse with proper partners. The other 17 responded positively, although also here people doubted whether that would mean always. Most respondents answered using condoms out of fear for HIV/STDs. 


\section{Enactment factors}

\section{Experienced barriers to use condoms}

Most drug users reported not experiencing problems, difficult situations or other barriers that would effect their ability to use condoms. Drugs - mainly heroine - were mostly reported to negatively effect sexual arousal, but not to reduce the motivation to use condoms, or the actual use of condoms. However, five drug users (three men and two women) reported drugs might have an effect, mostly referring to cocaine, alcohol, or amphetamines. Six drug users, reported other possible barriers, like for example when being in a rush, or because of difficult situations (e.g., 'being in a car', 'too excited, being in love'). One woman stated that men might be the barrier, 'Yes, if he [the male sex partner] does it [is willing to use condoms], then I have to put it [condom] on'. Other reasons were a reported lack of experience or not having condoms available.

Drug users who experienced barriers also put forward some solutions by which they might overcome their barriers. Solutions proposed were the use of female condoms, or females to put the condom on. Finally, some drug users were aware they should avoid situations in which they would not be able to oversee the situation.

\section{Communicating condom use}

The interviewed drug users were asked how they would communicate condom use. Most drug users had to answer this question hypothetically, as they never had discussed condom use with a sexual partner. Some drug users told they would not discuss condom use, because it was too difficult. One man stated, 'Yes, I don't know. Then I would be a little bit scared. Normally, it is the other way around, mostly the girl talks about condoms, not like... Most girls I know also carry condoms'. Others told they would wait until the partner initiates discussing the topic of condom use. Finally, a few drug users reported simply using condoms, without discussing them first. One man stated, 'I don't talk about that. Yes, if we are at my place, ...I always have them ready. That is something... if I don't do it...it is quite something, right: AIDS'

\section{Negotiated safety}

Negotiated safety is the idea to establish an agreement not to use condoms when sex partners are in a steady relationship, are HIV negative, are aware of each other's negative serostatus, agree about that any sexual practice outside the relationship is safe (Kippax et al., 1997), and in the case of drug users also meaning safe drug use. The majority of interviewees reported seeing no need for an understanding with their partner about sex with others, because sex with others would never happen. One male drug users stated, 'I don't have to discuss that. It is my wife'. Another man responded, 'If I could see that the chance that the girl would cheat doesn't exist, I would be relieved, and wouldn't have to discuss it, it might hurt her'. And finally, one man said, 'We don't have an understanding [about sex with others]. Yes, but it won't happen. I might do it, but not my wife, she would not ...gain anything from 
that. She only wants one person, she relies on me. [interviewer: But if you have sex with others won't you tell her?] Well, that probably would be very difficult'. Some drug users stated that they would discuss the topic with their partner, but this seemed mainly hypothetical.

Furthermore, some drug users stated that they had an arrangement about sexual contacts with others, but this seemed mainly a silent agreement, meaning that they assumed things are clear without actually having discussed the topic with their partner. Finally, a few drug users told having actually discussed the issue of having sexual contacts outside their relationship, but this mostly turns out to be the deal that when the other fools around, the relationship is over.

\section{Having condoms available}

Of the 23 drug users who answered this question, 12 drug users told never to carry condoms with them, seven drug users said sometimes to carry condoms with them, and four drug users stated they always carried condoms with them. The majority of the drug users who did not have condoms with them, said not to do so because they did not use condoms, or because they did not think they have to anticipate on possible situations in which sexual encounters might take place. One male drug user for example answered, 'To go to bed with someone. I would not do that so suddenly'. Another man responded, 'If I need them [condoms] I'll buy them. Should not be a problem?

Drug users who told carrying condoms with them inconsistently, reported having condoms available at home in case something might happen, or to feel certain to get condoms in time when a sexual encounter might occur. Others told that they usually carry condoms, mostly in their wallet, but not to have replaced the last ones the last time. The four drug users who told having always condoms available, were able to actually show them. Three of those drug users reported keeping condoms in their wallet.

\section{DISCUSSION}

Several studies have shown that drug users have reduced HIV risk behavior to some extent, mostly through drug-risk reduction (Des)arlais, 1992). The sample studied also showed awareness of HIV risks and related behavior, and reported strategies to reduce the chance of HIV risk. Besides reductions in injecting behavior, drug users reported having reduced their sexual risk behavior; having reduced the number of partners or unprotected sexual behavior with casual partners, although they are less likely to do so, when the partner seems decent or when amount of time spend with that partner increases. The majority of the interviewees, however, stated clearly that 
within steady relationships condom use is no option. The importance of the difference between casual and steady sexual relationships among drug users has been shown elsewhere (Corby, Jamner, \& Wolitski, 1996; Van Empelen, Kok, et al., 2001; Van Empelen, Schaalma et al., 2001), but also among other groups, like homosexual men (Hospers \& Kok, 1995) and heterosexuals (Sheeran, Abraham, \& Orbell, 1999). Several motivational factors may be related to this difference between steady and casual relationships.

Misperceptions were expressed about condom use, like for example the idea that cheap condoms tear easily. Misperceptions were also persistent when talking about the possibility to recognize someone being HIV infected and to reduce possible HIV risk; knowing someone thoroughly; or when several hygienic actions were taken, like washing. The drug users in the sample reported feeling less vulnerable to HIV/STD in the context of steady sexual relationships, and reporting less need to protect oneself. So, even when having knowledge about HIV/AIDS and HIV transmission routes, drug users report not feeling personally vulnerable for possible HIV transmission within steady relationships.

Furthermore the study provided information about positive and negative attitudinal beliefs with regard to condom use with casual and steady sex partners. In general, the participants had positive beliefs with regard to condom use with casual sex partners, related to fear of HIV and STDs. In the context of steady relationships, condoms were overall seen as negative, being unnatural, less pleasurable, less necessary and as violation of trust. Female drug users overall seemed more positive towards condom use than male drug users, reporting it is mainly their partner who is perceived as having negative feelings about condoms. It therefore seems relevant to make male partners aware of the norms female sex partners have about condoms.

A promising result that needs more research is whether the avoidance of pregnancies might be a motivator to promote condoms as a contraceptive within steady relationships. Using condoms as a contraceptive might be a good motivator, because it has been shown that at least heroin use can disrupt the menstruation cycle (Trimbos, 2001), making the contraceptive pill less of an option. This however may only be an argument for a part of the population.

The sample of drug users discussed in this article reported a small number of barriers related to (the technical aspect of) actual using condoms. The small number of barriers reported seems to suggest that mainly motivational factors are important with concern to condom use. However, another and perhaps better explanation might be the lack of concrete condom use experience in the majority of the sample. Some drug users in the sample reported that alcohol and drugs (cocaine and amphetamines) might inhibit them from using condoms. A possible explanation why people might engage in sexual risk behavior when intoxicated is proposed by alcohol myopia theory (Steel \& Josephs, 1990) that asserts that intoxication reduces someone's attentional capacity. Intoxicated people therefore pay only attention to the most salient aspects of the situation. People behave in a more impulsive manner, depending on which types of cues are made salient. Consistent with the notion of myopia, people are not able to see the possible long-term costs of their actions 
(HIV/AIDS), attending instead the more salient short-term benefits (pleasure)(cf. MacDonald, MacDonald, Zanna, \& Fong, 2000; MacDonald, Zanna, \& Fong, 1996). Hence, drug users should be made aware that even when being positive about condom use, this notion might be inhibited due to myopia, a situation they should anticipate on.

Although most drug users in this sample perceive themselves to be capable of using condoms, and actually being motivated in the case of casual sexual relationships, enactment factors of condom use, like having condoms available or communicating about condoms, seem more problematic, and might prevent actual condom use. The ability to discuss condom use has been shown to be essential in promoting condom use (Grimley, Prochaska, \& Prochaska, 1993). Communication about HIV/AIDS and condom use therefore seems a very important factor. These topics seem however taboo, especially within steady relationships while on the other hand other possibilities to reduce HIV risk, like for example negotiated safety are not negotiable. Furthermore, it seems essential to promote the actual carrying of condoms, because anticipation of actual condom use and possible sexual encounters seem essential enactment factors of getting motivated people to use condoms.

The behavioral, motivational and enactment factors described in this article provide some insight of how the intention-behavior relationship in the case of condom use among drug users can be strengthened, thereby presenting meaningful information for quantitative studies. Moreover this article presents information that can be used to develop more specific AIDS preventive interventions aimed at drug users, taking into account enactment factors of behavior, in this case condom use. 



\section{CHAPTER 4}

INTERVENTION MAPPING:

METHODS, STRATEGIES AND PROGRAM: STEP 2 AND 3

Overview

Section 4.1 Effectiveness of psychosocial HIV prevention programs: A review

Section 4.2 Matching methods and strategies to matrices

Section 4.3 The development of sexual risk reduction materials among Dutch drug users: Translating methods and strategies to program planning 

OVERVIEW 
The current chapter focuses on Steps 2 and 3 of Intervention Mapping. Following the first task of Step 2 we searched for theoretical methods. This search was conducted following the search strategies described in chapter 1:1) an issue-related approach that looks at topics such as 'HIV prevention' or 'sexual-risk behavior', 2) a conceptrelated approach, in which the theory search is based on theoretical concepts, 3) and a last approach that focuses on the use of familiar theoretical models.

Section 4.1 gives an overview of our issue-related approach. The section reviews the literature on psychosocial interventions aimed at the reduction of sexual risktaking behavior. The focus is on interventions focusing on target populations that have received only little attention until recent.

In Section 4.2 we describe the entire process of Intervention Mapping Step 2. Following Step 2 of Intervention Mapping we link the proximal program objectives (of chapter 2) to theoretical methods and practical strategies. The step is based on: a brainstorm about theoretical methods [task 1]; a specification of the most potentially useful methods and justification of the selections with the literature and theories from which the methods have been derived. Furthermore, the conditions under which such methods have shown to be effective are identified [task 2]; finally, the methods are translated into practical applications - strategies - that should match with the proximal program objectives specified in Step 1 [task 3].

Section 4.3 presents the development of a theory- and evidence-based AIDS program for Dutch drug users. The emphasis of this section is on the development process using Intervention Mapping. It focusses on program design, pretesting and development, following Step 3 of Intervention Mapping, and discusses the linkage approach applied. The tasks involved in Step 3 are: 1) the operationalization of strategies in a program plan, taking into account the context in which the program will be used [task 1];2) the designing of the program materials [task 2]; and 3) pretesting of the concept materials with target groups and implementers before the final materials can be produced.

Although the entire chapter describes the process of Steps 2 and 3, the sections should be read as freestanding. First, this means that chapters may overlap. Second, this explains the fact that although in section 4.2 a program aimed at casual sex partners and a program targeting condom use with steady partners is discussed, section 4.3 only discusses the development of the program for casual sex partners. 


\section{SECTION 4.1}

EFFECTIVENESS OF PSYCHOSOCIAL HIV PREVENTION PROGRAMS: A REVIEW

\section{Submitted for publication as}

Van Empelen, P., Kok, G., Van Kesteren, N. M. C., Van den Borne, B., Bos, E. A. R., Dijker, A. J., Hospers, H. J., Schaalma, H. P., Hogeweg, J. A., (2001). Effectiveness of psychosocial HIV prevention programs: A review. 


\section{INTRODUCTION}

HIV and AIDS are a serious threat to public health. In principle, HIV infection can be prevented by changes in people's behavior, but in practice these changes, particularly sexual risk behavior changes, have proved to be very difficult to accomplish. For years, health educators have tried to promote HIV-preventive behavior in various groups, in particular those with higher risk behavior. Initially, these interventions were poorly developed, but over time, more data on behavioral determinants and program effectiveness have become available, and various authors have urged educators to make better use of theoretical principles (Fisher \& Fisher, 1992; Kelly et al., 1993).

The use of theory is important in the analysis of possible determinants of HIV risk behavior. In addition, health education programs will be more likely to be effective when based on theories and empirical data (Bartholomew et al., 2001; Green \& Kreuter, 1999). A number of in-depth reviews have been published showing the relation between psychosocial factors and HIV risk behavior among different populations: men that have sex with men (MSM) (Flowers et al., 1997; Hospers \& Kok, 1995), youth (Sheeran et al., 1999; Sheeran \& Taylor, 1999), and heterosexuals (Sheeran et al., 1999). These reviews have found that psychosocial factors most closely related to condom use are a positive attitude towards the acceptance of condom use, a clear view of the acceptance of condom use by important others (especially sexual partners), the intention to actually use condoms, and the skills and self-efficacy to carry, communicate and use condoms. Throughout all reviews it has been shown that HIV/AIDS knowledge and perceived risk have little predictive value concerning risk behavior. Relationship status has shown to be very important, that is, people have more unsafe sex with primary partners than with casual partners. The reviews show that interventions should not only be informative, but should also persuade and empower people to perform safe sexual practices.

Reviews of psychosocial interventions among youth (Choi \& Coates, 1994; Kim et al., 1997; Kirby \& DiClemente, 1994), MSM (Kegeles \& Hart, 1998) and injection drug users (IDUs) (Booth \& Watters, 1994; Gibson et al., 1998) have shown that effective interventions are likely to be theory-based and focus on skills enhancement or on sustainability of resources.

In this article we will examine the current state of knowledge on the effectiveness of HIV prevention interventions for groups that have received more attention only recently: drug users (with respect to sexual behavior); people in developing countries, in particular Sub-Saharan Africa; minority populations; and people with HIV/AIDS (PWHA). Furthermore, we will give an overview of the psychosocial interventions that have targeted those groups. We will look explicitly into the relation between what we know about the psychosocial determinants of the behavior and the selected intervention methods. Also, we will compare the results of this review with the findings with regard to the well-studied groups of youth and MSM to see if there are specific differences or similarities between groups. 
Table 1 Theoretical models and their abbreviations mentioned in the reviewed articles

\begin{tabular}{ll}
\hline ARRM & AIDS Risk Reduction Model (Catania et al., 1990) \\
CHSCP & Comprehensive Health Seeking and Coping Paradigm \\
& (Nyamathi, 1989) \\
Diffusion of Innovations & (Rogers, 1983) \\
Empowerment Theory & (Zimmerman, 1995) \\
HBM & Health Belief Model (Becker, 1974) \\
KAB/KAP & Knowledge-Attitude-Behavior (Practice) model \\
MI & Motivational Interviewing (Miller \& Rollnick, 1991) \\
PMT & Protection Motivation Theory (Rogers \& Prentice-Dunn, 1997) \\
PST & Problem Solving Therapy (D' Zurilla, 1988) \\
RP & Relapse Prevention Theory (Marlatt \& Gordon, 1985) \\
SCT & Social Cognitive Theory (Bandura, 1986) \\
SLT & Social Learning Theory (Bandura, 1977) \\
TPB & Theory of Planned Behavior (Ajzen, 1991) \\
TRA & Theory of Reasoned Action (Fishbein \& Ajzen, 1975) \\
TTM & Transtheoretical Model (Prochaska \& DiClemente, 1984) \\
SAT & Social Action Theory (Ewart, 1991) \\
\hline
\end{tabular}

\section{METHODS}

Electronic searches were conducted and completed with publications that reached us through the professional network and recent conferences. The databases we used included Medline, PsycInfo, ERIC and Online Contents. We mainly focused on the last six years, building on a publication by Choi and Coates (1994) on the effectiveness of HIV prevention. Our main criterion was that the intervention had to be psychosocial in nature. The studies were reviewed on: 1) population and setting; 2) study design; 3) clear use of theory within intervention development; 4) clear targeting of determinants; 5) a description of the study or studies; and 6) an evaluation of the behavioral goals and targeted determinants.

If theories but none of the targeted determinants were mentioned, or if determinants but not the theoretical background were discussed, an assessment was made of the missing information if possible (see table 1 for an overview of the theories that are discussed and their abbreviations). Disagreements were resolved by means of discussion among the authors. 


\section{RESULTS}

Using the criterion of the intervention being psychosocially based, a total of 50 studies were included in the review. Studies that did not meet this criterion were excluded from the review, including many HIV testing and counseling programs. For every population studied ((IV) drug users, people in sub-Saharan African countries, minority populations, and PWHA) we will give a description of the most important determinants found, a description of the different interventions, and a conclusion of the most important findings.

\section{SEXUAL BEHAVIOR AMONG (INJECTING) DRUG USERS}

The majority of HIV programs targeting IDUs have concentrated upon drug use behavior through harm reduction programs. Although these programs have reduced unsafe injection behavior (Marsch, 1998), they have had no positive effect and might even have had a negative effect on safe sexual practices (Rhodes \& Quirk, 1995). Although these harm reduction programs are often necessary to reach IDUs, there is a necessity to alter sexual behavior by means of psychosocial programs. Recent studies have shown that sexual risk behavior of IDUs is a potential source of HIV transmission towards larger populations (Fennema, 1997; Rhodes et al., 1996). Also non-injecting drug users, like crack smokers are at risk for HIV infections because they report high sexual risk taking behavior (e.g., Booth et al., 2000).

\section{Determinants}

The knowledge about determinants of safe and risky sexual behavior of drug users is limited (see Van Empelen, Kok et al., forthcoming; Van Empelen, Schaalma et al., forthcoming). What we do know is that risk perception has not been shown to be related to safe sexual behavior. Positive attitudes have been found to be moderately good predictors of condom use. Perceived positive social norms, especially the perceived partner norm, is related to increased condom use. Furthermore, it seems that drug users who reported other people's safe sexual behavior were more likely to practice safe sex themselves. Self-efficacy has been found to be a strong predictor of condom use with casual and steady sex partners. Other psychosocial determinants have been studied less frequently. 


\section{Interventions}

The majority of counseling programs for (IV) drug users lack a theoretical basis and an appropriate evaluation design. Therefore, these studies have not been included. We found 16 psychosocial intervention studies targeting sexual risk behavior (see table 2): ten small-group interventions, four community-level interventions, one individual-level intervention, and one article describing several intervention methods (Cottler et al., 1998). Most of the studies do not report on psychosocial determinants that should be the basis for intervention development, nor do they contain a description on how the available data were used in the development of the intervention. Various theories are mentioned as a basis for the interventions - for example Social Cognitive Theory (SCT), the Transtheoretical Model (TTM), and the Health Belief Model (HBM) - but descriptions of the way these theories were used in the development of the interventions are missing. Studies that do show effects are often characterized by small numbers of participants.

\section{Small-group interventions}

The small-group interventions that were shown to be effective (e.g., El-Bassel et al., 1995; McCoy et al., 1998) were based upon multiple theories, like the TTM (Prochaska et al., 1997), AIDS RISK REDUCTION MODEL (ARRM, Catania et al., 1990), or SCT (Bandura, 1997). Most interventions focusing on a combined approach of skills training and social support consisted of approximately six sessions, targeting skills, self-efficacy, and social support, most skills being in the area of negotiation and problem solving.

\section{Community-level interventions}

A small number of studies have evaluated community-level interventions and seem to be promising. Community-level interventions (e.g., Jamner et al., 1997; Rietmeijer et al., 1996) are also based on multiple theories, including community development theories (Minkler, 1997). They have tried to establish some kind of ownership by the target group, by basing the HIV message on their experiences (role model stories) and by involving the target group in the distribution of those messages and HIV prevention materials (condoms, bleach). These interventions were effective in changing condom carrying and condom use.

\section{Conclusion}

Programs that have shown to be effective did not rely on a single theory, but made use of multiple theories and aimed at changing relevant determinants. The majority of effective interventions were based on small-group skills building and communitylevel intervention. The one individual-level intervention, based on a method of counseling, only used the HBM (Becker, 1974) in intervention development. Because the focus in that model is mainly on beliefs rather than behavior, a behavior change was unlikely to occur.

। I I 


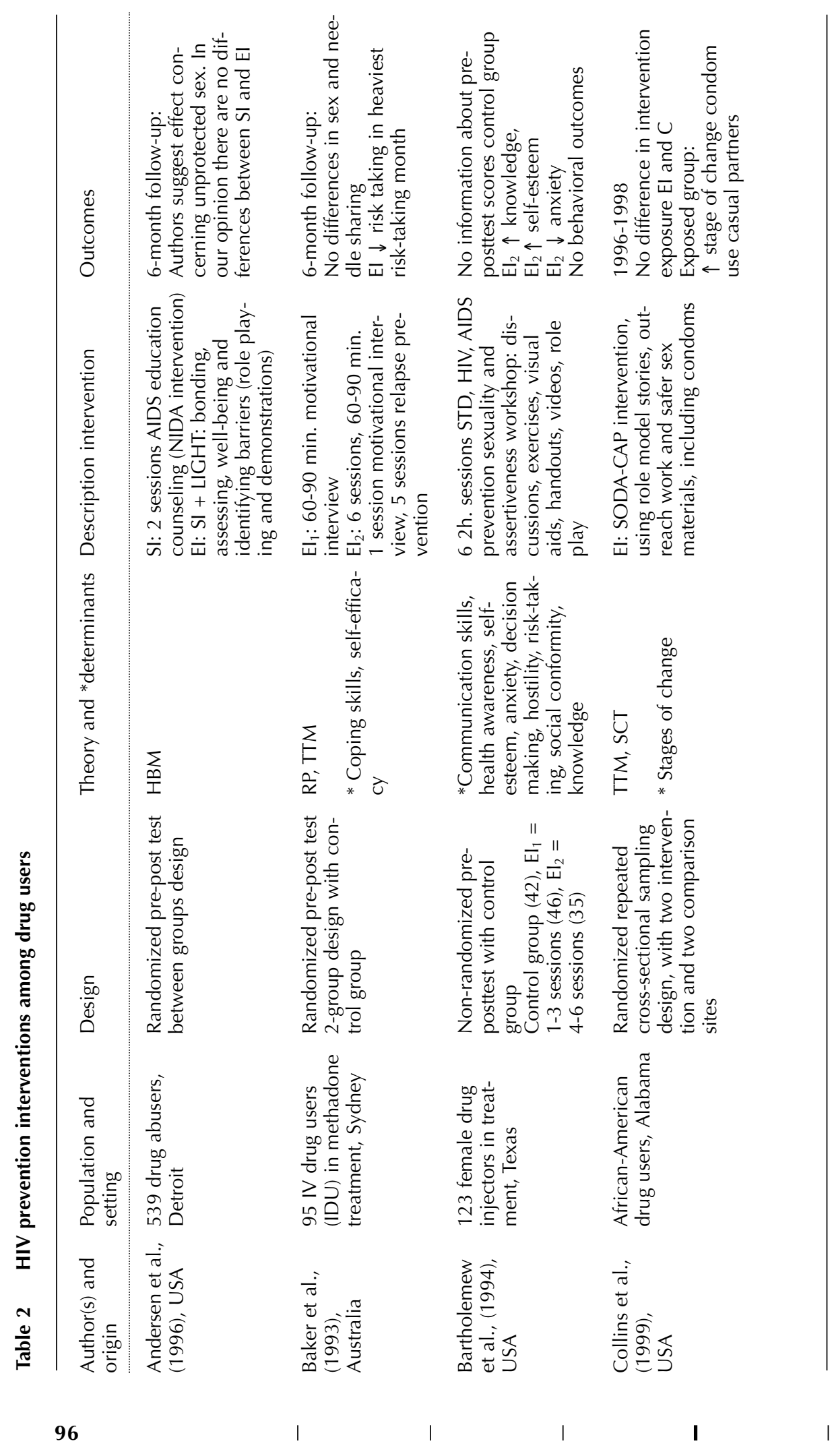




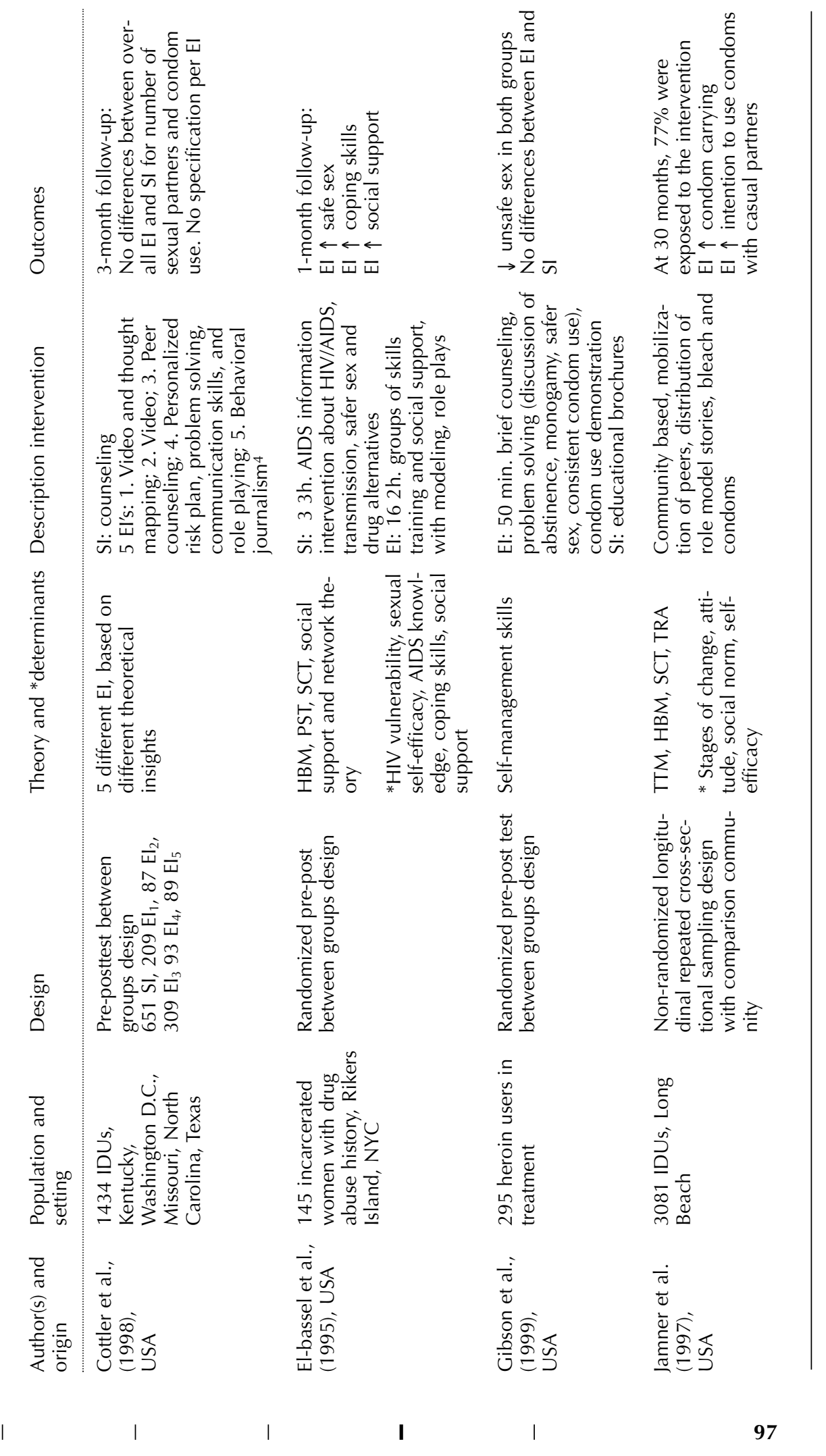




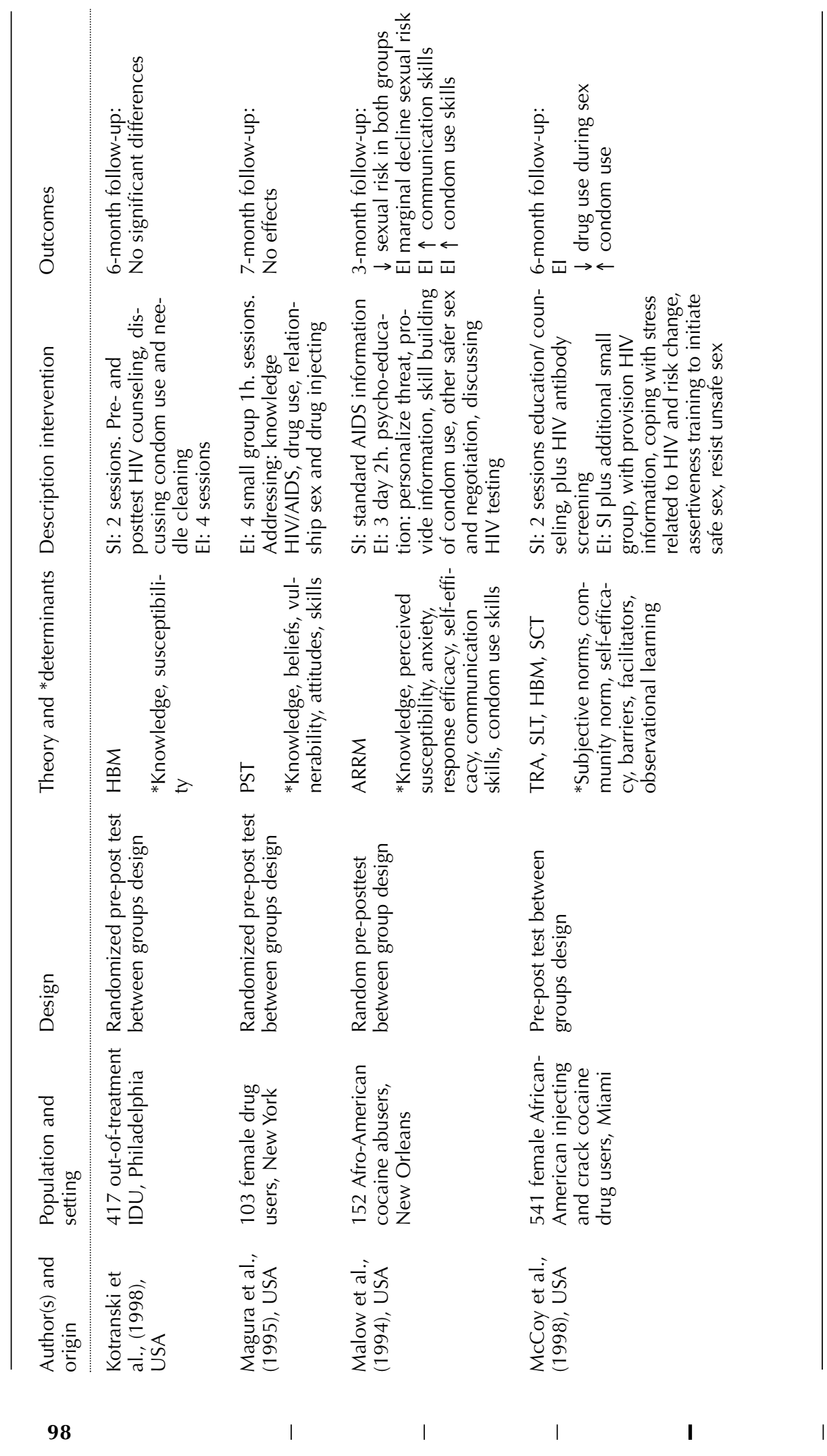




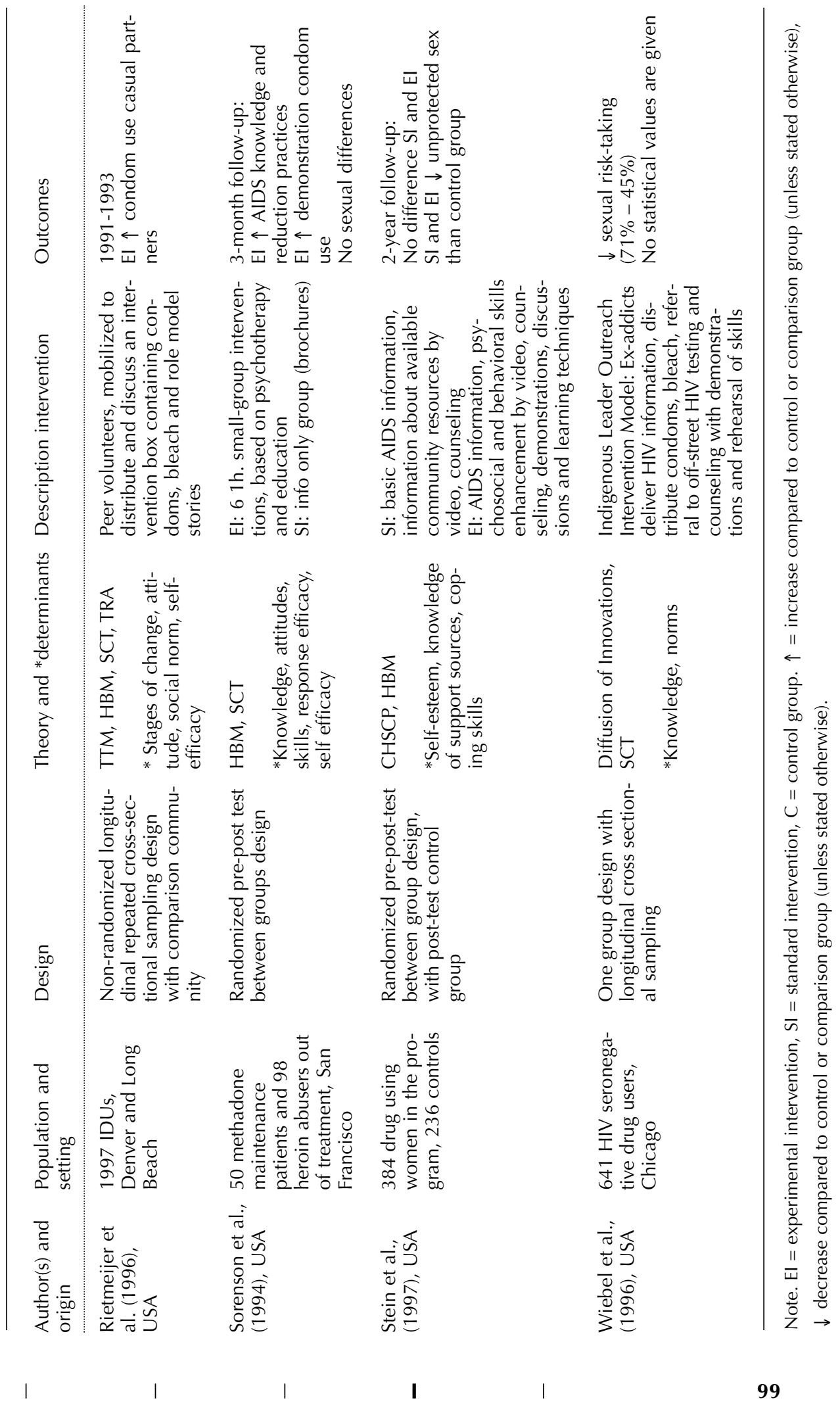




\section{DeVEloping COUNTRIES - SUb-SAHARAN AfRICA}

It is estimated that over $70 \%$ of all the people currently infected with HIV worldwide live in Sub-Saharan Africa (24.5 million), and that nearly 90\% of the children infected with HIV worldwide are African (UNAIDS, 2000). To slow down the African HIV/AIDS epidemic, a wide variety of prevention programs have been developed and implemented to promote condom use, long-term fidelity and reduced numbers of sex partners and to put an end to commercial sex practices. The scientific literature, however, hardly provides effect studies on theory and evidence-based prevention programs with a sound methodological basis.

\section{Determinants}

Various anthropological and ethnographic studies have addressed the socio-cultural context of AIDS/HIV in Africa to obtain insight into why HIV has spread at such great speed and why efforts to promote safe(r) sex have met with such a great deal of resistance. These studies suggest that in many parts of Africa a broad variety of political, economic and social factors - such as urbanization, the migrant labour system, and poverty - have increased prostitution, premarital sex and extramarital sex (e.g., Bassett \& Mhloyi, 1991; Larson, 1989; Van der Walle, 1990). Other researchers have linked the rapid spread of HIV with, for instance, loose sexual attitudes, the approval of sexual promiscuity, a preoccupation with virility, myths about health and sexually transmitted diseases, religious values and unbalanced gender relationships (e.g., Green, 1992; Mbizvo, 1996; Meyer Weitz et al.,1998). Studies among youth suggest that intentions to have sex and/or to use condoms are significantly related to attitudes and subjective norms toward condom use, perceived outcome-efficacy of condom use, embarrassment and social anxieties related to buying condoms, negotiating condom use and refusing high-risk sexual activity, and cultural beliefs and core values regarding sexuality (e.g., Abraham et al., 1995; Bandawe \& Foster, 1996; Wilson \& Lavelle, 1992).

\section{Interventions}

We found twelve effect studies of psychosocial programmes that met our criteria: five on school communities and adolescents, three on other specific community studies (farming, trucking companies, Muslims), two on sex workers, one on serodiscordant couples, and one on pregnant women (see Table 3).

Only one of the effect studies used an experimental design focusing on randomisation at the individual level (Stanton et al., 1998). Two other studies applied a quasi-experimental design with randomisation at the community level (Klepp et al., 1994; Laver et al., 1997). Six studies used a non-equivalent control group design 
without randomisation (Allen, Serufilira et al., 1992; Allen, Tice et al., 1992; Kagimu et al., 1998; Munodawafa et al., 1995; Ngugi et al., 1988; Van Rossem \& Meekers, 2000).

Most interventions were short of a solid base in theoretical principles. Their objectives were limited to the promotion of condom use and reduction of sexual partners and to such determinants of condom use as knowledge and attitudes (referred to as Knowledge-Attitude-Practice/Behavior paradigms). A number of studies targeted condom use and reduction of sex partners, based on a more extensive analysis of the determinants of risk behavior focusing on social norms, self-efficacy and skills and using a culture-sensitive approach (Harvey et al., 2000; Klepp et al., 1994; Laver et al., 1997; Stanton et al., 1998).

\section{Secondary school communities and adolescents}

Two out of five studies did not measure the effects on condom use because the schools involved objected to direct questions on sexual behavior (Klepp et al., 1994; Munodawafa et al., 1995). In two out of three studies an increase in condom use or a later onset of sexual activity was observed (Harvey et al., 2000; Van Rossem \& Meekers, 2000). Positive effects were found on knowledge of AIDS, communication about AIDS, attitudes towards people with AIDS, self-efficacy in condom use and intention to use condoms.

\section{Sex workers}

The two intervention studies with sex workers that mainly focused on improving condom use observed a significant growth in use (Ngugi et al., 1988; Williams et al., 1992). Knowledge of AIDS and self-efficacy in condom use increased.

\section{Specific community studies}

Most community programmes included existing intermediates in the intervention, such as Imams or farm health workers (Laver et al., 1997). In only one of the three community studies (Muslim community) the intervention showed a significant increase in self-reported condom use (Kagimu et al., 1998). Two of the studies observed a decrease in the number of (extramarital) sex partners (Jackson et al., 1997; Kagimu et al., 1998). In the two studies measuring knowledge about AIDS and AIDS prevention the interventions showed a significant increase (Kagimu et al., 1998; Laver et al., 1997).

\section{Discordant couples and pregnant women}

In a study on discordant couples and in another sample of pregnant women, Allen and colleagues (Allen, Serufilira et al., 1992; Allen, Tice et al., 1992) studied an intervention in which HIV testing was combined with a condom promotion intervention. Both studies observed a significant and relevant increase in condom use following the intervention. Data indicated less seroconversion after the interventions due to testing and condom use. 


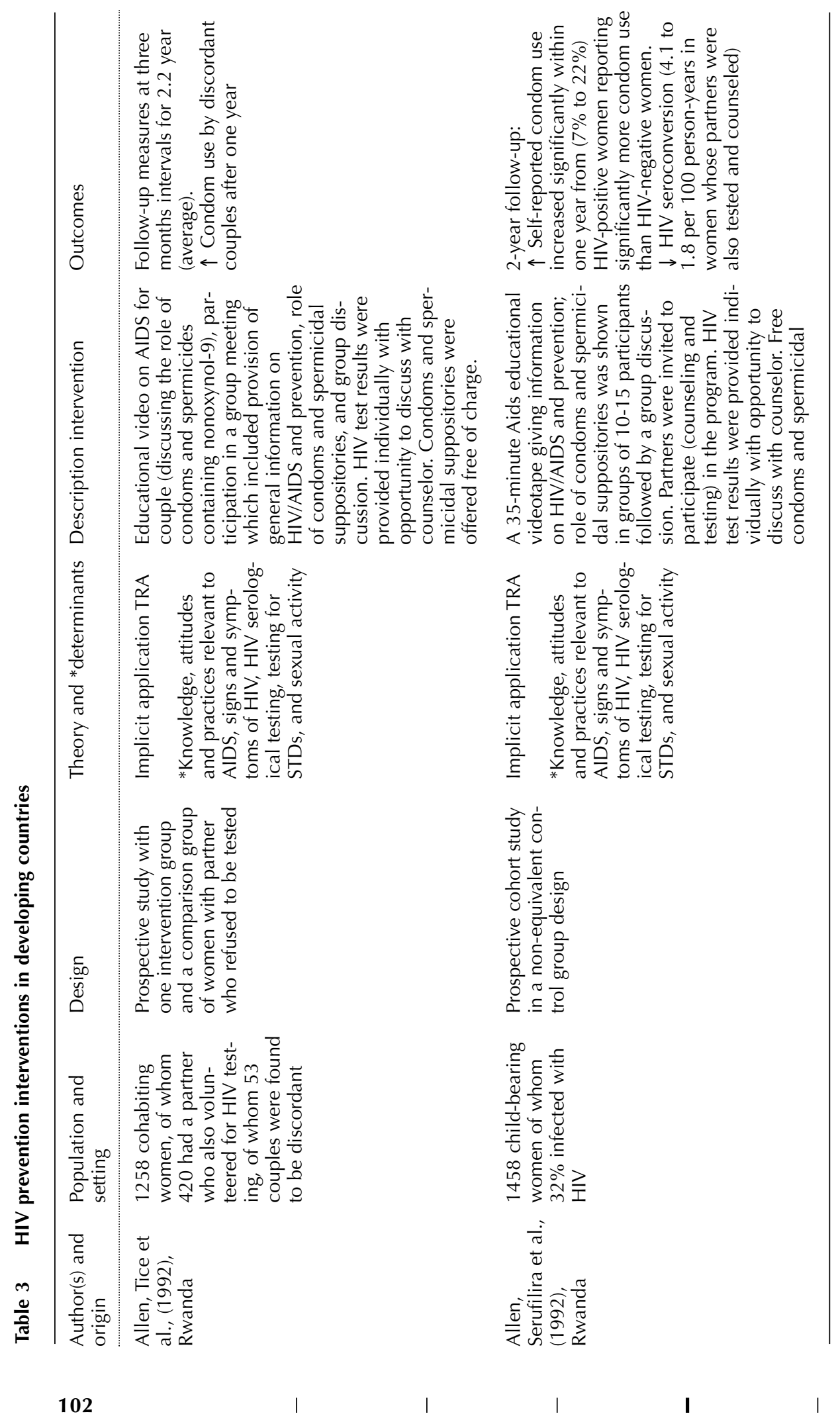




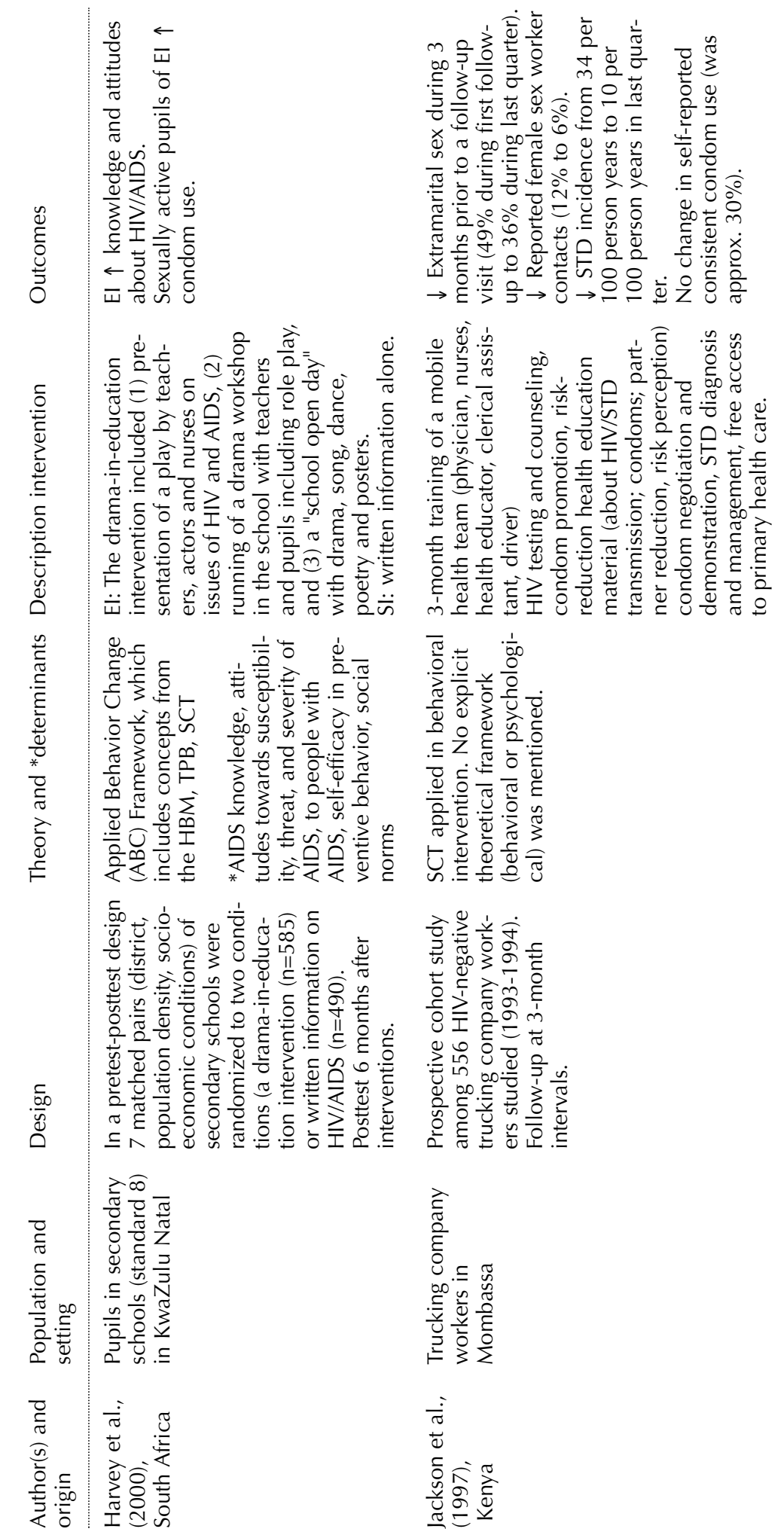

$\mid$ 


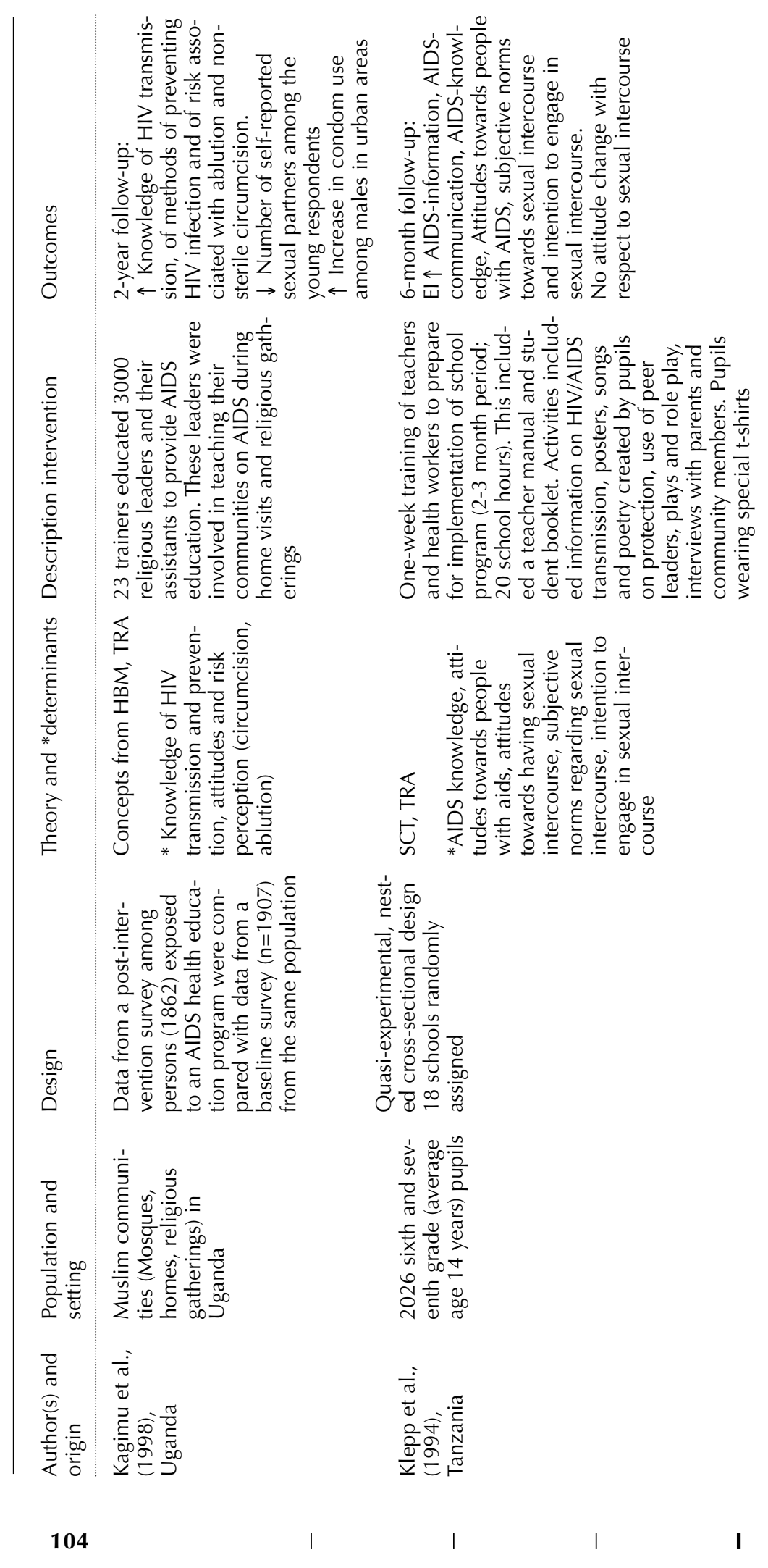



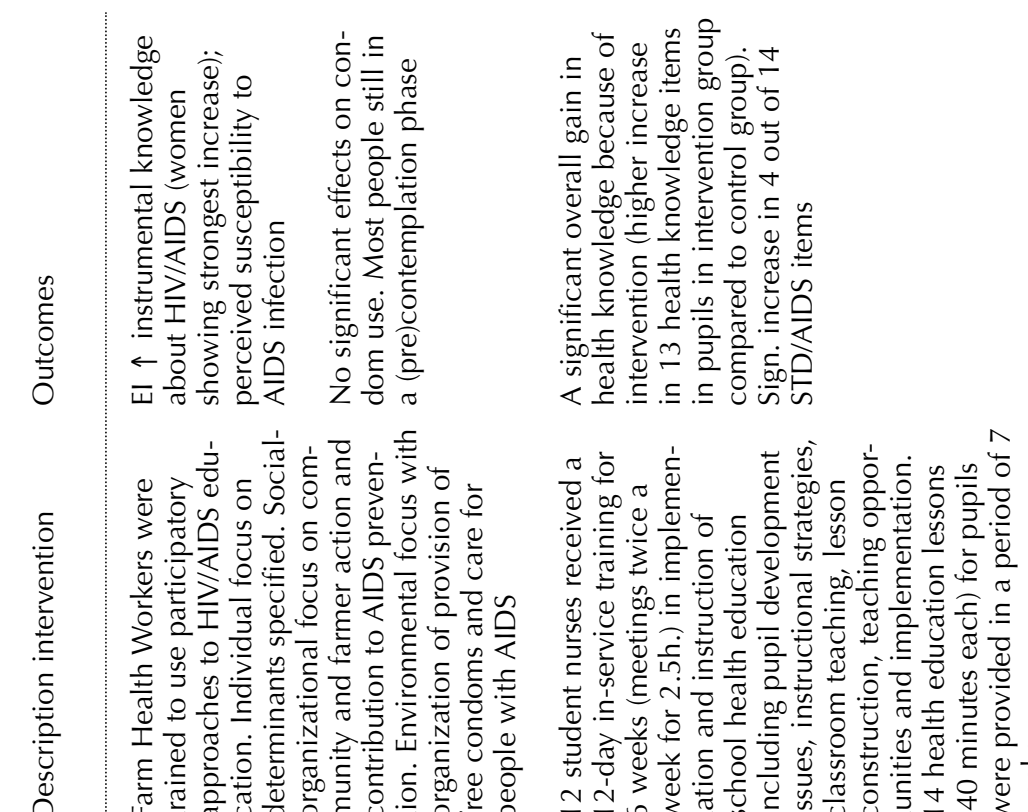

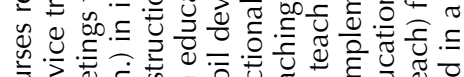

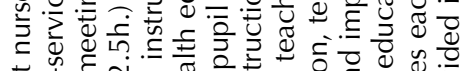

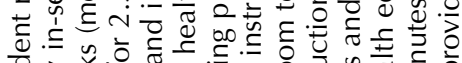

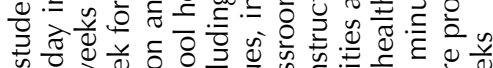

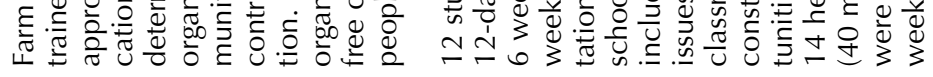

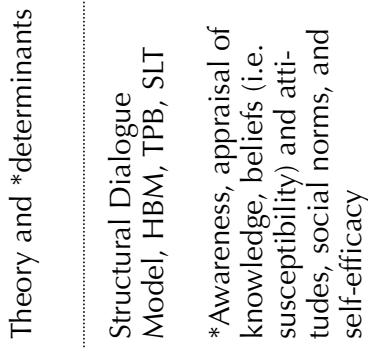

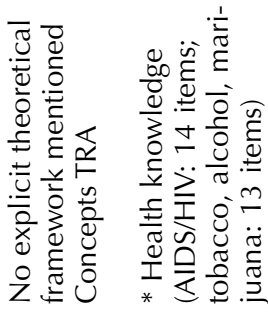

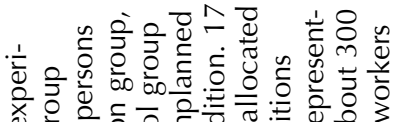

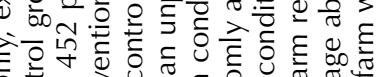

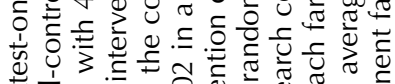

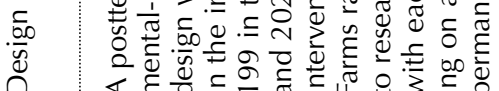

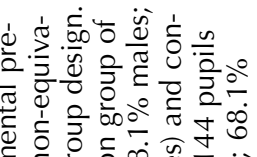

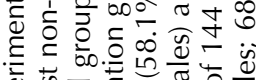

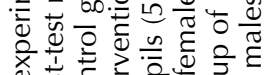

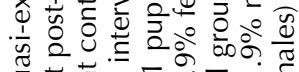

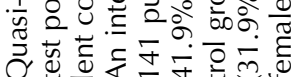

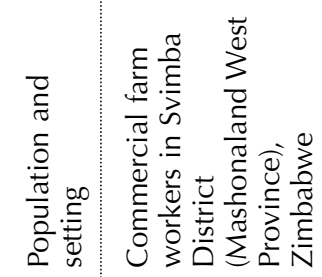

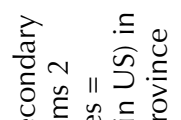

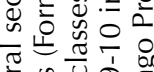

$5 \frac{0}{8} m=0$

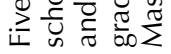

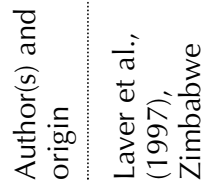

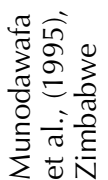

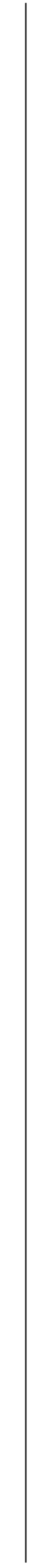




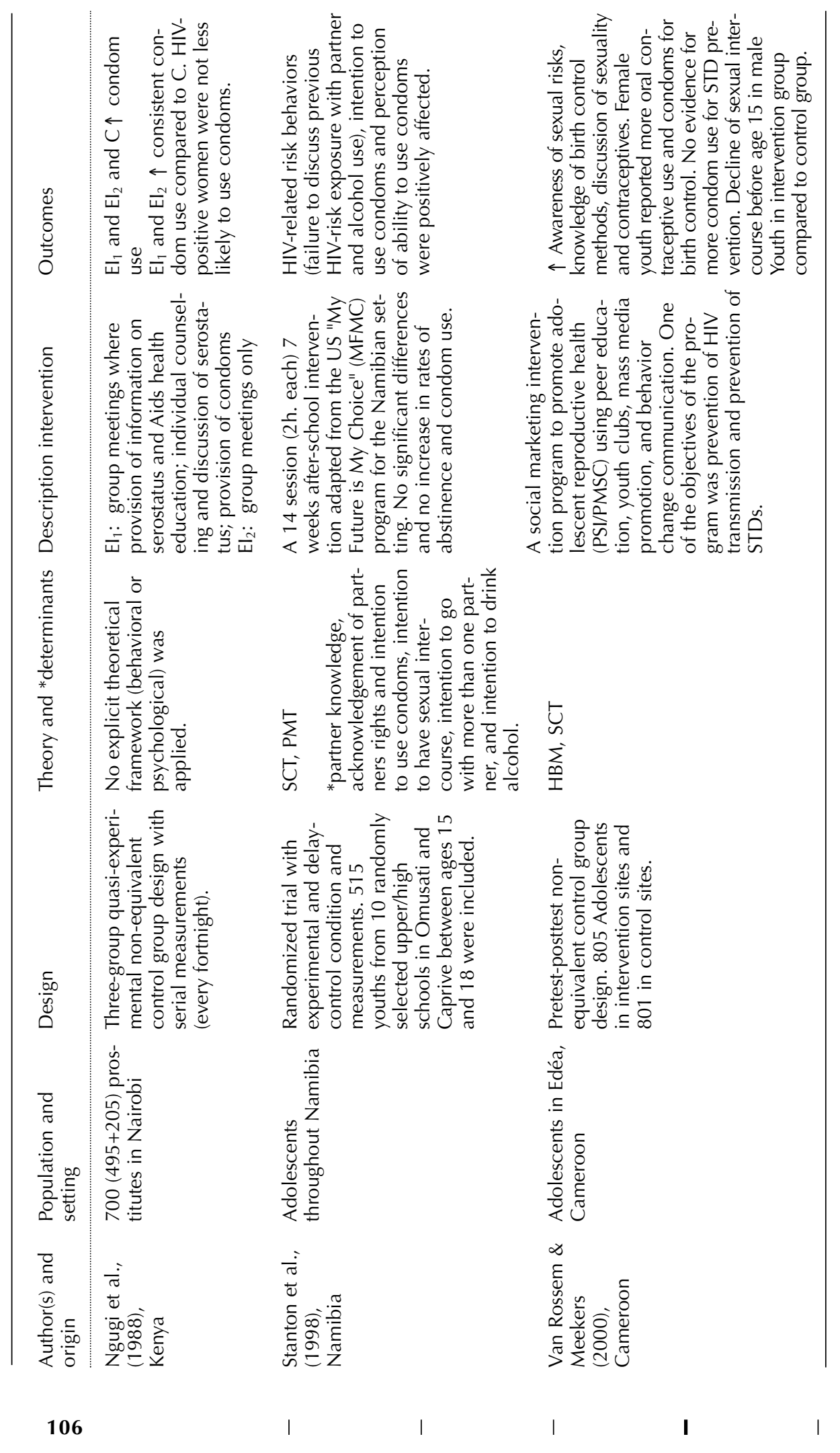



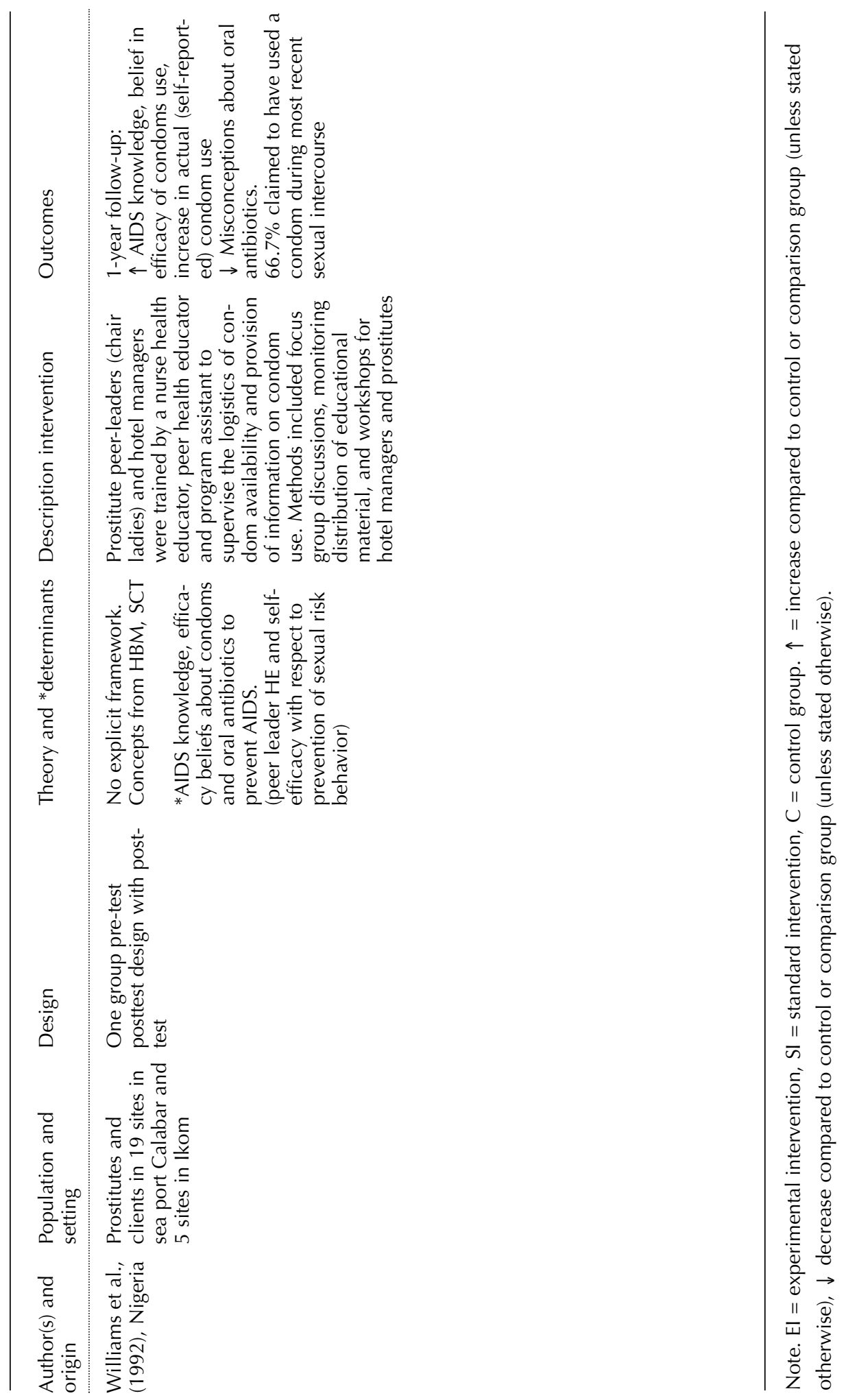

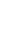

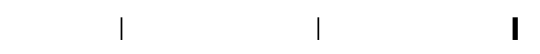




\section{Conclusion}

The limited number of HIV/AIDS programs evaluated in Sub-Saharan Africa have targeted a range of groups or communities. Also, a variety of programmes was used. With a few exceptions, the theories used in most studies were restricted to a KABparadigm.

In six out of ten studies the intervention showed a positive effect on condom use. A number of programs succeeded in establishing a change in behavior (an increase in condom use or a reduction in sex partners). However, caution with interpreting these findings should be warranted, because several studies did not use a comparison group. In addition to various health education strategies such as group education through lectures (Ngugi et al., 1988), an educational video (Allen, Serufilira et al., 1992), group discussions and peer education (Williams et al., 1992), religious gatherings (Kagimu et al., 1998), or HIV testing and STD diagnosis and management, these programmes included individual contacts or individual (couple or family) counselling of target group persons or intermediates. Community interventions that did not have an individual counselling component (Laver et al., 1997) seemed less likely to have a behavioral impact.

Four of the intervention studies combined the promotion of safe sex behavior with HIV testing and counselling. In three of these studies the interventions resulted in an increase in condom use while in the study that did not show increased condom use, truck company workers reported fewer sex worker contacts and less extramarital sex after the intervention.

With the exception of two earlier studies on secondary school children, practically all interventions made available free condoms, which seem to be a prerequisite for effectiveness.

\section{MINORITY POPULATIONS}

Data for the United States shows much higher levels of AIDS incidence among Blacks and Hispanics than among their white counterparts (Kalichman et al., 1996; Kalichman et al., 1997). In Europe, too, AIDS is more prevalent among minority populations than among the inhabitants of European origin (De Putter, 1998).

\section{Determinants}

Recent studies have contributed to an initial understanding of psychosocial factors related to risk-taking behavior among these target groups. Research has identified an accurate estimation of personal risk, positive attitudes and perceived positive peer norms towards condom use, high sexual communication with partners, self-efficacy 
to use condoms, and strong behavioral intentions to use condoms as important predictors of sexual risk reduction (e.g., Fernadez-Esquer et al., 1997; Reitman et al., 1996; Wingood \& DiClemente, 1998). Other issues contributing to increased HIV infection in minority populations are socio-cultural and gender sexual values that can be identified within different populations. For example, power imbalances in relationships due to traditional sexual roles may influence the ability of women to discuss the risk of STD/HIV infection and to negotiate condom use with their partner. Also, life stressors with greater immediate salience than the threat of AIDS, such as inadequate housing, unemployment and crime contribute to the increased risk of HIV infection (e.g., Margillo \& Imahori, 1997).

\section{Interventions}

We found 16 studies that intended to change sexual risk behavior among a number of minority populations. Fifteen of these were based on small-group behavioral change techniques and one on a community-level approach (see table 4). A lot of studies did not clearly report the use of theory and are not based on a randomized control trial. Most of the studies that report a theory-based approach relied on a single theory, mainly SCT. Only a small number of studies used a theoretical framework based on multiple theories (e.g., Lauby et al., 2000). The non-theory-based small-group interventions are often characterized by single-session treatments. Furthermore, it should be noted that most intervention studies have used only brief follow-up periods to examine behavior change maintenance.

\section{Small-group interventions}

HIV risk-reducing interventions among minority populations that were shown to be effective have been primarily based upon behavioral skills-training strategies derived from SLT (e.g., DiClemente \& Wingood, 1995; Hobfoll et al., 1994; Kalichman et al., 1996) and used peers to deliver the training program. Most of the reported skills interventions include: (a) accurate information concerning HIV transmission and personal sensitization; (b) sexual communication skills, including sexual assertiveness, negotiation and risk refusal; and (c) risk refusal and self-management skills, including identifying and managing risk 'triggers'. The majority of interventions were effective in changing communication skills, risk refusal skills and condom use. A number of intervention studies evaluated the effectiveness of culturally sensitive AIDS education, including information provided by a peer educator (volunteers from the target group serving as educators) (e.g., Martijn et al., 2001) and culturally tailored videotapes (e.g., Quirk et al., 1993). Some of these were effective not only in changing knowledge and risk appraisal but also in changing sexual risk taking behavior, although several methodological limitations can be identified. The results, however, provide some evidence for the importance of developing culturally tailored HIV prevention interventions. 


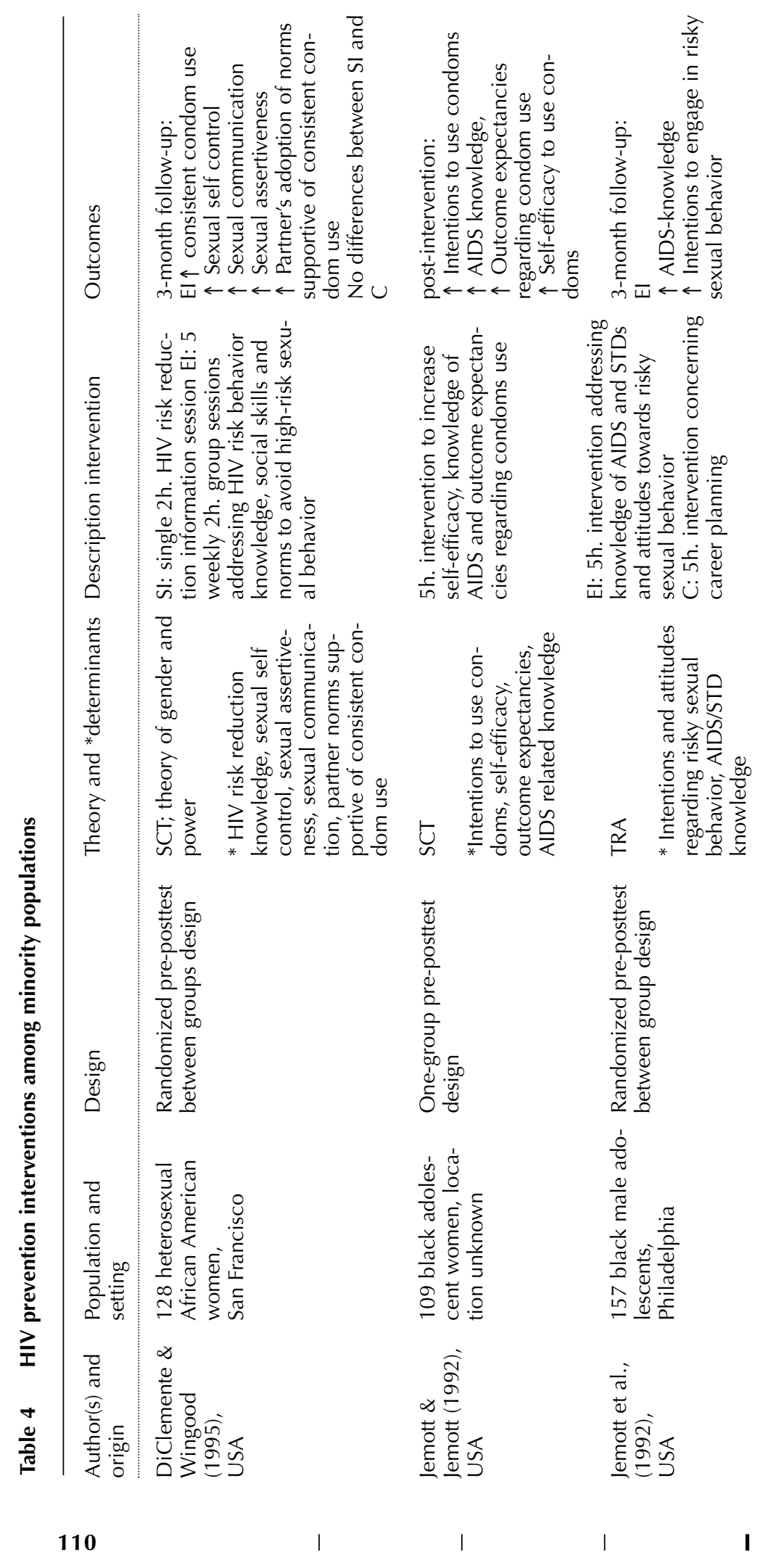




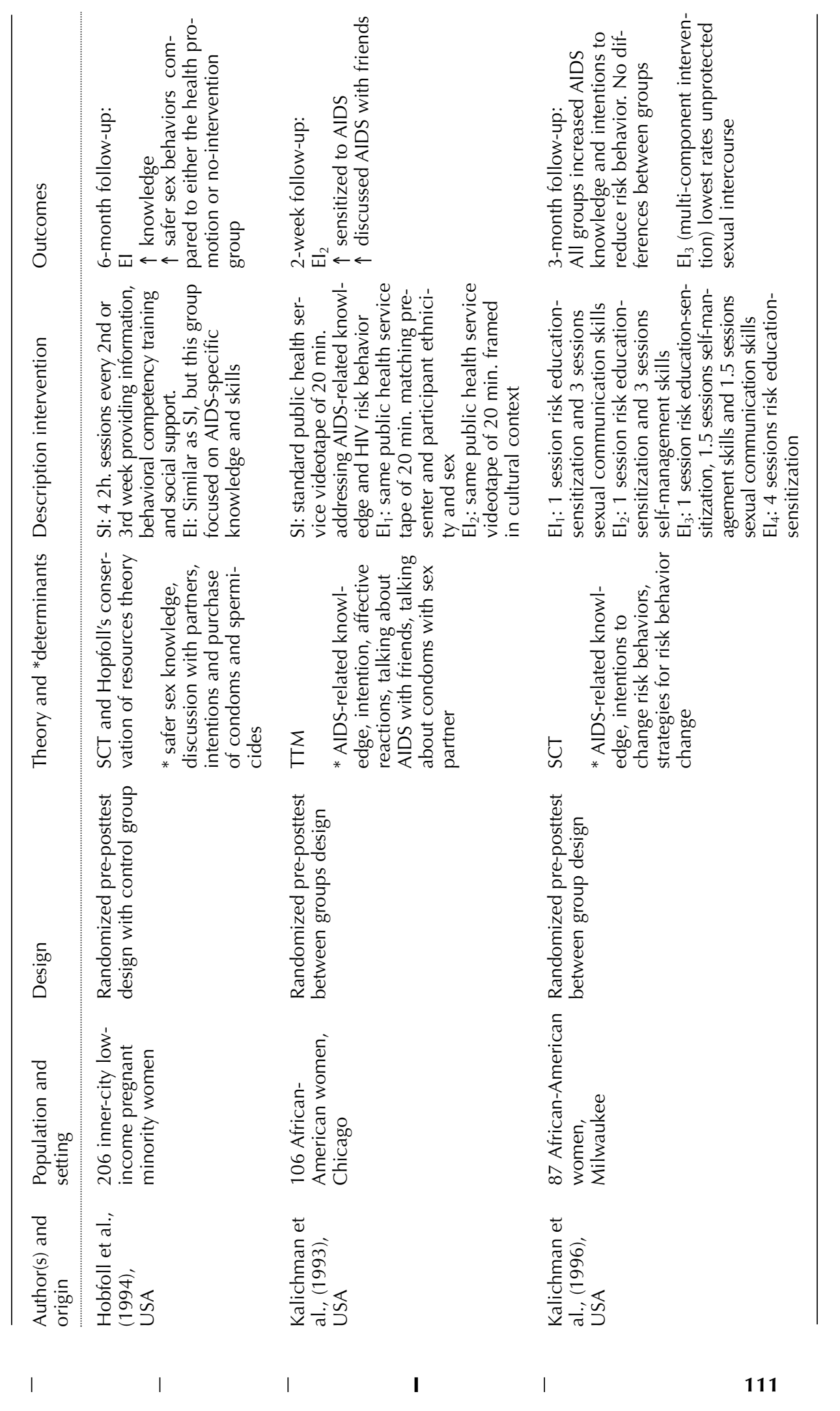




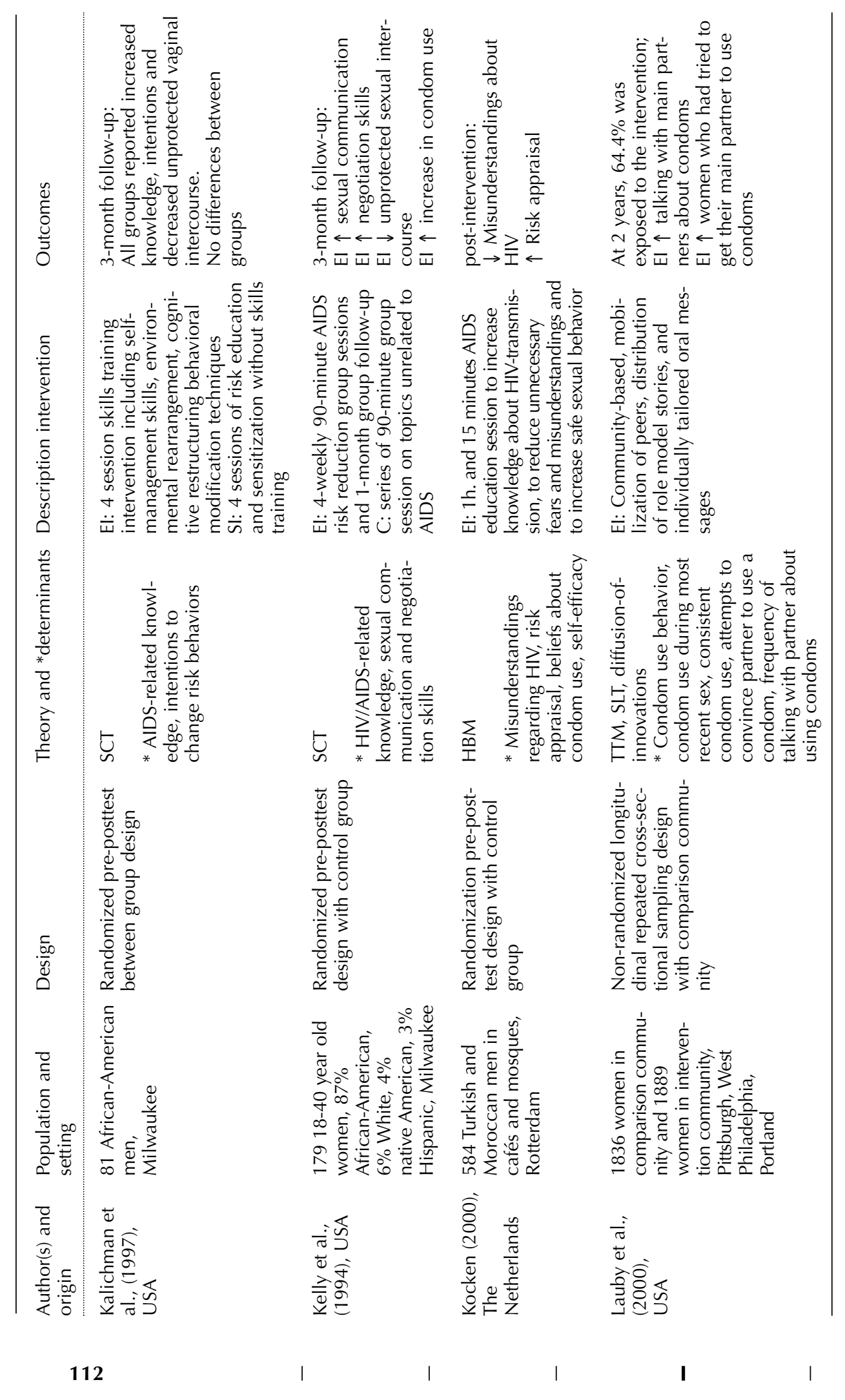




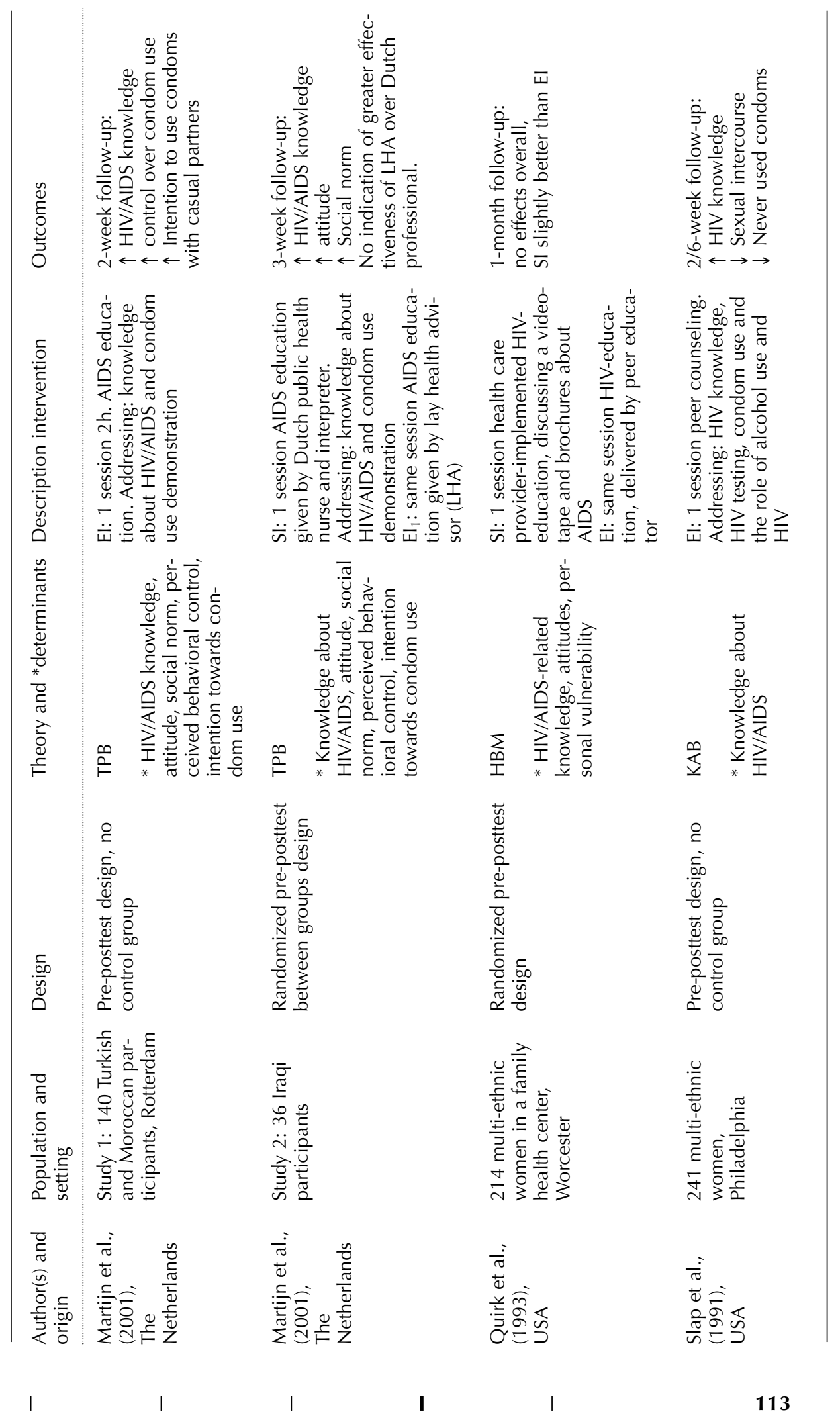




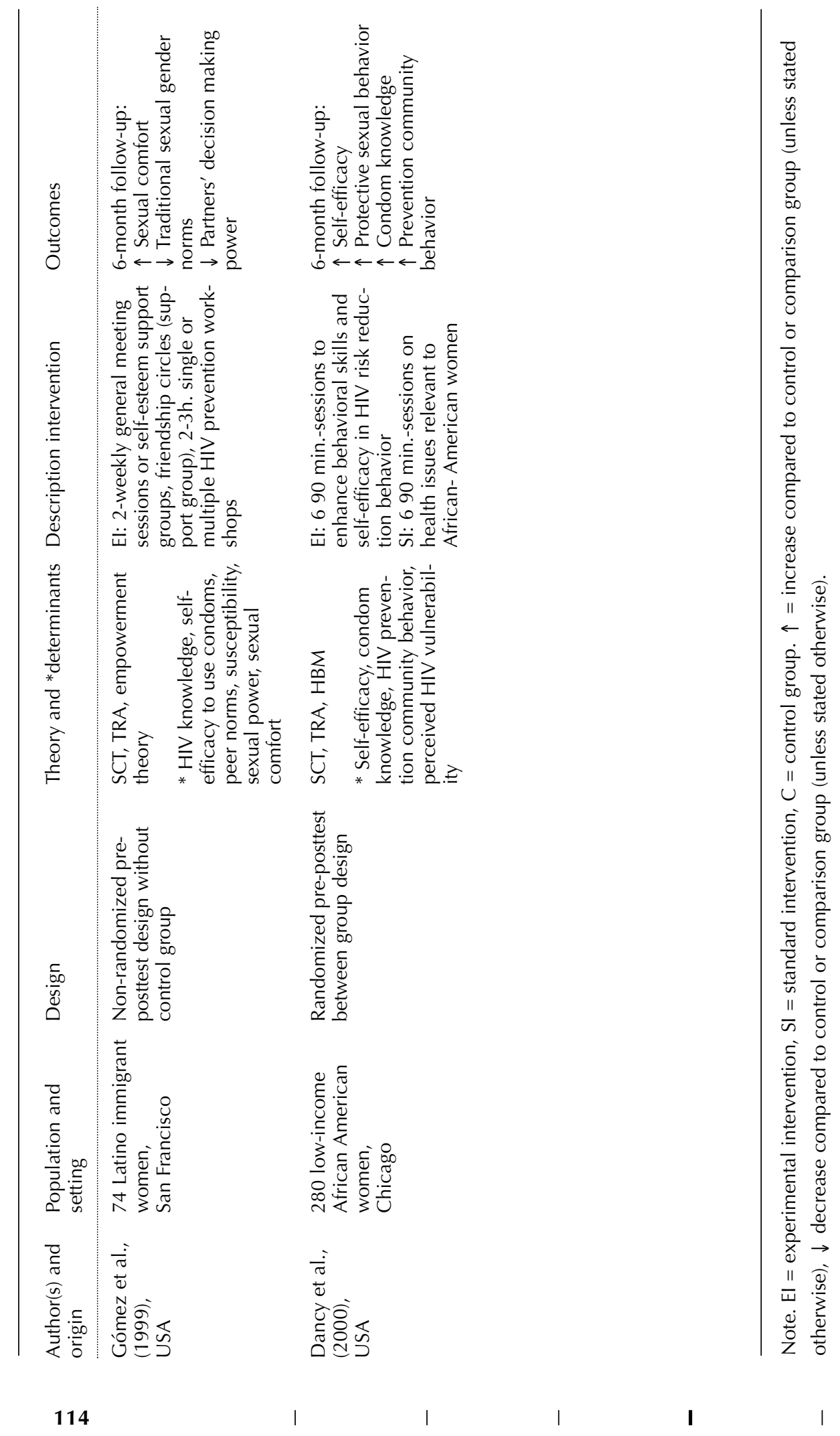




\section{Community-based interventions}

We only found one study that was based on community-level approach (Lauby et al., 2000). This study was based on multiple theories, including the TTM, SLT and diffusion-of-innovations. The intervention consisted of multiple activities throughout the community, including development and distribution of HIV prevention materials, the mobilization of a peer network, group discussions and individually tailored messages by outreach workers. The intervention reported has resulted in increased sexual communication efforts among the target group.

\section{Conclusion}

Most HIV/AIDS-preventive interventions aimed at minority populations that have proven to be effective used a behavioral skills training component. In general, SCT is identified as the theoretical model for intervention development, and several behavioral change techniques are combined to reduce sexual risk-taking behavior presented in multi-session programs. Studies investigating the effectiveness of community-level prevention interventions aimed at minority populations are in short supply. The results, however, show promise for reducing risk behaviors among minority populations.

\section{PeOPle WITH HIV AND AIDS}

Until recently, people with HIV and AIDS (PWHA) have seldom specifically been the target of prevention programs. However, King-Spooner (1999) argues that behavior change of PWHA has a disproportionately greater effect on the reduction of new infections. Kok (1999) concluded from a review that risk behaviors of PWHA are quite similar to those of other groups, but that the frequency of risk behaviors is lower.

\section{Determinants}

To some extent determinants found among PWHA seem to be similar as those are generally found among people without HIV/AIDS: younger, less educated, less coping, less (sexual) control, more use of alcohol and nitrate, low self-efficacy, low perceived support, and specifically: weak personal norms towards practicing unsafe sex and low responsibility towards the partner. Conflicting results have been found concerning the relation between disclosure and sexual behavior. Kok argues that most studies failed to include specific determinants that apply to PWHA, in particular the protection of others instead of oneself. In the literature, the risk of re-infection is still debated (Kok, 1999). Nevertheless, protecting oneself against re-infection with HIV or infection with another STD may also be relevant to PWHA. 


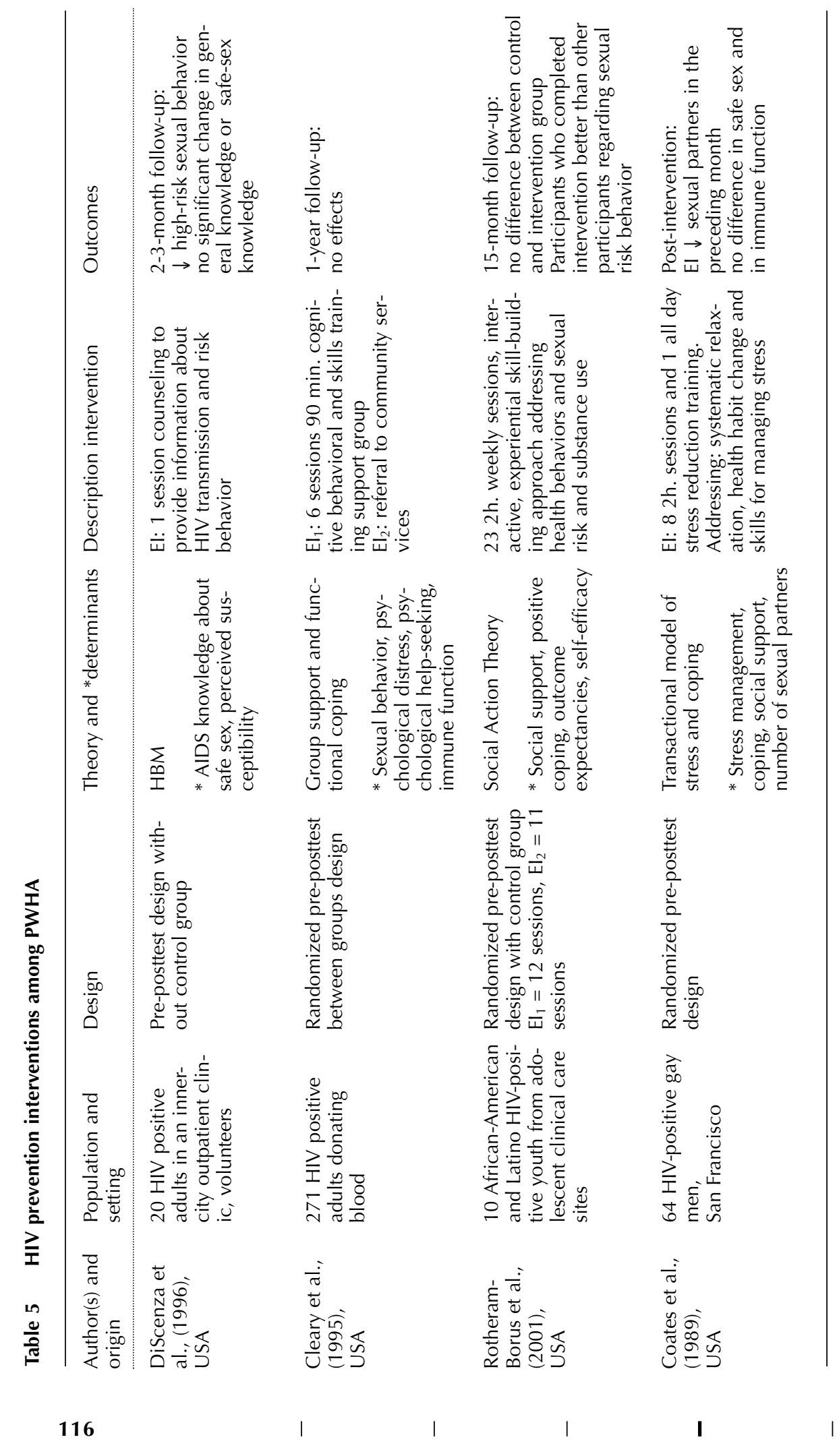



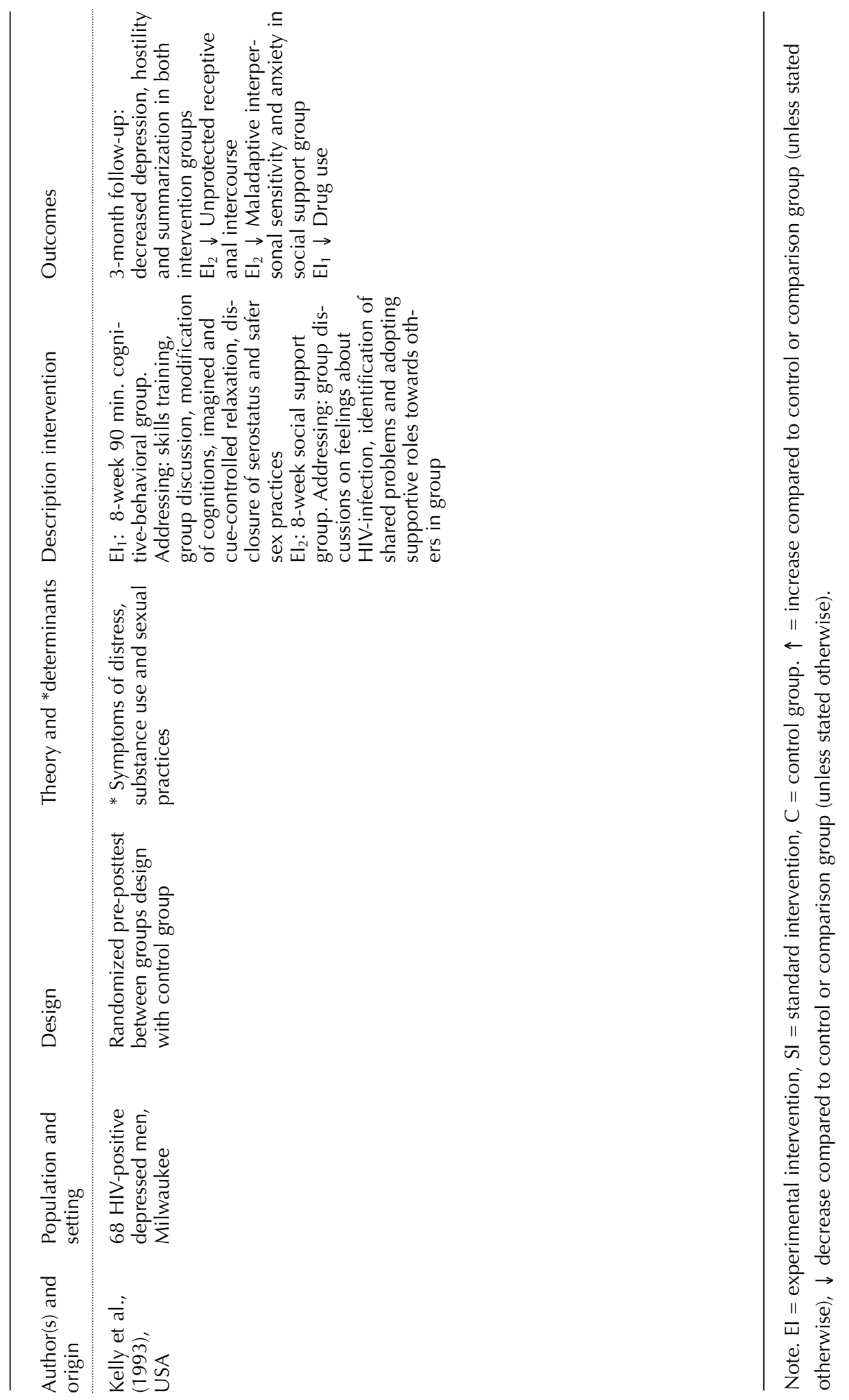

I

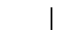

\section{I}

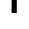




\section{Interventions}

We found six intervention studies specifically targeted at PWHA (see table 5). Earlier programs targeted PWHA for reduction of stress and depression and showed, as a side effect, a slight reduction of unsafe sex. Later programs included safer sex, e.g., condom use especially with HIV-negative partners, in a broader counseling approach and some of them showed small effects. Most of the reported studies did not identify a clear theoretical framework as part of intervention development and implementation, and some did not use a randomized study design.

\section{Individual interventions}

One study has examined the effects of preventive counseling (DiScenza et al., 1996). Following the intervention, less high-risk sexual behavior was reported. Although this study suggests that a counseling intervention might be a useful tool in changing the high-risk sexual behavior of PWHA, there are several methodological limitations.

\section{Small-group interventions}

Several studies have investigated the effects of small-group interventions on sexual behavior among PWHA (Cleary et al., 1995; Coates et al., 1989; Kelly et al., 1993; Rotheram-Borus et al., 2001). For example, Rotheram-Borus et al. (2001) evaluated an interactive skill-building approach, based on social support, positive coping, outcome expectations and self-efficacy. No main effect for condition was found, but when attenders alone were selected, the effect of the intervention was significant on sexual risk behavior, substance use, and medical contacts. Some of the other intervention studies have also partially relied on social support and positive coping. In general, however, they did not identify a clear theoretical framework as part of intervention development.

\section{Conclusion}

HIV/AIDS-preventive interventions aimed at PWHA are relatively rare. Most programs could be identified as small-group interventions addressing behavioral skills or 'quality of life' by reducing stress or increasing social support. Although only few interventions have been reported that address 'quality of life', they seem to be quite promising. In general, the majority of studies reported small or no effects. Most studies failed to clearly report the use of theory in intervention development, which might explain the occasionally minor effects of the programs. 


\section{DISCUSSION}

The present review shows that important psychosocial determinants for the target groups discussed are generally similar to those for target groups discussed in previous reviews (e.g., Hospers \& Kok, 1995; Sheeran et al., 1999). This does not necessarily mean that these determinants are based on the same salient beliefs and are equally important for all groups. Not only situations and cultures differ for populations, but also the product of different psychosocial determinants may, and in fact do, differ (see also Fishbein, 2000). The variability of attitudes, norms, values and behaviors, within and across target populations and geographic areas, calls for the careful design and implementation of HIV prevention programs tailored to the relevant behaviors of specific (sub-)populations (Gwede \& McDermott, 1992).

Regardless of the type of population, some interventions seem particularly successful in the battle against HIV/AIDS. We found many interventions that were based on small-group skill-building techniques, and most of these have shown to be effective in reducing sexual risk behavior. Community-level interventions also seem to be effective, but are reported less often, probably due to the laborious way of both implementing and evaluating the intervention. Furthermore, several studies show the importance of collaboration with the community. This is in line with findings for other target groups, such as MSM (Kegeles et al., 1996; Kelly et al., 1992) or schoolbased programs (e.g., Klepp et al., 1994; Schaalma et al., 1996).

In contrast to most school-based HIV prevention programs, the majority of the studies in this review or in HIV prevention programs aimed at MSM, do not address the issue of stigma. However, different issues related to HIV stigma seem to affect the effectiveness of psychosocial HIV prevention programs in the populations in question. In some populations (e.g., minority populations and people in sub-Saharan Africa), talking about sex is taboo and the stigma surrounding HIV is huge. In these populations, fear of stigmatization also seems to be related to delays in HIV testing and non-disclosure of one's HIV-positive status to others, resulting in the further spread of HIV. Thus, the issue of HIV stigma must be tackled in these target populations in order to make HIV prevention activities more useful.

PWHA may already experience stigmatizing reactions from others, and programs aimed at PWHA should be prevented from fostering negative reactions to PWHA in the general population. In addition, the intervention itself should be prevented from being experienced as stigmatizing by PWHA. The stigmatizing consequences of prevention programs will probably be limited if the programs are developed in close cooperation with PWHA.

\section{Study designs}

The research designs of a number of evaluation studies still show shortcomings, which make assessments about their effects difficult. However, recent studies are 
more often based on a pre-post-test design, including at least one control group. Several studies described show that this provides valuable information, because in a lot of cases positive behavioral changes in experimental groups do not seem to differ much from the behavioral changes in control groups.

Most interventions use safer sexual behavior or intentions to safer sexual behavior as outcome measures. Probably, this is not always the right choice of outcome measurement, as a result of which interventions might wrongly be seen as ineffective. Prochaska and colleagues (1997) describe several motivational stages of behavior change, ranging from precontemplation - the failure to recognize a problem or a need for change - to maintenance - long-term continuation of change. In the (pre)contemplation phases with regard to condom use, a change in behavior might be unrealistic. Can we, for instance, expect an actual change in behavior among youth living in developing countries who are unaware of the illness, the modes of transmission, and protection? In this case, attitude change seems a more appropriate aim. A similar finding is concerned with the difference between safe sex with casual sex partners and safe sex with steady partners. The majority of interventions do not distinguish between these different behaviors, although studies have shown most people are in different motivational stages with regard to safe sex with steady sexual partners and safe sex with casual sex partners. Interventions should address these differences, aim at different determinants, and might thus result in different programs and expected outcomes. Moreover, progression within stages of change as proposed in the TTM (Prochaska et al., 1997) might be more sensitive to changes and therefore be a better index for measuring program effects, than the sole focus on behavioral changes.

A major point that parallels these suggestions is the lack of analyzed determinants. The majority of the intervention studies fail to give information about the determinants targeted, why they were chosen, and the kind of changes observed following the intervention. In addition, the review has shown that effective studies were based on multiple theories, and incorporated determinants such as: increasing the ability to communicate condom use and actual condom use, personalizing risk avoidance as an accepted social norm, and support for sustaining risk reduction. Theories most often used in intervention development were a combination of HBM, TRA, SCT, or on theoretical frameworks such as TTM. The frequent use of SCT has also been found in interventions targeting youth and MSM. Most community-level interventions are based on SCT and Diffusion of Innovations theory.

We can divide the interventions into three categories: individual interventions, skill-building interventions, and community interventions.

\section{Individual-level interventions}

Individual interventions are mostly based upon individual counseling alone, or counseling with HIV testing. Higgins et al. (1991) and Weinhardt et al. (1999) have shown that these programs do not seem to be very effective as primary prevention strategies. On the basis of our review we agree with Weinhardt et al. that one reason for their ineffectiveness may be that most of these interventions lack a profound theoretical basis. For example, Kotranski et al. (1998) only target knowledge and sus- 
ceptibility, although an analysis of determinants has demonstrated that targeting those determinants is not enough to change behavior. Kamb et al. (1998) have shown that HIV counseling and testing can be effective if they are based on theory and systematically planned. In their study, short counseling interventions were conducted among STD clinic visitors. The counseling interventions were based upon personalized ('client-centered') risk reduction plans, and the interventions targeted several theoretical determinants underlying condom use.

\section{Small-group interventions}

Small-group interventions are generally quite effective. Most of these types of interventions are based on sound designs and are theoretically based. They usually focus on negotiation and problem-solving skills. A limitation of these interventions is that most of them targeted small groups of motivated individuals and that the evaluation period is rather small. Similar conclusions can be drawn with regard to HIV prevention interventions targeting youth, IDUs and MSM.

\section{Community-level interventions}

Community interventions have been shown to be effective and feasible. An important aspect of community interventions is their sustainability. With its AIDS Community Demonstration Project (ACDP), the CDC (1999) has shown that community-level interventions can be applied to diverse populations. This approach has also shown to be applicable to hard-to-reach populations such as IDUs. The ACDP is theory-based and culturally tailored. The interventions based upon HIV prevention endorsement messages, modeled and delivered in an outreach fashion by members of the social reference group, can reduce risk behavior in community populations. Many school-based community programs are based on similar methods and have also shown to be effective (Kirby \& DiClemente, 1994).

\section{Future HIV/AIDS programs}

\section{Use of multiple theories}

Intervention developers should not rely on one single theory. In order for interventions to be successful, they should encompass multiple theories to explain and change behavior. The link between explanatory theories of behavior and theories of behavior change is often unclear. Witte (1995) suggests an approach to this challenge of making this link: organizing the results of the determinant analysis in a list of relevant determinants, and then deciding which determinants need to be changed, which need to be reinforced, which need to be introduced, and which need to be taken into account.

\section{Planning interventions}

Future interventions should be planned more systematically and clearly state when and where theory and evidence were used as part of the intervention development. 
Intervention development models, such as Intervention Mapping (Bartholomew et al., 2001; Bartholomew et al., 1998), provide a program planner with suggestions about when and where to use information from the literature, theories and research. Interventions can be effective only if a clear needs assessment of the problem, the behavior at both individual and environmental levels, and the determinants of such behaviors is undertaken. Second, interventions should clearly state program objectives in terms of what people have to learn or what has to change in the environment to make sure that people will use condoms. Third, strategies used as part of the intervention program should fit with the underlying theoretical methods and the essential conditions in which these methods are successful. Fourth, programs should be pretested more carefully. Fifth, implementation should be anticipated by involving program users and the target population within the intervention development process to enhance ownership and ensure feasibility of an approach. This should be done as early as possible in the development process. Finally, the evaluation of interventions should be improved by measuring both the effect and the process.

\section{Sustained interventions}

Psychosocial interventions have shown to be effective. However, because these types of interventions often run for a short period of time, their effects decrease over time. People need to be reinforced consistently in order to maintain a low HIV risk behavior. Examples are harm reduction programs developed for IDUs (Cross et al., 1998), and the community-level interventions previously discussed in this review. Future programs should therefore be implemented more widely and be continued when their effectiveness has been proven.

\section{CONCLUSION}

During the last ten years, better-planned theory-based interventions have been developed compared to the first decade of the AIDS pandemic. Knowledge of effective programs has been used to create new interventions for new populations, or to foster new behaviors within populations. Future interventions should build on the progress made. Intervention evaluation studies should provide further insight both into the impact of interventions and into program development, assessing the needs, theory, process and efficiency of the program (Rossi et al., 1999). 
SECTION 4.2

MATCHING METHODS AND STRATEGIES TO MATRICES - STEP 2 


\section{INTERVENTION MAPPING STEP 2 TheOretical Methods AND PraCtiCAl Strategies}

In Chapter 2 we created the matrices of proximal program objectives. These matrices provide the foundation for the current chapter. In this chapter we describe the entire process of Intervention Mapping (IM) Step 2. In IM-Step 2 we link the proximal program objectives to theoretical methods and practical strategies. The tasks followed were: brainstorming of theoretical methods; specifying important methods and refer to sources - literature and theories - from which the methods have been derived; identifying the conditions under which such methods have been shown to be effective; and finally, translating the methods into practical applications - strategies which should match with the proximal program objectives specified in Step 1.

\section{Theoretical methods}

The next goal is to link the desired learning and change objectives to theoretical methods in order to change the determinants specified in Step 1. First, we reviewed the literature on safe-sex education interventions and other HIV prevention interventions that had targeted drug users (e.g., Booth \& Watters, 1994; Choi \& Coates, 1994; Gibson et al., 1998; Van Empelen, Kok et al., 2001) and theories about behavior change. The review suggested that an AIDS prevention program based on Diffusion of Innovations (Rogers, 1983) and Social Cognitive Theory (Bandura, 1986) is potentially effective in changing unsafe sexual behavior and norms among drug users, particularly in the context of casual sex partners. Social Cognitive Theory covers the behavioral determinants that we selected in Step 1 of Intervention Mapping, i.e. behavior change (condom use) is achieved when an individual:

$\mathrm{a}$ is aware of the personal risks of HIV/AIDS and of how to avoid HIV transmission (knowledge);

b emphasizes the benefits and fulfills the appropriate expectations about the costs (outcome expectations, attitude change);

c perceives and gets positive social influence of others (norms, support); and

d has expectations about the ability to practice the risk reduction behavior (selfefficacy).

The basic method suggested in Social Cognitive Theory (SCT) is that of modeling. SCT explicates that individuals can learn by observing others. People can be instructed and persuaded through modeling. Modeling is effective only if the following criteria are met:

a an individual pays attention to and perceives the relevant aspects of the modeled activity;

b an individual remembers the modeled information; 
c an individual has the skills for translating the modeled information into adequate action;

d an individual has an expectation about the positive reinforcement of the modeled activity;

e The model is similar to the intended population group, representing a copy rather than a mastery model and is reinforced for the behavior.

According to the diffusion theory, new products, technologies and behaviors spread across a population through dynamic change processes. New behaviors are more likely to be adopted by others when they are relatively advantageous, compatible with prevailing social norms, simple to use, and when they yield observable, tangible outcomes (Kalichman, 1998). The diffusion theory can be used to disseminate safer-sex messages and messages to change prevailing norms. Methods discussed within Social Cognitive Theory and diffusions of innovations theory are related to the mobilization of social networks, modeling, and skills training.

In addition to the general theories specified above, the literature review suggested other, more specific theories of change methods. Risk perception theories and information theories provide methods to increase the understanding of HIV/AIDS risk (e.g., Fabrigar, Priester, Petty, \& Wegener, 1998; Fisher \& Fisher, 1992; Weinstein, 1988). Attitude theories provide information about persuading individuals (e.g., Petty \& Cacioppo, 1986). Other studies discuss a number of methods to change social norms (e.g., Bandura, 1986; Rogers, 1983), or theories to enhance self-efficacy (e.g., Latham \& Locke, 1991; Weiner, 1986).

Next, we will describe several methods that we propose for changing the determinants specified, which are needed to accomplish the proximal program objectives. We have specified the methods selected per determinant. For each method we also identified the conditions - parameters - under which a method is expected to be effective. It is essential that these parameters be taken into account when translating the theoretical methods into practical strategies (see also tables 1a and 1b).

\section{Awareness}

Increased understanding of HIV risk, HIV-preventive behaviors and personal vulnerability to HIV and STDs is a prerequisite of behavior change. Such understanding is believed to increase one's readiness to change, although it is not assumed to lead to direct behavior change in itself (Fisher \& Fisher, 1992). Raising awareness is particularly important in the context of steady relationships. The best method to increase one's understanding is by providing basic information about HIV risk and HIV-preventive behaviors. The needs assessment showed that the perception of drug users regarding HIV vulnerability is related to risky drug use behavior rather than safe sexual behavior. Drug users feel less vulnerable when it comes to their sexual risk behavior, and even more invulnerable with steady sex partners. Risk perception theory suggests that perceived invulnerability may be due to an underestimation of 
Table 1a Methods - Steady sex partners

\begin{tabular}{|c|c|c|c|}
\hline Determinants & Methods & Theories & Parameters \\
\hline \multirow[t]{2}{*}{ Awareness } & Threat personalization & $\begin{array}{l}\text { Risk Perception; } \\
\text { Unrealistic Optimism }\end{array}$ & $\begin{array}{l}\text { Individual; undeniable; } \\
\text { congruent with actual } \\
\text { risk; cumulative; pre- } \\
\text { sented with qualitative } \\
\text { and quantitative exam- } \\
\text { ples }\end{array}$ \\
\hline & Framing & $\begin{array}{l}\text { Judgment under } \\
\text { Uncertainty }\end{array}$ & $\begin{array}{l}\text { Qualitative; loss frame } \\
\text { (risk behavior); gain } \\
\text { frame (preventive behav- } \\
\text { ior) }\end{array}$ \\
\hline \multirow{6}{*}{$\begin{array}{l}\text { Attitude change } \\
\text { (+Personal norm) }\end{array}$} & Active learning & ELM; HSM; SCT & Relevant; comprehension \\
\hline & Active participation & $\begin{array}{l}\text { Cognitive Dissonance; } \\
\text { Self-Perception Theory }\end{array}$ & $\begin{array}{l}\text { Voluntarily; not justifi- } \\
\text { able by rewards }\end{array}$ \\
\hline & Persuasion & ELM; HSM & $\begin{array}{l}\text { Adapting to existing } \\
\text { beliefs }\end{array}$ \\
\hline & & PCM & $\begin{array}{l}\text { Source; message; chan- } \\
\text { nel; receiver }\end{array}$ \\
\hline & Anticipated regret & Regret Theory & Must stimulate imaginary \\
\hline & Empathy & & Must stimulate imaginary \\
\hline \multirow[t]{2}{*}{ Self-efficacy } & Goal setting & Goal Setting Theory & $\begin{array}{l}\text { Commitment; feasible; } \\
\text { challenging goals; feed- } \\
\text { back; facilities }\end{array}$ \\
\hline & $\begin{array}{l}\text { Communication } \\
\text { skills building }\end{array}$ & SCT & $\begin{array}{l}\text { Attention; remem- } \\
\text { brance; skills }\end{array}$ \\
\hline
\end{tabular}


Table 1b Methods - Casual sex partners

\begin{tabular}{|c|c|c|c|}
\hline Determinants & Methods & Theories & Parameters \\
\hline \multirow[t]{3}{*}{ Awareness } & Threat personalization & $\begin{array}{l}\text { Risk Perception; } \\
\text { Unrealistic Optimism }\end{array}$ & $\begin{array}{l}\text { Individual; undeniable; } \\
\text { congruent with actual } \\
\text { risk; cumulative; pre- } \\
\text { sented both with quali- } \\
\text { tative and quantitative } \\
\text { examples }\end{array}$ \\
\hline & Active learning & ELM; SCT & Relevant; comprehension \\
\hline & Framing & $\begin{array}{l}\text { Judgment under } \\
\text { Uncertainty }\end{array}$ & $\begin{array}{l}\text { Qualitative; gain frame } \\
\text { (preventive behavior) }\end{array}$ \\
\hline \multirow{7}{*}{$\begin{array}{l}\text { Attitude change } \\
\text { (+personal norm) }\end{array}$} & Active learning & ELM; SCT & Relevant; comprehension \\
\hline & Active participation & $\begin{array}{l}\text { Cognitive Dissonance } \\
\text { Self-Perception Theory }\end{array}$ & $\begin{array}{l}\text { Voluntarily; not justifi- } \\
\text { able by rewards }\end{array}$ \\
\hline & Persuasion & ELM; HSM & $\begin{array}{l}\text { Adapting to existing } \\
\text { beliefs }\end{array}$ \\
\hline & & PCM & $\begin{array}{l}\text { Source message; chan- } \\
\text { nel; receiver }\end{array}$ \\
\hline & Modeling & SCT & $\begin{array}{l}\text { Coping model; rein- } \\
\text { forcement }\end{array}$ \\
\hline & Anticipated regret & Regret Theory & Must stimulate imaginary \\
\hline & Empathy & & Must stimulate imaginary \\
\hline \multirow[t]{3}{*}{ Social influence } & $\begin{array}{l}\text { Modeling and vica- } \\
\text { rious reinforcement }\end{array}$ & SCT & $\begin{array}{l}\text { Attention; remembrance; } \\
\text { skills; coping model; } \\
\text { positive reinforcement }\end{array}$ \\
\hline & $\begin{array}{l}\text { Mobilizing social } \\
\text { networks }\end{array}$ & $\begin{array}{l}\text { Diffusion of } \\
\text { Innovations }\end{array}$ & Credible; realistic \\
\hline & $\begin{array}{l}\text { Interpersonal skill } \\
\text { building }\end{array}$ & SCT & Favorable; capable \\
\hline Self-efficacy & Modeling & SCT & $\begin{array}{l}\text { Attention; remembrance; } \\
\text { skills }\end{array}$ \\
\hline
\end{tabular}


one's own HIV risk, referred to as unrealistic optimism (Weinstein, 1980). Factors influencing unrealistic optimism include an underestimation of what others do to protect themselves, and picturing stereotypes of people that run high risks. Methods that can be used to change (the lack of) awareness can be derived from behavioral decision-making theories. Holtgrave, Tinsley and Kay (1995) point out four constructs that may be used to personalize risk: a) Information about risk should be presented as individual and other risks that have comparable characteristics (involuntariness, high level of dread, lack of control, low level of knowledge, high catastrophic potential, high level of novelty and low level of equity of a particular risk) may also promote increased perceived risk; b) emphasize the cumulative risk of all 'single risk' situations; c) provide both qualitative and quantative expressions of risk; d) framing effects could also be used to address risk perceptions (Tversky \& Kahneman, 1981). Framing effects refer to the phenomenon of individuals responding differently to an equivalent outcome when the reference point is shifted due to a different wording of the outcome (e.g., a 5\% condom failure rate versus a $95 \%$ success rate). Framing condom use in terms of success may increase an individual's belief about the effectiveness of condoms as a protection against HIV/STD.

\section{Attitude change}

Theories of attitude formation and change, such as the Elaboration Likelihood Model (ELM, Petty \& Cacioppo, 1986), discuss the use of persuasive messages to change attitudes. ELM supposes two routes by which people process information, a peripheral route and a central route of information processing. Both routes, the peripheral route - in which individuals are not very motivated to or are unable to process the message - and the central route - in which people are both motivated and capable are important in persuading people. ELM predicts that high-quality arguments are effective only if processed via the central route, but that attitude change through the central route is more persistent, more resistant to counter arguments, and therefore more predictive of behavior. Active learning and active participation are useful methods to enhance elaboration of the message and consequently comprehension (Petty \& Cacioppo, 1986). Moreover, Self-Perception Theory (Bem, 1967) and the Theory of Cognitive Dissonance (Festinger, 1957) assume that individuals who publicly make a statement for a cause are more likely to adapt their attitudes consistent with that public statement. Janis (1959) labels this process as biased scanning, and explains this process by the fact that these people may be motivated to think about arguments in favor of the statement and suppress opposing arguments. In terms of active learning and active participation one could opt for the recruitment of drug users as advocates of the condom use message, which might be beneficial to the persuasive effect on the recruits themselves. Furthermore, the prevention message should be made relevant by adapting the message to existing beliefs, by reinforcing existing positive beliefs, by changing negative beliefs, or by introducing new information (Witte, 1995). 
As discussed in the former paragraph information may be processed via a central and a peripheral route. The peripheral route is also an important route as it can be used to promote central information processing. Drug users who might not perceive the content of the message as relevant can be attracted by the use of an attractive and likable source (Petty \& Cacioppo, 1986). Maibach \& Cotton (1995) state that modeling is a powerful method of changing beliefs, especially if the model's behavior resulted in a lower risk and other pleasant outcomes.

Finally, regret theories (Bell, 1982; Loomes \& Sugden, 1982) suggest that people's choices between options are dependent on the expected regret associated with these options. This suggests that linking negative affective consequences with unsafe sexual behavior and linking positive affective consequences with condom use could change attitudes (see also Richard, Van der Pligt \& De Vries, 1995, 1996). In line with this theory, we found in a study among drug users that those who linked more negative affect with unsafe sexual behavior were more willing to plan condom use, and had a more positive attitude regarding condom use (Van Empelen, Kok et al., 2001).

\section{Social influence}

The Diffusion of Innovations theory (Rogers, 1983) predicts that an innovation is best accepted and has a greater impact and sustaining power if it is promoted by others who are similar (realistic) to them and whom they respect (credibility). A method to increase an individual's acceptance of the innovation (condom use) is role modeling. Role modeling is the use of models comparable to the target group that can perform certain behavior, which can be observed by others. Essential conditions that have to be met for modeling to be effective have been discussed elsewhere. Because promotion of condoms with steady sex partners is unlikely to be supported by drug users, this method is less likely to be effective within that context. However, the majority of drug users support condom use with casual sex partners, and therefore role modeling appears to be feasible and effective within that context.

Another method based on the Diffusion of Innovations theory is the delivery of information and materials by mobilizing social networks, i.e., the drug-using community. An essential condition for this method is the existence of such a network. Preexisting channels of communication and influence in social networks in the drug-using community have to be identified and exploited to diffuse information and materials. Furthermore, community health workers can be used as change agents to diffuse information and materials within the drug-using community.

Social normative changes appear to be a necessary component with regard to steady sexual relationships. However, all of the methods addressing this issue require the existence of a positive norm as a necessary component. Drug users clearly do not favor condom use with steady partners. The qualitative study has shown that partners of drug users are not really in favor of condom use either (Van Empelen et al., 2000). We have no knowledge, however, about norms of non-drug- 
using partners regarding condom use. The most effective approach may be to address personal norms regarding condom use to enhance responsibility and to deal with difficulties to discuss the use of condoms within steady relationships. Personal normative beliefs could be addressed by means of anticipated affect (Richard, Van der Pligt, \& De Vries, 1995; Richard, van der Pligt, \& de Vries, 1996), in which case people are made aware of the negative consequences of certain behavior, e.g., regretting having had unprotected sex, and of the positive consequences of avoiding such negative events. Additionally, empathy with the partner could be created by making people vividly imagine how the other would feel after having been infected with HIV or an STD (Batson, Early, \& Salvarani, 1997).

Social Cognitive Theory (Bandura, 1986) assumes that interpersonal skills with regard to making arrangements about safe sex (mutual commitment) and resisting social pressure can be enhanced by observation of behavior and practice. Bandura (1986) suggests a combination of modeling and behavioral rehearsal to improve one's perceived capability to perform skills. Parameters required for modeling to be effective are, as stated, attention, remembrance, skills and reinforcement. Moreover, the models should be coping rather than mastery models, and the models should be reinforced for their behavior. Behavioral rehearsal (or guided practice) must include the division of skills into sub-skills, instruction, modeling, guided enactment and feedback in simple situations, guided enactment and feedback in complex situations, and reinforcement. Reinforcement can be vicarious in the sense that people observe a model to receive reinforcement, or it may be more like an internal (doing something right) or external incentive (receiving a reward).

\section{Self-efficacy enhancement}

Self-efficacy is based upon real skills and perceptions of those skills. As we described in the former section, Social Cognitive Theory (Bandura, 1986, 1994) suggests a combination of methods to increase knowledge and skills regarding condom use, i.e. training self-management skills and communication skills, modeling and behavioral rehearsal.

Peer modeling can be effective in enhancing self-efficacy with regard to condom use with casual sex partners (CDC, 1999), but seems to be less appropriate as a method in the context of steady sexual relationships because peer models should be credible, and the modeled behavior should be reinforcing.

Attribution Theory (Weiner, 1986) and Relapse Prevention Theory (Marlatt \& Gordon, 1985) are useful in the processes of reattribution and cognitive reframing for lapses. The Attribution Theory suggests that the self-efficacy of individuals depends on their perceived attributions about successes and failures. Pointing out successful experiences and restructuring failures can positively influence self-efficacy (Schilling, El Bassel, Hadden, \& Gilbert, 1995). For example, not using a condom on one single occasion should not be viewed as an inability to use condoms, but as a specific failure in effort, planning or negotiation, which can prepare 
an individual for successful safer sexual encounters in the future (Wight, Abraham, \& Scott, 1998).

Goal-setting theory (Locke \& Latham, 1990) assumes setting challenging, yet feasible goals, which can enhance self-efficacy. A necessary condition of goal setting is to take into account the difficulty of the task, the capabilities of the target population, and the necessity of feedback. In the case of our population, goal setting can be used to enhance the communication about condoms and HIV/AIDS within steady relationships as well as the anticipation of condom availability.

\section{Translating methods into strategies}

A brainstorm about possible strategies has led to the conclusion that most methods can easily be captured within a few strategies. We will separately discuss the strategies for behavioral change of condom use with steady sex partners and those concerning condom use within casual sexual relationships.

\section{Condom use with steady sex partners}

In the previous section we concluded that condom use behavior regarding steady sex partners requires another approach than condom use behavior with casual sex partners. Skill training has been shown to be effective in changing risk behavior among drug users (e.g., El-Bassel et al., 1995). However, skills training interventions posit that people are motivated to change. Therefore we propose first a strategy of clientcentered individual counseling by motivational interviewing (Miller \& Rollnick, 1991) to target sexual practices within steady relationships. In a study among heroin injectors, Gibson et al. (1989) showed modest reductions in unprotected sex among couples. Williams et al. (2001) showed, in a study among injecting drug users and crack cocaine users, that a brief theory-based educational intervention -using a similar approach- can be effective in reducing sexual risk taking. Motivational interviewing has also been shown to be an effective strategy among drug users with regard to addiction problems (Gerber \& Basham, 1999; Miller, 1996).

Motivational interviewing recognizes that people have to be ready for change, and is most appropriate to operationalize the methods discussed for awareness raising and changing attitudes. Feedback and reinforcement are important for all elements of motivational interviewing. Empathy and reflective listening are used to establish a working relationship with the drug users, and to gain insight into existing beliefs regarding safe sex in steady relationships. Within this context drug users get nonjudgmental feedback on the potential risks of their behavior. HIV transmission by unprotected sex can be discussed to personalize risk, and is valuable in creating discomfort, feelings of guilt about drug users' own behavior and the danger they are inflicting on significant others.

Persuasion within motivational interviewing is addressed by discrepancy development, avoidance of argumentation, and finally rolling with resistance. Discrepancy development is basically the creation or amplification of differences between 
arguments offered by drug users, in order to show them the difference between personal goals and behavior and shift perceptions. Confrontation is used, but the focus is on the behavior rather than the client (argument avoidance). Rolling with resistance is an operationalization of reframing, where the counselor offers new perspectives on perceptions of the drug users and reinforces solutions, in the context of selfresponsibility. Finally, motivational interviewing addresses the method of goal setting, by empowering drug users to make choices about sexual risk behavior change, and to provide multiple alternative options to reach that goal. At this point drug users should be motivated for action. Booklets could be used to summarize the content discussed or a diary could be used to record sexual and drug use behavior, so that on the basis of this material feedback and reinforcement can be given.

Communication skills training can also be applied within the context of individual counseling (Kelly, 1995). Kelly states that it is important to instruct clients in these skill elements and to model or demonstrate examples of assertive versus nonassertive ways to handle risk pressure or negotiate condom use. After that, drug users have to rehearse the behavior and practice assertiveness in risky situations. Role-playing enactment can be used, in which the counselor can play the pushy partner, thus enabling his client to practice assertive responses.

Although there is much variation in communication style, several elements are recommended and taught to drug users to communicate safe sex: 1) Affirm positive feelings toward the partner; 2) Communicate that safer sex is now the accepted norm among people becoming sexually active with one another; 3 ) Stress the benefits of safer sex and avoid an accusatory tone; 4) State exactly what safer sex means; and 5) Seek partner concurrence. Here too, goals can be set and a diary can be kept to record safe sex communication (see table 2a).

\section{Condom use with casual sex partners}

We selected behavioral journalism and (peer) outreach, because we expect it to be an effective strategy that could cover all described methods (McAlister, 1995). Several studies among drug users have shown that behavioral journalism is an effective strategy of altering condom use behavior with casual sex partners (see for example Jamner, Wolitski, \& Corby, 1997; Rietmeijer et al., 1996). Behavioral journalism is an approach of media-delivered behavioral modeling (see also Bandura's dual-link model (1986, p.145)). The two elements of the behavioral journalism strategy include the use of printed role model stories based on authentic interviews of the drug-using population, and to use networks of the drug-using community to distribute those role model stories, if possible together with other HIV prevention materials (further information, condoms). The role model stories address several of the methods discussed, and fit in with the necessary parameters (Corby, Enguidanos, \& Kay, 1996). Parameters discussed were a) similarity to the target population; b) a coping rather than a mastery model; c) available skills of the target population, and; d) reward (positive reinforcement). The use of authentic interviews ensures that the content of the message matches the understanding level of other drug users and gives a realistic and credible picture of their own lives. Because drug users are able 
Table 2a Strategies - Steady sex partners

\begin{tabular}{lll}
\hline Determinants & Methods & Strategies \\
\hline Awareness & $\begin{array}{l}\text { Provide basic factual information } \\
\text { Personalize risk } \\
\text { Framing }\end{array}$ & $\begin{array}{l}\text { Motivational interviewing } \\
\text { Booklet; diaries }\end{array}$ \\
Attitude change & $\begin{array}{l}\text { Active processing of information } \\
\text { Active participation }\end{array}$ & Motivational interviewing \\
& $\begin{array}{l}\text { Modeling } \\
\text { Anticipated regret/Empathy }\end{array}$ & \\
Persuasion & Booklet; diaries \\
& Communication skills building & $\begin{array}{l}\text { Demonstrations; role plays with } \\
\text { feedback }\end{array}$ \\
& Goal setting & Motivational interviewing; diaries \\
\hline
\end{tabular}

Table 2b Strategies - Casual sex partners

\begin{tabular}{|c|c|c|}
\hline Determinant & Method & Strategy \\
\hline \multirow[t]{3}{*}{ Awareness } & Provide basic factual information & $\begin{array}{l}\text { HIV prevention material; role model } \\
\text { stories in print }\end{array}$ \\
\hline & Personalize risk & Role model stories in print \\
\hline & Framing & Role model stories in print \\
\hline \multirow[t]{5}{*}{ Attitude change } & Active processing of information & $\begin{array}{l}\text { Peer discussions; outreach work } \\
\text { discussions; quiz }\end{array}$ \\
\hline & Active participation & $\begin{array}{l}\text { Behavioral Journalism (peer distri- } \\
\text { bution of HIV materials; role model } \\
\text { stories; condoms) }\end{array}$ \\
\hline & Modeling & Role model stories in print \\
\hline & Anticipated regret/Empathy & Role model stories in print \\
\hline & Persuasion & Role model stories in print; discussion \\
\hline \multirow[t]{2}{*}{ Social influence } & Community mobilization & $\begin{array}{l}\text { Outreach; peer distributors; peer } \\
\text { recruitment }\end{array}$ \\
\hline & Modeling & Behavioral Journalism \\
\hline Self-efficacy & Modeling & Role model stories in print \\
\hline
\end{tabular}

। I 
to identify with the models, the message would be hard to deny. In practice, however, it is not all that easy. The authenticity of the model, for example, also poses a problem, as it is often difficult to find an authentic story that matches all the parameters. It seems to us that the methods discussed (see table $2 b$ ) fit in well within the context of a role model story. Role model stories could increase HIV awareness by providing drug users with basic HIV risk and prevention information, by personalizing their risk, and by framing the condom use message within a success frame to underline the efficacy of condoms and therefore make that option a more desirable one (see table $2 \mathrm{~b}$ ). In addition to the role model stories, basic knowledge could be given and active learning could be enhanced by the inclusion of a knowledge quiz.

Anticipated regret and persuasive arguments can also be incorporated into role model stories in order to change the attitude of drug users. Because of the use of authentic interviews, the role model stories will match existing beliefs about condoms and risk behavior. Active participation is addressed by letting drug users participate as distributors of the HIV-preventive materials. The processing of information could be enhanced by reinforcing discussions of role model stories with other peers, peer distributors and health community outreach workers. Social influence is addressed by means of the role model stories, in which similar drug users function as positive models, but also by the participation of drug users as distributors of HIVpreventive materials and condoms, increasing the acceptance of the (content of the) materials. Finally, self-efficacy is targeted within the role model stories, by addressing skills, especially communication and self-management skills. By means of vicarious reinforcement an individual learns which behavior is reinforced and which is not. Moreover an individual can learn new skills and behavior. Participation could be enhanced by social reinforcement or incentives for the distribution of the materials, and by recruiting new peers as distributors (see table $2 \mathrm{~b}$ ).

\section{CONCLUSION}

The strategies proposed to improve condom use with casual sex partners and steady sex partners, fit with the most important learning objectives that were stated in the matrices of proximal program objectives. Also, the proposed strategies fit with the methods suggested and underlying theoretical assumptions and conditions. The strategies discussed targeting condom use with casual and steady sex partners might be linked, within one intervention program, as the target population may partly be the same. We however decided to study the programs separately, and first start with the program aiming at casual sex partners. Our priority-setting was based on several reasons: 1) This program would reach a larger number of people; 2) The actual implementation of the program probably would be easier, as it asks for a smaller 
investment by the program users. The other program would need more preparation time and would meet less support in short-term; 3) A combined approach would make it impossible to study the separate contribution of each of the elements.

On the basis of these arguments we started first with the development of the program aiming the promotion of condom use with casual sex partners among drug users. 


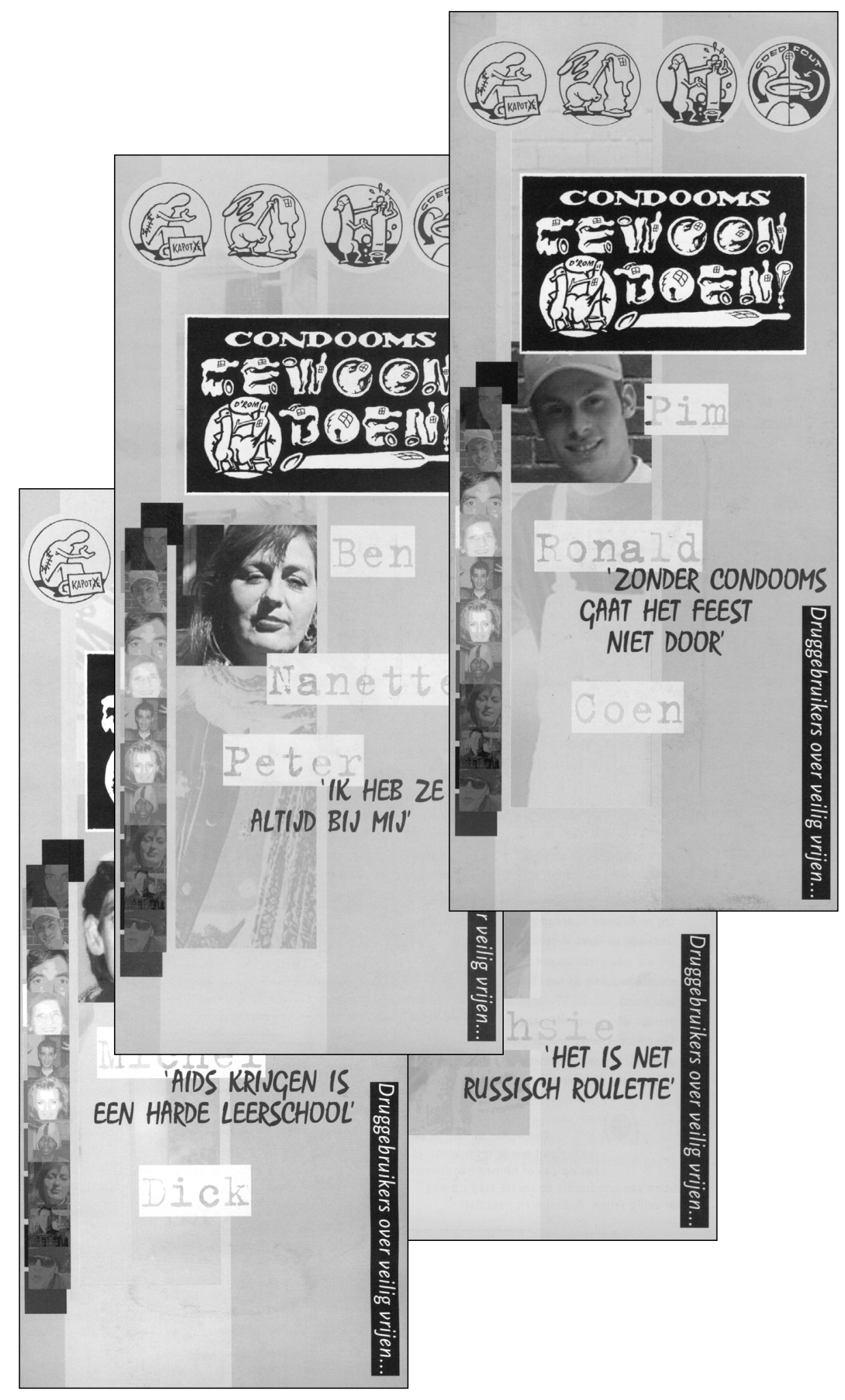




\section{SECTION 4.3}

AN AIDS RISK REDUCTION PROGRAM FOR DUTCH DRUG USERS:

AN INTERVENTION MAPPING APPROACH TO PROGRAM PLANNING

\section{Manuscript revised for publication as}

Van Empelen, P., Kok, G., Schaalma, H. P., \& Bartholomew, L. K. (2001). An AIDS risk reduction program targeting Dutch drug users: An Intervention Mapping approach to program planning. 


\section{BACKGROUND}

\section{Significance}

The prevalence of AIDS among IV drug users in the Netherlands is generally low in comparison to other countries in Europe and the US (UNAIDS/WHO, 2000). However, the prevalence level of HIV among drug users in some regions of the Netherlands is at a stable high level (e.g., Amsterdam, 26\%), whereas there has been an increase in other regions, such as South-Limburg (1994: 10\%, 1996: 12\% and 1998: 14\%) (Beuker, Berns, Van Ameijden, Houweling, \& Van de Laar, 2000). Furthermore, it has been shown that sexually transmitted infections (STIs), like Hepatitis B, are highly prevalent among (IV) drug users (e.g., Carsauw et al., 1997), which is a sign of risk behavior, moreover, people infected with other STIs might also increase their risk of contracting HIV (UNAIDS, 2000).

In the United States and Western Europe the relative proportion of heterosexually acquired AIDS cases is growing, and a considerable number of those cases can be attributed to sexual intercourse with IV drug users (e.g., CDC, 1998; Fennema, 1997). As it is common for IV drug users to have sex with non-IV drug users and non-drug users, HIV infections are likely to spread from (IV) drug users to the general population. Therefore targeting sexual HIV transmission is a very important prevention strategy to prevent HIV infections within and from the drug using community.

\section{Purpose}

This article presents the development of a theory- and evidence-based AIDS prevention program for Dutch drug users aimed at the promotion of condom use. The emphasis of this article is Intervention Mapping (Bartholomew, Parcel, \& Kok, 1998; Bartholomew, Parcel, Kok, \& Gottlieb, 2001). Intervention Mapping is a systematic process explicating a series of five steps for the development of health education programs based on theory, empirical evidence and additional qualitative and quantitative research (see figure 1). The steps are followed in an iterative way. And each step comprises several tasks, which result in a clear end product, providing the foundation for the next step. Intervention Mapping should enable health educators to make decisions on the basis of data and theory. This in turn would lead to theoryand data-based interventions, which have shown to be most effective (e.g., Mullen, Green, \& Persinger, 1985). Intervention Mapping is aimed at guiding the planning, development, implementation and evaluation of a program.

Prior to starting Intervention Mapping, it is essential to conduct a problem analysis to determine the need for a program and what the program should address. We based our analysis on the PRECEDE model (Green \& Kreuter, 1999). After the problem analysis, Step 1 looks not at risk or problem behavior, but at desired behaviors that will reduce the health problem. The product of Step 1 concerns the creation of 


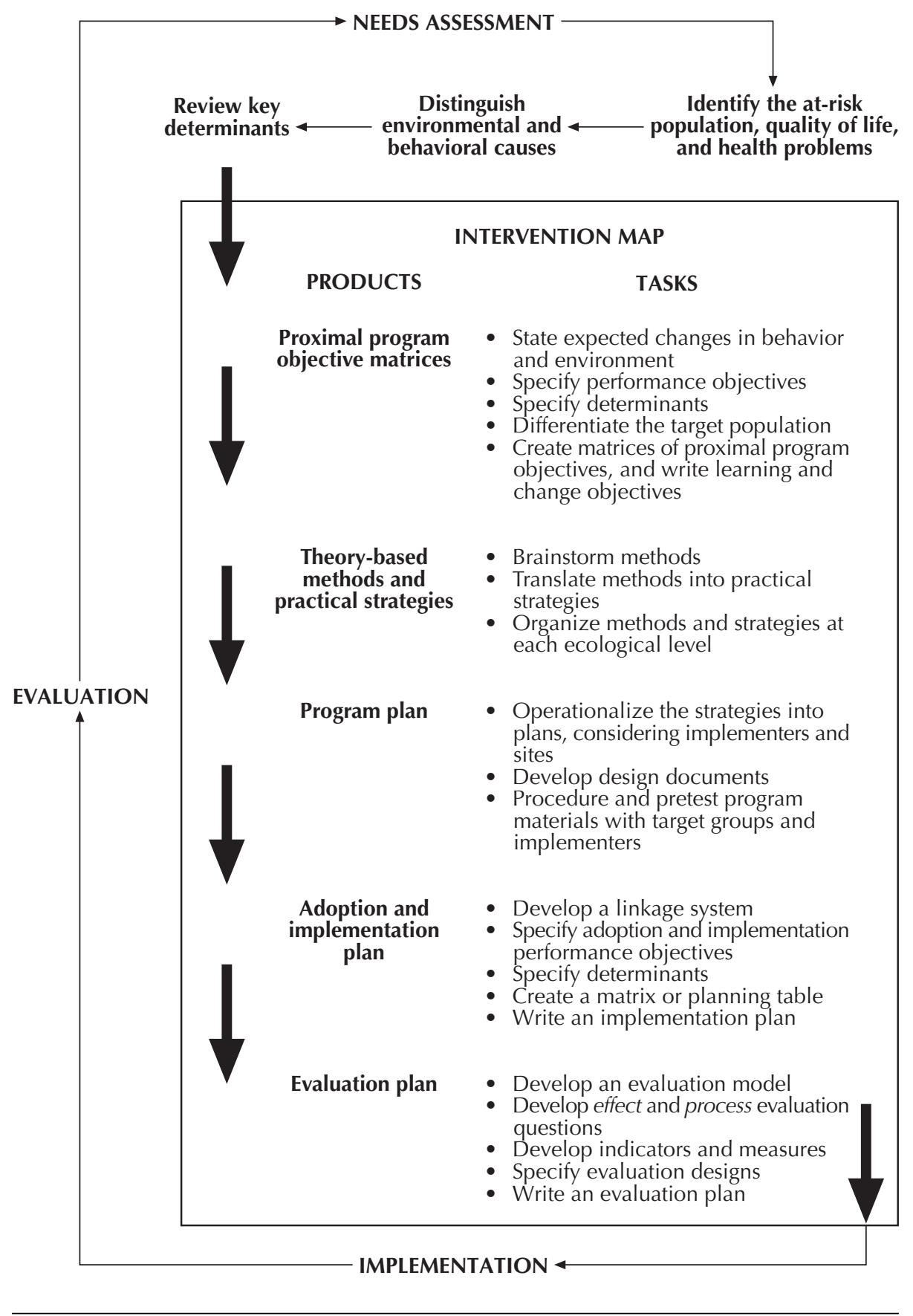

Figure 1 Intervention Mapping 
matrices of proximal program objectives. These objectives provide the foundation for who and what will change as a result of the intervention. The product of Intervention Mapping Step 2 is to link the proximal program objectives to theoretical methods and practical strategies. The product of Step 3 is a health education program.

Applying the first step of Intervention Mapping, we will describe how the program objectives were chosen. Second, we will describe the methods selected to address the program objectives and how these methods were translated into strategies fitting to the context of the behavior targeted and the intervention group. Following the third step of Intervention Mapping, we will describe how materials were developed, and a formative evaluation of the materials was carried out to ascertain appropriateness for the priority audience. In step four, we will describe the development of a linkage board to facilitate program adoption and implementation. And finally, we will discuss an evaluation plan.

\section{Problem ANAlysis: PreCeding INTERVENTION MAPPING}

Harm reduction programs have primarily focused on needle sharing (needle exchange programs) or drug-injecting frequency (methadone maintenance programs), thereby effectively reducing drug risk behavior, but have left sexual risk behavior unattended (Rhodes \& Quirk, 1995). The focus on needle risk behavior is understandable in itself in that it is the main source of HIV transmission in the drug-using community. However, when drug-risk behavior is effectively reduced, sexual transmission becomes a more important HIV transmission route (Blower, Hartel, Dowlatabadi, Andersan, \& May, 1991; Friedman et al., 1997). In the Netherlands, the sexual risk behavior of drug users has been addressed mainly through information campaigns, such as general safe-sex television commercials, or by providing information about HIV/AIDS and the risk of transmission (Van Haastrecht, 1995). This has led to little or no changes in sexual behavior over time, neither in terms of the reported number of sex partners, nor in terms of unprotected sex with steady or casual sex partners (e.g., Beuker et al., 2000; Des Jarlais et al., 1992; Myers et al., 1995; Van den Hoek, Van Haastrecht, \& Coutinho, 1992). The majority of drug users report being as sexually active as the general population, and a lot of those reporting intercourse do so without any form of protection (30-50\%) with casual sex partners (Beuker et al., 2000; Van Empelen, Kok, Jansen, \& Hoebe, 2001; Van Empelen, Schaalma, Kok, \& Jansen, 2001). The same applies to most drug users having a primary partner (79-96\%) (Berns, Van de Laar, Houweling, \& Wiessing, 2000; Van Empelen, Schaalma et al., 2001).

Although drug users have shown to be quite knowledgeable about HIV and the risk of transmission, they underestimate the risk of HIV transmission through unprotected sex both for themselves and for their partners (e.g., Van Empelen, Schaalma et 
al., 2001; Liebman, Mulia, Mcllvaine, 1992). Second, their attitude concerning safe sexual behavior - in particular condom use - is quite negative (e.g., Van Empelen, Schaalma et al., 2001). Third, drug users do not seem to feel responsible for preventing sexual HIV transmission to others (e.g., Van Empelen, Kok, et al., 2001). Fourth, a safe sex norm is not common (e.g., Rhodes, Stimson \& Quirk, 1996). Finally, it has appeared that drug users lack the practical, communication and self-management skills needed to use condoms (Van Empelen, Kok, Hoebe, \& Jansen, 2001; Van Empelen, Kok et al., 2001; Van Empelen, Schaalma et al., 2001). The use of alcohol and drugs may further increase HIV risk-taking in this population, although evidence about such a relation has only been established in non-drug abusing populations (e.g., Watkins, Metzger, Woody \& Mclellan, 1993). This is partly influenced by the fact that the use of drugs is part of everyday life.

\section{INTERVENTION MAPPING STEP 1 Matrices of Proximal Program Objectives}

\section{Priority population differentiation}

In Intervention Mapping, it is necessary to subdivide the priority population if either the behavior or the determinants of the behavior differ for subgroups. It is evident that sexual behavior with steady and casual sex partners differs, and we found that determinants of those behaviors also differ. Drug users reported a more negative attitude, less perceived HIV risk, absence of a perceived positive partner norm, and a higher self-efficacy concerning condom use with steady sex partners. Therefore we decided to differentiate the target behavior, implying a need to develop different programs for steady and casual sex partners. In this chapter we will only discuss the development of the program aimed at the promotion of condom use with casual sex partners (a brief description of the program aimed at the promotion of condom use with steady sex partners is given in section 4.2).

\section{Behavior change and performance objectives}

In order to identify program objectives we followed the tasks described in the first step of Intervention Mapping. After specifying performance objectives of the priority audience and the important and changeable determinants of the behavioral goal, we merged these into a matrix of program objectives.

So as to achieve our behavioral goal of consistent condom use, we subdivided it into the following preparatory behaviors (cf. Bagozzi, 1992) or performance objec- 
tives: deciding to use condoms, purchasing condoms, having condoms available, negotiating condom use, using condoms correctly and consistently, and maintaining condom use (e.g., Abraham, Sheeran, \& Johnston, 1998; Kelly, 1995). The identification of important and changeable determinants was based on studies among Dutch drug users (Paulussen, Kok, Knibbe, \& Cramer, 1990; Van Empelen, Kok et al., 2001; Van Empelen, Schaalma et al., 2001) as well as other available literature (e.g., Bowen \& Trotter, 1995; Corby, Jamner, \& Wolitski, 1996).

\section{Proposed determinants}

The next task is to specify personal or external determinants that are important to carry out the desired behavior. Personal determinants are inside the individual, for example, attitudes or perceived social norms. External determinants exist in the environment and include for example social support or pressure and barriers. The last task of Step 1 is to create the matrices by merging the performance objectives with the determinants. Knowledge is a prerequisite for any change, for example in risk perceptions or attitudes, but it is by no means sufficient. Yet knowledge is not indispensable, because a change in other determinants will also lead to a change in knowledge. Nevertheless, it is imperative that drug users have at least a basic understanding of HIV/AIDS and HIV transmission routes. Perceived vulnerability is another prerequisite for attitude change and seems to be particularly relevant to making the decision to use condoms. Furthermore, it is important to change existing negative attitudes or reinforce existing positive attitudes regarding condom use with casual sex partners in order to reach the performance objectives described. Several studies have shown that positive attitudes are related to intended condom use (Corby, Jamner, \& Wolitski, 1996; Magura, Shapiro, Siddiqi, \& Lipton, 1990; Van Empelen, Kok et al., 2001). In addition to attitudes, personal norms have been found to be important predictors of condom use with casual sex partners (Van Empelen, Kok et al., 2001). Personal norms might be of importance when deciding to use condoms and to have condoms available at all times. Perceived social norms are important with regard to condom use with casual sex partners, as they facilitates communication about condom use and the actual use of condoms (Corby, Jamner, \& Wolitski, 1996; Magura et al., 1990; Van Empelen, Kok et al., 2001; Van Empelen, Kok et al., 2001). Finally, perceived self-efficacy has proved to be one of the most important predictors of condom use with casual sex partners (Bowen, 1996; Bowen \& Trotter, 1995; Kowaleski, Longshore, \& Anglin, 1994; Paulussen et al., 1990; Van Empelen, Kok et al., 2001; Van Empelen, Schaalma et al., 2001). The studies provided specific information about the performance objectives specified. The self-efficacy expectations of drug users concerning their capability to use condoms, to negotiate condom use, and to have condoms available at all times proved to be most important. Both the skills and the perceived self-efficacy regarding skills appear to be important. Self-efficacy enhancement is important in the context of sex with casual partners, because drug users seem to be inclined to use condoms, but experience certain barriers. 


\section{Table 1 Proximal program objectives specified per determinant}

\begin{tabular}{|c|c|}
\hline Determinants & Proximal program objectives (Drug users....) \\
\hline Awareness & $\begin{array}{l}\text { - Explain the facts of AIDS/HIV } \\
\text { - Explain the difference between HIV and AIDS (incubation time) } \\
\text { - Explain the facts of STDs } \\
\text { - Explain how HIV/STDs are transmitted } \\
\text { - Understand they can transmit HIV/STD to other people } \\
\text { - Explain how to prevent HIV/STD transmission } \\
\text { - Understand that the chance of contracting HIV/STD increases with } \\
\text { the number of sexual partners } \\
\text { - Describe the risk of 'serial' monogamy } \\
\text { - Understand they have to fetch condoms in advance (at health centers, } \\
\text { buy them or borrow them) } \\
\text { - Discuss the need to have condoms available (at home, on the street, etc.) } \\
\text { - Explain how to initiate condom use } \\
\text { - Explain how to use condoms }\end{array}$ \\
\hline Attitude & $\begin{array}{l}\text { - Recognize the advantages of condom use as protection for HIV/STDs } \\
\text { - Recognize the advantages of condom use as protection for unwanted } \\
\text { pregnancy } \\
\text { - } \text { Recognize the advantages of condom use to avoid unwanted negative } \\
\text { feelings } \\
\text { - } \text { Anticipate the negative consequences of using condoms with casual } \\
\text { sex partners } \\
\text { - } \text { Recognize that the advantages of condom use outweigh the disadvan- } \\
\text { tages }\end{array}$ \\
\hline Social influence & $\begin{array}{l}\text { - Have an adequate perception of norms regarding safe sex with casual } \\
\text { sex partners } \\
\text { - Establish mutual commitment towards safe sex } \\
\text { - Feel responsible to protect others against HIV/STDs } \\
\text { - Adduce counter arguments towards unsafe sex } \\
\text { - Know important others who use condoms }\end{array}$ \\
\hline Self-efficacy/Skills & $\begin{array}{l}\text { - Express confidence in/demonstrate how to use condoms adequately } \\
\text { and consistently } \\
\text { - Express confidence in avoiding situations in which they feel less capa- } \\
\text { ble to use condoms adequately (e.g., withdrawal symptoms). } \\
\text { - Describe where they fetch condoms } \\
\text { - Demonstrate that they carry condoms on them } \\
\text { - Demonstrate how to discuss condom use } \\
\text { - Express confidence in resisting a proposal of unsafe sex by casual sex } \\
\text { partners }\end{array}$ \\
\hline
\end{tabular}


As stated previously, we defined the program objectives by merging the performance objectives and the identified determinants (see table 1). Program objectives are statements of what drug users should learn to change in order to achieve the desired health outcome - i.e., condom use - and provide the foundation for intervention development and for the evaluation plan.

\section{INTERVENTION MAPPING STEP 2 METHODS AND STRATEGIES FOR BEHAVIORAL CHANGE}

Upon identifying our program objectives we followed Step 2 of Intervention Mapping to develop a theory-based strategy map. Our first task was to search for possible theoretical methods of behavioral change fitting in with the objectives specified, ordered by determinants. We referred to literature and theories from which the methods have been derived, to identify the conditions under which such methods have shown to be effective. The next task was to translate these methods into practical strategies. In task 3, the strategies are matched with the program objectives to ensure full coverage of the most important program objectives. One method can lead to several strategies, but also several methods may be translated into one strategy. A method of modeling can be translated into several strategies, like role-playing, role models or demonstrations.

\section{Theoretical methods}

Our first approach to select theoretical methods was to review the literature related to the issue of interventions for condom use (Bartholomew et al., 2001; Kok, Schaalma, De Vries, Parcel, \& Paulussen, 1996): A review of literature about safe sex education interventions and other HIV prevention interventions that had targeted drug users (e.g., Booth \& Watters, 1994; Choi \& Coates, 1994; Gibson, McCusker, \& Chesney, 1998; Van Empelen, Kok et al., 2001). In addition, we reviewed theories about changing behavior in general, and changing behaviors by means of health education in particular in order to find theoretical methods, which is referred to as the general approach to theory selection. These reviews suggested that a social influence intervention to reduce HIV risk is potentially effective in changing unsafe sexual behavior among drug users. Such an intervention is based upon two major theoretical frameworks: Social Cognitive Theory (Bandura, 1997) and Diffusion of Innovations theory (Rogers, 1983). These frameworks cover the behavioral determinants selected in Step 1 of Intervention Mapping. In other words, behavior change is achieved if an individual: 
Table 2 Methods, theories and parameters specified per determinant

\begin{tabular}{|c|c|c|c|}
\hline Determinants & Methods & Theories & Parameters \\
\hline \multirow[t]{3}{*}{ Awareness } & Threat personalization & $\begin{array}{l}\text { Risk Perception; } \\
\text { Unrealistic Optimism }\end{array}$ & $\begin{array}{l}\text { Individual; undeniable; } \\
\text { congruent with actual } \\
\text { risk; cumulative; pre- } \\
\text { sented both with quali- } \\
\text { tative and quantitative } \\
\text { examples }\end{array}$ \\
\hline & Active learning & ELM; SCT & Relevant; comprehension \\
\hline & Framing & $\begin{array}{l}\text { Judgment under } \\
\text { Uncertainty }\end{array}$ & $\begin{array}{l}\text { Qualitative; gain frame } \\
\text { (preventive behavior) }\end{array}$ \\
\hline \multirow[t]{6}{*}{ Attitude change } & Active learning & ELM; SCT & Relevant; comprehension \\
\hline & Active participation & $\begin{array}{l}\text { Cognitive Dissonance } \\
\text { Self-Perception Theory }\end{array}$ & $\begin{array}{l}\text { Voluntarily; not justifi- } \\
\text { able by rewards }\end{array}$ \\
\hline & Persuasion & ELM; HSM & $\begin{array}{l}\text { Adapting to existing } \\
\text { beliefs }\end{array}$ \\
\hline & & PCM & $\begin{array}{l}\text { Source message; chan- } \\
\text { nel; receiver }\end{array}$ \\
\hline & Modeling & SCT & $\begin{array}{l}\text { Coping model; rein- } \\
\text { forcement }\end{array}$ \\
\hline & Anticipated regret & Regret Theory & Must stimulate imaginary \\
\hline \multirow[t]{3}{*}{ Social influence } & $\begin{array}{l}\text { Modeling and vica- } \\
\text { rious reinforcement }\end{array}$ & SCT & $\begin{array}{l}\text { Attention; remembrance; } \\
\text { skills; coping model; } \\
\text { positive reinforcement }\end{array}$ \\
\hline & $\begin{array}{l}\text { Mobilizing peer } \\
\text { influence }\end{array}$ & $\begin{array}{l}\text { Diffusion of } \\
\text { Innovations }\end{array}$ & Credible; realistic \\
\hline & $\begin{array}{l}\text { Interpersonal skill } \\
\text { building }\end{array}$ & SCT & Favorable; capable \\
\hline Self-efficacy & Modeling & SCT & $\begin{array}{l}\text { Attention; remembrance; } \\
\text { skills }\end{array}$ \\
\hline
\end{tabular}

Note. ELM = Elaboration Likelihood Model, SCT = Social Cognitive Theory, PCM = Persuasion

Communication Model, HSM = Heuristic Systematic Model 
a Has an understanding of the personal risks of HIV/AIDS and of how to avoid HIV transmission (awareness);

b Acknowledges the benefits and has the appropriate expectations about the costs (outcome expectations, attitude change);

c Percieves or gets support from others (norms, support);

d Expects to be able to practice the risk reduction behavior (self-efficacy; behavioral capability).

Social Cognitive Theory and the Diffusion of Innovations theory describe several methods to change determinants of behavior: reinforcement, vicarious learning (modeling) and persuasion. The basic method, however, is social modeling, a method based on the assumption that people learn from credible and trustworthy others, whom they observe and imitate by following a similar (but not necessarily identical) behavior. Moreover, behavior is more likely to be adopted by others when it is relatively advantageous. By means of modeling, people can be instructed and persuaded.

Every method has conditions under which it has shown to be effective. These conditions are referred to as parameters. Theories indicate which parameters have to be met. For the successful translation of methods into strategies it is essential to keep the parameters in mind. Modeling, for example, can be effective only if the role model is: a) similar to the priority population; b) a coping rather than a mastery model, and; c) is reinforced for the modeled behavior. The modeled behavior can be effective only if it: a) fits the available skills of the priority population; and b) is rewarding (positive reinforcement) (Bandura, 1986).

In addition to our review of existing interventions and general theories, we used a concept-related approach - the selection of concept-specific theories - to obtain insight into methods and parameters to increase awareness and change attitudes, social influence and self-efficacy. An overview of these methods, theories and parameters is given in table 2 .

\section{Translating methods into practical strategies}

Our next aim was to translate the methods into practical strategies appropriate for the priority audience and the program users. Intervention Mapping does not necessarily lead to new strategies, yet it ensures that the content of strategies is theoretically sound and linked to goals.

We selected behavioral journalism as the main strategy, as it was expected to be effective in covering all methods described (McAlister, 1995). Several studies among drug users have shown that behavioral journalism is an effective strategy in altering condom use behavior with casual sex partners (see, for example, Jamner, Wolitski, \& Corby, 1997; Rietmeijer et al., 1996). Behavioral journalism is an approach of media-delivered behavioral modeling (see also Bandura's dual-link model (1986, p.145)). The behavioral journalism strategy consists of two elements. First, the use of 
printed role model stories based on authentic interviews of the drug-using population, and second, the use networks of the drug-using community to distribute these role model stories, preferably together with other HIV prevention materials (further information and condoms). The role model stories address several of the methods discussed, and fit in with the necessary parameters (Corby, Enguidanos, \& Kay, 1996). Parameters discussed included a) similarity to the priority population, b) a coping rather than a mastery model, c) available skills of the priority population, and d) rewards/incentives (positive reinforcement). The use of authentic interviews ensures that the content of the message is appropriate to the understanding level of other drug users and gives a realistic and credible picture of their own lives. Because drug users are able to identify with the models, the message would be hard to deny. In actual practice, this is not all that easy. The authenticity of the model, for example, also poses a problem, as it is often difficult to find an authentic story that meets the parameters specified. Turning to the methods discussed (see table 2), they seem to fit in well in the context of a role model story. In role model stories, HIV awareness could be increased by providing drug users with basic information on HIV risk and prevention information. The risk they take should be made personal, and communicating the condom use message within a success frame would underline the efficacy of condoms and hence make that option more desirable (see table 2). In addition to the role model stories, a program including some kind of knowledge quiz could provide basic knowledge and enhance active learning.

Anticipated regret and persuasive arguments were also included in the role model stories in order to change the attitude of drug users. Because of the use of authentic interviews, the role model stories were consistent with existing beliefs about condoms and risk behavior. Active participation was addressed by letting drug users participate as distributors of the HIV preventive materials. The processing of information was enhanced by promoting discussions of role model stories with other peers, peer distributors and health community outreach workers. Social influence was addressed by means of the role model stories, in which similar drug users function as positive models, but also by the participation of drug users as distributors of HIV preventive materials and condoms, increasing the acceptance of the (content of the) materials. Finally, self-efficacy was targeted within the role model stories by addressing skills, especially communication and self-management skills. By means of vicarious reinforcement an individual learns which behavior is reinforced and which is not. Moreover an individual can learn new skills and behavior. Participation was enhanced by social reinforcement or incentives for the distribution of the materials, and by recruiting new peers as distributors. 


\section{INTERVENTION MAPPING STEP 3 PROGRAM DEVELOPMENT}

In order to create a program, three tasks have to be undertaken: Strategies have to be operationalized in a program plan, taking into account the context in which the program will be used [task 1]; Program materials are designed [task 2]; At the concept stage, materials are pretested with target groups and implementers; and final materials are produced [task 3]. We decided to develop ten leaflets, in collaboration with Mainline, an NGO developing well-read magazines for the drug-using community. Our choice of leaflets, and our aim to design materials identifiable as Mainline products, was expected to fit existing forms of communication. Each leaflet should contain different role model stories to assure the coverage of different behavioral stages and of role models drug users could relate to. In addition to the role models, the leaflets should contain basic HIV information as well as tips, a quiz or images. All leaflets should be readable independently from other leaflets. The materials should be in full color, with pictures and a unique logo to ensure attention and identification of the project. It was decided to distribute the leaflets every three weeks, via outreach workers of local health or drug addiction organizations, or the existing channels of the drug-using population. The development of the role model stories consisted of six steps: 1 ) specifying populations and behaviors of interest; 2 ) identifying a potential role model to interview; 3) conducting the interview; 4) writing the story; 5) formative evaluation of the role model stories among the priority audience; and 6) publishing the leaflets.

In order to ensure that professionals (e.g., text writers, designer) were able to transfer theory into the creative part of the process, they were provided with design instructions about the themes and motives of the program. Both the content of each role model story and the layout were discussed with the professionals. The materials were pretested as a kind of formative evaluation to ensure their effectiveness (cf. US Department of Health and Human Services, 1984). Although pretesting does not guarantee any effect, it answers questions about whether the materials are comprehensible and relevant, attract attention and whether they are recallable, attractive and reliable. The formative evaluation was carried out among 18 members of the priority audience (consisting of 15 men and 3 women with an average age of 37 years). First, we identified the behavioral stage respondents were in by assessing condom use, condom carrying and perceived personal risk. Although most of the participants felt at risk for HIV/STDs, the majority reported that they did not carry condoms and never or seldom used condoms. The respondents were then asked to read the leaflet, after which a process evaluation was carried out. The leaflet was evaluated overall as interesting $(62.5 \%)$, easily understandable $(83.3 \%)$, nobody thought is was not understandable), recognizable/realistic (67\%) and clear (67\%). Furthermore, the majority said they certainly would pass on brochures to friends (69\%). Recognizability and increased interest were clearly related. The majority was able to recapitulate the content of each of the stories. Moreover, the majority of the 
Rinus (39): 'In my surrounding several people have died of AIDS. That gives food for thought'.

I love sex, but I have become more careful in the course of years. That's why I always have condoms available at home. I am very strict about that. If I take a girl home and we get to a point of passionate sex, I always use them. I don't find it difficult to start talking about condoms. Condoms are a part of the package.

I once had a girlfriend who worked as a prostitute. She assured me that she always used condoms with her clients. One day she had to go to the hospital and it turned out she had gonorrhoea. She had also infected me. Fortunately I am cured now, but I was very upset about that.

In the past I thought differently about condoms. Then it wasn't well known what you could contract. I just did things, without thinking of the consequences. But nowadays, I am much more careful. One can get infected, just like that. In my surrounding several people have died of AIDS. Others are infected with HIV. That really scares me. I can't bear to think about something like that happening to me. I'd rather use a condom than get AIDS'

Etienne (34): 'Afterwards I regretted it'

I never had condoms on me, because I don't want to have sex just for the sex. First I want to get to know someone. I met my second girlfriend at a rehabilitation center. She told me she had been on the streets in the past. There wasn't anything going on yet.

One evening we had a drink together. We ended up in bed and then it happened. Totally unexpected, so we had sex without a condom. Afterwards I thought about it, and I was full of regret. To reassure me she told me she had hepatitis C, but not HIV. But I didn't trust her completely, so I took an HIV test, 3 months after the sexual event. Fortunately, the result was good. But from now on I want to be well prepared. I will take into account I may end up having sex with someone without really having planned it. So, if I have a date again I will buy condoms in advance, to play it safe.'

Figure 2 Role model stories targeting condom use among drug users

priority audience could relate at least to one or two stories in the leaflet that had been pilot-tested, which was the main purpose of combining the different role model stories.

The formative evaluation demonstrated that although the initial brochure was appreciated, some of the elements needed to be changed. Initially, the brochures contained photos of parts of the bodies of drug users. The faces of drug users were valued, but photographs of the feet or back of a drug user, for instance, were evaluated negatively: These drug users were seen as not being honest or open about their thoughts or opinions. In order to avoid this, we decided to include photographs and 
illustrations of faces only, created by an illustrator our development team was familiar with, and who had made illustrations for the same target populations for similar reasons. After the formative evaluation we became more confident that drug users were able to relate to the role model stories, found them realistic, and were interested in the content of the role model stories.

The final role model stories were similar to the stories stated in figure 2, covering methods and learning objectives that had been specified previously in the Intervention Mapping process. Examples are the anticipated negative feelings and condom availability in the story of Etienne, and threat personalization and expression of confidence to talk about condoms in the story of Rinus.

\section{INTERVENTION MAPPING STEP 4 ASSURING CO-OPERATION AND IMPLEMENTATION}

When creating programs, designers have to anticipate diffusion of the program. The first task of Step 4 is to develop a linkage board, a board to connect those who are developing the intervention and those who will use the program (Orlandi et al., 1990). The linkage system should enable collaboratively developed user-relevant interventions, and should furthermore stimulate the diffusion process of adoption and implementation. Task 2 and 3 of this step are actually similar to the process specified in Intervention Mapping Steps 1 through 3, but the priority population is different, being decision-makers and program users. In task 2 matrices are created in which proximal program objectives for adoption and implementation are specified. This again is the product of merging determinants with performance objectives. In task 3 an implementation plan is written.

We began our linkage board at the needs assessment phase of the project. It continued and was expanded throughout the project's progress, involving researchers, health educators, outreach workers, and social workers from various governmental and non-governmental organizations. The linkage board enabled us to foresee possible barriers to implementation, such as ethical dilemmas or time constraints, and to deal with these barriers by discussing and finding a solution for them with the program users themselves. 


\section{INTERVENTION MAPPING STEP 5 EVALUATION PLAN}

The first task in Step 5 is to develop an evaluation model. The content of the model is based upon the previous steps (needs assessment and Intervention Mapping steps). On the basis of the needs assessment and Intervention Mapping Step 1, effect evaluation questions can be created. On the basis of Step 4 process evaluation questions can be developed. To evaluate the effect of the intervention we relied on the information gathered in the Intervention Mapping process and needs assessment, looking at the objectives stated in the needs assessment and IM Step 1. This enabled us to measure changes in learning objectives, determinants, behavior, and even the health problem. Our evaluation plan, using a pre-posttest design with a comparison group, is expected to reveal a change in learning objectives, determinants and hopefully behavior (e.g., condom carrying and self-reported condom use).

For the process evaluation of the program we can rely on Steps 2 and 4 of Intervention Mapping, which enables us to evaluate whether the program was implemented as planned: Was the program disseminated, was it adopted and used (completely)? Which methods and strategies did and which did not work, and why was that?

\section{DISCUSSION}

We have tried to demonstrate that the process of AIDS prevention interventions - in this case the promotion of condom use with casual sex partners among drug users - may be improved by the application of theory and evidence in intervention development. Moreover we have tried to demonstrate the feasibility of such an approach, and the advantages of a systematic process using Intervention Mapping (Bartholomew et al., 2001).

We believe that by the systematic approach in developing an AIDS prevention intervention to promote condom use among Dutch drug users we have reduced possible barriers that might inhibit the effectiveness of the program.

The needs assessment and program objectives specified during the process of explaining behavior, by means of theory and data, led us to conclude that it was essential to distinguish seemingly similar behavior, condom use with casual and condom use with steady sex partners. It also gave us detailed information about determinants related to risk behavior, as well as factors that may improve safe sexual behavior among Dutch drug users.

The matrix of program objectives provided an foundation, which was very useful in our search for theoretical methods to change behavior. Moreover, indicating the most important learning objectives that had to be targeted, it enabled us to consider all possible consequences of chosen methods and strategies.

।

I

I $\quad$ I 
The co-operation with the actual program users led to the creation of a program, which was supported by the program users themselves. This should ensure successful implementation of the program. The iterative process of Intervention Mapping made us aware of the consequences of decisions made for objectives specified earlier in the process. In other words, erroneous or inconclusive decisions made during the process can be changed over time, preventing the final product from mismatching the goals set in advance.

Intervention Mapping has shown to be a practical instrument that gives guidance in intervention development. Although Intervention Mapping does not per se lead to new strategies, it ensures that the content of strategies is theoretically sound and linked to goals.

Intervention Mapping ensures a transparent, clear and systematic design process. Intervention Mapping guarantees that: 1) intervention goals have an empirical and theoretical basis; 2) the final program is linked to theory and to the intervention goals; 3) the most important intervention goals are covere; 4) a program is developed that is compatible with the priority audience, and finally; 5) that the diffusion of the program is anticipated throughout the process.

How feasible is Intervention Mapping in practice? Although the process of Intervention Mapping requires an investment in terms of time, this short-term investment may be rewarding in the long run, as all steps of the Intervention Mapping process provide measurable objectives that can be used for effect and process evaluation. The amount of time that has to be spent also depends on the amount of additional research that has to be undertaken. For many topics, information about important and changeable determinants of behavior, and specific goals related to that behavior, might be existing and readily available. In case such information is lacking, however, we stress the importance of additional empirical research. This will involve extra work, but what if the intervention fails due to a lack of information? In that case, a lot of time and money will be wasted, and one probably cannot answer the question why the intervention failed.

Another issue that has been addressed is the possible friction between parameters and choice of channel and messages to be used. On the one hand, positive behavior has to be modeled, but on the other hand people should be able to relate to the model. These may represent two quite different goals. Pretesting of the materials should reveal such incompatibilities, and a program should be developed fitting the parameters as closely as possible.

The major problem of Intervention Mapping, however, will be the funding of the materials. Funding agencies expect projects to give a clear description of what health education materials look like. Intervention Mapping cannot provide such a description in advance, because messages, channels, audience and source are defined during the process.

Nevertheless, using the Intervention Mapping process, developers of AIDS prevention interventions or any other intervention program can go beyond the provision of information in their program development, and provide methods and strategies that are specifically intended for changing specific objectives. 


\section{CHAPTER 5}

USING INTERVENTION MAPPING:

PROMISES AND PITFALLS 


\section{INTRODUCTION}

The purpose of this thesis was to apply Intervention Mapping to design an evidencebased AIDS prevention intervention for drug users. For this purpose, we reviewed the literature and applied additional research to explain unsafe and safe sexual behavior, to find methods and strategies for behavior change, to plan intervention development and to anticipate implementation. Because the project described in this thesis was planned using Intervention Mapping, we take this opportunity to address the promises and pitfalls experienced when working with Intervention Mapping. But let us first summarize the process followed during the project. Although the steps presented may seem to follow one after the other, in practice we moved back and forth between the steps during the project.

Prior to the application of Intervention Mapping (IM) to program planning we searched for literature and collected data to analyze the problem that had been identified by the collaborating health center. In IM Step 1 we collected data to explain condom use behavior among drug users, which resulted in two different matrices of proximal program objectives. These matrices indicated what the program had to change, what drug users needed to learn and what in the environment needed to be changed in order to establish increased condom use among drug users, thus providing the starting map for intervention development. We then moved on to IM Step 2 and brainstormed about possible methods (and strategies). We also conducted a review of existing empirical and theoretical evidence to find feasible methods to address the most important and changeable determinants. In IM Step 3 we developed a program plan and materials, involving a professional writer and designer, and we pretested the materials among the target population. A linkage board was established at the start of the project, following Step 4 - consisting of the research and development team and representatives from the local health centers, and eventually the NGO involved in the program development - with which we had established a close co-operation right from the beginning of the project. To anticipate implementation, we visited several organizations involved in drug-addiction care, where we explained the purpose of our program, and an inventory was made among these organizations of possible barriers in its implementation.

\section{INTERVENTION MAPPING STEP 1 EXPLAINING BEHAVIOR}

What did we learn from applying Intervention Mapping to explain condom use among drug users? At the start of the project, the knowledge of psychosocial factors 
of condom use among drug users was scarce, and most of the work that had been done was US-based (e.g., Bowen \& Trotter, 1995; Corby, Jamner, \& Wolitski, 1996; Montoya, 1997). Additionally, a number of interventions aimed at drug users failed to accomplish a change in sexual risk behavior (for reviews see Gibson, McCusker, \& Chesney, 1998; Van Empelen, Kok, Van Kesteren et al., 2001). The assumption that drug users are not willing or unable to change their behavior is not supported by studies that have shown a tremendous change in drug risk reduction behavior (e.g., DesJarlais \& Friedman, 1998). Similarly, the assumption that drug users are not really sexually active, except in prostitution, is not correct. Drug users have shown to be as sexually active as the general population (e.g., Rhodes, Stimson, \& Quirk, 1996), and most heterosexual HIV infections can be attributed to sex with a drug user (Des Jarlais, 1992; Fennema, 1997; Lukashove, Op de Coul, Coutinho, \& Goudsmit, 1998).

In order to shed more light on unsafe and safe sexual behavior among drug users we started the project - the needs assessment and Intervention Mapping Step 1 with collecting data regarding sexual behavior of drug users, whereby we departed from a general model of health behavior (Abraham, Sheeran, \& Johnston, 1998). This model was based on a review of theoretical concepts of multiple social cognitive models, which identified several key cognitive constructs of individual motivation and behavior, i.e., attitudes, self-representations, social influence, self-efficacy, and intention. Intention was viewed as a construct that mediates the effect of the other variables on behavior.

In a first study (see section 3.1) we operationalized attitudes via two constructs, i.e., the beliefs about condom use (Fishbein \& Ajzen, 1975) and the response efficacy of condom use (e.g., the perceived effectiveness of condom use in avoiding HIV infection) (R. W. Rogers, 1983). Social influence was operationalized by means of the subjective norm of condom use (i.e., the acceptance of condom use by the partner) (Fishbein \& Ajzen, 1975) and the descriptive norm of condoms (i.e., the perception of what others do, in this case whether others use condoms) (Cialdini, Reno, \& Kallgren, 1990; De Vries, Backbier, Kok, \& Dijkstra, 1995). Self-representation was operationalized by means of personal normative beliefs (i.e., an individual's own (moral) values related to a certain behavior) (Triandis, 1977). Finally, we also measured self-efficacy expectations about condom use (Bandura, 1986).

Being able to predict (a lack of) condom use among drug users to some extent, the model proved to be useful. Nevertheless, we extended the core model in a second study to improve the prediction of intended condom use (section 3.2). We examined the additional value of other determinants - anticipated regret (Richard, Van der Pligt, \& De Vries, 1995) and psychopathology (Hartgers, Van den Hoek, Coutinho, \& Van der Pligt, 1992) - in explaining intended condom use with primary and casual sex partners among drug users and slightly changed some of the constructs we had used originally. Thus, personal normative beliefs were operationalized in accordance with Godin et al. (Godin, Fortin, Michaud, Bradet, \& Kok, 1997), being more of a moral value of someone to use condoms. In addition to the indirect measurement of attitudes by means of beliefs, we also included a direct measure of 
attitude toward condom use. Finally, social norm measurement was extended to include not only the perceived partner norm, but also the norm of significant others in the direct environment.

The second study showed that a more comprehensive operationalization of the constructs proposed by Abraham et al. (1998) enabled us to account for $41 \%$ of the variance in drug users' intentions to use condoms with steady sex partners. Similar findings have been reported elsewhere (e.g., Corby et al., 1996). Although less successful, we found the model useful in explaining drug users' intentions to use condoms with casual sex partners. We also showed that it may be useful to include other possible predictors in explaining behavior, such as psychopathology, although with regard to psychopathology we were not able to include the findings as a part of the intervention, due to a lack of understanding of the processes underlying the relation of hostility and risk-taking behavior.

Finally, in our qualitative study (section 3.3) we showed that two essential factors may require more focus in order to ensure that intention will be translated into actual condom use: communication about HIV/AIDS and condom use with the partner, the need to have condoms available at all times, and the need to avoid situations that may enhance risk-taking (like using alcohol or cocaine).

The studies provided valuable information for the focus of the AIDS prevention interventions. However, the studies focused mainly on the general health behavior, that is: condom use. The majority of recent theoretical views point out the complexity of such behavior. According to Bartholomew et al. $(1998,2001)$ it is essential to differentiate, for each health behavior, performance objectives that are needed to accomplish one goal [IM Step 1, task 1]. Targeting specific sub-behaviors of one behavioral health goal is more likely to be effective in actually promoting the health goal. This approach is consistent with several other theoretical views, such as Bandura's recommendation to break up behavior in small steps (Bandura, 1986) or goal-setting theory (Locke \& Latham, 1991), but also with more recent insights like action-planning (Bagozzi, 1992; Gollwitzer, 1993; Schwarzer, 1992). However, such an approach also implies that each performance objective is based on its specific determinants. We therefore had to carry out a more detailed analysis. Intervention Mapping Step 1 is useful in the sense that it gave guidance to such a detailed analysis. First, we identified and validated sub-behaviors of condom use relying on theoretical and empirical evidence. For instance, following recent views like action-planning models or more traditional of behavior such as the Theory of Reasoned Action (Fishbein \& Ajzen, 1975) and Theory of Planned Behavior (Azjen, 1991) a primary performance objective was that people should make the decision to use condoms. Other evidence came from Kelly (1995), who specified a number of behavioral steps that needed to be carried out in order to achieve actual condom use, i.e., acquiring condoms and having them available, communicating condom use and establishing commitment with the partner, and being able to use condoms. Bagozzi (1992; see also Abraham, Sheeran, Norman, Conner, De Vries, \& Otten, 1999) also specified a series of actions required for the actual use of condoms, such as acquiring, suggesting and managing actual condom use. Finally, Relapse Prevention Theory (Marlatt \& 
Gordon, 1985) suggested the need to identify maintenance as a specific factor of condom use. Based on these theoretical insights as well as our own studies, we addressed several sub-behaviors focusing on specific skills needed to accomplish condom use behavior (see self-efficacy items), and intentional goals (see section 3.2 ), which were necessary in our view to accomplish our behavioral goal of condom use. In the quantitative study, too, we specifically addressed several performance objectives to gain insight into its importance.

The studies reported (section 3.1 through 3.3) provided information about performance objectives to some extent. We do not suggest that these studies supplied sufficient information to specify all performance objectives. In accordance with the former paragraph for the specification of performance and proximal program objectives we also relied on the theoretical assumptions presented by others (e.g., Catania et al., 1990).

Furthermore, Intervention Mapping Step 1 showed us the need of differentiating the target population, and to judge the importance of change objectives. With regard to the latter, we concluded that the availability of condoms was not a problem, because condoms are widely and readily available, and most drug users know where to obtain them. Furthermore, we pointed out that support of condom use both by health care workers and sex partners was required, but we concluded that both issues could be addressed within the program: Sex partners of drug users can be seen at both the external and individual level of the target population, and we believed that we should take into account these mixed levels by addressing them within one program simultaneously. Also, we aimed at developing a program providing the health care workers with a way to reinforce drug users and be more active in discussing sexuality and condom use.

In brief, Intervention Mapping Step 1 guided the examination of the target population and environment, important sub-behaviors of one specific behavior, each with unique learning and change objectives that need to be accomplished to ensure condom use. As such, the product of IM Step 1 is a more detailed and therefore better starting point for effective decision making, when focusing on intervention development. Thus, following Intervention Mapping, our end product of IM Step 1 is a more detailed analysis of condom use behavior among drug users, rather than an analysis based purely on the behavioral goal itself.

However, during the process of Intervention Mapping Step 1 we also found that we had to deal with knowledge gaps that could not be solved. Intervention Mapping suggests additional research to fill knowledge gaps and we were fortunate to be able to do substantial additional research. In practice, the time factor may play a crucial role, as there simply will not be enough time to carry out all the additional research. Nevertheless, the efforts made and time spent in the earlier steps may be rewarding in the long run. All of the Intervention Mapping steps provide, for instance, clearly stated objectives for effect and process evaluation. This is very important to understand why a program did or did not work. Moreover, the reiterative process of Intervention Mapping ensures that each decision is considered, which may be the very strength of the process. 
But also in our case it is clear that although additional research may be required throughout the process, it is not possible to continue endlessly searching for answers. Therefore, we sometimes had to rely on well-educated guesses and make arbitrary decisions. It should be pointed out, however, that even though it was impossible to make decisions based on clear-cut answers, the decision-making process following the different tasks of Intervention Mapping made the process transparent.

All the same, the current project underlines the need for future research to focus on sub-behaviors of one behavior and of antecedents of such sub-behaviors. Currently, such evidence is scarce.

\section{Matrices of proximal program objectives}

Having described the processes involved in IM Step 1, the end product of IM Step 1 concerned the matrix of proximal program objectives. The goal of the matrix is to specify measurable learning and change objectives. Our choice of these learning objectives was partly based on the perceptions, beliefs and expectations that were found to be important in our studies (sections 3.1-3.3). Change objectives concerning the reinforcement of health care workers were, among other things, identified on the basis of interviews with health care workers about their current activities. Moreover, we relied on other empirical evidence and theoretical insights. This gave us some confidence that we addressed the most important learning and change objectives, although, as we mentioned previously, we had to rely to some extent on well-educated guesses, backed up by sources of expertise within the linkage group.

The matrices proved to be very practicable because they provided us with information about the sequence in which learning process should be addressed. This is essential when specifying program components, but based on this detailed information we also realized that although performance objectives were similar for drug users in both casual and steady sexual relationships, determinants differed in importance and changeability. Originally, relying on one matrix in which we addressed the issue of condom use independent of relationship status, during the process we found ourselves going back and forth having one matrix to target condom use, or two matrices targeting condom use with casual and steady sex partners simultaneously. During IM Step 2, for instance, we found that the operationalization of methods that seemed applicable to change condom use within casual relationships, proved to be incompatible to target the learning and change objectives in the context of steady sexual relationships. This finally led to the decision to separate the behavior on the basis of relationship status.

The number of change and learning objectives was reduced to the most essential objectives based on discussions within the linkage group, and the importance of learning and change objectives was evaluated trying to find the most adequate fit between strategies and learning and change objectives.

The matrices proved to be useful during discussion group meetings. They pro- 
vided a starting point for the linkage group to brainstorm about theoretical methods expected to be effective in changing proximal program objectives. The matrices also proved to be helpful in explaining to the program development team which objectives we wanted to address in the role model stories to learn drug users how to use, obtain and communicate condoms, and why they should avoid situations that would prove less manageable than they might have thought initially. The learning objectives provided clear direction for themes to be addressed in the role model stories, and educational messages that needed to be included in the brochures.

Although the matrices were helpful in giving direction, they also caused us lots of struggles. It is not always clear whether objectives are learning or change objectives or whether they are performance objectives, for example in the case of correctly condom use. To be able to use condoms correctly, one should also be able to unpack the condom package, to unroll the condom correctly and afterwards to remove the condom correctly and dispose of it. However, regardless the sometimesexisting ambiguity it is most important that all objectives are covered, regardless of whether they should be defined as a learning, change or performance objective.

In sum, the process of explaining behavior is difficult and complex. Although Intervention Mapping Step 1 may not make that process easier, it ensures that the most important learning and change objectives are specified, providing a reference point for all of the following steps of Intervention Mapping.

\section{INTERVENTION MAPPING STEP 2 METHODS AND STRATEGIES}

In accordance with Step 2 of Intervention Mapping we started with a search for methods, trying to clarify parameters of those methods. A review of the literature using various ways to search for evidence - revealed several methods that could be used to address the proximal program objectives. The theories underlying these methods provided information about the correct use of the methods in intervention development. We do not argue that we would have been unable to search for methods and/or strategies without Intervention Mapping. The matrices in IM Step 1, however, provided clear topics to search for. Moreover, Intervention Mapping Step 2 guaranteed a very tight fit between objectives, methods and strategies.

Intervention Mapping forced us to be aware of the parameters that had to be considered for each method, and therefore prevented us from aiming at strategies that would not fit in with the learning objectives of our specific target audience. For instance, we found that the method of modeling could be a useful method to address several learning objectives. The practical strategy of role model stories by means of peer modeling, which seems to be a good strategy to target condom use in 
the context of sexual relationships, showed to be difficult in the context of steady relationships. We were not able to create role models that would promote condom use in steady relationships - a behavior that by our population would be considered undesirable - and at the same time would be perceived as credible.

The aim of the program targeting condom use with casual sex partners was to influence drug users by means of peer modeling, and by their active participation in the distribution of the materials, in accordance with Social Cognitive Theory (Bandura, 1997) and the Diffusion of Innovations theory (E. M. Rogers, 1983). Within this general approach several methods were integrated into the program based on specific theories, such as theories about awareness raising or attitude change. By linking the learning objectives specified in IM Step 1 with the strategies, we were able to check whether we had covered all the essential learning objectives so as to ensure that we achieved all the performance objectives of condom use specified in advance. We selected behavioral journalism as the main strategy, as it covered all methods described (McAlister, 1995). Behavioral journalism is an approach of media-delivered behavioral modeling (see also Bandura's dual-link model (1986, p.145)). The behavioral journalism strategy consists of two elements: the use of printed role model stories based upon authentic interviews of the drug-using population, and the use networks of the drug-using community to distribute these role model stories, combined with other HIV prevention materials (i.e., other information and condoms).

During the process of Intervention Mapping Step 2 we were not always able to find methods and/or strategies to address objectives. For instance, whereas we underlined the importance of hostility reduction, we did not know how to change it. But also we discussed peer education as a possible strategy that fitted well with methods, such as active participation and modeling, and also with objectives specified. However, this idea was unfeasible in the context of our target population.

Our program proposal to promote condom use with steady sex partners was given a heavier focus on awareness raising and attitude change, although it has been shown that it is best to promote attitude change and self-efficacy enhancement at the same time (Malotte et al., 2000). Our program is based on specific theories aimed at the promotion of risk personalization, attitude change and self-efficacy enhancement. The proposed main strategy was client-centered individual counseling by motivational interviewing (Miller \& Rollnick, 1991), which seems to be a good strategy to target sexual practices within steady relationships.

But even in the context of casual relationships, in which the use of peer model stories seems a good strategy (a lot of drug users are more positive towards condom use with casual sex partners), parameters may be conflicting. For instance, a role model should model positive behavior, but on the other hand people should be able to relate to the model. So it may well be that the drug users cannot relate to certain positive behavior, whereas certain behavior that is fitting with existing behavior might be undesirable to promote. In the case of the population we targeted, there is friction between these two parameters of effectiveness. Pretesting of the materials should reveal such incompatibilities and a program should be developed fitting the 
parameters as closely as possible.

In conclusion, we do not suggest that it would have been impossible without Intervention Mapping to achieve similar programs. However, the process of Step 2, in which we directly compared methods, strategies and objectives, also made this part of intervention planning more transparent, securing mature decision-making.

\section{INTERVENTION MAPPING STEP 3 Program DeVelopment and Pretesting}

What did with learn when applying Intervention Mapping to develop the program to promote condom use among drug users? In Step 3 we specified the elements of the program aimed at the promotion of condom use with casual sex partners among drug users. The matrix of IM Step 1 contributed to defining and structuring program components. Professionals that were involved in the creative process of translating the theoretical elements into actual materials were instructed about the specific proximal program objectives, the themes and the motives of each element of the materials. In this way, we tried to structure the program as clearly as possible, but, within the boundaries set, creativity flourished. We discovered that the translation of evidence-based principles into materials was far from easy. It appeared to be difficult to transfer the idea behind these principles to the creative professionals and we had to remind them from time to time of the essential conditions that had to be met. This led to a great many changes in the brochures, and eventually both the creative professionals and the research team were forced to make compromises.

Next, we evaluated the elements of the brochure. The formative evaluation demonstrated that although the initial brochure was appreciated, some of the elements needed to be changed (see section 4.3). After the formative evaluation we became more confident that drug users were able to relate to the role model stories, found them realistic, and were interested in the content of the role model stories. In brief, the formative evaluation as proposed in IM Step 3 enabled us to gain information about elements in the brochures requiring improvement, and about the elements that were favored. 


\section{INTERVENTION MAPPING STEP 4 PROGRAM ADOPTION AND IMPLEMENTATION}

What did we learn from the use of Intervention Mapping as a tool to ensure co-operation between theorists and practitioners in order to promote feasible and supported programs? The goal was to develop a program that would be useful for public health centers. During the project we found out, however, that it is not always clear who is responsible for the health education part of our drug-using community. In some regions the local health center is responsible, in other areas it is the bureau for alcohol and drug abuse, and in yet other regions we found other organizations to be responsible. Following IM Step 4, we developed a linkage board, a group consisting of members of various organizations, in order to anticipate possible differences between organizations. We believe that our collaboration with those different organizations has led to the creation of a program to promote condom use with casual sex partners among drug users that is acceptable for all organizations, as it complies with their terms of the program being inexpensive and fitting (in terms of time) with their regular activities. Moreover, we discussed the program proposals with different organizations to anticipate implementation problems, which led us to believe that this program is relatively easy to implement.

We discovered that the co-operation with the different organizations, and the consideration of not only the key-figures/gatekeepers, but also the people that were to make actual use of the program, was very fruitful. It enabled us to foresee potential barriers to implementation, such as ethical dilemmas or time constraints, and to deal with those barriers, by discussing possible problems with the program users themselves. Moreover, Intervention Mapping Step 4 forced us to consider performance objectives and determinants related to adoption and implementation of the program. It made us aware that with regard to the program aimed at casual sexual relationships we had to explain thoroughly the benefits of the program in terms of prevention as well as costs, such as the small time investment. This was necessary to let people decide to use the program and to explain to them and convince them of the need and method of distributing the materials and discussing the context of the materials with drug users. With regard to the program aimed at condom use in steady sexual relationships, we anticipated a number of difficulties in terms of time and employment, as well as a relatively negative attitude in the short run. It was clear that in order to make the program acceptable, we also needed to train counselors and to develop a clear protocol.

Following IM Step 4 we probably avoided unwillingness to participate and ensured a feeling of ownership with regard to the program(s). Moreover we were able to anticipate factors expected to influence the adoption and implementation of the program(s). 


\section{DISCUSSION}

Theory- and data-based intervention development is a complex and time-consuming process. Intervention Mapping is a way of easing the application of theory and empirical evidence in intervention development. Intervention development may not always become less complex, but the steps taken during the development process are more systematically considered. During the current project we have demonstrated the application of Intervention Mapping in the context of AIDS prevention. Following the process of Intervention Mapping we systematically used three valuable tools: brainstorming; searching and applying literature and theory; acquiring additional evidence. We have acknowledged several times that the processes in Intervention Mapping may not be new, and that theory- and evidence-based program development is also possible without the use of Intervention Mapping. Having said that, however, we believe that we have demonstrated that Intervention Mapping does have a number of strengths. The use of Intervention Mapping guarantees that:

1 Each program objective is grounded on empirical evidence and theory

2 The final materials and activities are linked both with theory, and with the objectives specified

3 All important ojectives are covered

4 The program is compatible with the target population

5 Diffusion issues are anticipated throughout the process.

In conclusion, many of the processes used in Intervention Mapping may not be new, but the systematic system of steps and tasks of Intervention Mapping certainly is and it ensures transparent decision-making in the context of theory-based intervention development. Moreover, the steps of Intervention Mapping provide an excellent basis for (process and effect) evaluation.

It can be argued that the great strength of Intervention Mapping also represents its weakness. Intervention Mapping implies that all decisions about the problem and solutions are made during the process. This means that a description of an intervention cannot be given in advance. This is highly undesirable when searching for funding for development and evaluation of a health promotion intervention. There seems to be disagreement about what an intervention really is: Where we imply to see the intervention as a process, funding agencies view the intervention as a product. Therefore, funding agencies expect projects to give a clear description of what health education materials look like. Because Intervention Mapping cannot provide such a description in advance, this is actually a point of critique that stands. The learning process for funding agencies would be to understand that health promotion interventions are fundamentally different from many bio-medical interventions in the sense that health promotion interventions have to be adapted to the actual health promotion setting.

However, having discussed the strengths of Intervention Mapping, arguing that IM covers all necessary elements in a decision-making process to ensure program 
effectiveness, this should be a very persuasive argument both for funders and practitioners to embrace Intervention Mapping as an important tool for evidence-based intervention development.

Unfortunately, it is too early to tell whether our application of Intervention Mapping for theory- and evidence-based AIDS prevention intervention development is actually more effective than existing standard programs. In order to evaluate the program targeting condom use with casual sex partners and to be able to answer the question just stated, we started preparing for an evaluation of the program targeting condom use with casual sex partners in March of 2001. For this purpose, we were able to rely on the information gathered in the Intervention Mapping process and needs assessment: expected changes in learning objectives, determinants, behavior or even health problem. We will compare our program that will be used by several health care or alcohol and drug abuse centers with other centers that will do whatever they think they should do. Our evaluation plan, using a quasi-experimental design, is expected to reveal a change in learning objectives, determinants and hopefully behavior (i.e., condom carrying and self-reported condom use). Apart from the effect evaluation we will also evaluate the process, using the information described in IM Step 2 and IM Step 4, the methods, strategies and implementation plan as a basis for the process evaluation.

Having laid a foundation for the development of the program targeting condom use with steady sex partners, our next aim will be to develop the program materials needed, trying to anticipate possible barriers to implementation. Finally, we will also evaluate the effect and process of the intervention, making use of the information gathered throughout the Intervention Mapping process. 


\section{REFERENCES}

Abdul-Quader, A. S., Tross, S., Friedman, S. R., Kouzi, A. C. and Des Jarlais, D. C. (1990) Streetrecruited intravenous drug users and sexual risk reduction in New York City. AIDS, 4, 1075 1079.

Abraham, C., Sheeran, P., \& Johnston, M. (1998). From health beliefs to self-regulation: theoretical advances in the psychology of action control. Psychology and Health, 13, 569591.

Abraham, C., Sheeran, P., Norman, N., Conner, P., de Vries, N., \& Otten, W. (1999). When good intentions are not enough: Modeling post-intention cognitive correlates of condom use. Journal of Applied Social Psychology, 12, 2591-2612

Abraham, S. C. S., Rubaale, T. K., \& Kipp, W. (1995). HIV preventive cognitions amongst secondary school students in Uganda. Health Education Research, 10, 155-162.

AIDSfonds. (1999). AIDS in Nederland [AIDS in the Netherlands]. AIDSbestrijding, 44, 10-11.

Ajzen, I. (1991). The theory of planned behavior. Organizational Behavior and Human Decision Processes, 50, 179-211.

Allen, S., Serufilira, A., Bogaerts, J., Van de Perre, P., Nsengumuremyi, F., Lindan, C., Carael, M., Wolf, W., Coates, T., \& Hulley, S. (1992). Confidential HIV testing and condom promotion in Africa. Impact on HIV and gonorrhea rates. JAMA, 268, 3338-3343.

Allen, S., Tice, J., Van de Perre, P., Serufilira, A., Hudes, E., Nsengumuremyi, F., Bogaerts, J., Lindan, C., \& Hulley, S. (1992). Effect of serotesting with counseling on condom use and seroconversion among HIV discordant couples in Africa. BMJ, 304, 1605-1609.

Andersen, M. D., Hockman, E. M., \& Smereck, G. A. D. (1996). Effect of a nursing outreach intervention to drug users in Detroit, Michigan. Journal of Drug Issues, 26, 619-634.

Arrindell, W. A., \& Ettema, J. H. M. (1986). SCL-90: Handleiding bij een multidimensionele psychopathology-indicator [SCL-90: Manual for a multi-dimensional psychopathology indicator]. Lisse: Swets \& Zeitlinger B.V.

Bagozzi, R. P. (1992). The self-regulation of attitudes, intentions, and behaviour. Social Psychology Quarterly, 55, 178-204.

Baker, A., Heather, N., Wodak, A., Dixon, J., \& Holt, P. (1993). Evaluation of a cognitive behavioural intervention for HIV prevention among injecting drug users. AIDS, 7, 247-256.

Bandawe, C. R., \& Foster, D. (1996). AIDS-related beliefs, attitudes and intentions among Malawian students in three secondary schools. AIDS Care, 8, 223-232.

Bandura, A. (1986). Social foundations of thought and action: A Social Cognitive Theory. Englewood Cliffs, NJ: Prentice-Hall.

Bandura, A. (1994). Social Cognitive Theory and exercise of control over HIV infection. In R. J. DiClemente \& J. L. Peterson (Eds.). New York, NY: Plenum Press.

Bandura, A. (1997). Self-efficacy: The exercise of control. New York: Freeman.

Bartholomew, K., Parcel, G., Kok, G., \& Gottlieb, N. (2001). Intervention mapping: designing theory- and evidence-based health promotion programs. Mountain View, CA: Mayfield.

Bartholomew, L. K., Parcel, G. S., \& Kok, G. (1998). Intervention Mapping: A process for developing theory- and evidence-based health education programs. Health Education and Behavior, 25, 545-563. 
Bassett, M. T., \& Mhloyi, M. (1991). Women and AIDS in Zimbabwe: The making of an epidemic. International Journal of Health Services, 21, 143-156.

Batson, C. D., Early, S., \& Salvarani, G. (1997). Perspective taking: Imagining how another feels versus imagining how you would feel. Personality and Social Psychology Bulletin, 23, 751 758.

Becker, M. H. (1974). The health belief model and personal health behavior. Health Education Monographs, 2, 324-508.

Bell, D. E. (1982). Regret in decision making under uncertainty. Operations Research, 30, 961 981.

Bem, D. J. (1967). Self-Perception: An Alternative Interpretation of Cognitive Dissonance Phenomena. Psychological Review, 74, 183-200.

Berns, M., Van de Laar, M., Houweling, H., \& Wiessing, L. (2000). National surveillance of HIV infection and risk behavior among injecting drug users in the Netherlands. Paper presented at the XIII International AIDS Conference, Durban, South-Africa.

Berns, M. P. H., Van Rozendaal, C. M., Toet, J., Snijders, B. M. and Houweling, H. (1998) Surveillance van HIV-infectie onder injecterende druggebruikers in Nederland: meting Rotterdam 1997 (RIVM rapport 441100 007) [Surveillance of HIV infection among injecting drug users in the Netherlands: survey Rotterdam 1997]. Bilthoven: Rijksinstituut Volksgezondheid en Milieu:.

Beuker, R. J., Berns, M.P.H., Van Rozendaal, C. M., Snijders, B. M., Jansen, M., Hoebe, C. J. P. A., \& Van de Laar, M. J. W. (2001). Surveillance van HIV-infectie onder injecterende druggebruikers in Nederland: meting Heerlen/Maastricht 1998/1999 (RIVM rapport 441100014). [Surveillance of HIV infection among injecting drug users in the Netherlands: survey Heerlen/Maastricht 1998/1999]. Bilthoven: Rijkinstituut Volksgezondheid en Milieu.

Beuker, R. J., Berns, M. P. H., Van Ameijden, E. J. C., Houweling, H., \& Van de Laar, M. J. W. (2000). HIV infection and risk behaviour among injecting drug users in Amsterdam, the Netherlands. Paper presented at the XIII International AIDS Conference, Durban, SouthAfrica.

Blower, S. M., Hartel, D., Dowlatabadi, H., Andersan, R. M., \& May, R. M. (1991). Drugs, sex and HIV: a mathematical model for New York City. Philosophical Transactions of the Royal Society of London, 321, 171-187.

Booth, R. E., Kwiatkowski, C. F., \& Chitwood, D. D. (2000). Sex related HIV risk behaviors: differential risk among injection drug users, crack smokers, and injection drug users who smoke crack. Drug and Alcohol Dependence, 58, 219-226.

Booth, R. E., \& Watters, J. K. (1994). How effective are risk-reduction intervention targeting injecting drug users? AIDS, 8, 1515-1524.

Bos, A., Dijker, A., \& Jansen, M. (2000). Stigma in the drug scene: An investigation of stigmatization of HIV+ drug users in a sample of HIV-drug users. Paper presented at the XIII International AIDS Conference, Durban, South-Africa.

Bowen, A. M. (1996). Predicting increased condom use with steady partners: Potential approaches for intervention. Drugs \& Society, 9, 57-74.

Bowen, A. M., \& Trotter, R. (1995). HIV risk in intravenous drug users and crack cocaine smokers: predicting stages of change for condom use. Journal of Consulting and Clinical Psychology, 2, 238-248. 
Buunk, A. P., \& Veen, P. (1995). Sociale psychologie en haar praktijkproblemen: Van probleem naar oplossing. [Social psychology and her practical problems: from problem to solution. Houten: Bohn Stafleu Van Loghum.

Campbell, B. K., \& Stark, M. J. (1990). Psychopathology and personality characteristics in different forms of substance abuse. The International Journal of the Addiction, 25, 1467-1474

Carey, M. P., Carey, K. B., Weinhardt, L. S., \& Gordon, C. M. (1997). Behavioral risk for HIV infection among adults with a severe and persistent mental illness: Patterns and psychological antecedents. Community Mental Health Journal, 33, 133-142.

Carsauw, H. H. C., Van Rozendaal, C. M., Scheepers, J. M. F. A., Hoebe, C. J. P. A., Meulders, W. A., Jansen, M., Dorigo-Zetsma, J. W., \& Houweling, H. (1997). Infecties met HIV, HBV en HCV onder injecterende druggebruikers in Heerlen/Maastricht [Infections of HIV, HBV and HCV among injecting drug uusers in Heerlen/Maastricht]( Rapport nr. 441100 006) Bilthoven: Rijksinstituut Volksgezondheid en Milieu.

Catania, J. A., Coates, T. J., \& Kegeles, S. (1994) A test of the AIDS risk reduction model: Psychosocial correlates of condom use in the AMEN cohort survey. Health Psychology, 13, 548-555.

Catania, J. A., Kegeles, S. M., \& Coates, T. J. (1990). Towards an understanding of risk behavior: An AIDS risk reduction model (ARRM). Health Education Quarterly, 17, 53-72.

CDC. (1998). AIDS Surveillance - General Epidemiology, [File: 1178.ppt]. Available: http://www.cdc.gov/nchstp/hiv_aids/graphics/surveill.htm [1999, April 8].

CDC. (1999). Community-level HIV intervention in 5 cities: Final outcome data from the CDC AIDS Community demonstration projects. American Journal of Public Health, 89, 336-345.

CESES. (2001). HIV/AIDS surveillance in Europe, [http://www.ceses.org/AidsSurv/rapport_n63_ 2000/euro_hiv63full.pdf] [2001, April 25].

Choi, K. H., \& Coates, T. J. (1994). Prevention of HIV infection. AIDS, 8, 1371-1389.

Cialdini, R. B., Reno, R. R., \& Kallgren, C. A. (1990). A focus theory of normative conduct: Recycling the concept of norms to reduce lettering in public places. Journal of Personality and Social Psychology, 58, 1015-1026.

Cleary, P. D., Devanter, N. van, Steilen, M., Stuart, A., Shipton-Levy, R., McMullen, W., Rogers, T.F., Singer, E., Avorn, J., Pindyck, J. (1995). A randomized trial of an education and support program for HIV-infected individuals. AIDS, 9, 1271-1278.

Coates, T. J., McKusick, L., Kuno, R., Stites, P. (1989). Stress Reduction Training Changed Number of Sexual Partners but not Immune Function in Men with HIV. American Journal of Public Health, 79, 885-887.

Collins, C., Kohler, C., DiClemente, R., \& Wang, M. Q. (1999). Evaluation of the exposure effects of a theory-based street based outreach HIV intervention on African-American drug users. Evaluation and Program Planning, 22, 279-293.

Conner, M., \& Armitage, C. J. (1998). Extending the theory of planned behavior: A review and avenues for further research. Journal of Applied Social Psychology, 28, 1429-1464.

Corby, N. H., Enguidanos, S. M., \& Kay, L. S. (1996). Development and use of role model stories in a community level HIV risk reduction intervention. Public Health Reports, 111, S54-S58.

Corby, N. H., Jamner, M. S., \& Wolitski, R. J. (1996). Using the theory of planned behavior to predict intention to use condoms among male and female injecting drug users. Journal of Applied Social Psychology, 26, 52-75. 
Cottler, L. B., Leukefeld, C., Hoffman, J., Desmond, D., Wechsberg, W., Inciardi, J. A., Compton, W. M., Abdallah, A. B., Cunningham Williams, R., \& Woodson, S. (1998). Effectiveness of HIV risk reduction initiatives among out-of-treatment non-injection drug users. Journal of Psychoactive Drugs, 30, 279-290.

Coumans, A. M., Neve, R. J. M., Van de Mheen, H. (2000). Het proces van marginalisering en verharding in de drugscene van Parkstad Limburg: Resultaten van het Drug Monitoring Systeem 1998-2000 [The process of marginalisation in the drug scene of Heerlen]. Rotterdam: IVO.

Coyle, S. L., Needle, R. H. and Normand, J. (1998) Outreach-based HIV prevention for injecting drug users: A review of published outcome data. Public Health Reports, 113, 19-30.

Cross, J. E., Saunders, C. M., \& Bartelli, D. (1998). The effectiveness of educational and needle exchange programs: A meta-analysis of HIV prevention strategies for injecting drug users. Quality and Quantity, 32, 165-180.

Dancy, B. L., Marcantonio, R., Norr, K. (2000). The long-term effectiveness of an HIV prevention intervention for low-income African American women. AIDS Education and Prevention, 12, 113-125.

De Graaf, R., VanWesenbeeck, I., Van Zessen, G., Straver, C. J., \& Visser, J. H. (1994) Male prostitutes and safe sex: different settings, different risks. AIDS Care, 6, 277-288.

De Putter, J. (1998). AIDS \& Mobility. The state of affairs in Europe on AIDS and STDs in migrants, ethnic minorities and other mobile groups. Haarlem, NL: European Committee.

Derogatis, L. R. (1977). SCL-90: Administration, scoring and procedures manual-I for the R(evised) version . Baltimore: Johns Hopkins University School of Medicine, Clinical Psychometrics Research Unit.

Des Jarlais, D. C. (1992). The first and second decades of AIDS among injecting drug users. British Journal of Addiction, 87, 347-353.

DesJarlais, D. C., \& Friedman, S. R. (1998). Fifteen years of research on preventing HIV infection among injecting drug users: What we have learned, what we have not learned, what we have done, what we have not done. Public Health Reports, 113, 182-188.

Des Jarlais, D. C., Friedman, S. R., Choopanya, K., Vanichseni, S., \& Ward, T. P. (1992). International epidemiology of HIV and AIDS among injection drug users. AIDS, 6, 10531068.

Des Jarlais, D. C., Paone, D., Milliken, J., Turner, C. F., Miller, H., Gribble, J., Shi, Q., Hagan, H., \& Friedman, S. R. (1999). Audio-computer interviewing to measure risk behaviour for HIV among injecting drug users: A quasi-randomised trial. The Lancet, 353, 1657-1661.

De Vries, H. and Backbier, E. (1994) Self-efficacy as an important determinant of quitting among pregnant women who smoke: the oe-pattern. Preventive Medicine, 23, 161-174.

De Vries, H., Backbier, E., Kok, G., \& Dijkstra, M. (1995). The impact of social influences in the context of attitude, self-efficacy, intention and previous behaviour as predictors of smoking onset. Journal of Applied Social Psychology, 25, 237-257.

De Vries, H., Dijkstra, M., \& Kuhlman, P. (1988). Self-efficacy: The third factor besides attitude and subjective norm as a predictor of behavioural intentions. Health Education Research, 3, 273-282.

De Wit, J. B. F. (1996) The epidemic of HIV among young homosexual men. AIDS, 10 (supplement), 21-25. 
DiClemente, C. C., Prochaska, J. O., Fairhurst, S., Velicer, W. F., Velasquez, M. and Rossi, J. S. (1991) The process of smoking cessation: An analysis of precontemplation, contemplation and preparation of stages of change. Journal of Consulting Clinical Psychology, 59, 295-304.

Donoghoe, M. C., Stimson, G. V., \& Dolan, K. A. (1989). Sexual behaviour of injecting drug users and associated risks of HIV infection for non-injecting sexual partners. AIDS Care, 1, 51-58.

Donoghoe, M. C., \& Wodak, A. (1998). Health and social consequences of injecting drug use. In G. Stimson \& D. C. Des Jarlais \& A. Ball (Eds.), Drug injecting and HIV infection (pp. 42 57). London, UK: UCL Press Limited.

Dowling Guyer, S., Johnson, M. E., Fisher, D. G., Needle, R., \& et al. (1994). Reliability of drug users' self-reported HIV risk behaviors and validity of self-reported recent drug use. Assessment, 1, 383-392.

Dutch AIDS Fund (1998) AIDS in Nederland [AIDS in the Netherlands]. Retrieved April 8, 1999 from the World Wide Web: www.aidsfonds.nl/list.asp? rubriek=2\&subrubriek=2\&pagina $=1$ \&alinea $=$

D' Zurilla, T. J. (1988). Problem-solving therapies. In K. S. Dobson (Ed.), Handbook of cognitive behavioral therapies (pp. 85-135). New York: The Guilford Press.

Eagly, A. H., \& Chaiken, S. (1993). The psychology of attitudes. Fort Worth, TX: Harcourt Brace Jovanovich.

El-Bassel, N., Ivanoff, A., Schilling, R. F., Gilbert, L., Borne, D., \& Chen, D. R. (1995). Preventing HIV/AIDS in drug-abusing incarcerated women through skills building and social support enhancement: Preliminary outcomes. Social Work Research, 19, 131-141.

Esparza, J., \& Bhamarapravati, N. (2000). Accelerating the development and future availability of HIV-1 vaccines: why, when, where, and how? The Lancet, 355, 2061-2066.

Ewart, C. K. (1991). Social action theory for a public for a public health psychology. American Psychologist, 46, 931-946.

Fabrigar, L. R., Priester, J. R., Petty, R. E., \& Wegener, D. T. (1998). The impact of attitude accessibility on elaboration of persuasive messages. Personality and Social Psychology Bulletin, 24, 339-352.

Fennema, H. (1997). HIV infection among drug users and the potential for heterosexual spread. Wageningen: Ponsen \& Looijer BV.

Fernadez-Esquer, M. E., Krepcho, M. A., Freeman, A. C., Magee, E., McAlister, A. L., Ross, M. W. (1997). Predictors of condom use among African American males at high risk for HIV. Journal of Applied Social Psychology, 27, 58-74.

Festinger, L. (1957). A theory of cognitive dissonance. Evanston, III.: Row, Peterson.

Fishbein, M. (2000). The role of theory in HIV prevention. AIDS Care, 12, 273-278.

Fishbein, M., \& Ajzen, I. (1975). Belief, attitude, intention and behavior: An introduction to theory and research. Reading, MA: Addison-Wesley.

Fisher, J. D., \& Fisher, W. A. (1992). Changing AIDS-risk behavior. Psychological Bulletin, 111, 455-474.

Flowers, P., Sheeran, P., Beail, N., \& Smith, J. A. (1997). The role of psychosocial factors in HIV reduction among gay and bisexual men: a quantitative review. Psychology and Health, 12, 197-230. 
Friedman, S. R., Neaigus, A., des Jarlais, D. C., Sotheran, J. L., Woods, J., \& Sufian, M. (1992). Social intervention against AIDS among injecting drug users. British Journal of Addiction, 87, 393-404.

Friedman, S. R., Neaigus, A., Jose, B., Curtis, R., Goldstein, M., Ildefonso, G., Rothenberg, R. B., \& Des Jarlais, D. C. (1997). Sociometric risk networks and risk for HIV infection. American Journal of Public Health, 87, 1289-1296.

Gerber, S., \& Basham, A. (1999). Responsive therapy and motivational interviewing: Postmodernist paradigms. Journal of Counseling and Development, 77, 418-422.

Gibson, D. R., McCusker, J., \& Chesney, M. (1998). Effectiveness of psychosocial interventions in preventing HIV risk behaviour in injecting drug users, AIDS, 12, 919-929.

Gibson, D. R., Wermuth, L., Lovelle Drache, J., Ham, J., \& Sorenson, J. L. (1989). Brief counseling to reduce AIDS risk in intravenous drug users and their sexual partners: Preliminary results. Counseling Psychology Quarterly, 2, 15-19.

Gillies, P. and Carballo, M. (1990) Adult perception of risk, risk behaviour and HIV/AIDS: A focus for intervention and research. AIDS, 4, 943-951.

Glanz, K., Lewis, F. M., \& Rimer, B. K. (1997). Health behavior and health education: Theory research and practice (2 ed.). San Francisco, CA: Jossey Bass.

Godin, G., Fortin, C., Michaud, F., Bradet, R., \& Kok, G. (1997). Use of condoms: Intention and behaviour of adolescents living in juvenile rehabilitation centres. Health Education Research, 12, 289-300.

Godin, G., \& Kok, G. (1996). The theory of planned behavior: A review of its applications to health-related behaviors. American Journal of Health Promotion, 11, 87-98.

Gomez, C. A., \& VanOss Marin, B. (1996). Gender, culture, and power: barriers to HIVprevention strategies for women. The Journal of Sex Research, 33, 355-362.

Gollwitzer, P. M. (1993). Goal achievement: The role of intentions. European Review of Social Psychology, 4, 141-185.

Green, E. C. (1992). Sexually transmitted diseases, ethno-medicine and health policy in Africa. Social Science \& Medicine, 35, 121-130.

Green, L. W. and Kreuter, M. W. (1991) Health promotion planning: An educational and environmental approach (2 ed.). Mountain View, CA:. Mayfield Publishing

Green, L. W., \& Kreuter, M. W. (1999). Health promotion and planning: An educational and ecological approach (3 ed.). Mountain View, CA: Mayfield.

Grimley, D. M., Prochaska, G. E., \& Prochaska, J. O. (1993). Condom use assertiveness and the stages of change with main and other partners. Journal of Applied Biobehavioral Research, 1, 152-173.

Gwede, C., \& McDermott, R. J. (1992). AIDS in sub-Saharan Africa: Implications for health education. AIDS Education and Prevention, 4, 350-361.

Hartgers, C., Van den Hoek, J. A., Coutinho, R. A., \& Van der Pligt, J. (1992). psychopathology, stress and HIV-risk behaviour among drug users. British Journal of Addiction, 87, 857-865.

Harvey, B., Stuart, J., \& Swan, T. (2000). Evaluation of a drama-in-education programme to increase AIDS awareness in South African high schools: a randomized community intervention trial. International Journal of STD \& AIDS, 11, 105-111. 
Helal, H., Momas, I., Prétet, S., Marsal, L., \& Poinsard, R. (1995). HIV prevalence and risk behaviour among intravenous drug users attending HIV counselling and testing centres in Paris. Addiction, 90, 1627-1633.

Hemenway, D., \& Solnick, S. J. (1993). Fuzzy dice, dream cars, and indecent gestures: Correlates of driver behavior. Accident Analysis and Prevention, 25, 161-170.

Higgins, D. L., Galavotti, C., O'Reilly, K. R., Schnell, D. J., Moore, M., Rugg, D. L., \& Johnson, R. (1991). Evidence for the effects of HIV antibody counseling and testing on behaviors. JAMA, 266, 2419-2429.

Hobfoll, S. E., Jackson, A. P., Lavin, J., Britton, P. J., \& Shepherd, J. B. (1994). Reducing Inner-City Women's AIDS Risk Activities: A Study of Single, Pregnant Women. Health Psychology, 13, 397-403.

Holtgrave, D. R., Tinsley, B. J., \& Kay, L. S. (1995). Encouraging risk reduction: A decisionmaking approach to message design. In: E. Maibach \& R.L. Parrott (Eds.), Designing health messages: Approaches from communication theory and public health practice (pp. 41-64). Thousand Oaks: Sage Publications.

Hospers, H. J., \& Kok, G. J. (1995). Determinants of safe sex and risk-taking behavior among gay men: A review. AIDS Education and Prevention, 7, 74-96.

Houston, B. K., \& Vavak, C. R. (1991). Cynical hostility: Developmental factors, psychosocial correlates, and health behaviors. Health Psychology, 10, 9-17.

Jackson, D. J., Rakwar, J. P., Richardson, B. A., Mandaliya, K., Chohan, B. H., Bwayo, J. J., Ndinya Achola, J. O., Martin, H. L., Jr., Moses, S., \& Kreiss, J. K. (1997). Decreased incidence of sexually transmitted diseases among trucking company workers in Kenya: results of a behavioral risk-reduction programme. AIDS, 11, 903-909.

Jamner, M. S., Wolitski, R. J., \& Corby, N. H. (1997). Impact of longituadinal community HIV intervention targeting injecting drug users' stage of change for condom and bleach use. American Journal of Public Health, 12, 15-24.

Janis, I. L. (1959). Motivational facotrs in the resolution of decisional conflicts. In M.R. Jones (Ed.), Nebraska Symposium on motivation, 1959 (Vol. 7, pp. 198-231). Lincoln: University of Nebraska Press.

Janz, N. K., \& Becker, M. H. (1984). The health belief model: a decade later. Health Education Quarterly, 11, 74-96.

Jemmott, J. B., Sweet Jemmott, L., \& Fong, G. T. (1992). Reductions in HIV Risk-Associated Sexual Behaviors among Black Male Adolescents: Effects of an AIDS Prevention Intervention. American Journal of Public Health, 82, 372-377.

Jemmott, L. S., Jemmott, J. B. (1992). Increasing Condom-Use Intentions Among Sexually Active Black Adolescent Women. Nursing Research, 41, 273-279.

Jones, C., \& Vlahov, D. (1989). Why don't intravenous drug users use condoms? [letter]. Journal of Acquired Immune Deficiency Syndrome, 2, 416-417.

Kalichman, S. C. (1998). Preventing AIDS: A sourcebook for behavioral interventions. London: Lawrence Erlbaum Associates, Inc.

Kalichman, S. C., Carey, M. P., \& Carey, K. B. (1996). Human immunodeficiency virus (HIV) risk among the seriously mentally ill. Clinical Psychology: Science and Practice, 3, 130-143

Kalichman, S. and Hospers, H. J. (1997) Efficacy of Behavioral Skills Enhancement. AIDS, 11, S191-S199. 
Kalichman, S. C., Kelly, J. A., Hunter, T. L., Murphy, D. A., \& Tyler, R. (1993). Culturally Tailored HIV Risk-Reduction Messages Targeted to African-American Urban Women: Impact on Risk Sensitization and Risk Reduction. Journal of Consulting and Clinical Psychology, 61, 291 295.

Kalichman, S. C., Rompa, D., \& Coley, B. (1996). Experimental Component Analysis of a Behavioral HIV-AIDS Prevention Intervention for Inner-City Women. Journal of Consulting and Clinical Psychology, 64, 687-693.

Kalichman, S. C., Rompa, D., \& Coley, B. (1997). Lack of positive outcomes from a cognitivebehavioral HIV and AIDS prevention intervention for inner-city men: lessons from a controlled pilot study. AIDS Education and Prevention, 9, 299-313.

Kagimu, M., Marum, E., Wabwire Mangen, F., Nakyanjo, N., Walakira, Y., \& Hogle, J. (1998). Evaluation of the effectiveness of AIDS health education interventions in the Muslim community in Uganda. AIDS Education and Prevention, 10, 215-228.

Kamb, M. L., Fishbein, M., Douglas, J. M., Jr., Rhodes, F., Rogers, J., Bolan, G., Zenilman, J., Hoxworth, T., Malotte, K., latesta, M., Kent, C., Lentz, A., Graziano, S., Byers, R. H., \& Peterman, T. A. (1998). Efficacy of risk-reduction counseling to prevent human immunodeficiency virus and sexually transmitted diseases: A randomized controlled trial. JAMA: Journal of the American Medical Association, 280, 1161-1167.

Kane, S. (1991). HIV, heroin and heterosexuals. Social Science \& Medicine, 32, 1037-1050.

Kegeles, S., Hays, R. B., \& Coates, T. (1996). The Mpowerment project: A community-level intervention among young gay men. American Journal of Public Health, 86, 1129-1136.

Kegeles, S. M., \& Hart, G. J. (1998). Recent HIV-prevention interventions for gay men: individual, small-group and community-based studies. AIDS, s209-s215.

Kelly, J. A. (1995). Changing HIV risk behavior: Practical strategies. New York, NY, US: The Guilford Press.

Kelly, J. A., Murphy, D. A., Sikkema, K. J., Kalichman, S. C. (1993). Psychological interventions to prevent HIV infection are urgently needed. American Psychologist, 48, 1023-1034.

Kelly, J. A., Murphy, D. A., Washington, C. D., Wilson, T. S., Koob, J. J., Davis, D. R., Ledezma, G., \& Davantes, B. (1994). The Effects of HIV/AIDS Intervention Groups for HIV-Risk Women in Urban Clinics. American Journal of Public health, 84, 1918-1922.

Kelly, J. A., Murphy, D. A., Bahr, G. R., Kalichman, S. C., Morgan, M. G., Stevenson, L. Y., Koob, J. J., Brasfield, T. L., \& Bernstein, B. M. (1993). Outcome of Cognitive-Behavioral and Support Group Brief Therapies for Depressed, HIV-Infected Persons. American Journal Psychiatry, 150, 1679-1686.

Kelly, J. A., St. Lawrence, J. S., Stevenson, L. Y., Hauth, A. C., Kalichman, S. C., Diaz, Y. E., Brashfield, T. L., Koob, J. J. and Morgan, M. G. (1992) Community AIDS/HIV risk reduction: The effects of endorsements by popular people in three cities. American Journal of Public Health, 82, 1483-1489.

Kennedy, C. A., Skurnick, J., Wan, J. Y., Quattrone, G., Sheffet, A., Quinones, M., Wang, W., \& Louria, D. B. (1993). Psychological distress, drug and alcohol use as correlates on condom use in HIV-serodiscordant heterosexual couples. AIDS, 7, 1493-1499.

Kim, N., Stanton, B., Li, X., Dickersin, K., \& Galbraith, J. (1997). Effectiveness of the 40 adolescent AIDS-risk reduction interventions: A quantitative review. Journal of Adolescent Health, 20, 204-215. 
King-Spooner, S. (1999). Review Article. HIV prevention and the positive population. International Journal of STD \& AIDS, 10, 141-150.

Kippax, S., Noble, J., Prestage, G., Crawford, J. M., Campbell, D., Baxter, D., \& Cooper, D. (1997) Sexual negotiation in the AIDS era: Negotiated safety revisited. AIDS, 11, 191-197.

Kirby, D., \& DiClemente, R. J. (1994). School-based interventions to prevent unprotected sex and HIV among adolescents. In R. J. DiClemente \& J. L. Peterson (Eds.), Preventing AIDS: Theories and methods of behavioral interventions. AIDS prevention and mental health. (pp. 117-139). New York, NY, USA: Plenum Press.

Klee, H., Faugier, J., Hayes, C., Boulton, T., \& Morris, J. (1990). Sexual partners of injecting drug users: The risk of HIV infection. British Journal of Addiction, 85, 413-418.

Klepp, K., Ndeki, S., Seha, A. M., Hannan, P., Lyimo, B. A., Msuya, M. H., Irema, M. N., \& Schreiner, A. (1994). AIDS education for primary school children in Tanzania: an evalution study. AIDS, 8, 1157-1162.

Kocken, P. (2000). Health promotion in migrants and older adults. Epidemiological diagnosis, intervention development and effect evaluation. Ridderkerk: Offsetdrukkerij Ridderprint b.v.

Kok, G. (1999). Targeted prevention for people with HIV/AIDS: feasible and desirable? Patient Education and Counseling, 36, 239-246.

Kok, G., Schaalma, H., De Vries, H., Parcel, G., \& Paulussen, T. (1996). Social psychology and health education. In W. Stroebe \& M. Hewstone (Eds.), European Review of Social Psychology (Vol. 7, pp. 241-282): New York: John Wiley \& Sons Ltd.

Kotranski, L., Semaan, S., Collier, K., Lauby, J., Halbert, J., \& Feighan, K. (1998). Effectiveness of an HIV risk reduction counseling intervention for out-of-treatment drug users. AIDS Education and Prevention, 10, 19-33.

Kowaleski, M. R., Longshore, D., \& Anglin, M. D. (1994). The AIDS risk reduction model: Examining intentions to use condoms among injecting drug users. Journal of Applied Social Psychology, 24, 2002-2007.

Krauss, B. J., Wolitski, R. J., Tross, S., Corby, N. H., \& Fishbein, M. (1999). Getting the message: HIV information sources of women who have sex with injecting drug users - a two-site study. Applied Psychology: An International Review, 48, 153-173.

Larson, A. (1989). Social context of human immunideficiency virus transmission in Africa: Historical and cultural bases of East and Central African sexual relations. Reviews of Infectious Diseases, 2, 716-731.

Latham, G. P., \& Locke, E. A. (1991). Self-regulation through goal setting. Organizational Behavior and Human Decision Processes, 50, 212-247.

Lauby, J. L., Smith, P. J., Stark, M., Person, B., \& Adams, J. (2000). A Community-Level HIV Prevention Intervention for Inner-City Women: Results of the Women and Infants Demonstration Projects. American Journal of Public Health, 90, 216-222.

Laver, S. M., van den Borne, B., Kok, G., \& Woelk, G. (1997). A pre-intervention survey to determine understanding of HIV and AIDS in farm worker communities in Zimbabwe. AIDS Educuation and Prevention, 9, 94-110.

Liebman, J., Mulia, N., \& Mcllvaine, D. (1992). Risk behavior for HIV infection of intravenous drug users and their sexual partners recruited from street settings in Philadelphia. The Journal of Drug Issues, 22, 867-884. 
Locke, E. A., \& Latham, G. P. (1990). A theory of goal setting \& task performance. Upper Saddle River, NJ, US: Prentice-Hall, Inc.

Longshore, D., \& Anglin, M. D. (1995). Number of sex partners and crack cocaine use: Is crack an independent marker for HIV risk behavior? Journal of Drug Issues, 25, 1-10.

Loomes, G., \& Sugden, R. (1982). Regret theory: An alternative theory of rational choice under uncertainty. Economic Journal, 92, 805-824.

Lukashove, V. V., Op de Coul, E. L. M., Coutinho, R. A., \& Goudsmit, J. (1998). HIV-1 strains specific for Dutch injecting drug users in heterosexually infected individuals in The Netherlands. AIDS, 12, 635-641.

MacDonald, T. K., MacDonald, G., Zanna, M. P., \& Fong, G. T. (2000). Alcohol, sexual arousal, and intentions to use condoms in young men: Applying alcohol myopia theory to risky sexual behavior. Health Psychology, 19, 290-298.

MacDonald, T. K., Zanna, M. P., \& Fong, G. T. (1996). Why common sense goes out the window: Effects of alcohol on intentions to use condoms. Personality and Social Psychology Bulletin, 22, 763-775.

Magura, S., Kang, S. Y., Shapiro, J. L., \& O'Day, J. (1995). Evaluation for an AIDS education model for women drug users in jail. International Journal of the Addictions, 30, 259-273.

Magura, S., Shapiro, J. L., Siddiqi, Q., \& Lipton, D. S. (1990). Variables influencing condom use among intravenous drug users. American Journal of Public Health, 80, 82-84.

Maibach, E. W., \& Cotton, D. (1995). A staged social cognitive approach to message design. In E. W. Maibach \& R. L. Parrott (Eds.), Designing Health Messages: Approaches From Communication Theory and Public Health Practice (pp. 41-64). Thousand Oaks, CA: Sage Publications.

Malotte, C. K., Jarvis, B., Fishbein, M., Kamb, M., latesta, M., Hoxworth, T., Zenilman, J., Bolan, G., \& Project, R. S. G. (2000). Stage of change versus an integrated psychosocial theory as a basis for developing effective behaviour change interventions. AIDS Care, 12, 357-364.

Malow, R. M., West, J. A., Corrigan, S. A., Pena, J. M., \& Cunningham, S. C. (1994). Outcome of psychoeducation for HIV risk reduction. AIDS Education and Prevention, 6, 113-125.

Margillo, G. A., \& Imahori, T. T. (1997). Understanding safer sex negotiation in a group of lowincome African-American women. In N. L. Roth \& L. K. Fuller (Eds.), Women and AIDS: Negotiating safer practices, care, and representation. (pp. 43-69). New York, USA: The Haworth Press.

Marlatt, G. A., \& Gordon, J. R. (1985). Relapse Prevention. New York: Guilford Press.

Marsch, L. A. (1998). The efficacy of methadone maintenance interventions in reducing illicit opiate use, HIV risk behavior and criminality: a meta-analysis. Addiction, 93, 515-532.

Martijn, C., De Vries, N. K., Hospers, H., Brandsma, J., Bree, K., Van 't Riet, H., Voorham, T., \& Meijs, M. (2001). LHA Based AIDS Prevention. The Effects of AIDS Prevention Programs by Lay Healh Advisors for Migrants in the Netherlands. Manuscript submitted for publication.

Mbizvo, M. T. (1996). Gender dynamics and the challenges of HIV prevention. Central African Journal of Medicine, 42, 351-354.

McAlister, A. (1995). Behavioral Journalism: Beyond the marketing model for health communication. American Journal of Health Promotion, 9, 417-420.

McKegany, N., \& Barnard, M. (1992). AIDS, drugs and sexual: Lives in the balance. Buckingham: Open University press. 
McCoy, H. V., McCoy, C. B., \& Lai, S. (1998). Effectiveness of HIV interventions among women drug users. In S. J. Stephens, S. Tortu \& S. L. Coyle (Ed.), Women, Drug Use, and HIV Infection (pp. 49-66). New York: The Howarth Medical Press.

McGuire, W. J. (1985). Attitudes and attitude change. In G. Lindzey \& E. Aronson (Eds.), Handbook of social psychology (Vol. 1, pp. 233-346). New York: Random House.

Meyer Weitz, A., Reddy, P., Weijts, W., Van Den Borne, B., \& Kok, G. (1998). The socio-cultural contexts of sexually transmitted diseases in South Africa: Implications for health education programs. AIDS Care, 10, S39-S55.

Miller, W. R. (1996). Motivational interviewing: Research, practice, and puzzles. Addictive Behaviors, 21, 835-842.

Miller, W. R., \& Rollnick, S. (1991). Motivational Interviewing: Preparing people to change addictive behavior. New York: Guilford Press.

Minkler, M. E. (1997). Community organizing and community building for health. New Brunswick: Rutgers University Press.

Montoya, I. D. (1997). Attitudes, norms, self-efficacy, and stage of change among out-of-treatment female crack cocaine users: a pilot study. AIDS Education and Prevention, 9, 424-441.

Mullen, P. D., Green, L. W., \& Persinger, G. S. (1985). Clinical trails of patien education for chronic conditions: a comparative meta-analysis of intervention types. Preventive Medicine, 14, 753-781.

Munodawafa, D., Marty, P. J., \& Gwede, C. (1995). Effectiveness of health instruction provided by student nurses in rural secondary schools of Zimbabwe: A feasibility study. International Journal of Nursing Studies, 32, 27-38.

Needle, R., Fisher, D. G., Weatherby, N., Chitwood, D., Brown, B., Cesari, H., Booth, R., Williams, M. L., Watters, J., Andersen, M., \& Braunstein, M. (1995). Reliability of selfreported HIV risk behaviors of drug users, Psychology of Addictive Behaviors, 9, 242-250.

Ngugi, E. N., \& Plummer, F. A., Simonson J. N., Cameron, D. W., Bosire, M., Waiyaki, P., Ronald, A. R., \& Ndinya-Achola, J. O. (1998). Prevention of transmission of human immunodeficiency virus in Africa: effectiveness of condom promotion and health education among prostitutes. The Lancet, 2, 887-890.

Nyamathi, A. (1989). Comprahansive health seeking and coping paradigm. Journal of Advanced Nursing, 14, 281-290.

Op de Coul, E. L. M., Lukashov, V. V., Van Doornum, G. J. J., Goudsmit, J., \& Countinho, R. A. (1998) Multiple HIV-1 subtypes present amongst heterosexuals in Amsterdam 1988-1996: No evidence for spread of non-B subtypes. AIDS, 12, 1253-1255.

Orlandi, M. A., Landers, C., Weston, R. \& Haley, N. (1990). Diffusion of health promotion interventions. In: K. Glanz, F. M. Lewis, \& B. Rimer (Eds.), Health behavior and health education (pp.288-313). San Francisco: Jossey Bass.

Paulussen, T. G. W. M., Kok, G. J., Knibbe, R. A., \& Cramer, A. (1990). Determinanten van aan AIDS gerelateerde risicogedragingen van intraveneuze druggebruikers. [Determinants of AIDS-related risk behaviors among intravenous drug users]. Tijdschrift voor Sociale Gezondheidszorg, 68, 129-136.

Perkins, D. O., Leserman, J., Murphy, C., \& Evans, D. L. (1993). Psychosocial predictors of highrisk sexual behavior among HIV-negative homosexual men. AIDS Education and Prevention, 5, 141-152. 
Petty, R. E., \& Cacioppo, J. T. (1986). Communication and persuasion: Central and peripheral routes to attitude change. New York: Springer-Verlag.

Prochaska, J. O., \& DiClemente, C. C. (1984). The transtheoretical approach: crossing traditional boundaries of therapy. Homewood, IL.: Dow Jones-Irwin.

Prochaska, J. O., Redding, C. A., \& Evers, K. E. (1997). The transtheoretical model and stages of change. In K. Glanz, F. M. Lewis \& B. K. Rimer (Eds.), Health Behavior and Health Education: Theory, Research and Practice (2 ed., pp. 60-84). San Francisco: Jossey-Bass Publishers.

Quirk, M. E., Godkin, M. A., \& Schwenzfeier, E. (1993). Evaluation of Two AIDS Prevention Interventions for Inner-City Adolescent and Young Adult Women.

Reitman, D., St.Lawrence, J. S., Jefferson, K. W., Alleyne, E., Brafield, T. L., \& Shirley, A. (1996). Predictors of African American Adolescents' Condom Use and HIV Risk Behavior. AIDS Education and Prevention, 8, 499-515.

Rhodes, T., \& Quirk, A. (1995). Where is the sex in harm reduction. International Journal of Drug Policy, 6, 76-82.

Rhodes, T., Stimson, G. V., \& Quirk, A. (1996). Sex, drugs, intervention and research: From the individual to the social. Substance Use and Misuse, 31, 375-407.

Richard, R., Van der Pligt, J., \& De Vries, N. (1995). Anticipated affective reactions and prevention of AIDS. British Journal of Social Psychology, 34, 9-21.

Richard, R., van der Pligt, J., \& de Vries, N. (1996). Anticipated affect and behavioral choice. Basic and Applied Social Psychology, 18, 111-129.

Rietmeijer, C. A., Kane, M. S., Simons, P. Z., Corby, N. H., Wolitski, R. J., Higgins, D. I., Judson, F. N., \& Cohn, D. I. (1996). Increasing the use of bleach and condoms among injecting drug users in Denver: outcomes of a targeted, community-level HIV prevention program. AIDS, 10, 291-198.

Robles, R. R., Lourdes, I. C., Colón, H. M., Matos, T. D., Freeman, D. H., \& Sahai, H. (1995). Prospective effects of perceived risk of developing HIV/AIDS on risk behaviors among injection drug users in Puerto Rico. Addiction, 90, 1105-1111.

Rogers, E. M. (1983). Diffusion of innovations. New York: The Free Press.

Rogers, E. M. (1995). Diffusion of innovations (4 ed.). New York: The Free Press.

Rogers, R. W., \& Prentice-Dunn, S. (1997). Protection motivation theory. In D. S. Gochman (Ed.), Handbook of health behavior research I: Personal and social (Vol. 1, pp. 113-132). New York: Plenum Press.

Rossi, P. H., Freeman, H. E., \& Lipsey, M. W. (1999). Evaluation: a systematic approach. Thousand Oaks: Sage Publications.

Rotheram-Borus, M. J., Lee, M. B., Murphy, D. A., Futterman, D., Duan, N. \&, Birnbaum, J. M. (2000). Youth Living With HIV. Seropositive Youth Make Positive Life Changes. Manuscript submitted for publication.

Schaalma, H., \& Kok, G. (2001). A school AIDS prevention program in the Netherlands. In L. K. Bartholomew, G. S. Parcel, G. Kok, \& N. H. Gottlieb (Eds.), Intervention Mapping: Designing theory- and evidence-based health promotion programs (pp. 353-386). Mountain View, California: Mayfield Publishing Company.

Schaalma, H., Kok, G., Bosker, R., Parcel, G. S., Peters, L., Poelman, J., \& Reinders, J. (1996). Planned development and evaluation of AIDS/STD education for secondary school students in the Netherlands: Short term effects. Health Education Quarterly, 23, 469-487. 
Schwarzer, R. (1992). Self-efficacy in the adoption and maintenance of health behaviors: Theoretical approaches and a new model. In R. Schwarzer (Ed.), Self-efficacy: Thought control of action (pp. 217-243). Washington: Hemisphere Publishing Corporation.

Sheeran, P., Abraham, C., \& Orbell, S. (1999). Psychosocial correlates of heterosexual condom use: A meta-analysis. Psychological Bulletin, 125, 90-132.

Sheeran, P., \& Taylor, S. (1999). Predicting intentions to use condoms: A meta-analysis and comparison of the theories of reasoned action and planned behavior. Journal of Applied Social Psychology, 29, 1624-1675.

Schilling, R. F., El Bassel, N., Hadden, B., \& Gilbert, L. (1995). Skills-training groups to reduce HIV transmission and drug use among methadone patients. Social Work, 40, 91-101.

Slap, G. B., Plotkin, S. L., Khalid, N., Michelman, D. F., \& Forke, C. M. (1991). A Human Immunodeficiency Virus Peer Education Program for Adolescent Females. Journal of Adolescent Health, 12, 434-442.

Sorenson, J. L., London, J., Heitzmann, C., Gibson, D. R., Morales, E. S., Dumontet, R., \& Acree, M. (1994). Psychoeducational group approach: HIV risk reduction in drug users. AIDS Education and Prevention, 6, 95-112.

Stall, R., Coates, T. J., \& Hoff, C. (1988) Behavioral risk reduction for HIV infection among gay and bisexual men: A review of results from the United States. American Psychologist, 43, 878-885.

Stanton, B. F., Li, X., Kahihuata, J., Fitzgerald, A. M., Neumbo, S., Kanduuombe, G., Ricardo, I. B., Galbraith, J. S., Terreri, N., Guevara, I., Shipena, H., Strijdom, J., Clemens, R., \& Zimba, R. F. (1998). Increased protected sex and abstinence among Namibian youth following a HIV risk-reduction intervention: a randomized, longitudinal study. AIDS, 12, 2473-2480.

Steele, C. M., \& Josephs, R. A. (1990). Alcohol myopia: Its prized and dangerous effects. American Psychologist, 45, 921-933.

Stein, J. A., Nyamathi, A., \& Kington, R. (1997). Changes in AIDS risk behaviors among impoverished minority women after a community based cognitive behavioral outreach program. Journal of Community Psychology, 25, 519-533.

Thornton, S., \& Catalan, J. (1993). Preventing the sexual spread of HIV infection. What we have learned? International Journal of STD \& AIDS, 4, 311-316.

Triandis, H. C. (1977). Interpersonal behavior. Monterey, CA: Brooks/Cole.

Trimbos (2001). Heroine: De antwoorden. [Heroin: The answers]. Retrieved April 20, 2001 from the World Wide Web: http://www.trimbos.nl/drugslyn/heroine.html.

Tversky, A., \& Kahneman, D. (1981). The framing of decisions and the psychology of choice. Science, 211, 453-458.

UNAIDS. (2000). Report on the global HIVIAIDS epidemic. June 2000. Geneva: UNAIDS.

UNAIDS/WHO. (2000). Epidemiological fact on HIV/AIDS and sexually transmitted infections: 2000 update. Geneva.

Van der Walle, E. (1990). The social impact of AIDS in sub-Saharan Africa. The Millbank Quarterly, 68, s154-s162.

Van Ameijden, E. J. C. (1998). HIV-combination therapy among drug users [HIV-combinatietherapie onder druggebruikers. Paper presented at the World AIDS Day, Amsterdam.

Van Ameijden, E., \& Van den Hoek, A. (1998) AIDS among injection drugusers in the Netherlands: The epidemic and the response. In T. Sandfort (Ed.), The Dutch Response to HIV: Pragmatism and Consenses (pp. 61-85). London: UCL Press. 
Van Empelen, P., Kok, G. J., Hoebe, C. J. P. A., \& Jansen, M. W. J. (2000). HIV risk behavior and behavior change explained: individual interviews with drug users. Paper presented at the XIII International AIDS Conference, Durban, South-Africa.

Van Empelen, P., Kok, G. J., Hoebe, C. J. P. A., \& Jansen, M. W. J. (2001). A qualitative focus on transitional factors of the motivation-action relationship in condom use among drug users. Manuscript submitted for publication.

Van Empelen, P., Kok, G. J., Jansen, M. W. J., \& Hoebe, C. J. P. A. (2001). The additional value of anticipated regret and psychopathology in explaining intended condom use among drug users. AIDS Care, 13, 309-318.

Van Empelen, P., Kok, G. J., Van Kesteren, N. M. C., Van den Borne, B., Bos, E. A. R., Dijker, A. J., Hospers, H. J., Schaalma, H. P., \& Hogeweg, J. A. (2001). Effectiveness of psychosocial HIV prevention programs: A review. Manuscript submitted for publication.

Van Empelen, P., Schaalma, H. P., Kok, G. J., \& Jansen, M. W. J. (2001). Predicting condom use with casual and steady sex partners among drug users. Health Education Research, 16, 293 306.

Van Haastrecht, H. J. A. (1995) The evolving HIV epidemic, mortality and morbidity among drug users in Amsterdam. Delft: EburonP\&L.

Van Rossem, R., \& Meekers, D. (2000). An evaluation of the effectiveness of targeted social marketing to promote adolescent and young adult reproductive health in Cameroon. AIDS Education and Prevention, 12, 383-404.

VanWesenbeeck, I., De Graaf, R., Van Zessen, G., Straver, C. J., \& Visser, J. H. (1993) Condom use by prostitutes: Behavior, factors and considerations. Journal of Psychology \& Human Sexuality, 6, 69-91.

Vlahov, D., \& Junge, B. (1998) The role of needle exchange programs in HIV infection. Public Health Reports, 113, 75-80.

Weiner, B. (1986). An attributal theory of motivation and emotion. New York: Springer.

Weinhardt, L. S., Carey, M. P., Johnson, B. T., \& Bickham, N. L. (1999). Effects of HIV counseling and testing on sexual risk behavior: A meta-analytic review of published research, 19851997. American Journal of Public Health, 89, 1397-1405.

Weinstein, N. D. (1980). Unrealistic optimism about future life events. Journal of Personality and Social Psychology, 39, 806-820

Weinstein, N. D. (1988). The precaution adoption process. Health Psychology, 7, 355-386.

Weiss, S. H., Weston, C. B., \& Quirinale, J. (1993). Safe sex? Misconceptions, gender differences and barriers among injection drug users: A focus group approach. AIDS Education and Prevention, 5, 279-293.

WHO. (1993). An international comparative study of HIV prevalence and risk behaviour among IV drug users in 13 cities. Bulletin on Narcotics, XLV, 19-46.

Wiebel, W. W., Jimenez, A., Johnson, W., Ouellet, L., Jovanovic, B., Lampinen, T., Murray, J., \& Utne O'Brien, M. (1996). Risk behavior and HIV seroincidence among out-of-treatment injection drug users: a four-year prospective study. Journal of Acquired Immune Deficiency Syndromes and Human Retrovirology, 12, 282-289.

Wight, D., Abraham, C., \& Scott, S. (1998). Towards a psycho-social theoretical framework for sexual health promotion. Health Education Research, 13, 317-330. 
Williams, E., Lamson, N., Efem, S., Weir, S., \& Lamptey, P. (1992). Implementation of an AIDS prevention program among prostitutes in the Cross River State of Nigeria [letter]. AIDS, 6, 229-230.

Williams, M., McCoy, H. V., Bowen, A., Saunders, L., Freeman, R., \& Chen, D. (2001). An evaluation of a brief HIV risk reduction intervention using empirically derived drug use and sexual risk indices. AIDS \& Behavior, 5, 31-43.

Williams, M. L., Zhao, Z., Bowen, A. M., Freeman, R. C., Elwood, W. N., \& Rusek, R. (1997). Introduction of HIV into drug injector networks outside AIDS epicentres. International Journal STD \& AIDS, 8, 629-635.

Wilson, D., \& Lavelle, S. (1992). Psychosocial predictors of intended condom use among Zimbabwean adolescents. Health Education Research, 7, 55-68.

Wingood, G. M., \& DiClemente, R. J. (1998). Gender-related correlates and predictors of consistent condom use among young adult African-American women: a prospective analysis. International Journal of STD \& AIDS, 9, 139-145.

Witte, K. (1995). Fishing for success: Using the persuasive health message framework to generate effective campaign messages. In E. W. Maibach \& R. L. Parrott (Eds.), Designing Health Messages: Approaches From Communication Theory and Public Health Practice (pp. 145-166). Thousand Oaks, CA: Sage Publications.

Zimmerman, M. A. (1995). Psychological empowerment: Issues and illustrations. American Journal of Community Psychology, 23, 581-600. 


\section{SUMMARY}

AIDS risk has been associated with people who use drugs, being both at risk by drug risk behavior and sexual risk taking. Drug users are assumed to be the main source of heterosexual HIV transmission in Europe and the United States.

The Dutch response towards HIV/AIDS among drug users has mainly focused at the reduction of drug risk behavior, by means of harm reduction programs. Although these programs have effectively reduced needle-sharing and drug injection frequency, sexual risk taking has been left unattended. Sexual risk behavior of drug users has mainly been addressed by information campaigns, such as the general safe sex television campaigns, or by the provision of information about HIV/AIDS and transmission risk via leaflets and similar written materials. These programs have mainly focused upon raising AIDS awareness and have contributed little or nothing to changing unsafe sexual behavior among drug users. Although quite knowledgeable about HIV and HIV risk, drug users have continued unsafe sexual practices both with casual sex partners and within steady sexual relationships. Targeting sexual risk behavior therefore seems a very important prevention strategy to prevent HIV infections within and from the drug using community.

The purpose of this thesis was to apply Intervention Mapping to creating an AIDS prevention intervention for drug users. In the course of this application we addressed the following research questions:

- What are the predictors of unsafe and safe sexual behaviors among drug users?

- What role does anticipated regret and psychopathology play in explaining intended condom use among drug users?

- Which factors play a role in the transition of intended condom use into actual use?

- What are the pros and cons of using Intervention Mapping?

Chapter 1 gives an outline of the thesis. First, the Intervention Mapping protocol is explained, describing the five fundamental steps: 1) the creation of matrices of proximal program objectives based on the determinants of behavior and environmental conditions; 2) the selection of theory-based intervention methods and practical strategies; 3) the translation of methods into organized programs; 4) the integration of adoption and implementation plans; 5) the generation of an evaluation plan.

Second, related health promotion tools are described that are used within the context of Intervention Mapping. The PRECEDE/PROCEED model is discussed as a planning model to analyze the need for a program. Furthermore, a brief overview is given of theories originating from behavioral and social sciences, and their application in problem analysis and intervention development and implementation are discussed.

Third, the chapter gives an overview of the project, describing the application of Intervention Mapping in developing theory- and evidence-based AIDS prevention interventions targeting Dutch drug users. 
Chapter 2 focuses on the needs assessment preceding Intervention Mapping and Intervention Mapping Step 1. The needs assessment describes the problem of HIV/AIDS, the related behavioral and environmental factors, and antecedents of the behavioral and environmental factors among drug users. Next, Intervention Mapping Step 1 is followed: discussing the performance objectives of the behavior desired condom use; specifying the most important and changeable determinants; and finally, creating matrices of proximal program objectives by merging the performance objectives of condom use with the determinants specified. The needs assessment and Intervention Mapping Step 1 are based on a literature review, interviews with outreach workers, and the additional research described in chapter 3 . The final products of chapter 2 are the matrices of proximal program objectives, which provide the foundation for intervention development.

Chapter 3 describes three studies, which were conducted to gather information about current HIV risk behavior among Dutch drug users and to examine which factors might predict safe sexual behavior -meaning condom use. The first two sections present surveys among Dutch drug users. Section 3.1 describes an analysis of determinants related to condom use with casual and steady sex partners among drug users, based upon a general model of health behavior that has been described in chapter 1 . The study was conducted among 103 Dutch drug users. The participants indicated their intentions, vulnerability, attitude, personal norms, subjective norms, descriptive norms, self-efficacy and response efficacy regarding condom use with steady and casual sex partners. The results showed that some drug users had borrowed used syringes, and that most drug users practice unsafe sex, especially with steady partners. Most drug users were hardly motivated to start using condoms. The study further showed that antecedents of condom use differ with regard to steady sex partners and casual sex partners. Self-efficacy and subjective norms were predictors of intentions to use condoms with steady partners; intention to use condoms with casual partners was only predicted by self-efficacy.

In section 3.2 a survey study is described, which again examined determinants of intended condom use with casual and steady sex partners among drug users. However, in that study the aim was to find out whether anticipated regret and psychopathology represent additional factors in explaining condom use behavior, on top of the constructs defined in traditional psychosocial models of behavior. The results showed that similar results were found when only including similar constructs as described in the first study. However, when including additional factors, we found that intended condom use with steady sex partners was mainly predicted by self-efficacy, personal norm and anticipated regret, and that the variance explained was significantly higher. Lower feelings of hostility and a more positive personal norm, subjective norm and attitude significantly predicted intended condom use with casual sex partner, and also increased the explanatory value. The results showed that intended condom use with steady sex partners seems related to anticipating possible barriers, whereas condom use with casual sex partners is largely a matter of having safe sex norms. 
Section 3.3 describes a study based on semi-structured interviews with 34 drug users. The purpose of this study was to gain insight into factors that may improve the transition from motivation to use condoms to action. The study showed that most drug users in steady sexual relationships were negatively motivated. But also in casual sexual relationships, where most drug users were motivated to use condoms, several enactment factors might inhibit them from actually using condoms. The majority reported that they did not anticipate sexual encounters, and did not communicate or have experience with communicating HIV/AIDS and safe sex with their sex partners. Both the enactment factors discussed and the difference in the type of sexual relationship should be taken into account in efforts to promote safe sex among drug users.

Chapter 4 describes the process of AIDS prevention intervention development among Dutch drug users. Following Step 2 of Intervention Mapping, methods are selected focusing on issue-related, concept-related and general theory approaches. Section 4.1 gives an overview of the issue-related approach. Section 4.1 reviews the effect of psychosocial HIV prevention programs on sexual risk behavior. Studies reviewed focused on populations that received attention only recently: drug users with regard to sexual practices, developing countries, minority populations, and people infected with HIV/AIDS. The studies were reviewed on: 1) study design; 2) the clear use of theory within intervention development; 3) the clear targeting of determinants; 4) a description of the study or studies; and 5) an evaluation of the behavioral goals and targeted determinants. The review shows that a large deal of interventions lack good research designs, and that information about the use of theory, prior objectives and outcome measures is sparse. Important determinants for the studied groups seem similar for other well-studied groups. Recommendations for future HIV prevention programs are: the use of multiple theories, systematically planned programs, sustainability of programs and the inclusion of stigma reduction strategies.

In section 4.2 we describe the entire process of Intervention Mapping Step 2. Following Step 2 of Intervention Mapping we link the proximal program objectives (of chapter 2) to theoretical methods and practical strategies. The step is based on: a brainstorm about theoretical methods [task 1]; a specification of the most potentially useful methods and justification of the selections with the literature and theories, from which the methods have been derived. Furthermore, the conditions under which such methods have shown to be effective are identified [task 2]. Finally, the methods are translated into practical applications - strategies - that should match with the proximal program objectives specified in Step 1 [task 3].

Section 4.3 presents the development process of an AIDS prevention program targeting Dutch drug users, guided by Intervention Mapping (IM). The aim of the program is the promotion of condom use with casual sex partners. The section describes the needs assessment of the HIV problem among drug users. Second, IM Step 1 is described, analyzing the desired behavior (i.e. condom use), performance objectives and underlying determinants. And a matrix of proximal program objectives is created, specifying what drug users should learn in order to use condoms. In Step 2, theoreti- 
cal methods for influencing the most important determinants are chosen and translated into practical strategies that fit the program objectives specified in Step 1. The main strategy chosen was behavioral journalism. Attention is given to the essential conditions - the parameters - that have to be met in order for theoretical methods to be successful. In Step 3, a description is given of the program developed to promote condom use, describing the leaflets that contain role model stories based on authentic interviews with drug users, and of the pilot test conducted to evaluate the strengths and weaknesses of the program, in order to make last changes. Finally, the need for co-operation with the program users throughout the entire development process, and the planning of the program evaluation are discussed in IM Steps 4 and 5.

Chapter 5, finally, discusses the promises and pitfalls of Intervention Mapping we experienced during our application of Intervention Mapping in the context of HIV prevention interventions for drug users. Attention is given to the usefulness of the steps of Intervention Mapping in explaining and changing behavior, as well as in the application of theory in developing an AIDS prevention program. Furthermore, the aspect of collaboration with practitioners is discussed. The main conclusion of this thesis is that Intervention Mapping is helpful in the development theory and evidence-based AIDS prevention programs, in the sense that it makes the decisionmaking process of intervention development transparent. This, so we believe, is the great strength of the Intervention Mapping protocol. 


\section{SAMENVATTING}

HIV/AIDS wordt veelvuldig geassocieerd met druggebruikers, zowel door hun risicovolle druggebruik, als wel hun seksueel risicogedrag. In Europa en de Verenigde Staten lijken druggebruikers de belangrijkste HIV transmissie bron te zijn, daar waar het gaat om heteroseksuele overdracht.

In Nederland wordt middels 'harm reduction' programma's gepoogd HIV/AIDS infecties onder druggebruikers te voorkomen, door enerzijds het verminderen van de spuitfrequentie door het verstrekken van methadon, en anderzijds door het verminderen van het delen van spuiten, middels spuitenomruil programma's. Deze zogenaamde harm reductie benadering is zeer effectief gebleken, daar waar het gaat om het reduceren van risicovol druggebruik, maar heeft weinig invloed gehad op het seksueel risicogedrag van druggebruikers. Het aspect van seksueel risicogedrag is hoofdzakelijk aangepakt via nationale massamediale campagnes voor de algemene bevolking en via het verstrekken van basale informatie via folders en brochures. Dit soort programma's richt zich met name op bewustwording van risico's, maar ze dragen weinig bij aan daadwerkelijke gedragsverandering. Dientengevolge blijken druggebruikers over het algemeen behoorlijke kennis te hebben over HIV en HIV risico, maar rapporteren ze op grote schaal onveilig seksueel contact met niet-commerciële losse en vaste seks partners. Om verspreiding van HIV binnen en buiten de populatie van druggebruikers te voorkomen lijkt het dan ook van belang om het seksueel risicogedrag terug te dringen.

Dit proefschrift beschrijft de toepassing van Intervention Mapping bij het ontwikkelen van theorie- en onderzoeksgestuurde AIDS preventie programma's voor druggebruikers. Binnen dit kader behandelen we de volgende onderzoeksvragen:

- Wat zijn de mogelijke voorspellers van (on)veilig seksueel gedrag door druggebruikers?

- Welke rol spelen geanticipeerde spijt en psychopathologie bij het verklaren van condoomgebruik door druggebruikers?

- Welke factoren verklaren wanneer intentie tot condoomgebruik zich vertaalt in daadwerkelijk condoomgebruik?

- Wat zijn de mogelijke voordelen en/of valkuilen bij de toepassing van Intervention Mapping bij interventie ontwikkeling?

Hoofdstuk 1 geeft een overzicht van dit proefschrift. Allereerst wordt het Intervention Mapping protocol uitgewerkt, waarbij het vijftal fundamentele stappen wordt beschreven: 1) het creëren van matrices van programmadoelen, gebaseerd op determinanten van gedrag en omgevingscondities; 2) het selecteren van theoretische methodieken en praktische methoden; 3) de vertaling van de methoden in geïntegreerde programma's; 4) de integratie van adaptatie en implementatie plannen; 5) het genereren van een evaluatieplan.

Verder wordt een aantal hulpmiddelen beschreven, die gebruikt worden in de context van Intervention Mapping. Ten eerste wordt het PRECEDE/PROCEED model 
beschreven, een van de meest gebruikte planmatige modellen als het gaat om het analyseren van het probleem. Ten tweede wordt er een kort overzicht gegeven van theoretische principes afkomstig uit de sociale of gedragswetenschappen en wordt de mogelijke toepassing van deze principes binnen de probleemanalyse, interventieontwikkeling en -implementatie beschreven.

Ten slotte wordt er een overzicht gegeven van het project, waarin beschreven wordt hoe Intervention Mapping is toegepast bij de ontwikkeling van een theorie- en evidentiegestuurde AIDS preventieprogramma voor Nederlandse druggebruikers.

Hoofdstuk 2 beschrijft een analyse van het probleem HIV/AIDS, de daaraan gerelateerde gedrags- en omgevingsfactoren, en de antecedenten van die gedragsen omgevingsfactoren onder druggebruikers. Tevens wordt er een beschrijving gegeven van Intervention Mapping Stap 1, namelijk: 1) het specificeren van gedragsdoelen van het gewenste gedrag - condoomgebruik; 2 ) het specificeren van de meest belangrijke en veranderbare determinanten; 3 ) het creëren van de matricen met programmadoelen op basis van een kruising van de gedragsdoelen van condoomgebruik met de gespecificeerde determinanten. De probleemanalyse en Intervention Mapping stap 1 zijn gebaseerd op literatuuronderzoek, interviews met veldwerkers, en additioneel onderzoek dat is beschreven in hoofdstuk 3 .

Hoofdstuk 3 beschrijft een drietal studies, die werden uitgevoerd om aan de ene kant het huidige HIV risicogedrag van druggebruikers in kaart te brengen, en daarnaast te onderzoeken welke psychosociale factoren goede voorspellers van veilig vrijgedrag (lees: condoomgebruik) zijn. De eerste twee studies werden uitgevoerd middels vragenlijstonderzoek onder Nederlandse druggebruikers. Paragraaf 3.1 beschrijft een analyse van determinanten van condoomgebruik met vaste en losse sekspartners, gebaseerd op een algemeen model van gezond gedrag, zoals beschreven in hoofdstuk 1 . Het onderzoek werd uitgevoerd onder 103 druggebruikers. De respondenten gaven hun intentie, attitude, persoonlijke norm, subjectieve norm, descriptieve norm, eigen-effectiviteit en respons-effectiviteit ten aanzien van condoomgebruik met losse en vaste sekspartners aan. Tevens rapporteerden ze in welke mate ze zichzelf en andere druggebruikers kwetsbaar achtten voor de kans op HIVinfectie via onbeschermde seks. De resultaten lieten zien dat sommige druggebruikers vuile spuiten delen met anderen, en dat de meeste druggebruikers onveilig vrijen, in het bijzonder in vaste seksuele relaties. De meeste druggebruikers waren nauwelijks gemotiveerd om condooms te gaan gebruiken. Het onderzoek liet ook zien dat antecedenten van condoomgebruik verschillen voor vaste en losse sekspartners. Eigen-effectiviteit en subjectieve norm waren de belangrijkste voorspellers van intentie tot condoomgebruik met vaste partners. Intentie tot condoomgebruik met losse partners werd uitsluitend voorspeld door de mate van eigen-effectiviteit.

In paragraaf 3.2 werd opnieuw gekeken naar determinanten van intentie tot condoomgebruik met losse en vaste sekspartners. Echter, in deze studie was het doel te onderzoeken of geanticipeerde spijt en psychopathologie een extra bijdrage zouden kunnen bieden in het verklaren van condoomgebruik, bovenop de reeds gespecificeerde constructen zoals die in de oorspronkelijke modellen van gedragsverklaring worden gedefinieerd. De studie liet zien dat vergelijkbare resultaten als in de eerste 
studie werden gevonden wanneer alleen dezelfde determinanten als in studie 1 bestudeerd werden. Echter, wanneer de toegevoegde factoren werden meegenomen in de analyses, dan bleek dat intentie tot condoomgebruik met vaste partners hoofdzakelijk door eigen-effectiviteit, persoonlijke norm en geanticipeerde spijt werd verklaard, en dat de verklaarde variantie significant groter was. Een lagere mate van ervaren hostiliteit, en een positieve persoonlijke norm, subjectieve norm en attitude waren significant gerelateerd aan intentie tot condoomgebruik met losse sekspartners, waarbij ook in dit geval de verklaarde variantie groter was in vergelijking met de eerste studie. De resultaten uit de tweede studie lijken er met name op te duiden dat intentie tot condoomgebruik met vaste sekspartners gerelateerd is aan de mate waarin men in staat is te anticiperen op mogelijke barrières, terwijl intentie tot condoomgebruik met losse partners met name lijkt af te hangen van de normen ten aanzien van beschermde seks.

In paragraaf 3.3 wordt ten slotte een studie beschreven, gebaseerd op semigestructureerde interviews met druggebruikers. Het doel van deze studie was om inzicht te verkrijgen in factoren die de transitie van intentie tot condoomgebruik naar daadwerkelijk condoomgebruik bevorderen, dan wel belemmeren. De studie liet zien dat druggebruikers over het algemeen niet gemotiveerd waren om condooms te gebruiken in vaste seksuele relaties. Maar ook met losse seksuele contacten, waar de meeste druggebruikers enigszins gemotiveerd lijken om condooms te gebruiken, bleken er verscheidene factoren te bestaan die daadwerkelijk condoomgebruik in de weg kunnen staan. De meerderheid rapporteerde dat ze niet anticiperen op mogelijke onverwachte seksuele situaties. Tevens bleek uit de interviews dat de meerderheid bewust niet communiceert over HIV/AIDS en veilige seks met hun sekspartners, of daar überhaupt geen ervaring mee heeft. Deze factoren zouden naast het type seksuele relatie dienen te worden meegenomen bij pogingen om beschermde seks bij druggebruikers te bevorderen.

Hoofdstuk 4 beschrijft het interventie ontwikkelingsproces gericht op AIDS preventie voor Nederlands druggebruikers, waarbij met name Intervention Mapping Stap 2 en 3 centraal staan. Het proces van Stap 2 volgend, worden methodes geselecteerd, die via een onderwerpsgebonden, conceptgebonden en algemeen theoretische benadering waren verkregen. De onderwerpsgebonden benadering is gebaseerd op basis van literatuur naar de effecten van HIV/AIDS preventie interventies, waaronder de review, die is beschreven in paragraaf 4.1. In die paragraaf wordt het effect van psychosociale HIV preventie programma's op seksueel risicogedrag besproken, voor groepen die slechts recentelijk in de belangstelling staan: druggebruikers met betrekking tot seksuele activiteiten, mensen uit ontwikkelingslanden, minderheidsgroepen, en mensen die reeds geïnfecteerd zijn met HIV/AIDS. De studies werden kritisch bekeken omtrent: 1) het design; 2) het gebruik van theorie bij de interventieontwikkeling; 3) de beoogde verandering betreffende psychosociale determinanten; 4) het duidelijk beschrijven van de interventie(s); en 5) de effect evaluatie met betrekking tot de gedragsdoelen en determinanten. De review liet zien dat een groot aantal interventies gekenmerkt wordt door een onduidelijk onderzoeksdesign. Tevens is de informatie omtrent het gebruik van theorie, en de vooraf 
gestelde doelstellingen en uitkomstmaten schaars. Belangrijke determinanten voor de bestudeerde groepen lijken hetzelfde te zijn als voor andere reeds veelvuldig bestudeerde groepen. Aanbevelingen voor toekomstige HIV preventie programma's zijn: het gebruik van multipele theorieën; systematische geplande programma's; continuerende programma's; de inclusie van stigmareducerende strategieën.

In paragraaf 4.2. wordt een beschrijving gegeven van het totale proces van Intervention Mapping Stap 2. Allereerst worden theoretische methoden geselecteerd. De geselecteerde theoretische methoden worden vervolgens vertaald in praktische strategieën, waarbij rekening wordt gehouden met de parameters waaraan elke methode dient te voldoen om effectief te zijn.

In paragraaf 4.3. wordt het ontwikkelingsproces van een AIDS preventie programma voor druggebruikers beschreven, ontwikkeld volgens het Intervention Mapping (IM) protocol. Het programma heeft als doelstelling condoomgebruik met losse sekspartners door druggebruikers te bevorderen. De paragraaf beschrijft allereerst de analyse van de HIV problematiek onder druggebruikers. Ten tweede wordt IM Stap 1 beschreven, waarin een analyse van het gewenste gedrag - condoomgebruik -, gedragsdoelen en onderliggende factoren wordt gegeven. Vervolgens wordt de creatie van een matrix van programmadoelen beschreven, waarin gespecificeerd wordt wat druggebruikers moeten leren om tot consequent condoomgebruik te komen. In Stap 2, wordt de selectie van de theoretische methoden beschreven. Vervolgens worden deze methoden vertaald in praktische technieken, die passen bij de in Stap 1 gespecificeerde programmadoelen. De hoofdstrategie waarvoor gekozen is betreft 'Behavioral Journalism'. In deze stap wordt aandacht gegeven aan de paramaters waarmee rekening dient te worden gehouden. Vervolgens wordt Stap 3 beschreven, waarbij aandacht wordt gegeven aan de ontwikkeling van brochures, die rolmodelverhalen bevatten, gebaseerd op het principe van Behavioral Journalism. Tevens wordt de pretest van de materialen beschreven, waarbij de sterke en zwakke punten van het programma worden besproken, en de daaraan gerelateerde veranderingen. Tenslotte, wordt de behoefte aan het anticiperen op implementatie en het evaluatieplan besproken volgens IM Stappen 4 en 5 .

Hoofdstuk 5 beantwoordt, tenslotte, de hoofdvraag van het proefschrift zoals die in hoofdstuk 1 werd beschreven. Om deze vraag te beantwoorden wordt het proces van Intervention Mapping nog eens nader bestudeerd. Aandacht wordt geschonken aan de bruikbaarheid van de verschillende stappen van Intervention Mapping bij het verklaren van gedrag, het veranderen van gedrag, en bij het ontwikkelen van theoriegestuurde interventies. Tevens wordt ingegaan op het aspect van samenwerking tussen onderzoekers en de praktijk. De hoofdconclusie van het proefschrift betreft de constatering dat gebruik van Intervention Mapping het besluitvormingsproces rondom het interventie-ontwikkelingsproces transparant maakt, en dat is daarmee dan ook de voornaamste sterkte van Intervention Mapping. 


\section{CURRICULUM VitAE}

Pepijn van Empelen was born on August 12, 1973 in Amsterdam. In 1991 he received his VWO diploma at De Scholengemeenschap "Hervormd Lyceum West" in Amsterdam. In 1991 he started the study Psychology at the University of Amsterdam. He completed his Masters on Social Psychology in 1996. In 1997 he started at the Department of Health Education of Universiteit Maastricht on the PhD project entitled 'Intervention Mapping: Systematic development of theory-based and data-based AIDS prevention interventions'.

In 1999 he moved to the Department of Experimental Psychology of the same university, continuing the $\mathrm{PhD}$ project. Since July 1, 2001 he works as a post-doc fellow at the same department. The studies conducted from 1997-2001 are described in the current thesis. 